Leopoldo Pisanelli Rodrigues de Oliveira

\title{
INTERAÇÃO ENTRE OS EXCITADORES DE VIBRAÇÃO E A ESTRUTURA SOB ESTUDO EM ENSAIOS COM MÚLTIPLA EXCITAÇÃO
}

Dissertação apresentada à Escola de Engenharia de São Carlos da Universidade de São Paulo, como parte dos requisitos para obtenção do título de Mestre em Engenharia Mecânica

ORIENTADOR: Prof. Dr. Paulo Sergio Varoto

São Carlos

2003 
A meus pais, Abílio e Vera, e minha noiva Maíra 


\section{AgradeCimentos}

Ao Prof. Dr. Paulo Sérgio Varoto, por ter me oferecido a oportunidade de realizar este trabalho e por ter proporcionado as condições necessárias à sua execução.

À Fapesp - Fundação de Amparo à Pesquisa do Estado de São Paulo - pela bolsa de estudos concedida durante a realização do trabalho.

Aos colegas da pós-graduação, pela amizade, companheirismo, incentivo e colaboração.

Aos professores e funcionários da EESC, especialmente aos da pós-graduação e do Laboratório de Dinâmica, principalmente a Sra. Cristina Marcia M. Pessa Fonseca e o Sr. José Francisco de Moraes, pelo apoio.

A Deus, por tudo. 


\section{SUMÁRIO}

LISTA DE FIGURAS......................................................................................................................................ii

LISTA DE TABELAS .....................................................................................................................

LISTA DE ABREVIATURAS E SIGLAS..............................................................................................viii

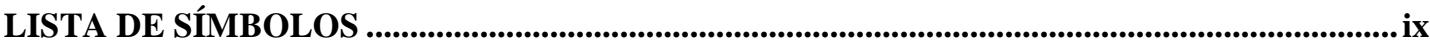

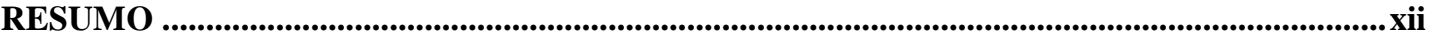

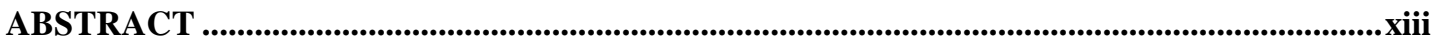

1 INTRODUÇÃO................................................................................................................................. 1

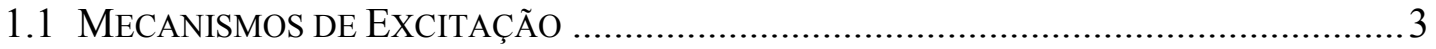

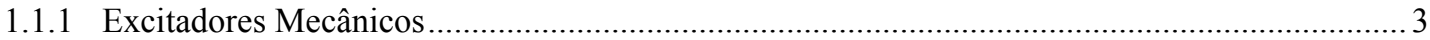

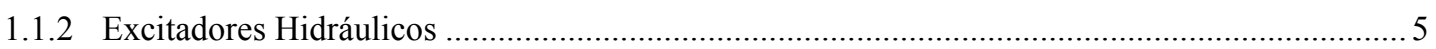

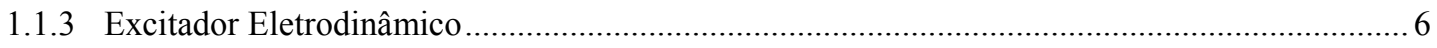

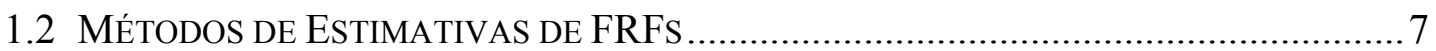

2 SÍNTESE DA BIBLIOGRAFIA FUNDAMENTAL.................................................................. 14

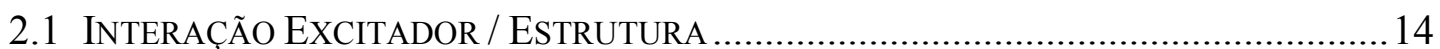

2.2 Ensaios com Múltiplas EnTRadas E Múltiplas SaÍdAS ...............................15

3 INTERAÇÃO EXCITADOR / ESTRUTURA: SIMULAÇÕES NUMÉRICAS.......................19

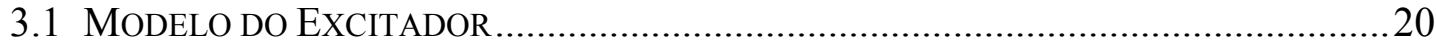

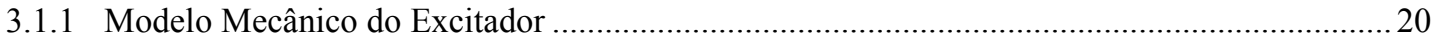

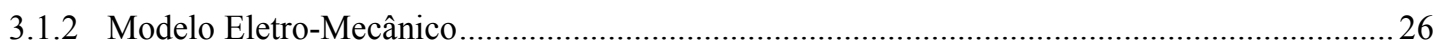

3.1.3 Modelo Considerando Graus de Liberdade Rotacionais .............................................................. 31

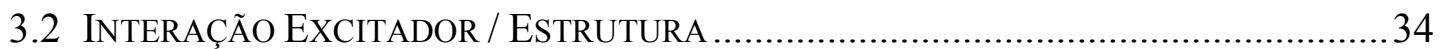

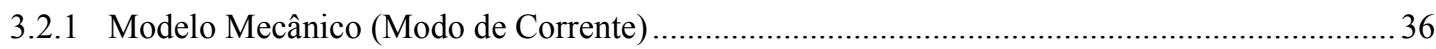

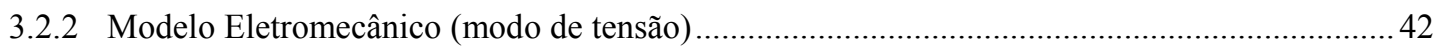

3.2.3 Modelo Considerando Graus de Liberdade Rotacionais ............................................................. 49

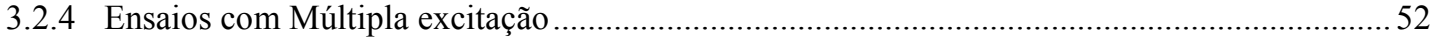

4 INTERAÇÃO EXCITADOR / ESTRUTURA: RESULTADOS EXPERIMENTAIS..............59

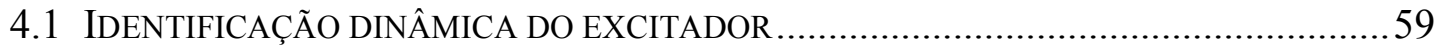




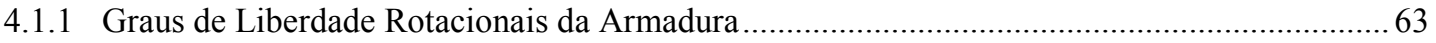

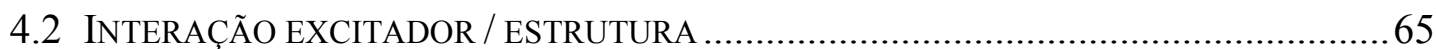

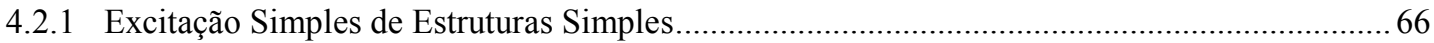

4.2.2 Excitação Simples de Estruturas Complexas........................................................................ 74

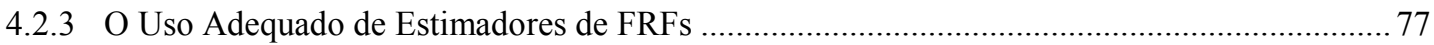

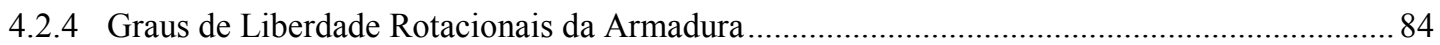

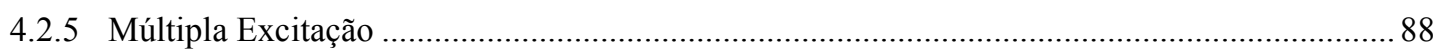

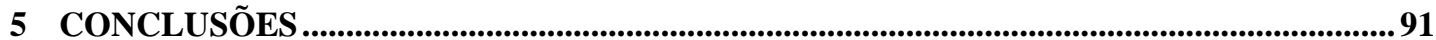

5.1 TRABALHOS FUtUROS ...............................................................................93

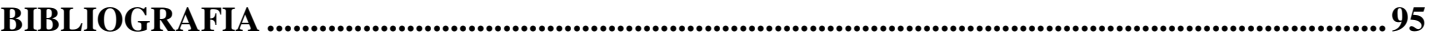




\section{LiSTA DE FIGURAS}

FIGURA 1.1 - EXCITADOR MECÂNICO DE DESLOCAMENTO..................................................................... 4

FIGURA 1.2 - EXCITADORES MECÂNICOS DE REAÇÃO (A) E (B) CIRCULAR (C) RETILÍNEO .............................5

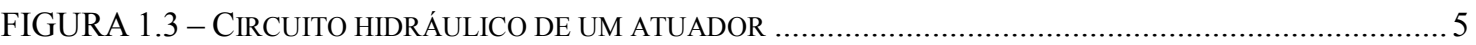

FIGURA 1.4 - ATUADORES HIDRÁULICOS EM ENSAIO DE AUTOMÓVEL (WWW.MTS.COM)............................ 6

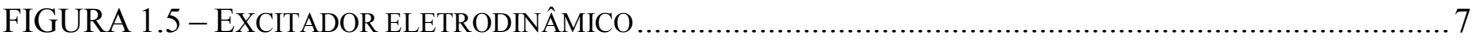

FIGURA 1.6 - DIAGRAMA DE BLOCOS DE UM SISTEMA COM UMA ENTRADA E UMA SAÍDA .......................... 8

FIGURA 1.7 - DIAGRAMA DE BLOCOS DE UM ANALISADOR DE 2 CANAIS GERANDO FRFS........................... 8

FIGURA 1.8 - DIAGRAMA DE BLOCOS PARA A OBTENÇÃO DE H3 ……………………............................. 10

FIGURA 1.9 - DiAGRAMA DE BLOCO DE UM SISTEMA COM MÚLTIPLAS ENTRADAS E MÚLTIPLAS (...) .......11

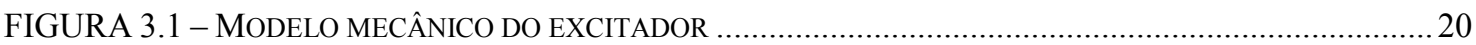

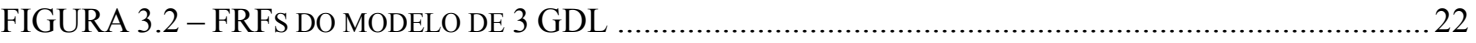

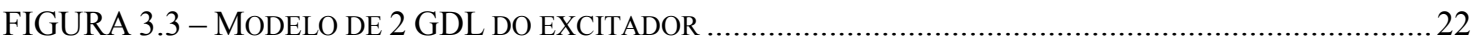

FIGURA 3.4 - ESPECTRO DE ACELERAÇ̃̃O DO EXCITADOR (A) FUNDAÇ̃̃o FLEXÍVEL (B) FUNDAÇÃO (...) 23

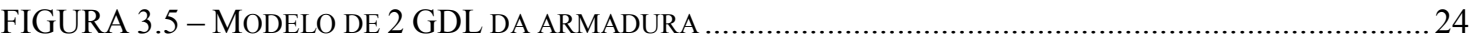

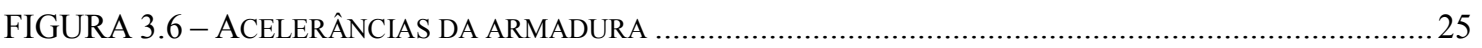

FIGURA 3.7 - MODELO MECÂNICO E ELÉTRICO DE UM EXCITADOR ELETRODINÂMICO.................................26

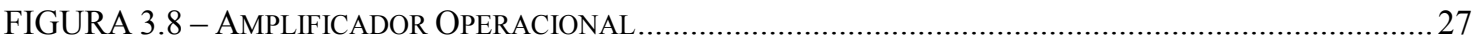

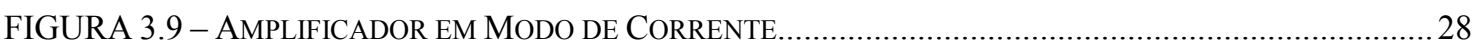

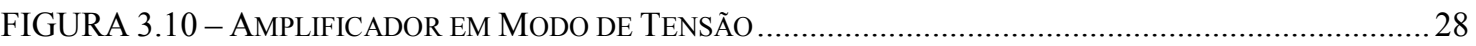

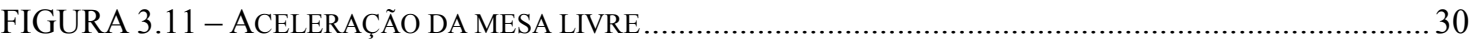

FIGURA 3.12 - TENSÃO PARA MODO DE CORRENTE E CORRENTE PARA MODO DE TENSÃO.......................... 31

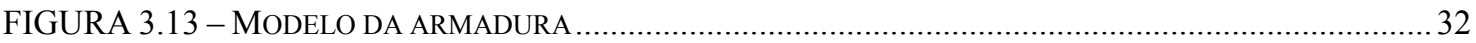

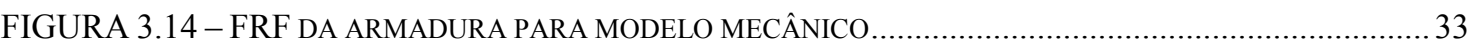

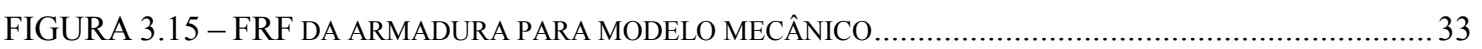

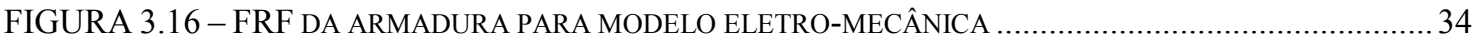


FIGURA 3.17 - MODELO DO EXCITADOR ACOPLADO A ESTRUTURA

FIGURA 3.18 - FORÇA DE ENTRADA E FRFS DO EXCITADOR E DA ESTRUTURA 36

FIGURA 3.19 - FORÇA DE ENTRADA E FRFS PARA ESTRUTURA DE 0,2 KG. 37

FIGURA 3.20 - FORÇA DE ENTRADA E FRFS PARA ESTRUTURA DE 10 KG. 37

FIGURA 3.21 - FORÇA DE ENTRADA E FRFS PARA ESTRUTURA DE 0,2 KG. 38

FIGURA 3.22 - FORÇA DE ENTRADA E FRFS PARA ESTRUTURA DE 10 KG 38

FIGURA 3.23 - FORÇA DE ENTRADA E FRFS PARA ESTRUTURA DE 0,2 KG. 39

FIGURA 3.24 - FORÇA DE ENTRADA E FRFS PARA ESTRUTURA DE 10 KG 40

FIGURA 3.25 - FORÇA DE ENTRADA E FRFS PARA ESTRUTURA DE 0,2 KG. 40

FIGURA 3.26 - FORÇA DE ENTRADA E FRFS PARA ESTRUTURA DE 10 KG. 41

FIGURA 3.27 - FORÇA DE ENTRADA E FRFS PARA ESTRUTURA DE 5 GDL E 0,2 KG 41

FIGURA 3.28 - FoRÇA DE ENTRADA E FRFS PARA ESTRUTURA DE 5 GDL E 0,2 KG 42

FIGURA 3.29 - FORÇA DE ENTRADA E FRFS PARA ESTRUTURA DE 0,2 KG 43

FIGURA 3.30 - FORÇA DE ENTRADA E FRFS PARA ESTRUTURA DE 10 KG 44

FIGURA 3.31 - FORÇA DE ENTRADA E FRFS PARA ESTRUTURA DE 0,2 KG. 44

FIGURA 3.32 - FORÇA DE ENTRADA E FRFS PARA ESTRUTURA DE 10 KG 45

FIGURA 3.33 - FORÇA DE ENTRADA E FRFS PARA ESTRUTURA DE 0,2 KG. .45

FIGURA 3.34 - FORÇA DE ENTRADA E FRFS PARA ESTRUTURA DE 10 KG 46

FIGURA 3.35 - FORÇA DE ENTRADA E FRFS PARA ESTRUTURA DE 0,2 KG. 46

FIGURA 3.36 - FORÇA DE ENTRADA E FRFS PARA ESTRUTURA DE 0,2 KG. 47

FIGURA 3.37 - FORÇA DE ENTRADA E FRFS PARA ESTRUTURA DE $10 \mathrm{KG}$ 47

FIGURA 3.38 - COMPARAÇÃO ENTRE AS FORÇAS DE ENTRADA PARA ESTRUTURA DE 0,2 KG 48

FIGURA 3.39 - COMPARAÇÃO ENTRE AS FORÇAS DE ENTRADA PARA ESTRUTURA DE 10 KG .48

FIGURA 3.40 - COMPARAÇÃO ENTRE AS FORÇAS DE ENTRADA PARA ESTRUTURA DE 10 KG 48

FIGURA 3.41 - ESTRUTURA COM 2 GDL 49

FIGURA 3.42 - ACELERÂNCIAS DE TRANSLAÇÃO E ROTAÇÃO. 49

FIGURA 3.43 - FORÇAS E MOMENTOS ENTRE O EXCITADOR E A ESTRUTURA …………….............................50

FIGURA 3.44 - FORÇA E MOMENTOS ATUANDO NA ESTRUTURA ........................................................... 51

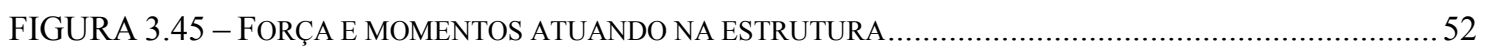

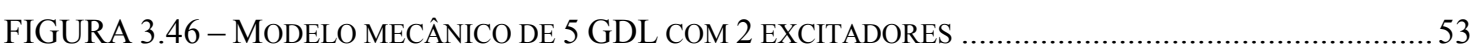

FIGURA 3.47 - MODOS DE VIBRAR DO SISTEMA DE 5 GDL .54 


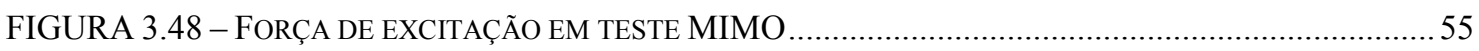

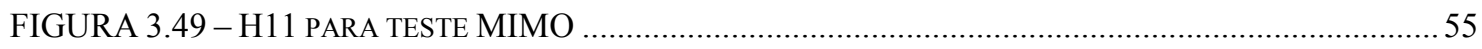

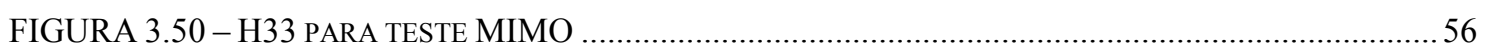

FIGURA 3.51 - COMPARAÇÃO ENTRE FORÇAS: SISO E MIMO ….......................................................56

FIGURA 3.52 - COMPARAÇÃO ENTRE FORÇAS: EXCITADORES IGUAIS (F1) E DIFERENTES (F1*) ..............57

FIGURA 3.53 - COMPARAÇÃO ENTRE FRFS: EXCITADORES IGUAIS (H11) E DIFERENTES (H11*) .............57

FIGURA 3.54 - COMPARAÇÃO ENTRE FORÇAS: EXCITADORES IGUAIS (F3) E DIFERENTES (F3*)..............57

FIGURA 3.55 - COMPARAÇÃO ENTRE FRFS: EXCITADORES IGUAIS (H33) E DIFERENTES (H33*) ............58

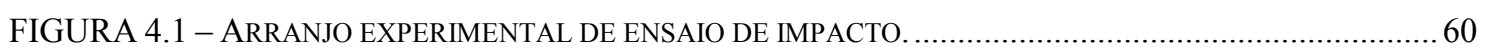

FIGURA 4.2 - FRF DE PONTO DA MESA DO EXCITADOR - BASE RÍGIDA E FLEXÍVEL................................60

FIGURA 4.3 - FRF DE PONTO DA MESA DO EXCITADOR - AMPLIFICADOR LIGADO E DESLIGADO ..............61

FIGURA 4.4 - ARRANJO EXPERIMENTAL DE EXCITADOR CONTRA EXCITADOR....................................... 61

FIGURA 4.5 - ACELERAÇÃO, FORÇA E TENSÃO MEDIDAS DO EXCITADOR B\&K 4812 .............................62

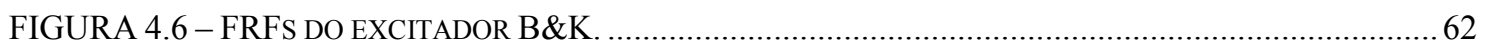

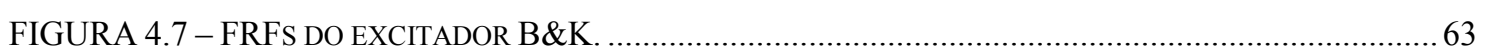

FIGURA 4.8 - FRFS DO EXCITADOR B\&K E FORÇAS DE ENTRADA. ................................................. 63

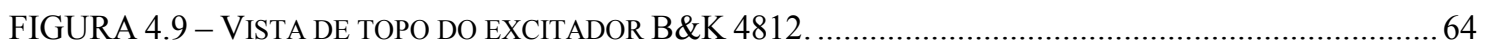

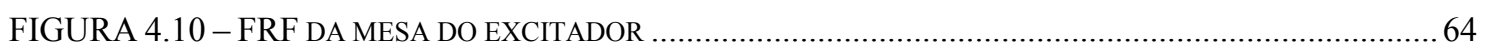

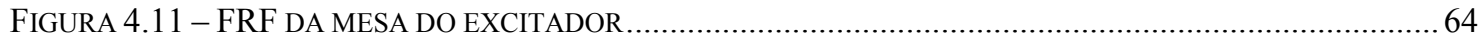

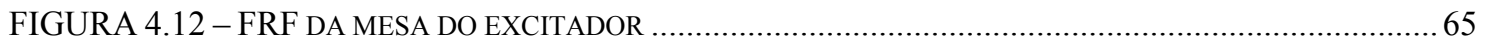

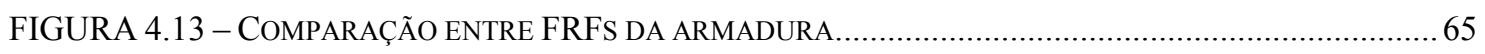

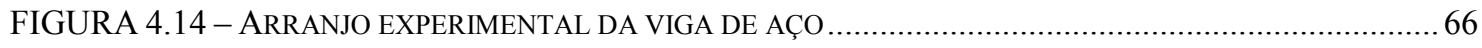

FIGURA 4.15 - DIAGRAMA DE BLOCOS DO ARRANJO EXPERIMENTAL EM MALHA FECHADA....................67

FIGURA 4.16 - DAE DA FORÇA CONTROLADA E SUAS FAIXAS DE TOLERÂNCIA .......................................67

FIGURA 4.17 - DAE DA ACELERAÇÃO CONTROLADA E SUAS FAIXAS DE TOLERÂNCIA ...........................68

FIGURA 4.18 - FRFS DA VIGA PARA IMPACTO E EXCITADOR EM MODO DE TENSÃO ................................68

FIGURA 4.19 - FRFS DA VIGA PARA IMPACTO E EXCITADOR EM MODO DE CORRENTE .............................69

FIGURA 4.20 - FRFS E COERÊNCIA DA VIGA PARA EXCITADOR EM MODO DE CORRENTE.......................70

FIGURA 4.21 - COMPARAÇÃO ENTRE FRFS E COERÊNCIA PARA MODO DE TENSÃO E CORRENTE..............70

FIGURA 4.22 - FRFS DA VIGA PARA IMPACTO E EXCITADOR COM ACELERAÇÃO CONSTANTE ..................71

FIGURA 4.23 - FRFS DA VIGA PARA IMPACTO E EXCITADOR COM FORÇA CONSTANTE............................. 71 
FIGURA 4.24 - COMPARAÇÃO ENTRE FRFS E COERÊNCIA PARA ACELERAÇÃO E FORÇA CONSTANTE .......71

FIGURA 4.25 - DAE DE ACELERAÇÃO PARA ENSAIOS DE MALHA FECHADA ............................................. 72

FIGURA 4.26 - DAE DE ACELERAÇÃO PARA ENSAIOS DE MALHA FECHADA E MODO DE TENSÃO ..............72

FIGURA 4.27 - DAE DE ACELERAÇÃO PARA ENSAIOS DE MALHA FECHADA E MODO DE CORRENTE ......... 72

FIGURA 4.28 - DAE DE FORÇA PARA ENSAIOS DE MALHA FECHADA................................................ 73

FIGURA 4.29 - DAE DE FORÇA PARA ENSAIOS DE MALHA FECHADA E MODO DE TENSÃO ........................ 73

FIGURA 4.30 - DAE DE FORÇA PARA ENSAIOS DE MALHA FECHADA E MODO DE CORRENTE....................73

FIGURA 4.31 - FORÇA DE ENTRADA, FRF E COERÊNCIA................................................................... 74

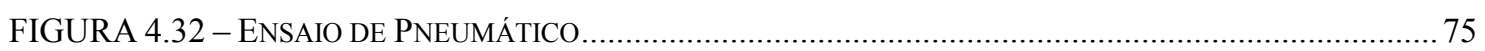

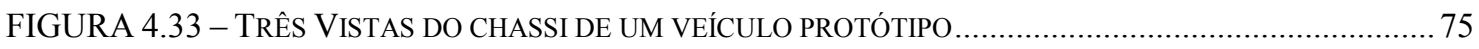

FIGURA 4.34 - VISTA ISOMÉTRICA DO CHASSI E PONTOS DE APLICAÇÃO DE FORÇA ................................76

FIGURA 4.35 - FORÇA DE EXCITAÇÃO F1 …................................................................................ 76

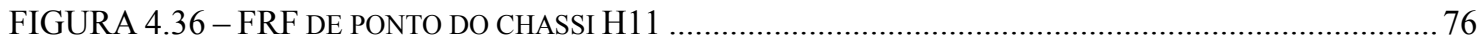

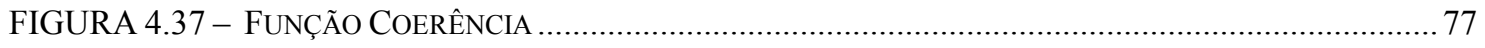

FIGURA 4.38 - ESTRUTURA CONSTRUÍDA PARA ENSAIOS (DIMENSÕES EM MM) ...................................78

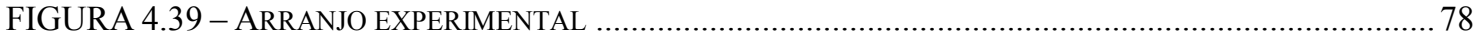

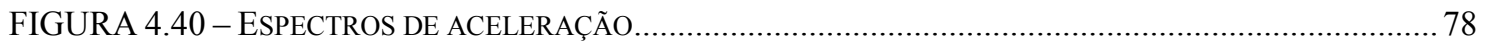

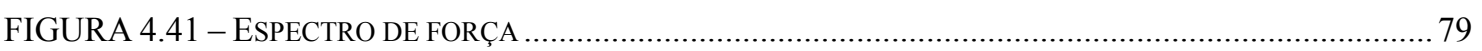

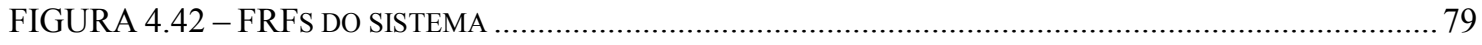

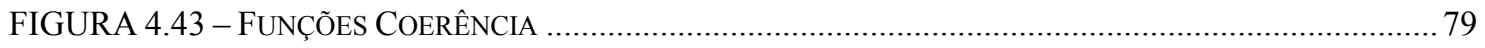

FIGURA 4.44 - ARRANJO EXPERIMENTAL COM ADIÇÃO DE RUÍDO AO SINAL DE ENTRADA .......................8 80

FIGURA 4.45 - FRFS DE PONTO E FUNÇÕES COERÊNCIA COM RUÍDO NO SINAL DE ENTRADA ..................80

FIGURA 4.46 - FRFS DE TRANSFERÊNCIA E FUNÇÃO COERÊNCIA COM RUÍDO NO SINAL DE ENTRADA ......81

FIGURA 4.47 - FRF DE PONTO COM RUÍDO NO SINAL DE ENTRADA .................................................... 81

FIGURA 4.48 - FRF DE TRANSFERÊNCIA COM RUÍDO NO SINAL DE ENTRADA.................................... 82

FIGURA 4.49 - ARRANJO EXPERIMENTAL COM ADIÇÃO DE RUÍDO AO SINAL DE SAÍDA ............................82

FIGURA 4.50 - FRFS DE PONTO E FUNÇÕES COERÊNCIA COM RUÍDO NO SINAL DE SAÍDA..........................83

FIGURA 4.51 - FRFS DE TRANSFERÊNCIA E FUNÇÕES COERÊNCIA COM RUÍDO NO SINAL DE ENTRADA ... 83

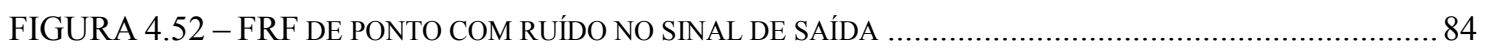

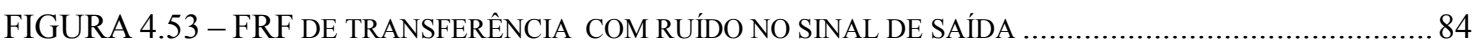

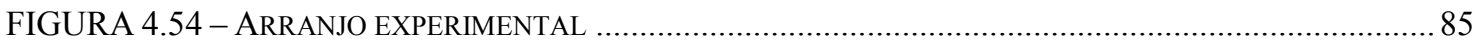




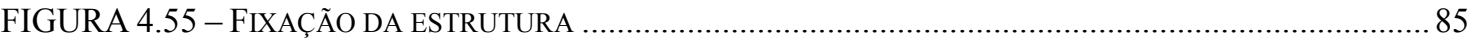

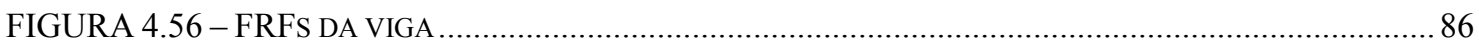

FIGURA 4.57 - FRFS MEDIDAS NO PONTO DE EXCITAÇÃO E NA MESA DO EXCITADOR.............................86

FIGURA 4.58 - FRFS ANGULARES MEDIDAS NO PONTO DE EXCITAÇÃO E NA MESA DO EXCITADOR..........87

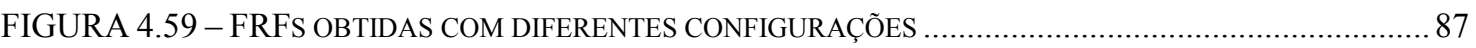

FIGURA 4.60 - FRFS ANGULARES OBTIDAS COM DIFERENTES CONFIGURAÇÕES ...................................8 87

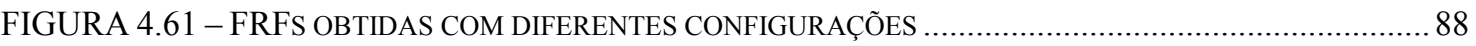

FIGURA 4.62 - FRFS OBTIDAS COM DIFERENTES CONFIGURAÇÕES ….......................................... 88

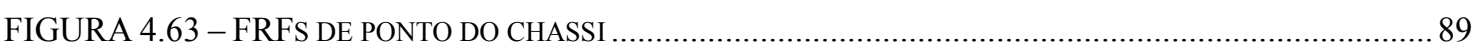

FIGURA 4.64 - COMPARAÇÃO ENTRE FORÇAS PARA OS CASOS SISO E MIMO .....................................90

FIGURA 4.65 - COMPARAÇÃO ENTRE FUNÇÕES COERÊNCIA PARA OS CASOS SISO E MIMO ...................90 


\section{LISTA DE TABELAS}

TABELA 3.1 - GRANDEZAS FÍSICAS DO EXCITADOR B\&K 4801/4812 ………………………….......2 23 


\section{Lista de Abreviaturas e Siglas}

$\begin{array}{ll}\text { CG } & \text { Centro de Gravidade } \\ \text { DAE } & \text { Densidade Auto-Espectral } \\ \text { DEC } & \text { Densidade Espectral Cruzada } \\ \text { ERA } & \text { Eigenvalue Realisation Algorithm } \\ \text { FRF } & \text { Função de Resposta em Freqüência } \\ \text { GDL } & \text { Grau De Liberdade } \\ \text { MEA } & \text { Múltipla Excitação Aleatória } \\ \text { MIMO } & \text { Multiple Input Multiple Output } \\ \text { MISO } & \text { Multiple Input Single Output } \\ \text { MMIF } & \text { Multiple Modal Indicator Function } \\ \text { SIMO } & \text { Single Input Multiple Output } \\ \text { SISO } & \text { Single Input Single Output }\end{array}$




\section{LiSTA DE SÍMBOLOS}

\section{OPERADORES E NOTAÇÃO MATRICIAL:}

$*$

conjugado complexo

[]

matriz

[]$^{\mathrm{H}}$

matriz hermitiana

[]$^{\mathrm{T}}$

matriz transposta

[]$^{-1}$

matriz inversa

\{\}

vetor

\{\}$^{\mathrm{T}}$

vetor transposto

$\dot{\mathrm{x}}$

primeira derivada temporal de ' $\mathrm{x}$ '

$\ddot{\mathrm{x}}$ segunda derivada temporal de ' $x$ '

$\sum_{n=i}^{j} x_{n}$ somatório dos elementos de ' $x$ ' para ' $n$ ' variando de i a j

\section{ALFABETO ROMANO:}

$\mathrm{A}_{\mathrm{n}} \quad$ aceleração do ponto ' $\mathrm{n}$ ' no domínio da freqüência

$\mathrm{A}_{\mathrm{m}, \mathrm{n}} \quad$ FRF de linear / linear da saída ' $\mathrm{m}$ ' pela entrada ' $\mathrm{n}$ '

B intensidade do campo magnético $\mathrm{T}$

$\mathrm{B}_{\mathrm{m}, \mathrm{n}} \quad$ FRF de linear / angular da saída ' $m$ ' pela entrada ' $n$ '

$c_{n} \quad$ n-ésimo fator de amortecimento do sistema em $\mathrm{kg} / \mathrm{s}$

$\mathrm{C}_{\mathrm{m}, \mathrm{n}} \quad \mathrm{FRF}$ angular / linear da saída ' $\mathrm{m}$ ' pela entrada ' $\mathrm{n}$ '

$\mathrm{D}_{\mathrm{m}, \mathrm{n}} \quad$ FRF angular / angular da saída ' $\mathrm{m}$ ' pela entrada ' $\mathrm{n}$ '

$\mathrm{E}_{\mathrm{i}} \quad$ tensão em modo de corrente em V

$\mathrm{E}_{\mathrm{bmf}} \quad$ tensão de retorno em $\mathrm{V}$

$\mathrm{F}_{\mathrm{e}} \quad$ força eletromagnética em $\mathrm{N}$

$f_{n} \quad$ força de entrada no ponto ' $n$ ' em N 


\begin{tabular}{|c|c|}
\hline $\mathrm{F}_{\mathrm{n}}$ & força de entrada no ponto 'n' no domínio da freqüência \\
\hline $\mathrm{G}_{\mathrm{i}}$ & ganho do amplificador em modo de corrente \\
\hline $\mathrm{G}_{\mathrm{v}}$ & ganho do amplificador em modo de tensão \\
\hline Grx & espectro cruzado de um dado sinal pelo sinal de entrada \\
\hline Gry & espectro cruzado de um dado sinal pelo sinal de saída \\
\hline Gxx & auto-espectro do sinal de entrada \\
\hline [Gxxy] & matriz espectral \\
\hline Gxy & espectro cruzado do sinal de entrada pelo sinal de saída \\
\hline Gyx & espectro cruzado do sinal de saída pelo sinal de entrada \\
\hline Gyy & auto-espectro do sinal de saída \\
\hline $\mathrm{H}_{1}$ & algoritmo de estimativa de FRF \\
\hline $\mathrm{H}_{2}$ & algoritmo de estimativa de FRF \\
\hline $\mathrm{H}_{3}$ & algoritmo de estimativa de FRF \\
\hline $\mathrm{Hv}$ & algoritmo de estimativa de FRF \\
\hline $\mathrm{H}_{\mathrm{m}, \mathrm{n}}$ & FRF da saída 'm' pela entrada 'n' \\
\hline I & corrente elétrica em A \\
\hline$I_{v}$ & corrente em modo de tensão em A \\
\hline$I_{n}$ & momento de inércia do n-ésimo elemento em kg.m² \\
\hline j & $\sqrt{-1}$ \\
\hline $\mathrm{K}_{\mathrm{f}}$ & constante de força eletromagnética por corrente em N/A \\
\hline $\mathrm{K}_{\mathrm{v}}$ & constante de tensão de retorno em $\mathrm{V} / \mathrm{m} / \mathrm{s}$ \\
\hline $\mathrm{k}_{\mathrm{n}}$ & n-ésima rigidez do sistema em N/m \\
\hline $\mathrm{L}$ & indutância elétrica do sistema em H \\
\hline$\ell$ & comprimento de uma espira da bobina em $\mathrm{m}$ \\
\hline $\mathrm{m}_{\mathrm{a}}$ & massa da armadura em $\mathrm{kg}$ \\
\hline $\mathrm{m}_{\mathrm{b}}$ & massa da bobina em $\mathrm{kg}$ \\
\hline $\mathrm{m}_{\mathrm{B}}$ & massa da base em $\mathrm{kg}$ \\
\hline $\mathrm{m}_{\mathrm{n}}$ & massa do n-ésimo elemento em $\mathrm{kg}$ \\
\hline $\mathrm{M}_{\mathrm{n}}$ & momento de entrada no ponto ' $n$ ' no domínio da freqüência \\
\hline MCoh & função coerência múltipla \\
\hline $\mathrm{r}$ & razão de freqüência adimensional \\
\hline
\end{tabular}


$\mathrm{R} \quad$ resistência elétrica do sistema em $\Omega$

$\mathrm{x} \quad$ sinal de entrada no domínio do tempo

$\mathrm{X}_{\mathrm{m}} \quad$ sinal de entrada no domínio da freqüência

y sinal de saída no domínio do tempo

$\mathrm{Y}_{\mathrm{m}} \quad$ sinal de saída no domínio da freqüência
ALFABETO GREGO:
$\gamma$
função coerência
$\eta$
sinal de ruído no sinal de entrada no domínio do tempo
$\mu$
sinal de ruído no sinal de saída no domínio do tempo
$\theta$
sinal de saída angular no domínio do tempo
$\omega$
freqüência em $\mathrm{rad} / \mathrm{s}$
$\zeta$
fator de amortecimento adimensional 


\section{RESUMO}

OLIVEIRA, L.P.R., (2003). Interação entre os Excitadores de Vibração e a Estrutura Sob Estudo em Ensaios com Múltipla Excitação. São Carlos, 2003. 97p. Dissertação (Mestrado) - Escola de Engenharia de São Carlos, Universidade de São Paulo.

Apresenta-se um estudo analítico e experimental do fenômeno de interação entre excitadores eletrodinâmicos e a estrutura em ensaios de vibração e discutem-se causas e efeitos desta interação na qualidade dos resultados obtidos. Inicialmente, realizam-se simulações numéricas que contemplam as características mecânicas e eletromagnéticas do excitador. Definido o modelo para o excitador, realizam-se simulações de teste com estruturas, dos quais obtêm-se as forças de entrada e funções de resposta em freqüência (FRFs) estimadas que serão comparadas às FRF reais da estrutura. Posteriormente, considera-se a inclusão de graus de liberdade rotacionais aos modelos do excitador e da estrutura. Finalmente, as simulações de testes com múltipla excitação têm como objetivo principal o de observar os fenômenos de queda de força de excitação e seus efeitos sobre as FRFs estimadas. Com os resultados experimentais verificam-se os principais fenômenos da interação excitador / estrutura observados nas simulações numéricas tais como a queda da força de excitação e a influência da dinâmica do conjunto excitador / amplificador na resposta da estrutura. Através dos resultados experimentais obtidos com uma viga metálica observam-se os principais efeitos previstos pelas simulações. Ainda, comparam-se as alterações nos dados obtidos com outros métodos de excitação tais como, martelo impulsivo e excitação em malha fechada. Testes realizados com diferentes estruturas, como um pneumático e um chassi tubular, vêem complementar os dados obtidos até então para excitação com um único excitador. Os testes realizados com a finalidade de validar os modelos que incluem graus de liberdade rotacionais mostram que tais grandezas não podem ser negligenciadas, principalmente no que se referem aos testes com excitação via base, em que o item de teste é montado diretamente sobre o excitador. Ainda, verificam-se os resultados obtidos com diversos estimadores de FRFs em ensaios com acréscimo de ruído aos sinais de entrada e saída. Os resultados experimentais realizados com dois excitadores mostram os mesmos efeitos observados nas simulações, em geral uma redução na queda da força de excitação e uma melhor distribuição de energia pela estrutura.

Palavras Chave: Análise Modal Experimental, Excitador Eletrodinâmico, Múltipla Excitação, Dinâmica Estrutural. 


\begin{abstract}
OLIVEIRA, L.P.R., (2003). Interação entre os Excitadores de Vibração e a Estrutura Sob Estudo em Ensaios com Múltipla Excitação. São Carlos, 2003. 97p. Dissertação (Mestrado) - Escola de Engenharia de São Carlos, Universidade de São Paulo.
\end{abstract}

An analytical and experimental study of the interaction between electrodynamic exciters and the structure under test is presented, and the causes and effects of this interaction on the obtained data quality are discussed. Initially, some numerical simulations are performed concerning the shaker's mechanical and electrical features. Once the shaker model is defined, some tests with structures were simulated in order to obtain the input forces and the estimated frequency response functions to be compared with the measured FRFs. Afterwards, the rotational degrees of freedom were included in the shaker and structure models. Ending this section, tests with multiple input forces were simulated. The experimental results confirm most of the phenomena observed in the simulation section, such as the input force drop-off and the influence of the shaker / power amplifier assembly on the structure's response. The tests conducted with a steal beam confirmed the effects predicted by the simulations. Therefore, these results are compared with others, obtained from alternative methods such as impact test and closed loop shaker tests. Tests with structures like a truck tyre and a tubular chassis complement the assessment of single input tests. The tests performed with the objective of validating the models considering rotational degrees of freedom show that these quantities cannot be neglected, mainly when base driven tests are concerned. Also, the efficiency of FRF estimators applied to shaker tests, in the presence of noise on the input and output channels is verified experimentally. The multiple input tests corroborate the effects observed in the simulations, in general, a reduction of the droopoff on the force and an improvement on the input energy distribution on the structure.

Key Words: Experimental Modal Analysis, Electrodynamic Shaker, Multiple Input Tests, Structural Dynamics. 


\section{INTRODUÇÃO}

A análise modal teórica e experimental representa um papel de interligação entre áreas como análise estrutural, dinâmica e controle de máquinas e acústica. Com a aplicação de novos métodos e técnicas computacionais e experimentais de simulação, identificação e determinação das características dinâmicas de estruturas, a análise modal vem se tornando uma área interdisciplinar, agregando conceitos de engenharia mecânica, elétrica e computacional (ALLEMANG, 1994).

A análise modal experimental tem como objetivo principal a obtenção de características dinâmicas de estruturas, tais como: freqüências naturais, modos de vibrar e fatores de amortecimento modais. Tais parâmetros representam subsídios para a análise do comportamento dinâmico de estruturas, seja na predição de sua resposta a um dado carregamento, seja para análises aeroelásticas ou vibroacústicas, ou mesmo como base para atualizações em modelos de elementos finitos ou análises de fadiga.

Neste contexto, a Análise Modal Experimental contribui de forma decisiva para o aprimoramento dos modelos analíticos e computacionais, sendo também capaz de auxiliar no monitoramento de qualidade de processos, manutenção preditiva quanto à vibração, bem como na pesquisa e desenvolvimento de novos produtos. Estes métodos experimentais envolvem a medição dos níveis de resposta da estrutura (deslocamento, velocidade ou aceleração) a determinados estímulos de entrada que podem ser tanto na forma de esforços, quanto movimentos (excitação via base). Estes níveis de resposta, juntamente com as excitações, são usados na determinação das Funções de Resposta em Freqüência (FRF) da estrutura, que por sua vez são de fundamental importância no processo de identificação modal. O sucesso de uma análise modal experimental é atribuído ao cuidado em cada passo do processo, que ALLEMANG (1994) divide em: análise teórica, métodos experimentais, aquisição de dados, estimativa de parâmetros e, finalmente, validação dos resultados.

Dos métodos experimentais, os ensaios de análise modal com excitador eletrodinâmico (mais conhecido como shaker) estão dentre os mais populares, graças a uma variada seleção de possíveis sinais de excitação que este equipamento pode fornecer durante os ensaios. No entanto, este mecanismo de excitação interage com a estrutura sob estudo, pelo fato de o mesmo ser mecanicamente conectado à estrutura. Os efeitos desta interação nos dados obtidos em ensaios com excitador eletrodinâmico 
preocupa os pesquisadores praticamente desde os primórdios da análise modal (UNHOLTZ, 1961). No entanto, novas técnicas e abordagens do problema vêem sendo propostas continuamente, podendo-se citar TOMLINSON (1979), OLSEM (1986), RAO (1987), MOUCH et al. (1990), McCONNELL (1995), VAROTO (1996), OLBRECHTS et al. (1997), LANG (1997 e 2001), COMSTOCK (1999) e OLIVEIRA \& VAROTO (2002a, 2002b e 2002c).

O presente trabalho situa-se no contexto da análise modal experimental, em particular no ambiente do laboratório, onde a principal fonte de excitação é o excitador eletrodinâmico. Buscando uma melhoria da qualidade dos dados adquiridos e conseqüentemente dos parâmetros estimados, propõe-se o estudo da interação excitador / estrutura visando os seguintes objetivos:

- Estudar analítica e experimentalmente o fenômeno de interação excitador / estrutura.

- Criar modelos que possibilitem a identificação e quantificação dos fenômenos como a queda de força e o amortecimento eletromagnético.

- Realizar ensaios que busquem validar ou redefinir tais modelos e identificar de forma prática os seus efeitos.

- Realizar ensaios com excitação controlada, visando a redução ou mesmo a eliminação do fenômeno de queda na força de excitação. O objetivo aqui é comparar as FRFs medidas a partir destes ensaios com aquelas obtidas em ensaios com malha aberta, a fim de identificar possíveis variações nos parâmetros modais identificados.

- Realizar simulações de testes MIMO que permitam estimar as forças de entrada na estrutura, a fim de verificar os efeitos de um segundo excitador em fenômenos como o da queda de força.

- Ainda em relação a testes MIMO, verificar o efeito do uso simultâneo de excitadores com valores de massa de armadura diferentes.

Busca-se com isto a resposta para algumas das seguintes perguntas:

○ O fenômeno de drop-off (queda da força de excitação quando a estrutura passa por uma freqüência natural) pode ser usado como indicativo para uma localização mais precisa das freqüências naturais do sistema? Ou seria mais conveniente realizar um ensaio com excitação controlada a fim de manter constante o nível da força de excitação?

- De que maneira o excitador interage com os modos de vibrar da estrutura? Qual seria o local (ou locais) mais apropriado(s) para o posicionamento da(s) fonte(s) de excitação? 
- Como desenvolver experimentos que possibilitem a quantificação do amortecimento eletromagnético introduzido pelos circuitos elétricos do excitador nos diferentes modos de operação do amplificador de potência?

- Em ensaios com excitação via base, qual o efeito causado sobre a armadura do excitador quando uma estrutura não simétrica é testada? A falta de simetria causa movimentos de rotação significativos da armadura do excitador?

○ É possível utilizar o mesmo sinal de excitação na alimentação de diversos excitadores simultaneamente?

- Qual o efeito na qualidade dos dados adquiridos de uma estrutura de geometria complexa quando se faz uso de múltipla excitação?

\subsection{MECANISMOS DE EXCITAÇÃO}

A fim de se obter as características dinâmicas de uma determinada estrutura, busca-se conhecer a resposta da mesma a entradas específicas. Existem inúmeras técnicas de excitação dependendo das exigências para um determinado tipo de teste. Para tanto, vários mecanismos de excitação estão disponíveis comercialmente com as funções e características dirigidas a cada necessidade.

Em se tratando de análise modal experimental, as técnicas de excitação mais comuns são aquelas que usam os martelos impulsivos e os excitadores eletrodinâmicos. Com o martelo impulsivo busca-se reproduzir uma entrada do tipo impulso na estrutura e, para tanto, faz-se uso de martelos instrumentados com células de carga que medem a força introduzida na estrutura. As técnicas de excitação com excitadores eletromagnéticos permitem que uma gama variada de sinais seja utilizada, dentre outros, ondas senoidais estacionárias, varreduras senoidais, sinais aleatórios, e até mesmo sinais de conteúdo em freqüência pré-definidos, buscando-se por exemplo, reproduzir uma condição de uso da estrutura sob estudo. Alguns dos principais mecanismos de excitação serão brevemente descritos a seguir.

\subsubsection{EXCITADORES MECÂNICOS}

Existem dois tipos de excitadores mecânicos, os de deslocamento e os de reação. No primeiro, um mecanismo transforma o movimento de rotação de um motor em um deslocamento, enquanto no segundo a força é gerada por uma massa desbalanceada em rotação.

Os excitadores de deslocamento consistem basicamente de uma mesa (onde é fixado o item de teste) ligada a um eixo excêntrico ou a um came que fornece o deslocamento à mesa (Fig. 1.1). Uma das principais características deste tipo de excitador é a de fornecer o mesmo deslocamento independentemente da freqüência de excitação ou da carga a qual esteja sujeita. 


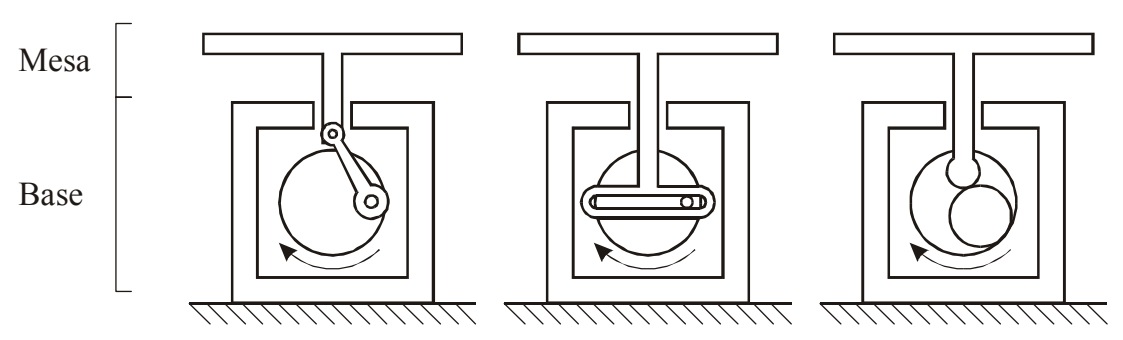

FIGURA 1.1 - Excitador mecânico de deslocamento.

Suas principais características são:

○ Baixas freqüências de operação e grandes deslocamentos;

- Deslocamento constante de excitação, dentro dos limites de carga e freqüência;

- Sua base deve estar sempre ligada de forma rígida às fundações do laboratório;

- Com uma faixa de freqüência útil baixa, é possível projetar a mesa e os dispositivos de fixação para que possuam freqüências naturais fora desta faixa;

- O item de teste deve ter massa menor que a da mesa e deve ser montado de forma a manter a linha do CG alinhada com o eixo principal da mesa de forma a evitar flexões da mesma e carregamentos angulares;

- É possível utilizar mais de um excitador para excitar duas direções principais, por exemplo, mas há que se garantir controle de freqüência e ângulo de fase independentes;

- O estado de conservação, ou mesmo o tipo de mecanismo utilizado na conversão do movimento de rotação em deslocamento, podem gerar sinais de excitação com componentes harmônicas. Eventuais folgas no mecanismo podem introduzir impacto significativo no item de teste.

Os excitadores de reação geram a força de excitação a partir de uma massa desbalanceada (Fig. 1.2). Estes excitadores são conhecidos como de reação pelo fato da força fornecida pela mesa consistir da força de reação à força gerada pela massa desbalanceada em rotação (UNHOLZ, 1961).

As principais características deste tipo de excitador são:

○ A força gerada é transmitida diretamente à mesa e ao item de teste;

- A força de excitação pode ser obtida de forma a passar pelo CG da mesa e do item de teste minimizando eventuais rotações da mesa;

- A freqüência de utilização é limitada a $60 \mathrm{~Hz}$ para estruturas maiores e pode chegar aos $120 \mathrm{~Hz}$ para estruturas leves; 
○ A força aumenta em razão da freqüência de forma quadrática.

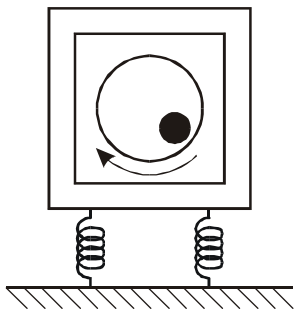

(a)

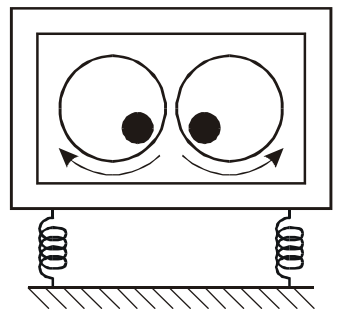

(b)

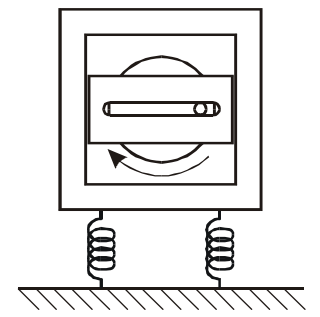

(c)

FIGURA 1.2 - Excitadores mecânicos de reação (a) e (b) circular (c) retilíneo

\subsubsection{EXCITADORES HidRÁulicos}

Excitadores hidráulicos transformam um sinal elétrico em movimento vibratório linear de um escoamento de fluido sob alta pressão. Um diagrama do circuito eletrohidráulico de um excitador pode ser visto na Fig. 1.3. A válvula intermediária trata-se de um estágio de potência.

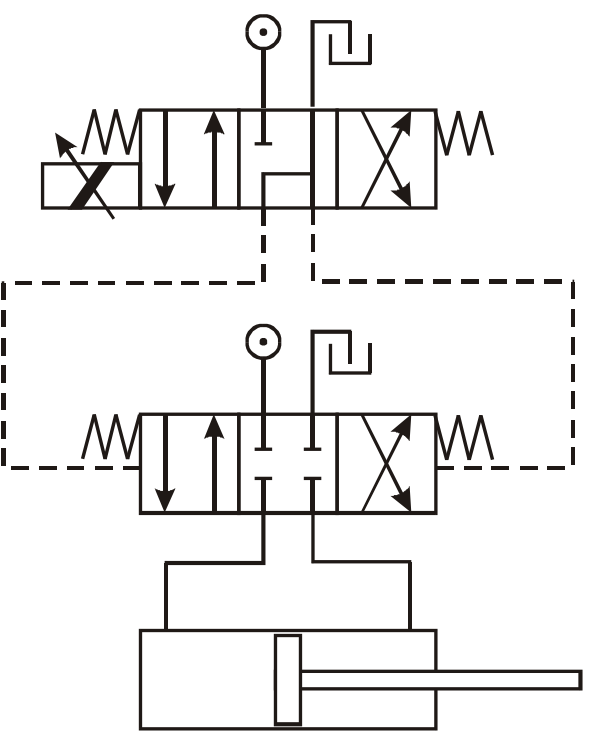

FIGURA 1.3 - Circuito hidráulico de um atuador

O princípio de funcionamento é bastante simples. O sinal gerado é enviado para a bobina da servo-válvula que por sua vez pilota a válvula de 4 vias que fornece pressão a uma das extremidades do atuador. Em geral este tipo de excitador requer algum tipo de controle de excitação (McCONNELL, 1995).

As principais características deste tipo de excitador são:

- Forças e deslocamentos de grande magnitude

○ Em sua instalação, são necessárias uniões rígidas com a fundação ou grandes massas inerciais. 
○ O limite inferior de freqüência é praticamente zero (DC) visto que a fonte de energia é hidráulica.

- Pode apresentar efeitos não lineares significativos entre o sinal de entrada e a velocidade ou escoamento de saída.

- A forma de onda gerada na saída não é tão boa quanto a gerada por excitadores eletrodinâmicos, devido às características inerentes às válvulas e atrito nos atuadores.

- Em geral o item de teste é facilmente suportado pelas forças hidráulicas dos atuadores, sem requerer suporte externo.

- A geração e manutenção de energia hidráulica requer mais espaço e despende mais recursos que no caso eletromagnético.

A Fig. 1.4 ilustra uma das aplicações de atuadores hidráulicos, o caso em ensaios com veículos que requerem força e baixas freqüências. Outra aplicação freqüente se dá em ensaios sísmicos de edificações (McCONNELL, 1995).
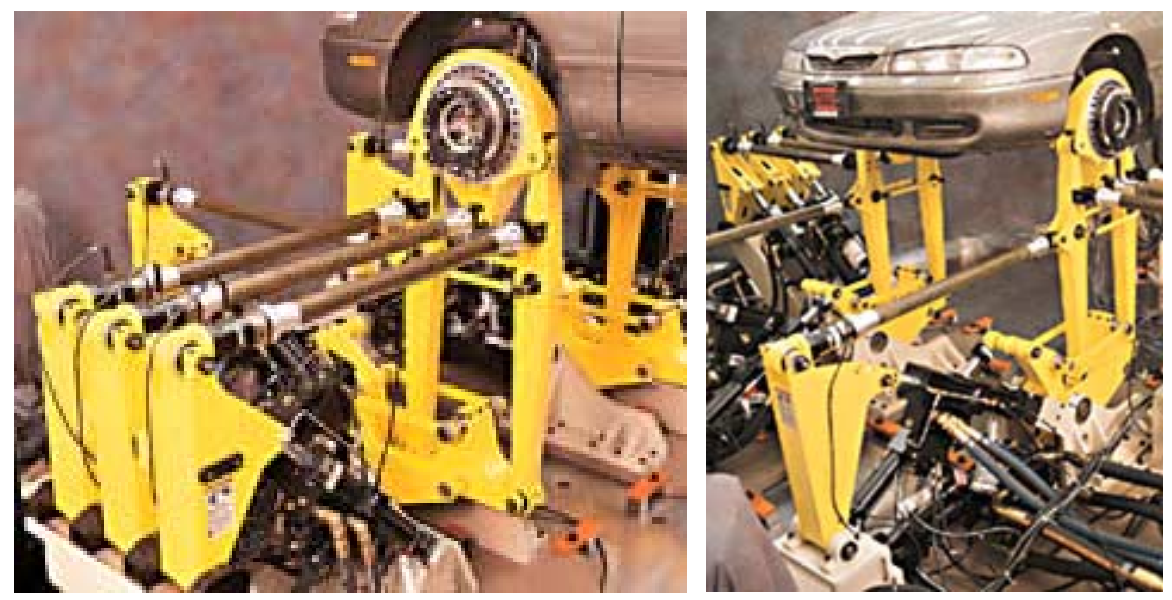

FIGURA 1.4 - Atuadores hidráulicos em ensaio de automóvel (www.mts.com)

\subsubsection{EXCITADOR ELETRODINÂMICO}

Um dos principais mecanismos de excitação, em se tratando de testes de vibração, é o excitador eletrodinâmico. Apresenta-se em uma vasta gama de configurações, podendo-se encontrar desde pequenos excitadores que fornecem menos de $0,5 \mathrm{~N}$ numa faixa de freqüência de praticamente 0 a $10 \mathrm{kHz}$, até excitadores que fornecem $200 \mathrm{kN}$ numa faixa mais reduzida que vai de aproximadamente 0 a $3 \mathrm{kHz}$ (McCONNELL, 1995). A estrutura básica de um excitador eletrodinâmico pode ser vista na Fig. 1.5.

A armadura, parte móvel do excitador onde é conectado o item de teste, está ligada à estrutura do excitador através de um sistema de suspensão que permite o movimento vertical do mesmo, porém sendo rígida quanto à movimentos de rotação e deslocamento lateral. 


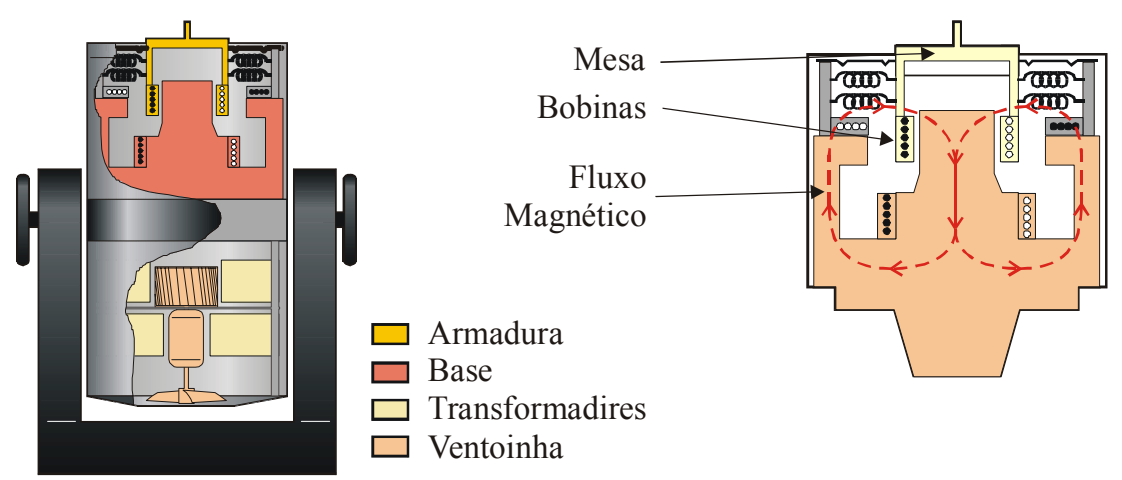

FIGURA 1.5 - Excitador eletrodinâmico

A base do excitador possui grande inércia e é ferromagnética. Alguns excitadores possuem um imã permanente, outros necessitam de um conjunto de fontes que gerem um campo magnético. O sistema de ventilação muitas vezes é necessário, dado o calor gerado no interior do excitador devido principalmente ao efeito Joule.

Considerado uma ferramenta versátil em ensaios de vibração, o excitador eletrodinâmico permite que uma estrutura seja excitada com uma grande variedade de sinais de excitação, tais como aleatório, pseudo aleatório, dente de serra, senoidal, transiente senoinoidal (chirp), etc.

\subsection{MÉTODOS DE ESTIMATIVAS DE FRFS}

Em se tratando de análise modal experimental, as Funções de Resposta em Freqüência (FRF) são as medidas mais importantes a serem feitas (ALLEMANG, 1994). Contudo, a qualidade destas funções obtidas está diretamente relacionada com fatores que antecedem o cálculo, como o arranjo experimental adotado, escolha adequada dos equipamentos, configuração do sistema de aquisição, no que diz respeito à freqüência de amostragem, uso de filtros e janelas e algoritmos de estimativa de parâmetros.

Este capítulo apresenta alguns dos principais algoritmos para estimativa de FRFs, a partir de funções no domínio da freqüência como auto-espectros e espectros cruzados dos sinais de entrada e saída da estrutura sob estudo. Pretende-se portanto, fornecer as formulações básicas e as aplicações propostas para estimadores como $\mathrm{H}_{1}$, $\mathrm{H}_{2}, \mathrm{H}_{3}$ e Hv.

A importância do entendimento destes mecanismos se dá na escolha adequada de estimadores de FRFs para ensaios com excitadores eletrodinâmicos, na presença de quedas significativas da força de excitação, bem como em testes com excitação ou aceleração controlada. Nestes casos os sinais de entrada ou de saída podem estar sujeitos a níveis significativos de ruído, e como será discutido, o uso do estimador adequado tem efeito direto sobre a qualidade dos dados adquiridos. 
Em resumo, o processo de obtenção das FRFs passa pelas seguintes etapas: (i) depois de processados os sinais no tempo e (ii) aplicadas as janelas e filtros convenientes, (iii) realizam-se as Transformadas de Fourier a fim de converter os dados do domínio do tempo para o domínio da freqüência. Como resultado têm-se os espectros de cada sinal, calculados como densidade auto-espectral (DAE) ou densidade de espectral cruzada (DEC). Estes por sua vez, formam a base para os métodos de estimativa das Funções de Resposta em Freqüência.

A seguir, demonstra-se o equacionamento dos métodos aplicados a sistemas com uma estrada (SISO e SIMO). Fig 1.6.

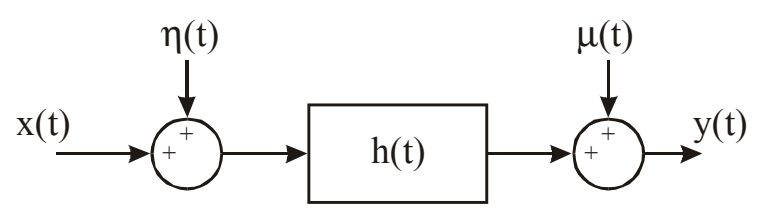

\section{FIGURA 1.6 - Diagrama de blocos de um sistema com uma entrada e uma saída}

A FRF que relaciona a saída $y(t)$ em um ponto ' $m$ ' referente a uma única entrada $\mathrm{x}(\mathrm{t})$ no ponto ' $\mathrm{n}$ ' de determinada estrutura, no domínio da freqüência é expressa da forma:

$$
\mathrm{Y}_{\mathrm{m}}(\omega)=\mathrm{H}_{\mathrm{m}, \mathrm{n}}(\omega) \mathrm{X}_{\mathrm{n}}(\omega)
$$

Sendo:

$\mathrm{Y}_{\mathrm{m}}(\omega) \quad=$ sinal de saída no ponto ' $\mathrm{m}$ '

$\mathrm{H}_{\mathrm{m}, \mathrm{n}}(\omega) \quad=$ FRF da saída em ' $\mathrm{m}$ ' relativa a entrada em ' $\mathrm{n}$ '

$\mathrm{X}_{\mathrm{n}}(\omega) \quad=$ sinal de entrada em ' $\mathrm{n}$ '

Os métodos utilizados na estimativa das FRFs fazem uso dos auto-espectros e espectros cruzados dos sinais de entrada e saída (Fig 1.7), definidos como:

$$
\text { Gxx }=X . X^{*} \quad \text { Gyy }=Y . Y^{*} \quad \text { Gyx }=Y . X^{*} \quad \text { Gxy }=X . Y^{*}
$$

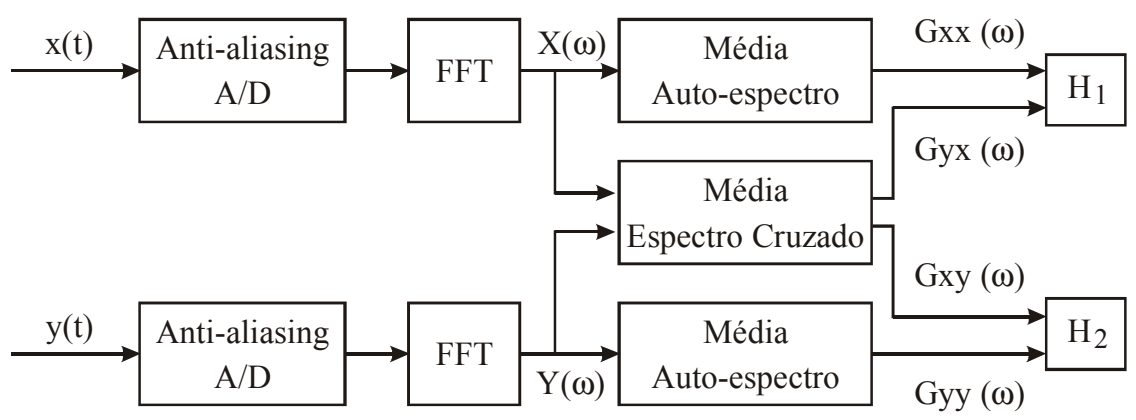

FIGURA 1.7 - Diagrama de blocos de um analisador de 2 canais gerando FRFs 
Todas estas funções pertencem ao domínio da freqüência, porém, por uma questão de conveniência de notação, daqui para frente o termo $(\omega)$ será omitido.

Um dos métodos mais comuns no cálculo de FRFs, o denominado $\mathrm{H}_{1}$, é calculado da seguinte forma (Eq. 1.3):

$$
\sum_{\mathrm{k}=1}^{\mathrm{p}} \mathrm{Gyx}=\mathrm{H}_{1} \sum_{\mathrm{k}=1}^{\mathrm{p}} \mathrm{Gxx} \Rightarrow \mathrm{H}_{1}=\frac{\sum_{\mathrm{k}=1}^{\mathrm{p}} \mathrm{Gyx}}{\sum_{\mathrm{k}=1}^{\mathrm{p}} \mathrm{Gxx}}
$$

sendo 'p' o número de amostras utilizadas no cálculo das médias.

Outro método muito utilizado é o $\mathrm{H}_{2}$, calculado conforme Eq. 1.4:

$$
\sum_{\mathrm{n}=1}^{\mathrm{p}} \mathrm{Gyy}=\mathrm{H}_{1} \sum_{\mathrm{n}=1}^{\mathrm{p}} \mathrm{Gxy} \Rightarrow \mathrm{H}_{2}=\frac{\sum_{\mathrm{n}=1}^{\mathrm{p}} \mathrm{Gyy}}{\sum_{\mathrm{n}=1}^{\mathrm{p}} \mathrm{Gxy}}
$$

Cada um destes métodos apresenta vantagens e desvantagens. O método $\mathrm{H}_{1}$, por exemplo, se mostra sensível a ruído no sinal de entrada, enquanto $\mathrm{H}_{2}$, se mostra sensível a ruído no sinal de saída (ALLEMANG, 1994). Outro problema que $\mathrm{H}_{2}$ pode apresentar é o espectro cruzado Gxy assumir valor zero em determinada freqüência.

Uma função adicional na análise de sinais em freqüência é a função Coerência, definida como:

$$
\gamma^{2}=\frac{\sum_{n=1}^{p} G y x \cdot \sum_{n=1}^{p} G_{y x}^{*}}{\sum_{n=1}^{p} G x x \cdot \sum_{n=1}^{p} G y y}=\frac{H_{1}}{H_{2}}
$$

Nota-se ainda que a coerência pode ser escrita como a razão entre $\mathrm{H}_{1}$ e $\mathrm{H}_{2}$ (MAIA \& SILVA, 1997). Para várias amostras, esta função adimensional tende a 1, em freqüências para as quais o sinal de saída medido se deve tão somente ao sinal de entrada medido. Sendo assim, a função Coerência é uma ferramenta poderosa na determinação de irregularidades nos sinais medidos, como: ruído externo, não linearidade entre entrada e saída ou mesmo outras entradas (não medidas) que contribuam para a saída.

Outro método experimental de estimativa da FRF de uma estrutura é o denominado $\mathrm{H}_{3}$ (MAIA \& SILVA, 1997). Buscando minimizar os efeito de ruído, fazse uso dos espectros cruzados da entrada e da saída por um terceiro sinal, por exemplo, o sinal que alimenta o excitador (Fig. 1.8). 
Desta forma, defini-se $\mathrm{H}_{3}$ como:

$$
\sum_{n=1}^{p} G_{r y}^{\prime}=H_{1} \sum_{n=1}^{p} G_{r x}^{\prime} \Rightarrow H_{3}=\frac{\sum_{n=1}^{p} G r y^{\prime}}{\sum_{n=1}^{p} G r x^{\prime}}
$$

sendo x' e y' os sinais de entrada e saída acrescidos de ruído.

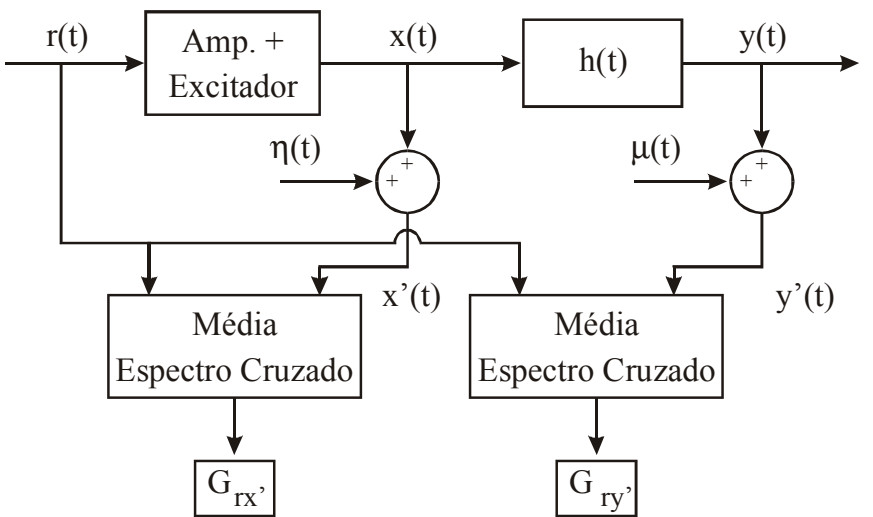

FIGURA 1.8 - Diagrama de blocos para a obtenção de $\mathrm{H}_{3}$

Outro algoritmo existente, com grande aplicação nos casos de sistemas com múltiplas entradas e múltiplas saídas, é o Hv (ALLEMANG, 1994). O cálculo de Hv requer a aquisição de todos os auto-espectros e espectros cruzados relativos a cada par de sinais de entrada e saída, para os quais se obtém a matriz espectral [Gxxy]:

$$
[G x x y]=\left[\begin{array}{ll}
G x x & G x y \\
G y x & G y y
\end{array}\right]
$$

Com os autovalores e autovetores associados a [Gxxy], obtém-se Hv normalizando-se o autovetor $\{\mathrm{V}\}$ associado ao menor autovalor encontrado da seguinte forma:

$$
\{\mathrm{V}\}=\left\{\begin{array}{c}
\mathrm{Hv} \\
-1
\end{array}\right\}
$$

A fim de se obter a FRF, a mesma operação deve ser repetida para cada freqüência analisada.

MAIA \& SILVA (1997) ainda observam, que tendo $\mathrm{H}_{1}$ como um limite inferior, e $\mathrm{H}_{2}$ como um limite superior, pode-se definir um intervalo no qual a FRF verdadeira estaria contida. Ainda, $\mathrm{H}_{\mathrm{V}}$ estaria contida neste intervalo como média geométrica entre $\mathrm{H}_{1}$ e $\mathrm{H}_{2}$ :

$$
\mathrm{H}_{\mathrm{V}}(\omega)=\sqrt{\mathrm{H}_{1}(\omega) \mathrm{H}_{2}(\omega)}
$$


Os mesmos algoritmos, apresentados até aqui, aplicam-se aos sistemas com múltiplas entradas (MISO e MIMO). Contudo assume-se que para tais sistemas, todas as entradas são conhecidas, isto é, podem ser medidas. Considerando um sistema com 'Ni' entradas e 'No' saídas, conforme a Fig. 1.9:

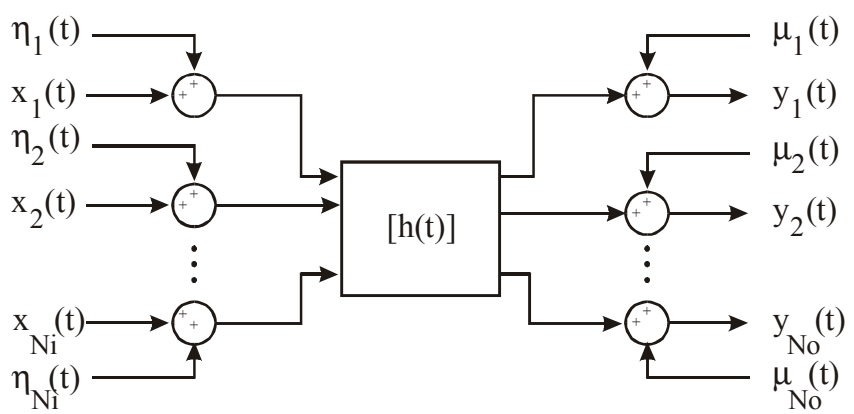

FIGURA 1.9 - Diagrama de bloco de um sistema com múltiplas entradas e múltiplas saídas

Desta forma o sistema fica determinado em termos das $F R F s \mathrm{H}_{\mathrm{m}, \mathrm{n}}$ como

$$
Y_{n}(\omega)=\sum_{n=1}^{N i} H_{n, m}(\omega) X_{m}(\omega)
$$

Sendo:

$\mathrm{Y}_{\mathrm{n}}(\omega) \quad=$ sinal de saída no ponto ' $\mathrm{m}$ '

$\mathrm{H}_{\mathrm{n}, \mathrm{m}}(\omega) \quad=$ FRF da saída em ' $\mathrm{m}$ ' relativa a entrada em ' $\mathrm{n}$ '

$\mathrm{X}_{\mathrm{m}}(\omega) \quad=$ sinal de entrada em ' $\mathrm{n}$ '

Reescrevendo-se a Eq. 1.10 para o sistema completo em termos dos autoespectros e espectros cruzados:

$\begin{array}{cccc}\text { Output 1 } \\ \text { Output 2 } \\ \text { Output 3 } \\ \vdots \\ \text { Output n }\end{array}\left[\begin{array}{cccc}\mathrm{Gyx}_{11} & \cdots & \mathrm{Gyx}_{1 \mathrm{~m}} \\ \mathrm{Gyx}_{21} & \cdots & \mathrm{Gyx}_{2 \mathrm{~m}} \\ \mathrm{Gyx}_{31} & \cdots & \mathrm{Gyx}_{3 \mathrm{~m}} \\ \vdots & \ddots & \vdots \\ \mathrm{Gyx}_{\mathrm{n} 1} & \cdots & \mathrm{Gyx}_{\mathrm{nm}}\end{array}\right]=\left[\begin{array}{ccc}\mathrm{H}_{11} & \cdots & \mathrm{H}_{1 \mathrm{~m}} \\ \mathrm{H}_{21} & \cdots & \mathrm{H}_{2 \mathrm{~m}} \\ \mathrm{H}_{31} & \cdots & \mathrm{H}_{3 \mathrm{~m}} \\ \vdots & \ddots & \vdots \\ \mathrm{H}_{\mathrm{n} 1} & \cdots & \mathrm{H}_{\mathrm{nm}}\end{array}\right]\left[\begin{array}{ccc}\mathrm{Gxx}_{11} & \cdots & \mathrm{Gxx}_{1 \mathrm{~m}} \\ \vdots & \ddots & \vdots \\ \mathrm{Gxx}_{\mathrm{m} 1} & \cdots & \mathrm{Gxx}_{\mathrm{mm}}\end{array}\right]$ Input 1

sendo:

$[\mathrm{Gyx}]_{\mathrm{n}, \mathrm{m}}=$ vetor de espectros cruzados das $\mathrm{n}$ entradas pelas $\mathrm{m}$ saídas

$[\mathrm{H}]_{\mathrm{n}, \mathrm{m}} \quad=$ matriz $\mathrm{m}, \mathrm{n}$ das FRFs

$[\mathrm{Gxx}]_{\mathrm{m}, \mathrm{m}}=$ vetor de auto-espectros das ' $\mathrm{n}$ ' entradas 
Desta forma pode-se obter as FRFs de várias formas, por exemplo com inversão das matrizes Gxx:

$$
[\mathrm{H}]=[\mathrm{Gyx}][\mathrm{Gxx}]^{-1}
$$

Assim, a Eq. 1.12 descreve o algoritmo $\mathrm{H}_{1}$ para o caso de múltiplas entradas.

Para o método $\mathrm{H}_{2}$, ou mesmo para o cálculo de função Coerência Ordinária Múltipla ou Parcial (que serão descritas a seguir), torna-se necessário adquirir as matrizes de auto-espectro das saídas Gyy. Com isso, analogamente aos sistemas SISO, tem-se o estimador $\mathrm{H}_{2}$ definido como:

$$
[\mathrm{H}]=[\mathrm{Gyy}][\mathrm{Gxy}]^{-1}
$$

Observa-se ainda que o uso do método $\mathrm{H}_{2}$ em sistemas MIMO se restringe àqueles cujo número de entradas é igual ao número de saídas, visto que esse requer a inversão de Gxy.

O algoritmo Hv, também é similar ao ilustrado para sistemas SISO e SIMO. Contudo, a matriz [Gxxy] é definida como:

$$
[\mathrm{Gxxy}]=\left[\begin{array}{cc}
{[\mathrm{Gxx}]} & {[\mathrm{Gyx}]^{\mathrm{H}}} \\
{[\mathrm{Gyx}]} & {[\mathrm{Gyy}]}
\end{array}\right]
$$

na qual ' $\mathrm{H}$, denota a Hermitiana (complexo conjugado transposto) da matriz. Observase ainda, que [Gxxy] deve ser obtida para cada saída 'y', o mesmo para Gyx e $\mathrm{Gyx}^{\mathrm{H}}$ e Gyy, o que resulta em [Gxxy $\left.y_{\mathrm{Ni}+1}\right]$. Ainda, este conjunto de equações, bem como as matrizes resultantes também são função da freqüência.

Da solução do autoproblema envolvendo [Gxxy], obtém-se Hv normalizando-se o autovetor $\{\mathrm{V}\}$ associado ao menor autovalor encontrado da seguinte forma:

$$
\{\mathrm{V}\}=\left\{\begin{array}{lllll}
\mathrm{H}_{\mathrm{n}, 1} & \mathrm{H}_{\mathrm{n}, 2} & \ldots & \mathrm{H}_{\mathrm{n}, \mathrm{Ni}} & -1
\end{array}\right\}^{\mathrm{T}}
$$

Funções Coerência também podem ser obtidas de sistemas com múltiplas entradas. Entretanto, novas funções precisam ser definidas e a função coerência ordinária, admite outra interpretação. Ainda, GADE et al. (1996) apresenta uma interpretação gráfica das relações entrada / saída em medidas SISO e MIMO, que ajuda no entendimento de grandezas como coerência parcial e múltipla, comuns em medidas MIMO, e de que forma o ruído e existência de correlação entre as diversas entradas afetam estas grandezas.

Neste caso, a função coerência obtida entre uma saída e uma entrada pode assumir valores muito menores que 1,0, mesmo que a linearidade entre elas seja válida. 
Isto ocorre devido ao efeito das outras entradas (ALLEMANG, 1994). A mesma formulação pode ser aplicada a dois sinais de força. A coerência obtida entre dois sinais de força é um indicativo da correlação entre estas das entradas, sendo desejável que assuma o menor valor possível na faixa de freqüência de interesse.

Defini-se, então, a coerência parcial, como sendo a função coerência obtida a partir de sinais pré-condicionados, ou seja, de cada um dos sinais são extraídos os efeitos das demais entradas. Este condicionamento tem efeito direto sobre a coerência obtida, quanto mais evidente for a correlação entre duas ou mais entradas. Desta forma é possível obter funções coerência parcial de quaisquer combinações de entrada / entrada, entrada / saída ou saída / saída. Contudo, ALLEMANG (1994) questiona a utilidade deste tipo de função em análise modal, em especial as obtidas entre duas entradas.

Desta forma, torna-se necessário o uso da função coerência múltipla, que descreve a linearidade entre determinada saída e todas as entradas do sistema. Sendo assim, existe uma função coerência múltipla para cada saída do sistema definida como:

$$
\operatorname{MCoh}_{n}=\sum_{\mathrm{q}=1}^{\mathrm{Ni}} \sum_{\mathrm{p}=1}^{\mathrm{Ni}} \frac{\mathrm{H}_{\mathrm{nq}} \mathrm{Gxx}_{\mathrm{qp}} \mathrm{H}_{\mathrm{nt}}^{*}}{\mathrm{Gyy}_{\mathrm{nn}}}
$$

Espera-se que a função coerência múltipla de determinada saída assuma valores próximos de 1,0, se a configuração de entradas adotada favorece a aquisição daquela saída. Ainda, diferentemente dos casos SISO e SIMO, a coerência não deve apresentar valores baixos nas regiões de anti-ressonância, visto que estas ocorrem em diferentes freqüências para cada uma das entradas, o que significa que as razões entre sinal e ruído para estas freqüências são compensadas pelas outras entradas (ALLEMANG, 1994).

Ainda, em ensaios com múltiplas entradas não correlatas, espera-se que o valor da coerência múltipla seja próximo de 1,0 . Se houver uma pequena correlação entre as forças, este valor ainda não deve ser muito menor do que um. Entretanto, é inevitável que haja alguma correlação entre as forças em regiões próximas às ressonâncias da estrutura, devido justamente aos fenômenos de interação entre os excitadores e a estrutura. Contudo, mesmo havendo uma considerável correlação entre as entradas, ainda é possível obter as características dinâmicas da estrutura baseando-se nas matrizes de espectros cruzados (MAIA \& SILVA, 1997). 


\section{SínTESE da Bibliografia Fundamental}

Este capítulo apresenta uma revisão de literatura sobre o tema abordado. Buscando melhor clareza, a revisão bibliográfica está dividida em dois subtópicos relativos respectivamente à interação excitador / estrutura e ensaios com múltiplas entradas e múltiplas saídas (do inglês MIMO).

\subsection{INTERAÇÃO EXCITADOR / ESTRUTURA}

Sempre que um excitador eletrodinâmico é usado em malha aberta para excitar uma estrutura, pode-se observar um decremento na amplitude da força quando sua freqüência se aproxima de uma determinada freqüência natural da estrutura (RAO, 1987).

RAO (1987) divide a interação excitador / estrutura em duas parcelas, a mecânica e a eletrodinâmica. A interação mecânica depende basicamente da massa da armadura e do fator de amortecimento modal da estrutura. A interação eletrodinâmica depende de dois outros fatores: rigidez e amortecimento eletromagnéticos. Em resumo, segundo RAO (1987) estruturas leves requerem armaduras mais pesadas enquanto estruturas engastadas, armaduras mais leves.

TOMLINSON (1979) mostra que as distorções harmônicas verificadas no sinal de entrada de força num sistema em ressonância são devidas ao comportamento não linear do excitador nestas freqüências. $O$ comportamento não linear é devido principalmente ao comportamento quadrático do campo magnético do excitador predominantemente em freqüências harmônicas de segunda ordem. $\mathrm{O}$ fator de amortecimento do sistema possui influência relevante no processo de distorção. A fim de minimizar esta causa, este fator deve ser significantemente maior que a razão entre a rigidez do excitador e da estrutura. Ainda, se as amplitudes de vibração impostas durante os testes forem pequenas, o efeito também é minimizado devido a dois fatores: as pequenas amplitudes restringem o movimento da armadura a regiões próximas do equilíbrio minimizando os efeitos não lineares do campo magnético; modos de vibrar associados a freqüências mais altas produzem um aumento das forças de amortecimento que resultam num aumento das componentes fundamentais de força, ao passo que em 
freqüências harmônicas de segunda ordem e superiores, as forças de amortecimento permanecem constantes.

Tanto em OLSEM (1986), como em MOUCH et al. (1990), ressalta-se a massa da armadura como elemento fundamental no fenômeno de queda na força de excitação. Ambos propõem um modelo matemático para o sistema amplificador / excitador / estrutura. O modelo de OLSEM (1986) despreza o efeito de indutância do sistema elétrico do excitador. Já no modelo de MOUCH et al. (1990), alguns valores como resistência e indutância da bobina, força versus corrente, velocidade versus tensão, e a corrente gerada pelo movimento da bobina no campo magnético, são tidos como objetos de estudo e são propostos métodos experimentais de obtenção de algumas destas relações.

OLIVEIRA \& VAROTO (2002a) verificam alguns dos modelos propostos e validam experimentalmente os modelos do excitador e do sistema composto por amplificador / excitador / estrutura. Ainda, propõe-se um método experimental para obtenção da relação entre velocidade da armadura e a tensão gerada nas bobinas.

Conhecer o fenômeno de interação excitador / estrutura é de fundamental importância em testes de avaliação de uma estrutura, seja uma máquina, um veículo ou sub-conjunto, o qual deseja-se submeter a condições similares a que ele esteja sujeito quando em operação (VAROTO, 1996). Neste caso, faz-se necessário o uso de um controlador que anule o efeito da interação, fornecendo a entrada desejada ao sistema.

CAMPEDELLI \& TONI (1991) descreve em detalhes um arranjo experimental em malha fechada utilizado em testes com força e (ou) aceleração controlada. Apesar de disponíveis no mercado, e aparentemente de fácil operação, este tipo de teste requer certa experiência do operador, no que diz respeito à estrutura sob estudo, bem como dos fenômenos físicos envolvidos neste tipo de ensaio, o que de outra forma poderia levar a danos no item de teste ou nos equipamentos utilizados.

\subsection{ENSAIOS COM MÚLTIPLAS ENTRADAS E MÚlTIPLAS SAÍDAS}

De forma geral, os ensaios de vibração são realizados com o intuito de se verificar um modelo teórico, suas características dinâmicas e seus modos de falha, para desenvolver métodos seguros de avaliação da qualidade na produção, avaliar um produto quanto a determinado número de especificações ou para desenvolver entradas dinâmicas a partir de dados colhidos em campo para posterior aplicação em modelos em elementos finitos ou outras ferramentas de projeto (McCONNELL, 1995). Porém, na maioria dos ensaios realizados em laboratório, mede-se apenas uma entrada e uma saída das 36 combinações possíveis, para cada par de pontos da estrutura, se considerados os três graus de liberdade translacionais e os três graus de liberdade rotacionais (LOFRANO et al. 2002). 
Medidas de FRF a partir de simples e múltipla excitação com excitador eletrodinâmico, têm sido uma das formas mais amplamente utilizadas em identificação estrutural experimental, particularmente no que se referem às estruturas automotivas e aeroespaciais (McCONNELL, 1995).

O tipo de excitação, bem como a técnica de aquisição e processamento dos sinais podem influenciar consideravelmente a qualidade dos resultados obtidos em um ensaio envolvendo múltipla excitação. A escolha apropriada destes fatores deve levar em consideração o tipo de estrutura a ser estudada. Estruturas com fator de amortecimento maior ou menor requerem procedimentos diferenciados.

Em um ensaio típico, com o qual se busca, por exemplo, obter algumas FRFs da estrutura, é comum fazer tais medidas excitando-se a estrutura em um ponto e se medindo as acelerações nos demais pontos. Entretanto, em ensaios de estruturas grandes e complexas, realizados com uma única fonte de excitação (SISO e SIMO), a dissipação de energia pode causar grandes diferenças na amplitude das grandezas medidas. Este problema pode ser contornado com o uso de múltipla excitação (WEAVER \& PASTRNAK, 1985). Ainda, no caso de uma única fonte de excitação, se o ponto de aplicação da força for escolhido nas proximidades de uma linha nodal da estrutura, a identificação de alguns modos de vibrar pode tornar-se impossível. Outro problema resolvido pela múltipla excitação é o de consistência das FRFs medidas em um único ensaio, já que se tornam desnecessárias mudanças de posicionamento dos excitadores, transdutores e acelerômetros, sendo todas as grandezas medidas simultaneamente (ALLEMANG, 1994).

GADE \& GATZWILLER (1996) apresentam uma interpretação gráfica das relações entrada / saída em medidas SISO e MIMO, que ajuda no entendimento de grandezas como coerência parcial e múltipla, comuns em medidas MIMO, e de que forma o ruído e existência de correlação entre as diversas entradas afetam estas grandezas.

Bem como com as técnicas envolvendo excitação aleatória, as técnicas de excitação senoidal vêm sendo amplamente desenvolvidas e aplicadas no estudo dinâmico de estruturas, principalmente no caso de estruturas mais complexas como aeronáuticas e espaciais (OTTE et al., 1991).

Contudo, existem duas formas de se proceder um ensaio de Múltipla Excitação Senoidal: Ressonância em Fase e Separação de Fase (VAN der AUWERAER et al., 1991). Apesar de diferirem completamente uma da outra, estas duas abordagens dependem da aplicação de sinais de força bem definidos bem como da medição de suas respostas.

Nos ensaios de Ressonância em Fase, os mais tradicionais, a estrutura é forçada a vibrar em seus modos normais, separadamente. Isto requer que cada modo de vibrar seja sintonizado, o que é feito tradicionalmente de forma empírica e interativa durante o 
ensaio. Porém, quando o número de excitadores começa a aumentar, este processo se torna trabalhoso, requerendo habilidade e experiência do experimentalista para uma sintonia precisa de cada um dos modos de vibrar. Indicadores especiais, provenientes de ensaios preliminares podem tornar este processo mais rápido e preciso, principalmente no caso de modos de vibrar que possuam freqüências naturais muito próximas.

A escolha do método de excitação é importante no projeto de um ensaio de vibração (HUNT, 1991). Múltiplas entradas aleatórias têm se mostrado mais eficientes do ponto de vista da rapidez e quantidade de modos de vibrar identificados em relação aos métodos clássicos, como varreduras senoidais e excitação aleatória em um único ponto. No entanto, bons resultados extraídos deste tipo de ensaio dependem, entre outros, do nível de excitação, boas medidas de força, bem como do equipamento e dos algoritmos utilizados.

Ainda, OTTE et al. (1991) fazem uma abordagem das vantagens e desvantagens dos dois métodos e propõe uma nova técnica, resultante da integração destas duas, na qual parâmetros extraídos de um pré-teste alimentam a configuração do experimento final quanto ao balanceamento e posicionamento das forças, resultando num ganho de tempo de testes.

Os métodos de Múltipla Excitação Aleatória (MEA) têm se mostrado uma poderosa ferramenta em ensaios modais. Se combinada a outras ferramentas de análise modal como ERA, Polireferência, MMIF, o MEA permite a identificação simultânea de muitos modos de vibrar de forma precisa, mesmo que haja freqüências próximas, e em um curto intervalo de tempo, já que todas as medidas podem ser feitas simultaneamente em uma única configuração de ensaio (HUNT, 1991). Para tanto, torna-se necessária a escolha criteriosa do número de excitadores a serem utilizados, seu posicionamento, nível de excitação e sinal adequado ao tipo de ensaio e estrutura sob estudo.

Os ensaios de Separação de Fase são divididos em dois passos: no primeiro algumas FRFs são obtidas (relativas a todos os pontos de medida e excitação) por varredura senoidal. No segundo passo, estas FRFs são processadas por um algoritmo de identificação. Apesar dos requisitos para os sinais de excitação serem menos críticos neste caso que no anterior, este tipo de ensaio geralmente resulta em um maior tempo de aquisição e processamento, o que tende a aumentar em função do número de varreduras necessárias e do número de excitadores.

Apesar de um dos principais requisitos para realização de testes envolvendo múltiplas fontes de excitação ser a garantia de que tais fontes sejam não-correlatas, técnicas de obtenção de FRFs a partir de sinais correlatos têm sido propostos (WEAVER \& PASTRNAK, 1985). A grande vantagem destes métodos é a possibilidade de utilização de um sistema de aquisição convencional, sem a opção de diversos canais de saída, em geral mais dispendiosos. 
Assim como nos testes com um único excitador, testes com sinais múltiplos sinais modificados são propostos por CLARK (1985) a fim de obter dados de força e resposta com maior qualidade. Neste caso faz-se uso de múltiplos sinais aleatórios, modificados de forma a propiciar melhor distribuição de energia pelos modos e conseqüentemente melhor relação sinal / ruído. 


\section{INTERAÇÃO EXCITADOR / ESTRUTURA: SiMUlaÇões NuMÉRICAS}

O objetivo principal deste capítulo é fornecer, através de simulações numéricas dos modelos do excitador e do conjunto excitador / estrutura, um entendimento claro sobre os fenômenos físicos envolvidos, bem como gerar os subsídios necessários para a análise dos resultados experimentais descritos no capítulo seguinte. Através da análise dos resultados obtidos com tais simulações, observam-se os principais fenômenos envolvidos na interação excitador / estrutura, como a queda da força de excitação, tensão de retorno ( $\left.\mathrm{E}_{\mathrm{bemf}}\right)$, bem como as principais características dinâmicas do excitador em suas diversas condições de uso, no que diz respeito à fixação da base, faixa útil de operação, modos de operação do amplificador de potência, etc.

A modelagem do fenômeno de interação entre o excitador eletrodinâmico e a estrutura sob estudo descrita a seguir, envolve a análise de vários parâmetros tais como, número de graus de liberdade do modelo do excitador e da estrutura, modelo de fixação da base, modelo de fixação da estrutura, interações eletromecânicas, dentre outros. Tais características, inerentes ao sistema real, tornam complexas quaisquer abordagens diretas por meio de modelos analíticos completos (McCONNELL, 1995). Para facilitar a compreensão dos modelos e dos fenômenos físicos envolvidos propõe-se um desenvolvimento analítico de modelos intermediários que procuram representar cada uma das características do excitador e, posteriormente, do conjunto excitador / estrutura sob estudo.

Busca-se com os resultados identificarem-se os seguintes efeitos na dinâmica do excitador e do conjunto excitador / estrutura:

○ Efeito da suspensão da base do excitador;

- Efeito da dinâmica da armadura;

- Faixa de freqüência útil de um excitador;

○ Modos de operação do amplificador de potência;

- Efeito da dinâmica do circuito elétrico do amplificador e do excitador, sobre a resposta do excitador;

○ Influência dos graus de liberdade rotacionais do excitador e estrutura;

o Parcela mecânica da interação entre o excitador e a estrutura; 
- Efeito da dinâmica do circuito elétrico sobre a resposta da estrutura.

As seções seguintes tratam de cada um dos modelos separadamente. Inicialmente aborda-se a modelagem mecânica do excitador, acrescendo-se posteriormente ao modelo, as características eletromagnéticas dos circuitos de excitador e do amplificador de potência. Num segundo estágio, adotado o modelo para o excitador, são propostos os modelos para o conjunto excitador / estrutura.

\subsection{MODELO DO EXCITADOR}

A modelagem de um excitador eletrodinâmico subdivide-se em duas partes: Inicialmente o modelo mecânico que considera as características dinâmicas da estrutura do excitador como massa da base e da armadura e rigidez da suspensão. Posteriormente o modelo eletro-mecânico, para o qual consideram-se as características elétricas do amplificador de potência e dos circuitos do excitador.

\subsubsection{MODELO MECÂNICO DO EXCITADOR}

O objetivo desta seção é o de estudar o comportamento do excitador como um sistema mecânico. Inicialmente adota-se o modelo mecânico completo, ou seja, com três graus de liberdade (3 GDL). Baseado nos resultados obtidos para este modelo, propõese hipóteses simplificadoras, reduzindo-se então o modelo do excitador para um de 2 GDL composto pela base e pela armadura. Posteriormente, considera-se a base como referencial inercial e a armadura como um sistema de 2 GDL. Este estudo, em particular, permite a análise da faixa útil de operação do excitador. Por fim, adota-se o modelo mecânico de 1 GDL para o excitador, assumindo-se que este opere dentro de sua faixa útil. Este modelo servirá de base para o modelo eletromecânico proposto na seção seguinte.

A Fig. 3.1 sugere o seguinte modelo mecânico para o excitador, no qual, $\mathrm{m}_{\mathrm{B}}, \mathrm{m}_{\mathrm{m}}$ e $m_{b}$ representam as massas da base, mesa e bobinas, respectivamente.

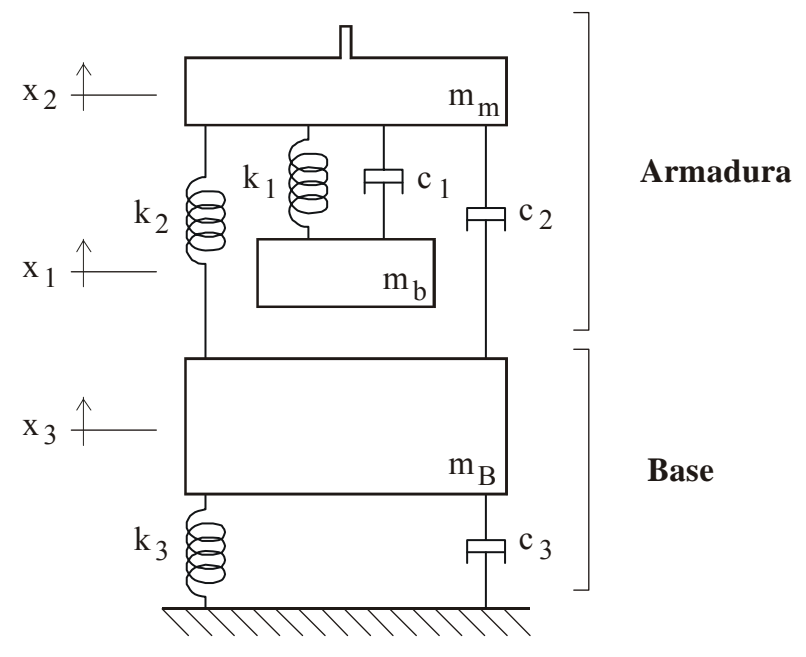

FIGURA 3.1 - Modelo mecânico do excitador 
A equação de movimento para este sistema pode ser escrita na forma matricial como (CRAIG, 1995):

$$
[\mathrm{m}]\{\ddot{\mathrm{x}}\}+[\mathrm{c}]\{\dot{\mathrm{x}}\}+[\mathrm{k}]\{\mathrm{x}\}=\{\mathrm{f}\}
$$

na qual $\{\mathrm{x}\}$ é o vetor de posição, $\{\mathrm{f}\}$ o de carregamento ambos no domínio do tempo e as matrizes de massa, amortecimento e rigidez, respectivamente $[\mathrm{m}],[\mathrm{c}] \mathrm{e}[\mathrm{k}]$, são dados por:

$$
\begin{aligned}
& {[\mathrm{m}]=\left[\begin{array}{ccc}
\mathrm{m}_{\mathrm{B}} & 0 & 0 \\
0 & \mathrm{~m}_{\mathrm{m}} & 0 \\
0 & 0 & \mathrm{~m}_{\mathrm{b}}
\end{array}\right]} \\
& {[\mathrm{c}]=\left[\begin{array}{ccc}
\mathrm{c}_{1}+\mathrm{c}_{2} & -\mathrm{c}_{2} & 0 \\
-\mathrm{c}_{2} & \mathrm{c}_{2}+\mathrm{c}_{3} & -\mathrm{c}_{3} \\
0 & -\mathrm{c}_{3} & \mathrm{c}_{3}
\end{array}\right]} \\
& {[\mathrm{k}]=\left[\begin{array}{ccc}
\mathrm{k}_{1}+\mathrm{k}_{2} & -\mathrm{k}_{2} & 0 \\
-\mathrm{k}_{2} & \mathrm{k}_{2}+\mathrm{k}_{3} & -\mathrm{k}_{3} \\
0 & -\mathrm{k}_{3} & \mathrm{k}_{3}
\end{array}\right]}
\end{aligned}
$$

Para as simulações realizadas com este sistema, adotam-se valores de um excitador típico, como proposto por McCONNELL (1995), para o qual:

$$
\begin{aligned}
& \frac{\mathrm{m}_{\mathrm{B}}}{\left(\mathrm{m}_{\mathrm{m}}+\mathrm{m}_{\mathrm{b}}\right)}=100 \quad \text { e } \quad \frac{\mathrm{m}_{\mathrm{m}}}{\mathrm{m}_{\mathrm{b}}}=10 \\
& r=\frac{\omega}{\omega_{1}}, \quad \frac{\omega_{2}}{\omega_{1}}=60 \quad \text { e } \quad \frac{\omega_{3}}{\omega_{1}}=600 \\
& \zeta_{1}=0,01, \quad \zeta_{2}=0,01 \quad \text { e } \quad \zeta_{3}=0,01
\end{aligned}
$$

A Eq. 3.3 ilustra os modos de vibrar normalizados expressos na forma de vetores.

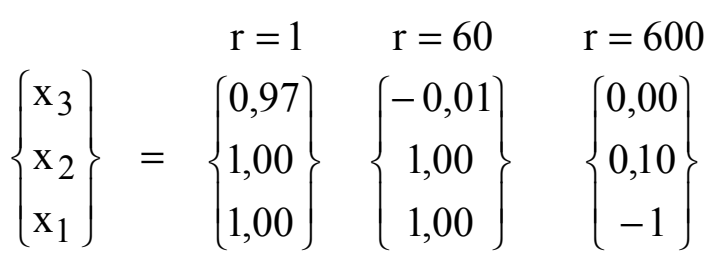

As FRFs de ponto, ou seja, com entrada e saída no mesmo elemento de massa, para este sistema podem ser vistas na Fig. 3.2. 


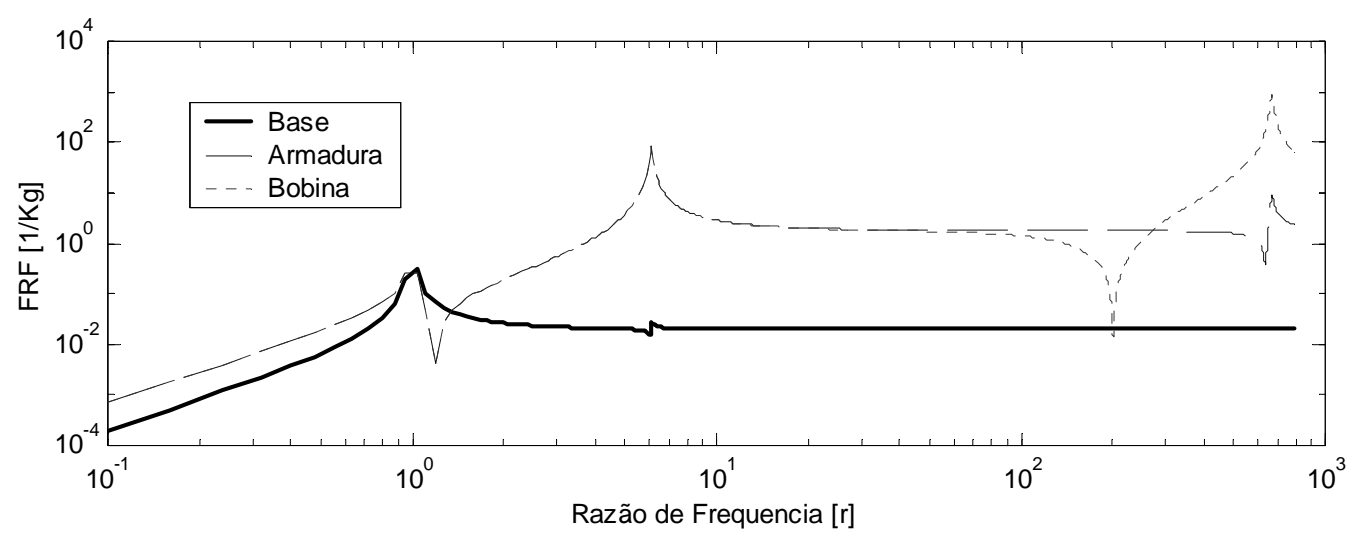

FIGURA 3.2 - FRFs do modelo de 3 GDL

Observa-se que as FRFs da armadura e da bobina são praticamente idênticas até aproximadamente $r=100$. Ainda, a Eq. 3.3 indica que não há movimento relativo entre a mesa e as bobinas para o $1^{\circ}$ e $2^{\circ}$ modos de vibrar. Portanto, sugere-se a adoção de um modelo de 2 GDL para estudos nesta faixa de freqüência, formado pela base e pela armadura.

A Fig. 3.3 ilustra o sistema de 2 GDL com entradas de força $F_{e}$ (força eletromagnética) que age na base e na armadura do excitador. É importante observar que estas forças são de ação e reação (McCONNELL, 1995) e (MAIA \& SILVA, 1997).

Seguindo o equacionamento matricial para um sistema de 2GDL tem-se:

$$
[\mathrm{m}]=\left[\begin{array}{cc}
\mathrm{m}_{\mathrm{B}} & 0 \\
0 & \mathrm{~m}_{\mathrm{a}}
\end{array}\right],[\mathrm{c}]=\left[\begin{array}{cc}
\mathrm{c}_{1}+\mathrm{c}_{2} & -\mathrm{c}_{2} \\
-\mathrm{c}_{2} & \mathrm{c}_{2}
\end{array}\right] \text { e }[\mathrm{k}]=\left[\begin{array}{cc}
\mathrm{k}_{1}+\mathrm{k}_{2} & -\mathrm{k}_{2} \\
-\mathrm{k}_{2} & \mathrm{k}_{2}
\end{array}\right]
$$

Os gráficos da Fig. 3.4 mostram a aceleração da base e da armadura. Os valores utilizados nesta simulação foram obtidos no manual de operação $(B \& K, 1974)$ de um dos excitadores do Laboratório de Dinâmica da EESC-USP. Estes valores podem ser encontrados na Tab. 3.1.

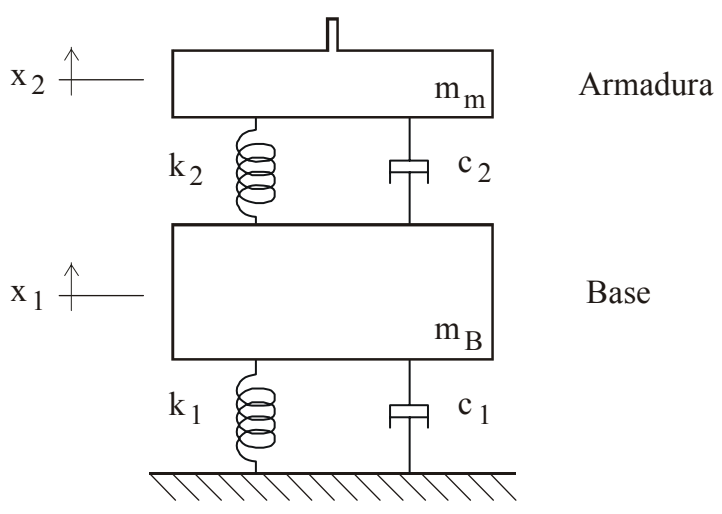

FIGURA 3.3 - Modelo de 2 GDL do excitador

Graças ao fato de haver sempre forças de mesma magnitude e sentidos opostos atuando simultaneamente na base e na armadura, este sistema apresenta um 
comportamento dinâmico peculiar. Por esta razão, a simples observância de suas FRFs não representa uma forma eficaz de interpretar seu comportamento. Sendo assim a Fig. 3.4 apresenta gráficos de aceleração adimensional para a base e armadura. Tais acelerações são resultado de forças de mesma magnitude e sentidos opostos atuando simultaneamente sobre as massas.

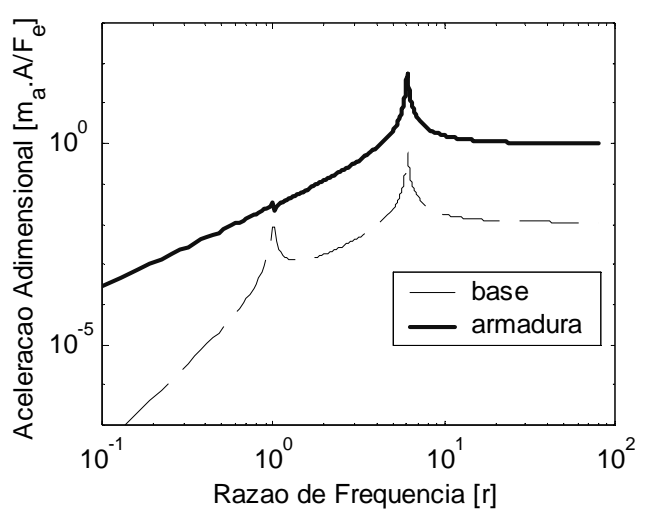

(a)

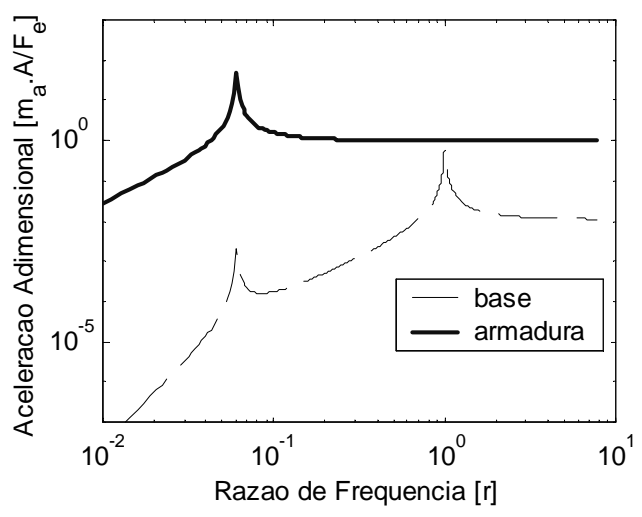

(b)

FIGURA 3.4 - Espectro de Aceleração do excitador (a) fundação flexível (b) fundação rígida

TABELA 3.1 - Grandezas físicas do excitador B\&K 4801/4812

\begin{tabular}{rcc}
\hline \hline & Base Flexível & Base Rígida \\
\hline $\mathrm{m}_{\mathrm{B}}[\mathrm{kg}]$ & 88 & 88 \\
\hline $\mathrm{m}_{\mathrm{a}}[\mathrm{kg}]$ & 0,454 & 0,454 \\
\hline $\mathrm{k}_{1}[\mathrm{kN} / \mathrm{m}]$ & 350 & 350000 \\
\hline $\mathrm{k}_{2}[\mathrm{~N} / \mathrm{m}]$ & 21000 & 21000 \\
\hline $\mathrm{c}_{1}[\mathrm{~kg} / \mathrm{s}]$ & 110 & 3300 \\
\hline $\mathrm{c}_{2}[\mathrm{~kg} / \mathrm{s}]$ & 3,4 & 3,4 \\
\hline $\mathrm{L}[\mu \mathrm{H}]$ & 26 & 26 \\
\hline $\mathrm{R}[\Omega]$ & 0,49 & 0,49 \\
\hline
\end{tabular}

Na Fig. 3.4a podem-se observar as acelerações para o caso da base se encontrar apoiada sobre um suporte flexível (freqüência natural entre 0,5 e $20 \mathrm{~Hz}$ ), enquanto na Fig. $3.4 \mathrm{~b}$ as mesmas acelerações são obtidas para o caso de um suporte rígido (freqüência natural entre 500 e $2000 \mathrm{~Hz}$ ). Comparando-se os resultados obtidos para as duas configurações de fundação, pode-se observar que as ressonâncias da base ocorrem em freqüências maiores e menores que a da armadura para os casos flexível e rígido respectivamente. Como pode ser notado, quase não há influência da dinâmica da base na resposta da armadura, sendo que esta última tem um comportamento típico de um sistema de 1 GDL. Isto ocorre graças à oposição das forças atuantes e à razão entre as massas da base e da armadura.

Ainda, observa-se que em ambos os casos têm-se um comportamento similar para freqüências acima das naturais, para os quais a base vibra com aceleração de ordem $\mathrm{m}_{\mathrm{a}} / \mathrm{m}_{\mathrm{B}}$ (em geral de ordem 0,01$)$ da aceleração da armadura, ou seja, como um sistema 
livre no espaço com forças de mesma amplitude e sentidos opostos aplicadas em cada uma das massas (McCONNELL, 1995).

Portanto, é possível assumir a base como referencial inercial, ou seja, como se estivesse rigidamente conectada à terra, o que reduz em uma unidade a ordem do modelo.

Entretanto, em termos práticos, vale ressaltar que no caso da fundação flexível tem-se menos energia sendo trocada entre a base e a fundação, fato este que deve ser levado em conta quando a estrutura sob estudo e o excitador compartilham da mesma fundação. Vale lembrar, que o transdutor de forças mede a força transmitida pela mesa à estrutura, e que forças externas, mesmo as provenientes da base, podem afetar as medidas (McCONNELL, 1995).

Sendo assim, procede-se com a análise da dinâmica da armadura. Como dito anteriormente a base passa a ser o referencial inercial e a armadura então, é subdividida em 2 partes como proposto inicialmente (Fig. 3.1), de forma a permitir o estudo do comportamento do excitador em altas freqüências. Desta forma o modelo se baseia em um sistema de 2GDL como ilustrado na Fig. 3.5, na qual $\mathrm{m}_{\mathrm{m}}$ é a massa da mesa, $\mathrm{m}_{\mathrm{b}} \mathrm{a}$ massa das bobinas, $\mathrm{k}_{1}$ a rigidez da suspensão da armadura e $\mathrm{k}_{2}$ a rigidez da estrutura que une a mesa e as bobinas, também denominada spider (McCONNELL, 1995).

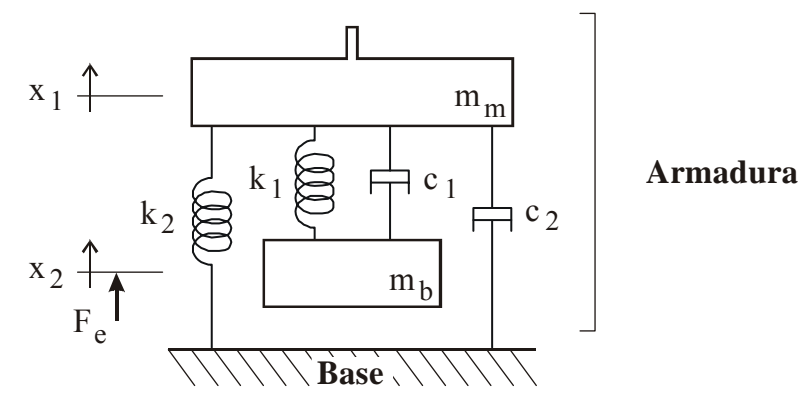

\section{FIGURA 3.5 - Modelo de 2 GDL da armadura}

Para facilitar a compreensão dos fenômenos físicos envolvidos, observam-se as acelerâncias $\mathrm{H}_{11}, \mathrm{H}_{12}$ e $\mathrm{H}_{22}$, sendo as acelerações da mesa e da bobina dadas por:

$$
A_{m}=H_{11}(\omega) F_{1}+H_{12}(\omega) F_{2} \text { e } A_{b}=H_{21}(\omega) F_{1}+H_{22}(\omega) F_{2}
$$

Conforme a Eq. 3.5, $\mathrm{H}_{11}$ representa a parcela de aceleração da mesa devido a forças aplicadas na mesa, $\mathrm{H}_{12}$ representa a parcela de aceleração da mesa devido a forças aplicadas na bobina e $\mathrm{H}_{22}$ representa a parcela de aceleração da bobina devido a forças aplicadas nela mesma, sendo $\mathrm{H}_{21}=\mathrm{H}_{12}$. A dinâmica destas três parcelas pode ser observada na Fig. 3.6, sendo que assumem comportamento idêntico até $r \cong 10$, passando pela ressonância da armadura em $\mathrm{r}=1$, até divergirem abruptamente. 


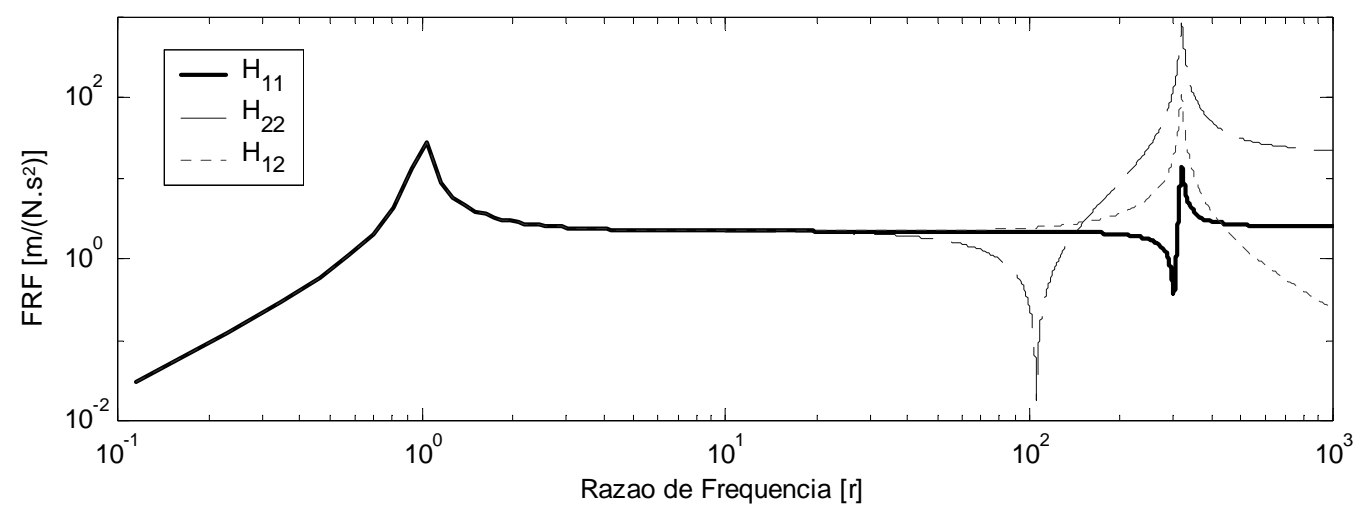

FIGURA 3.6 - Acelerâncias da armadura

Analisando-as uma a uma: a acelerância da bobina $\mathrm{H}_{22}$, após $\mathrm{r} \cong 50$, decai até $\mathrm{r} \cong$ 100 onde se observa um fenômeno de absorção dinâmica. A seguir ela volta a crescer até $\mathrm{r} \cong 320$, ou seja, a ressonância das bobinas, e se mantém com valor considerável mesmo após a ressonância. Já no caso da mesa, observa-se em $\mathrm{H}_{11}$ uma anti-ressonância em $r \cong 300$, seguida da ressonância em $r \cong 320$ e atingindo finalmente um patamar constante. Considerando-se finalmente $\mathrm{H}_{12}$, ou seja, a parcela de aceleração na mesa devido à entrada de força nas bobinas, observa-se a ressonância em $r \cong 320$ e uma queda após a ressonância. Esta dinâmica sugere que se torna inviável controlar a mesa a partir de $\mathrm{r} \cong 500$, ou seja, é preciso introduzir muita força nas bobinas para obter pouca resposta da mesa, que fica muito mais susceptível às forças externas.

Portanto, torna-se de grande importância para o estudo de viabilidade de um ensaio o valor desta freqüência de ressonância. Conforme McCONNELL (1995), a freqüência de ressonância das bobinas pode ser obtida pela Eq. 3.6, com isso definindose um limite máximo de freqüência de trabalho para um determinado excitador, ou seja:

$$
\omega=\sqrt{\frac{\mathrm{k}_{2}\left(\mathrm{~m}_{1}+\mathrm{m}_{2}\right)}{\mathrm{m}_{1} \mathrm{~m}_{2}}}
$$

Portanto, levando-se em consideração os resultados obtidos com os modelos de 2 e 3 GDL do excitador, e finalmente com o modelo de 2 GDL da armadura, considerando-se que o equipamento opera dentro de sua faixa útil, adota-se como modelo mecânico do excitador, um sistema de 1 GDL cuja massa, rigidez e amortecimento são aquelas da armadura e de sua suspensão, sendo considerada a base inercial.

A continuação natural deste estudo consiste na modelagem das características elétricas do excitador e do acoplamento entre os modelos elétrico e mecânico em um modelo misto. 


\subsubsection{Modelo Eletro-MeCÂNico}

O modelo eletromecânico proposto (Fig. 3.7), trata do sistema mecânico de 1 GDL da armadura, com uma força de entrada eletromagnética denominada $F_{e}$, e do modelo elétrico 'RL' em série da bobina. A força $F_{e}$ depende de alguns parâmetros construtivos do excitador como resistência $\mathrm{R}$ e indutância $\mathrm{L}$ das bobinas, parâmetros de entrada como o sinal de tensão $\mathrm{E}(\mathrm{t})$ do amplificador e dados passíveis de cálculo como a tensão de retorno $\mathrm{E}_{\mathrm{bemf}}$ gerada pelo movimento da bobina no campo magnético. Esta última pode ser obtida aplicando-se as leis de Ampère e de Lenz ao circuito, como será visto mais adiante (McCONNELL, 1995) e (LANG, 2001).
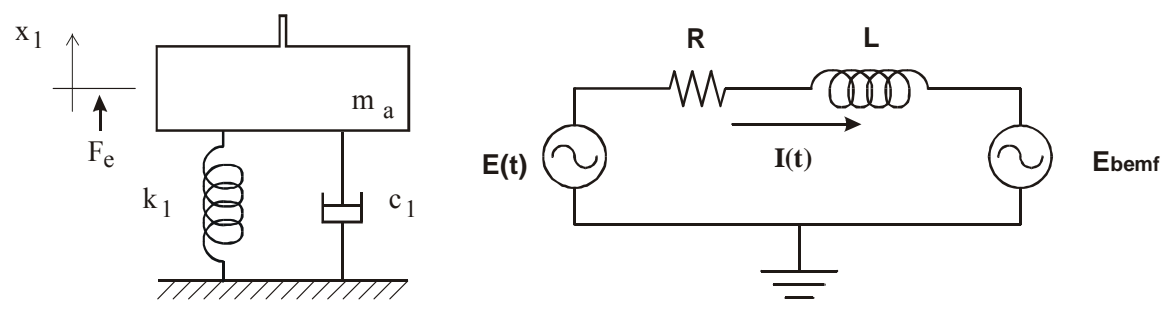

FIGURA 3.7 - Modelo mecânico e elétrico de um excitador eletrodinâmico

As equações que regem este sistema são:

$$
\begin{aligned}
& \mathrm{m}_{\mathrm{a}} \ddot{\mathrm{x}}+\mathrm{c}_{1} \dot{\mathrm{x}}+\mathrm{k}_{1} \mathrm{x}=\mathrm{F}_{\mathrm{e}}(\mathrm{t}) \\
& \mathrm{RI}+\mathrm{LI}+\mathrm{E}_{\text {bemf }}=\mathrm{E}(\mathrm{t})
\end{aligned}
$$

O fenômeno de queda na força de excitação está relacionado com o fato de haver interação entre a tensão nas bobinas do excitador com o movimento da armadura.

A lei de Ampère relaciona a força na armadura com a corrente introduzida nas bobinas:

$$
\mathrm{F}_{\mathrm{e}}=(\mathrm{nB} \ell) \mathrm{I}=\mathrm{K}_{\mathrm{f}} \mathrm{I}
$$

Neste caso, B representa a intensidade do campo magnético gerado pela corrente I nas $\mathrm{n}$ espiras de comprimento $\ell$ das bobinas do excitador. Denota-se $\mathrm{K}_{\mathrm{f}}$ a constante de força-corrente que é igual ao produto $\mathrm{nB} \ell$. TOMLINSON (1979) demonstra que as relações entre $\mathrm{B}$ e a posição $\mathrm{x}$ da bobina são não-lineares, ou seja:

$$
\mathrm{B}=\frac{\mathrm{d} \psi}{\mathrm{dx}}=\mathrm{B}_{0}\left[1-\left(\frac{\mathrm{x}+\mathrm{x}_{0}}{\mathrm{x}_{\max }}\right)^{2}\right]
$$

em que $\mathrm{B}_{0}$ é a intensidade máxima que o campo $\mathrm{B}$ pode atingir, $\mathrm{x}_{0}$ é a posição inicial em torno da qual a armadura oscila com amplitude $\mathrm{x}$, e $\mathrm{x}_{\max }$ é a amplitude máxima da 
armadura. Ainda, pode-se verificar que as relações entre força e corrente também são não-lineares combinando-se as Eqs. 3.9 e 3.10:

$$
\mathrm{F}_{\mathrm{c}}=\mathrm{nB}_{0} \ell\left[1-\left(\frac{\mathrm{x}+\mathrm{x}_{0}}{\mathrm{x}_{\max }}\right)^{2}\right] \mathrm{I}=\mathrm{K}_{\mathrm{f}}\left[1-\left(\frac{\mathrm{x}+\mathrm{x}_{0}}{\mathrm{x}_{\max }}\right)^{2}\right] \mathrm{I}
$$

Contudo, deve-se levar em consideração o efeito gerado pelo movimento da bobina no campo magnético sobre a tensão na própria bobina, efeito este que gera uma tensão de retorno $\left(\mathrm{E}_{\text {bemf }}\right)$ que tende a anular o efeito do campo, ou seja, em sentido oposto à que gera o campo. O valor desta tensão é obtido através da lei de Lenz:

$$
\mathrm{E}_{\mathrm{bemf}}=\mathrm{nB} \ell \dot{\mathrm{x}}=\mathrm{K}_{\mathrm{f}}\left[1-\left(\frac{\mathrm{x}+\mathrm{x}_{0}}{\mathrm{x}_{\max }}\right)^{2}\right] \dot{\mathrm{x}}
$$

Pode-se observar que a $E_{\text {bemf }}$ também obedece a uma relação não-linear quadrática, proporcional à relação entre amplitude de excitação e amplitude máxima da armadura, e também à velocidade da mesma, ou seja, à freqüência de excitação (TOMLINSON, 1979).

Contudo, existe ainda outra variável a ser considerada nesta modelagem, que se refere ao modo de operação do amplificador (Fig 3.8). Este possui dois modos de operação denominados, modo de corrente e o modo de tensão. No modo de corrente (Fig 3.9), o sinal enviado ao excitador é uma corrente proporcional ao sinal de tensão enviado pelo gerador, enquanto no modo de tensão (Fig 3.10), o sinal enviado ao excitador é uma tensão proporcional a esta tensão gerada.

A Fig. 3.8 ilustra a simbologia utilizada na representação de amplificadores operacionais. $\mathrm{O}$ amplificador gera uma tensão $\mathrm{E}_{0}$ proporcional à tensão de entrada em um de seus terminais. As configurações em modo de corrente e tensão podem ser vistas nas Figs. 3.9 e 3.10 .

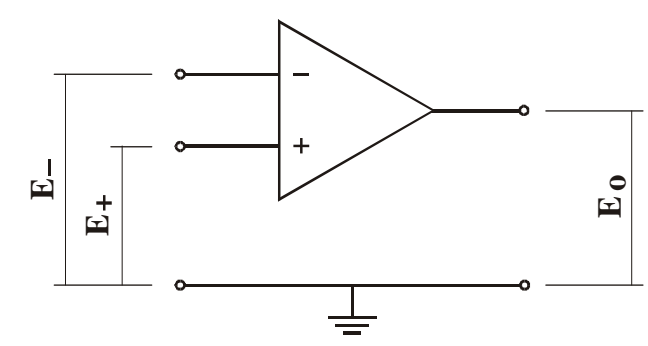

FIGURA 3.8 - Amplificador Operacional 


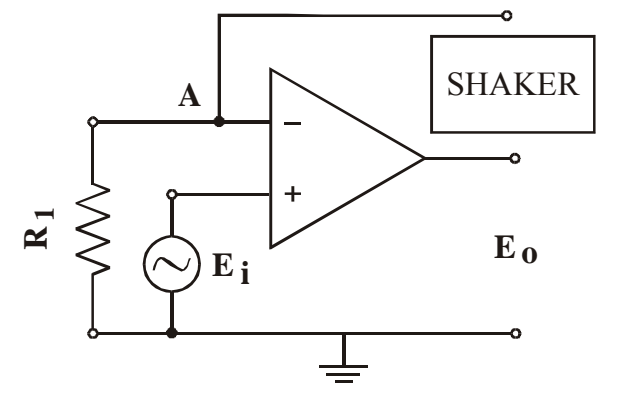

FIGURA 3.9 - Amplificador em Modo de Corrente

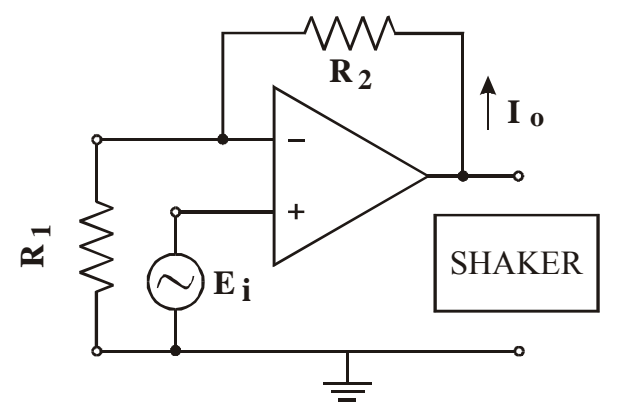

\section{FIGURA 3.10 - Amplificador em Modo de Tensão}

Um amplificador operacional é um amplificador diferencial de ganho muito elevado, com uma impedância de entrada muito alta e baixa impedância de saída. Tipicamente são utilizadas para se obter amplitudes variáveis de tensão.

Em um amplificador operacional ideal é suposto que nenhuma corrente de entrada seja drenada, isto é, a corrente do sinal entre terminais positivo e negativo são ambas iguais a zero. Em outras palavras, a impedância de entrada é supostamente infinita. Ainda, o amplificador ideal deve ter um valor de ganho muito elevado ou mesmo infinito. Contudo, em quase todas as aplicações, o amplificador não é utilizado na configuração de malha aberta. Ao invés disso, aplica-se uma realimentação, conectando-se a saída a uma das entradas, fechando-se assim a malha em torno do amplificador e controlando-se o ganho.

Devido aos circuitos de compensação interna, o ganho de tensão cai com o aumento da freqüência, ou seja, em baixas freqüências, próximo à operação $\mathrm{DC}, \mathrm{o}$ ganho assume um valor muito alto. Quando a freqüência do sinal de entrada aumenta, o ganho se estabiliza e cai novamente a uma razão de $20 \mathrm{~dB} / \mathrm{dec}$ a partir da denominada freqüência de corte (McCONNELL, 1995). Ou seja, basta garantir que a faixa de freqüência de operação é menor que a freqüência de corte do amplificador, para considerá-lo como um ganho constante no domínio da freqüência.

Quando operando em modo de corrente, o excitador é conectado entre a saída e uma das entradas do amplificador, agora em malha fechada. No modo de corrente, o amplificador mantém a tensão em $\mathrm{A}$ igual a $\mathrm{E}_{\mathrm{i}}(\mathrm{t})$ (Fig 3.9), assumindo a hipótese de que sua resistência interna tende ao infinito. Desta forma $E_{o}(t)$ é o sinal amplificado de $E_{i}(t)$. Como a impedância do amplificador é muito grande, não há corrente do ponto $\mathrm{A}$ ao 
amplificador e, portanto, pode-se afirmar que toda corrente que passa pela bobina também passa por $\mathrm{R}_{1}$.

Neste caso, quem controla o fator de amplificação são as resistências $R_{1}$ e $R_{2}$. Desta forma, assumindo que $\mathrm{G}_{\mathrm{i}}(\omega)$ é o ganho do amplificador no modo de corrente, constante em freqüência, pode-se escrever:

$$
\mathrm{I}_{\mathrm{o}}(\omega)=\mathrm{G}_{\mathrm{i}}(\omega) \mathrm{E}_{\mathrm{i}}(\omega)
$$

Dadas a Eq. 3.7 de movimento e a Eq. 3.11 da força eletromagnética (assumindo $\mathrm{x}$ pequeno em relação a $\mathrm{x}_{\max }$ ), pode-se afirmar:

$$
\left(\mathrm{k}_{1}-\mathrm{m}_{\mathrm{a}} \omega^{2}+\mathrm{jc}_{1} \omega\right) X=\mathrm{K}_{\mathrm{f}} \mathrm{I}_{\mathrm{o}}
$$

na qual $\mathrm{I}_{\mathrm{o}}$ é a magnitude da corrente $\mathrm{I}_{\mathrm{o}}(\mathrm{t})$ e $\mathrm{X}$ é posição da armadura.

Ainda com as Eqs. 3.8 e 3.12 obtém-se:

$$
(R+j L \omega) I_{0}+j K_{f} \omega X=E_{0}
$$

em que $E_{o}$ é a magnitude da tensão $E_{0}(t)$. Com a Eq. 3.15 pode-se verificar a dependência entre $E_{o}$ e $X$, ou seja, o acoplamento bilateral do sistema híbrido. É importante lembrar que este equacionamento só é válido para amplitudes da armadura significantemente pequenas, a fim de tornar as não linearidades descritas por TOMLINSON (1979) desprezíveis.

Como dito anteriormente, quando operando em modo de tensão, o comportamento do amplificador pode ser considerado como um ganho constante em freqüência, o que faz da Eq. 3.16 uma equação linear.

$$
\mathrm{E}_{\mathrm{o}}(\omega)=\mathrm{G}_{\mathrm{v}}(\omega) \mathrm{E}_{\mathrm{i}}(\omega)
$$

Ainda, pode-se escrever as equações que relacionam a tensão $E_{0}(t)$ com a corrente $\mathrm{I}(\mathrm{t})$ no excitador e a velocidade da armadura $\dot{\mathrm{x}}$, bastando para isso somar as quedas de tensão.

$$
\mathrm{RI}+\mathrm{LI}+\mathrm{E}_{\text {bemf }}=\mathrm{E}(\mathrm{t})
$$

Substituindo-se os resultados obtidos na Eq. 3.12 tem-se:

$$
\mathrm{RI}+\mathrm{LI}+\mathrm{K}_{\mathrm{f}} \dot{\mathrm{x}}=\mathrm{E}(\mathrm{t})
$$

Esta equação mostra como a tensão $E_{o}(t)$ e a corrente $I(t)$ interagem com a velocidade da armadura. Das Eqs. 3.14, 3.15 e 3.18, que descrevem o modelo eletromecânico, observa-se o acoplamento entre os sistemas por meio da força eletromagnética e tensão de retorno. Isto sugere o modelo unificado para o estudo do sistema híbrido desenvolvido a seguir. 
Como os valores de indutância das bobinas são em geral muito baixos (Tab. 3.1), da ordem de $\mu \mathrm{H}$, alguns autores como (RAO, 1987) e (MAIA \& SILVA, 1997) sugerem que seu efeito seja desprezado. Desta forma, o sistema de equações para o modelo completo é da forma:

$$
\left\{\begin{array}{l}
\mathrm{m}_{\mathrm{a}} \ddot{\mathrm{x}}+\mathrm{c}_{1} \dot{\mathrm{x}}+\mathrm{k}_{1} \mathrm{x}-\mathrm{K}_{\mathrm{f}} \mathrm{I}=0 \\
\mathrm{RI}+\mathrm{K}_{\mathrm{f}} \dot{\mathrm{x}}=\mathrm{E}(\mathrm{t})
\end{array}\right.
$$

Neste tipo de modelagem, a contribuição do sistema elétrico pode ser interpretada como uma componente de amortecimento eletromagnético. Este amortecimento pode ser estimado levando-se em consideração a Eq. 3.19. Com isso a corrente no excitador pode ser escrita em função da tensão de entrada e da velocidade da armadura:

$$
\mathrm{RI}+\mathrm{K}_{\mathrm{f}} \dot{\mathrm{x}}=\mathrm{E} \Rightarrow \mathrm{I}=\frac{\mathrm{E}}{\mathrm{R}}-\frac{\mathrm{K}_{\mathrm{f}} \dot{\mathrm{x}}}{\mathrm{R}}
$$

Substituindo a Eq. 3.20 na Eq. 3.19:

$$
\mathrm{m}_{\mathrm{a}} \ddot{\mathrm{x}}+\mathrm{c}_{1} \dot{\mathrm{x}}+\mathrm{k}_{1} \mathrm{x}-\mathrm{K}_{\mathrm{f}}\left(\frac{\mathrm{E}}{\mathrm{R}}-\frac{\mathrm{K}_{\mathrm{f}} \dot{\mathrm{x}}}{\mathrm{R}}\right)=0 \Rightarrow \mathrm{m}_{\mathrm{a}} \ddot{\mathrm{x}}+\left(\mathrm{c}_{1}+\frac{\mathrm{K}_{\mathrm{f}}^{2}}{\mathrm{R}}\right) \dot{\mathrm{x}}+\mathrm{k}_{1} \mathrm{x}=\frac{\mathrm{K}_{\mathrm{f}}}{\mathrm{R}} \mathrm{E}
$$

A Fig. 3.11 ilustra a resposta obtida para mesa livre do excitador, enquanto que a Fig. 3.12 ilustra a corrente e a tensão nas bobinas para os modos de tensão e corrente respectivamente. Observando o comportamento da tensão em modo de corrente, verifica-se a compensação de tensão devido à tensão de retorno $E_{\text {bemf. }}$ Estes valores de tensão podem exceder a capacidade do amplificador, além de prejudicar sua faixa útil de freqüência, como observado anteriormente. O comportamento da corrente no modo de tensão, ilustrado na Fig. 3.12, revela a queda na força de excitação devida ao efeito da tensão de retorno $\mathrm{E}_{\mathrm{bemf}}$.

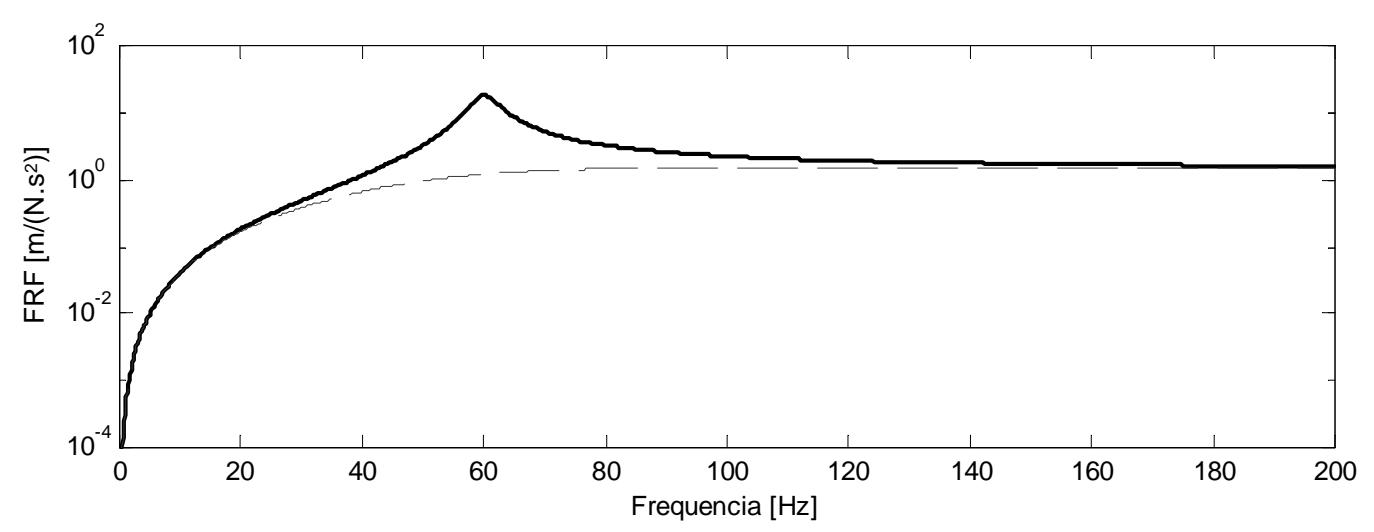

_ modo de corrente _ _ modo de tensão

FIGURA 3.11 - Aceleração da mesa livre 

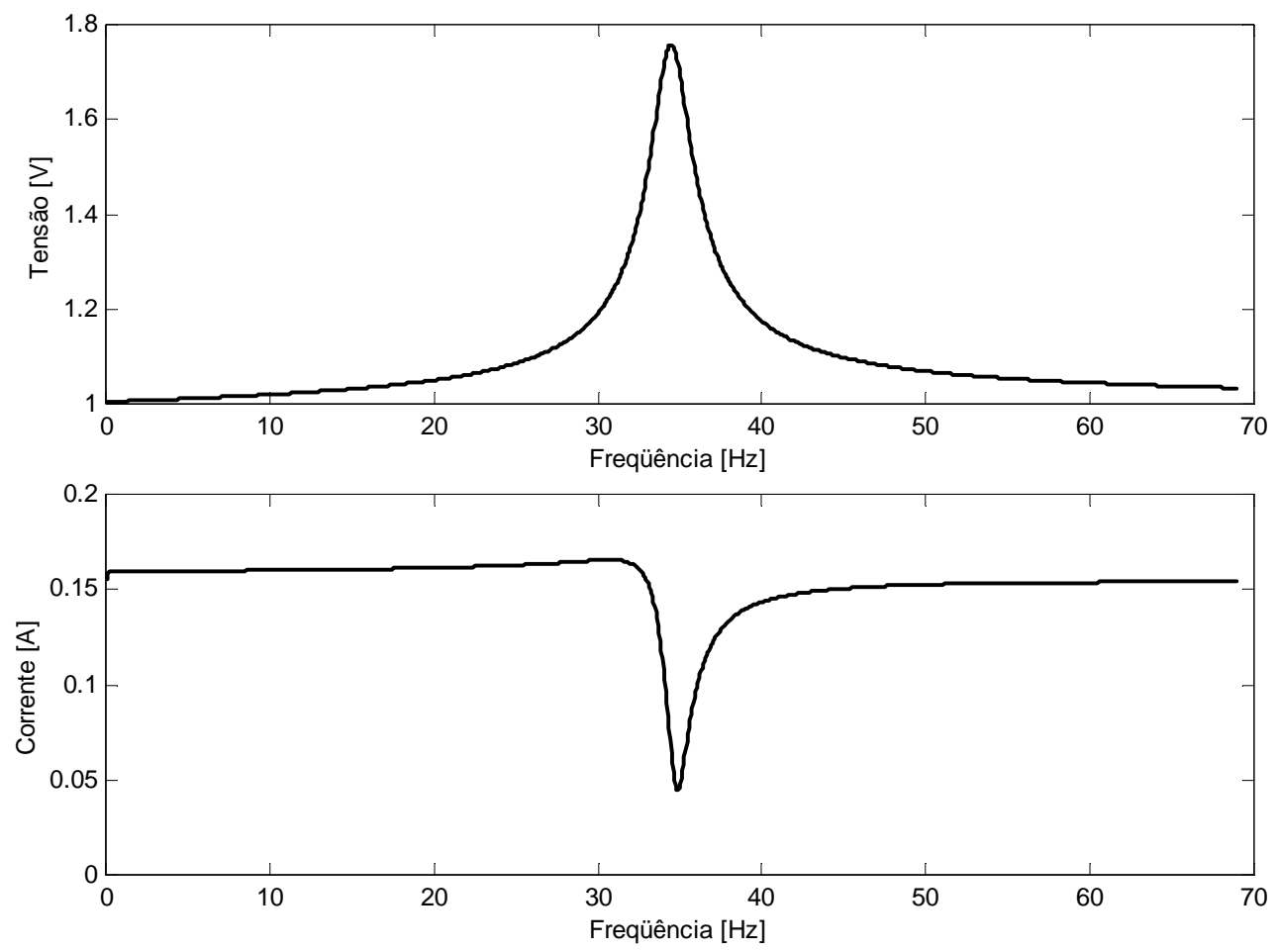

FIGURA 3.12 - Tensão para modo de corrente e corrente para modo de tensão.

\subsubsection{Modelo Considerando Graus de Liberdade Rotacionais}

Um aspecto importante a se considerar quanto à qualidade dos dados obtidos em testes com excitadores eletrodinâmicos, principalmente em testes com excitação via base, são os momentos que surgem ente o excitador e o ponto de fixação na estrutura. Tais momentos ocorrem da mesma forma, se for utilizada uma stinger muito rígida (VAROTO \& McCONNELL, 1993b).

Portanto, deve-se dispensar atenção especial em testes com excitação via base, principalmente com estruturas não simétricas em relação ao eixo de excitação, ou que apresentem rotação significativa deste ponto. Estes graus de liberdade rotacionais, raramente são levados em consideração na modelagem do excitador e da estrutura, contudo podem influir consideravelmente na resposta do sistema e conseqüentemente na qualidade dos dados adquiridos.

O excitador, quando submetido a forças verticais excêntricas, apresenta movimento angular significativo (OLIVEIRA \& VAROTO, 2002c). Portanto o novo modelo proposto (Fig. 3.13) considera deslocamentos e rotações dos componentes da armadura do excitador, bem como as características eletrodinâmicas do seu circuito. 


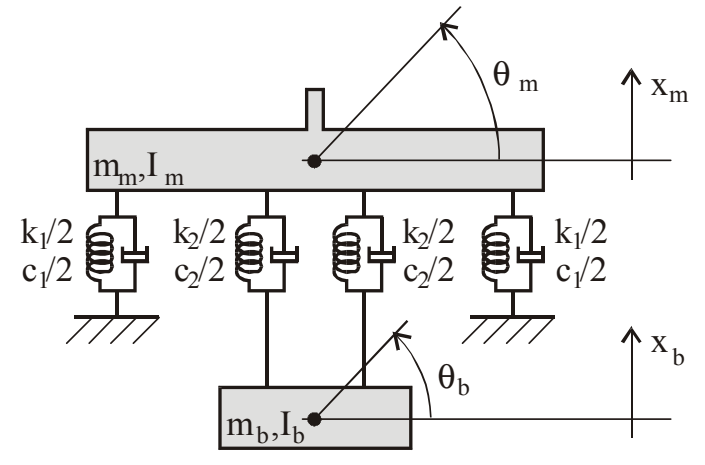

FIGURA 3.13 - Modelo da armadura

A Fig. 3.13 ilustra o modelo mecânico da armadura, no qual ' $\mathrm{m}_{\mathrm{m}}$ ' e ' $\mathrm{I}_{\mathrm{m}}$ ' representam a massa e o momento de inércia da mesa, bem como ' $\mathrm{m}_{\mathrm{b}}$ ' e ' $\mathrm{I}_{\mathrm{b}}$ ' representam a massa e o momento de inércia das bobinas. As equações de movimento que descrevem o comportamento deste sistema são:

$$
[\mathrm{m}]\left\{\begin{array}{c}
\ddot{\mathrm{x}}_{\mathrm{m}} \\
\ddot{\mathrm{x}}_{\mathrm{b}} \\
\ddot{\theta}_{\mathrm{m}} \\
\ddot{\theta}_{\mathrm{b}}
\end{array}\right\}+[\mathrm{c}]\left\{\begin{array}{c}
\ddot{\mathrm{x}}_{\mathrm{m}} \\
\ddot{\mathrm{x}}_{\mathrm{b}} \\
\ddot{\theta}_{\mathrm{m}} \\
\ddot{\theta}_{\mathrm{b}}
\end{array}\right\}+[\mathrm{k}]\left\{\begin{array}{c}
\ddot{\mathrm{x}}_{\mathrm{m}} \\
\ddot{\mathrm{x}}_{\mathrm{b}} \\
\ddot{\theta}_{\mathrm{m}} \\
\ddot{\theta}_{\mathrm{b}}
\end{array}\right\}=\left\{\begin{array}{c}
\mathrm{F}_{1} \\
\mathrm{~F}_{2} \\
\mathrm{M}_{1} \\
\mathrm{M}_{2}
\end{array}\right\}
$$

na qual

$$
\begin{aligned}
& {[\mathrm{m}]=\left[\begin{array}{cccc}
\mathrm{m}_{\mathrm{m}} & 0 & 0 & 0 \\
0 & \mathrm{~m}_{\mathrm{b}} & 0 & 0 \\
0 & 0 & \mathrm{I}_{\mathrm{m}} & 0 \\
0 & 0 & 0 & \mathrm{I}_{\mathrm{b}}
\end{array}\right]} \\
& {[\mathrm{c}]=\left[\begin{array}{cccc}
\left(\mathrm{c}_{1}+\mathrm{c}_{2}\right) & -\mathrm{c}_{2} & \left(\frac{\mathrm{c}_{1}}{2}\left(1_{2}-1_{1}\right)+\frac{\mathrm{c}_{2}}{2}\left(1_{4}-1_{3}\right)\right) & \frac{\mathrm{c}_{2}}{2}\left(1_{3}-1_{4}\right) \\
-\mathrm{c}_{2} & \mathrm{c}_{2} & \frac{\mathrm{c}_{2}}{2}\left(1_{3}-1_{4}\right) & \frac{\mathrm{c}_{2}}{2}\left(1_{4}-1_{3}\right) \\
\left(\frac{\mathrm{c}_{1}}{2}\left(1_{2}-1_{1}\right)+\frac{\mathrm{c}_{2}}{2}\left(1_{4}-1_{3}\right)\right) & \frac{\mathrm{c}_{2}}{2}\left(1_{3}-1_{4}\right) & \left(\frac{\mathrm{c}_{1}}{2}\left(1_{1}^{2}+1_{2}^{2}\right)+\frac{\mathrm{c}_{2}}{2}\left(1_{3}^{2}+1_{4}^{2}\right)\right) & -\frac{\mathrm{c}_{2}}{2}\left(1_{3}^{2}+1_{4}^{2}\right) \\
\frac{\mathrm{c}_{2}}{2}\left(1_{3}-1_{4}\right) & \frac{\mathrm{c}_{2}}{2}\left(1_{4}-1_{3}\right) & -\frac{\mathrm{c}_{2}}{2}\left(1_{3}^{2}+1_{4}^{2}\right) & \frac{\mathrm{c}_{2}}{2}\left(1_{3}^{2}+1_{4}^{2}\right)
\end{array}\right]} \\
& {[\mathrm{k}]=\left[\begin{array}{cccc}
\left(\mathrm{k}_{1}+\mathrm{k}_{2}\right) & -\mathrm{k}_{2} & \left(\frac{\mathrm{k}_{1}}{2}\left(\mathrm{l}_{2}-\mathrm{l}_{1}\right)+\frac{\mathrm{k}_{2}}{2}\left(\mathrm{l}_{4}-\mathrm{l}_{3}\right)\right) & \frac{\mathrm{k}_{2}}{2}\left(\mathrm{l}_{3}-\mathrm{l}_{4}\right) \\
-\mathrm{k}_{2} & \mathrm{k}_{2} & \frac{\mathrm{k}_{2}}{2}\left(\mathrm{l}_{3}-\mathrm{l}_{4}\right) & \frac{\mathrm{k}_{2}}{2}\left(1_{4}-1_{3}\right) \\
\left(\frac{\mathrm{k}_{1}}{2}\left(\mathrm{l}_{2}-\mathrm{l}_{1}\right)+\frac{\mathrm{k}_{2}}{2}\left(1_{4}-\mathrm{l}_{3}\right)\right) & \frac{\mathrm{k}_{2}}{2}\left(\mathrm{l}_{3}-\mathrm{l}_{4}\right) & \left(\frac{\mathrm{k}_{1}}{2}\left(\mathrm{l}_{1}^{2}+\mathrm{l}_{2}^{2}\right)+\frac{\mathrm{k}_{2}}{2}\left(1_{3}^{2}+1_{4}^{2}\right)\right) & -\frac{\mathrm{k}_{2}}{2}\left(1_{3}^{2}+1_{4}^{2}\right) \\
\frac{\mathrm{k}_{2}}{2}\left(\mathrm{l}_{3}-1_{4}\right) & \frac{\mathrm{k}_{2}}{2}\left(1_{4}-1_{3}\right) & -\frac{\mathrm{k}_{2}}{2}\left(1_{3}^{2}+1_{4}^{2}\right) & \frac{\mathrm{k}_{2}}{2}\left(1_{3}^{2}+1_{4}^{2}\right)
\end{array}\right]}
\end{aligned}
$$

As primeiras simulações consideram a mesa livre. Os resultado obtidos podem ser vistos nas Figs. 3.14 a 3.16. 
Considerando a faixa útil de freqüência do Excitador como demonstrado por OLIVEIRA \& VAROTO (2002b), a acelerância da mesa do excitador é tipicamente uma acelerância de um sistema de 1 GDL.

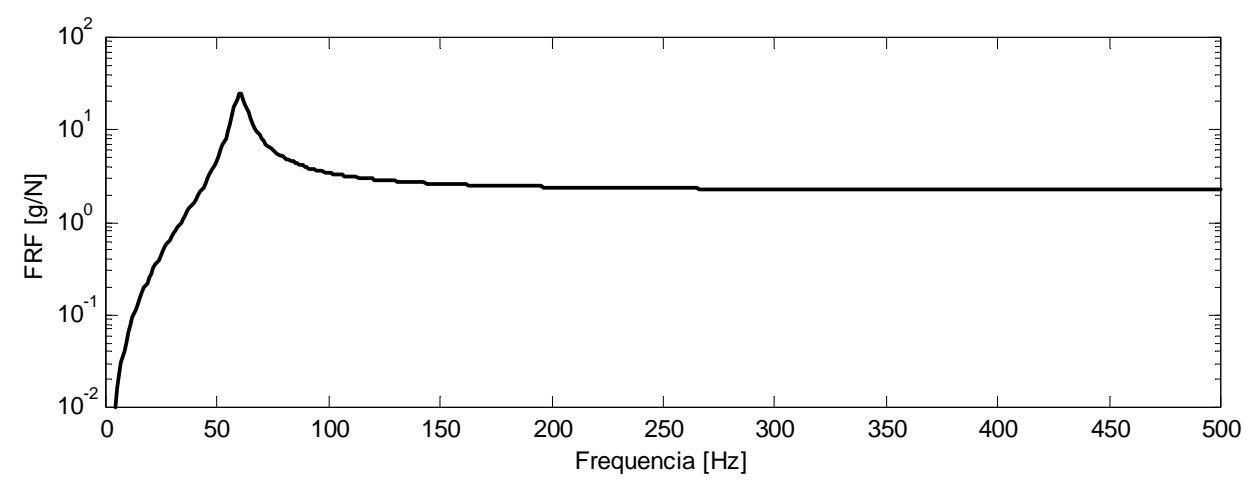

FIGURA 3.14 - FRF da armadura para modelo mecânico

Contudo, se tomada a acelerância de um ponto fora do centro da mesa, surge uma nova componente, não prevista nos primeiros modelos, contudo observada em alguns testes (OLIVEIRA \& VAROTO, 2002c) como demonstrada na Fig. 3.15.

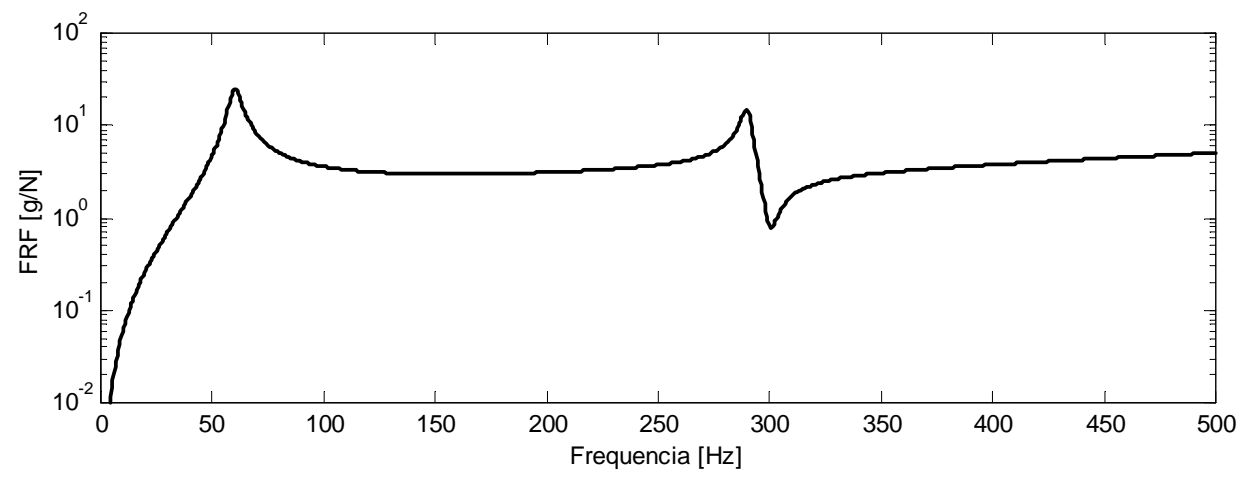

FIGURA 3.15 - FRF da armadura para modelo mecânico

Um outro aspecto relevante deste fenômeno é o de que esta segunda ressonância da armadura, diferentemente da primeira, é muito pouco afetada pelos efeitos eletromagnéticos dos circuitos do excitador. Isto se deve ao fato da tensão de retorno $\left(\mathrm{E}_{\text {bemf }}\right)$ estar relacionada com movimento translacional das bobinas no campo magnético. As simulações realizadas considerando os efeitos eletromagnéticos ilustram este fenômeno (Fig 3.16). 


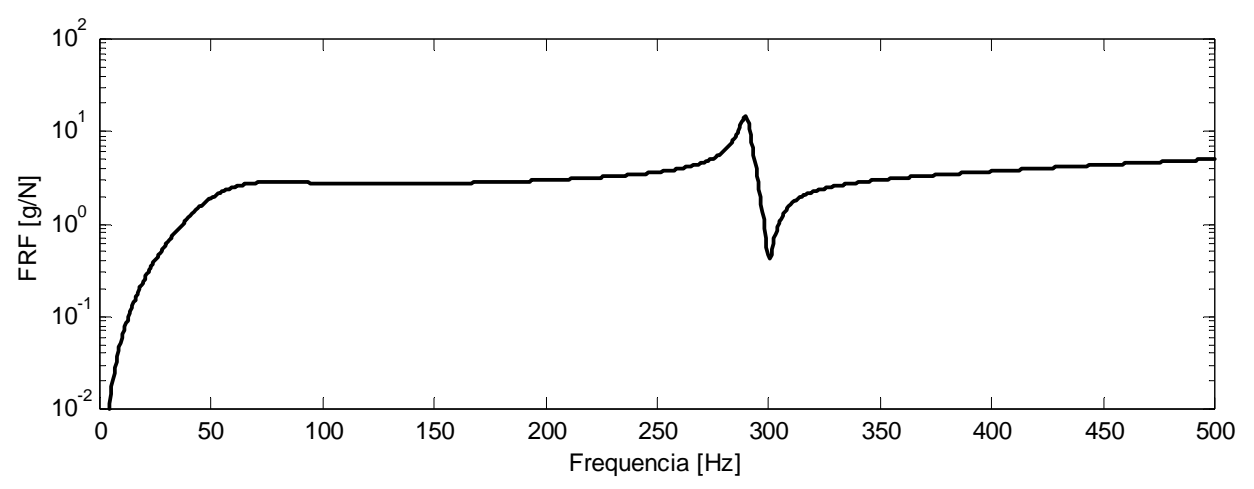

FIGURA 3.16 - FRF da armadura para modelo eletro-mecânica

\subsection{INTERAÇÃO EXCITADOR / ESTRUTURA}

Para melhor observar os fenômenos envolvidos na interação entre o excitador e a estrutura sob estudo, dividem-se as simulações em duas partes. Na primeira apresentamse modelos mecânicos, nos quais o excitador é representado pelo modelo de 1 GDL da armadura. Como visto anteriormente, estes modelos podem ser interpretados como o excitador operando em modo de corrente. Na segunda parte, as características eletromagnéticas do sistema são integradas ao modelo. Desta forma pode-se observar as parcelas de influência mecânica e elétrica no fenômeno de interação.

O modelo utilizado como base para estas simulações pode ser visto na Fig. 3.17, no qual $F_{e}$ é a força eletromagnética aplicada na armadura e $F_{1}$ a força que é efetivamente transmitida à estrutura, e medida pelo transdutor de força.

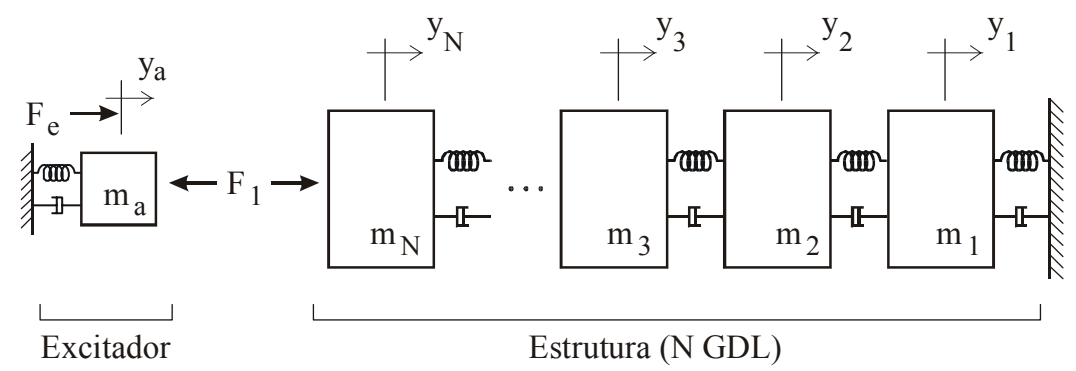

\section{FIGURA 3.17 - Modelo do excitador acoplado a estrutura}

Supondo que a união entre a armadura e a estrutura seja rígida, pode-se afirmar que suas acelerações são as mesmas, ou seja:

$$
\mathrm{A}_{\mathrm{a}} \cong \mathrm{A}_{\mathrm{N}}
$$

Ainda:

$$
\left\{\begin{array}{l}
\mathrm{A}_{\mathrm{a}}=\mathrm{H}_{\mathrm{aa}}\left(\mathrm{F}_{\mathrm{e}}-\mathrm{F}_{1}\right) \\
\mathrm{A}_{\mathrm{N}}=\mathrm{H}_{\mathrm{NN}}\left(\mathrm{F}_{1}\right)
\end{array}\right.
$$

Substituindo a Eq. 3.25 na Eq. 3.24 tem-se: 


$$
\mathrm{F}_{1}=\mathrm{F}_{\mathrm{e}} \frac{\mathrm{H}_{\mathrm{aa}}}{\left(\mathrm{H}_{\mathrm{aa}}+\mathrm{H}_{\mathrm{NN}}\right)}
$$

Desta forma é possível calcular a força efetiva atuando na estrutura, bastando para tanto obter as FRFs de ponto da armadura $\mathrm{H}_{\mathrm{aa}}$, da estrutura $\mathrm{H}_{\mathrm{NN}}$ e o sinal da força eletromagnética $\mathrm{F}_{\mathrm{e}}$, seja em modo de corrente ou em modo de tensão.

Ainda, do modelo completo (excitador / estrutura), calcula-se a aceleração do ponto de excitação devido à força de entrada no sistema $F_{e}$, que dividida pela força efetiva de excitação $F_{1}$, fornece a FRF estimada da estrutura para o teste simulado. Nas simulações descritas a seguir, estas FRFs estimadas são comparadas às FRFs calculadas da estrutura.

Contudo antes de partir para as simulações, faz-se uma ressalva à hipótese assumida quanto ao modelo da base do excitador. Na seção 3.1, item 3.1.1, que trata da modelagem do excitador, observa-se que a dinâmica da base no modelo flexível praticamente não interfere no comportamento dinâmico da armadura. Tais simulações foram realizadas para o caso de mesa livre, ou seja, sem que uma estrutura fosse conectada ao excitador. No entanto, à medida que se aumenta a massa da armadura, a dinâmica do conjunto é afetada, tornando a resposta da armadura mais susceptível à influência da ressonância da base. Tal fenômeno pode ser observado na Fig 3.18.

Como pode ser observado na Fig. 3.18, a freqüência natural do sistema de 1 GDL permanece inalterada, mas o conjunto excitador / estrutura apresenta duas freqüências naturais, sendo a primeira, relativa à freqüência da suspensão flexível do conjunto. Neste caso a estrutura utilizada tem massa efetiva da ordem de grandeza da massa da base do excitador. A simples adição de massa à mesma reduz a freqüência e a intensidade desta interferência, garantindo a hipótese assumida.

As simulações descritas a seguir tomam como base o excitador B\&K 4812. Quatro estruturas foram idealizadas para as simulações, buscando-se observar o efeito da rigidez, e principalmente da massa da estrutura em relação à massa da armadura no fenômeno de interação, como sugerem UNHOLTZ (1961), OLSEM (1986), RAO (1987) entre outros. As estruturas em questão possuem massas 0,2 kg e $10 \mathrm{~kg}$ e freqüências naturais de $20 \mathrm{~Hz}$ e $100 \mathrm{~Hz}$, sendo a armadura de $0,45 \mathrm{~kg}$ e freqüência natural de $59 \mathrm{~Hz}$. Desta forma, inicialmente consideram-se as estruturas com $1 \mathrm{GDL}$, posteriormente $2 \mathrm{GDL}$ e finalmente $5 \mathrm{GDL}$, aumentando gradativamente a complexidade dos modelos. 

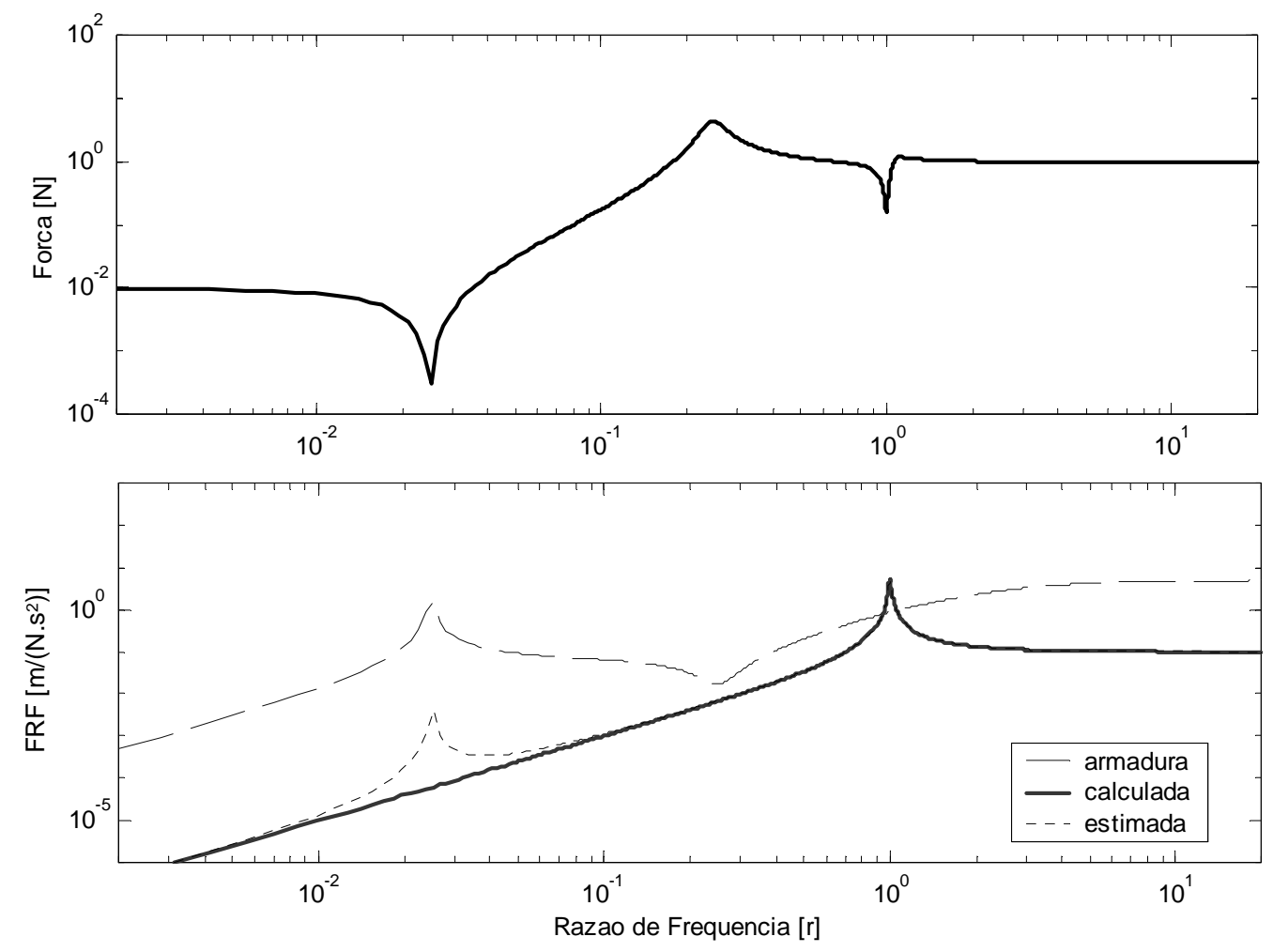

FIGURA 3.18 - Força de entrada e FRFs do excitador e da estrutura

\subsubsection{Modelo MecÂnico (Modo De CoRRENTE)}

As estruturas utilizadas nas simulações são basicamente quatro: duas com freqüência natural de $20 \mathrm{~Hz}$ e massa de $2 \mathrm{~kg}$ e $10 \mathrm{~kg}$, e duas com freqüência natural de $100 \mathrm{~Hz}$ e, do mesmo modo, massas de $2 \mathrm{~kg}$ e $10 \mathrm{~kg}$. Desta forma tem-se estruturas com freqüência natural e massa, maiores e menores que freqüência natural e a massa da armadura.

Inicialmente consideram-se as estruturas com 1 GDL e freqüência natural de 20 Hz. A seguir as estruturas com freqüência natural de $100 \mathrm{~Hz}$. Os resultados obtidos para força, FRF teórica (calculada) e FRF estimada estão ilustrados nas Figs. 3.19 e 3.22.

Observa-se que o fenômeno de queda de força da excitação tem uma parcela considerável de contribuição mecânica, ou seja, mesmo operando em modo de corrente com o amplificador compensando as quedas de tensão, a força de excitação sofre uma queda considerável nas vizinhanças da freqüência natural da estrutura. Portanto, antes de um fenômeno eletromecânico, trata-se de um fenômeno mecânico.

Dos resultados obtidos observa-se que mesmo com a queda na força de excitação praticamente não existe diferença entre as FRFs calculadas e estimadas. Contudo vale lembrar que os resultados aqui demonstrados não levam em consideração questões como não linearidades da estrutura ou mesmo ruído nos sinais de força e aceleração. O simples fato de haver ruído nos sinais de força, por exemplo, poderia 
afetar sobremaneira os resultados obtidos, já que em freqüências próximas da queda de força, as relações sinal / ruído se tornariam desfavoráveis.
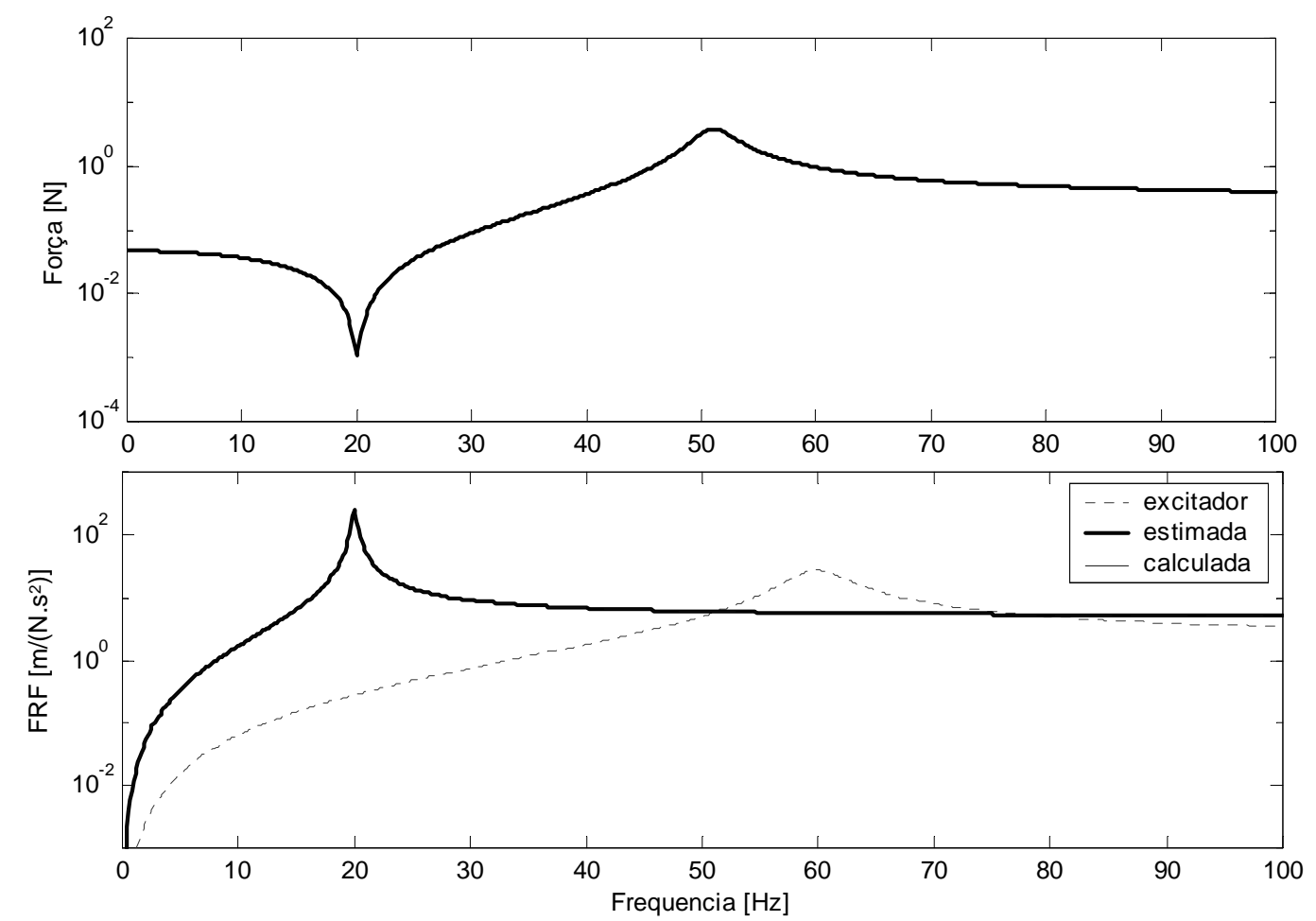

FIGURA 3.19 - Força de entrada e FRFs para estrutura de $0,2 \mathrm{~kg}$
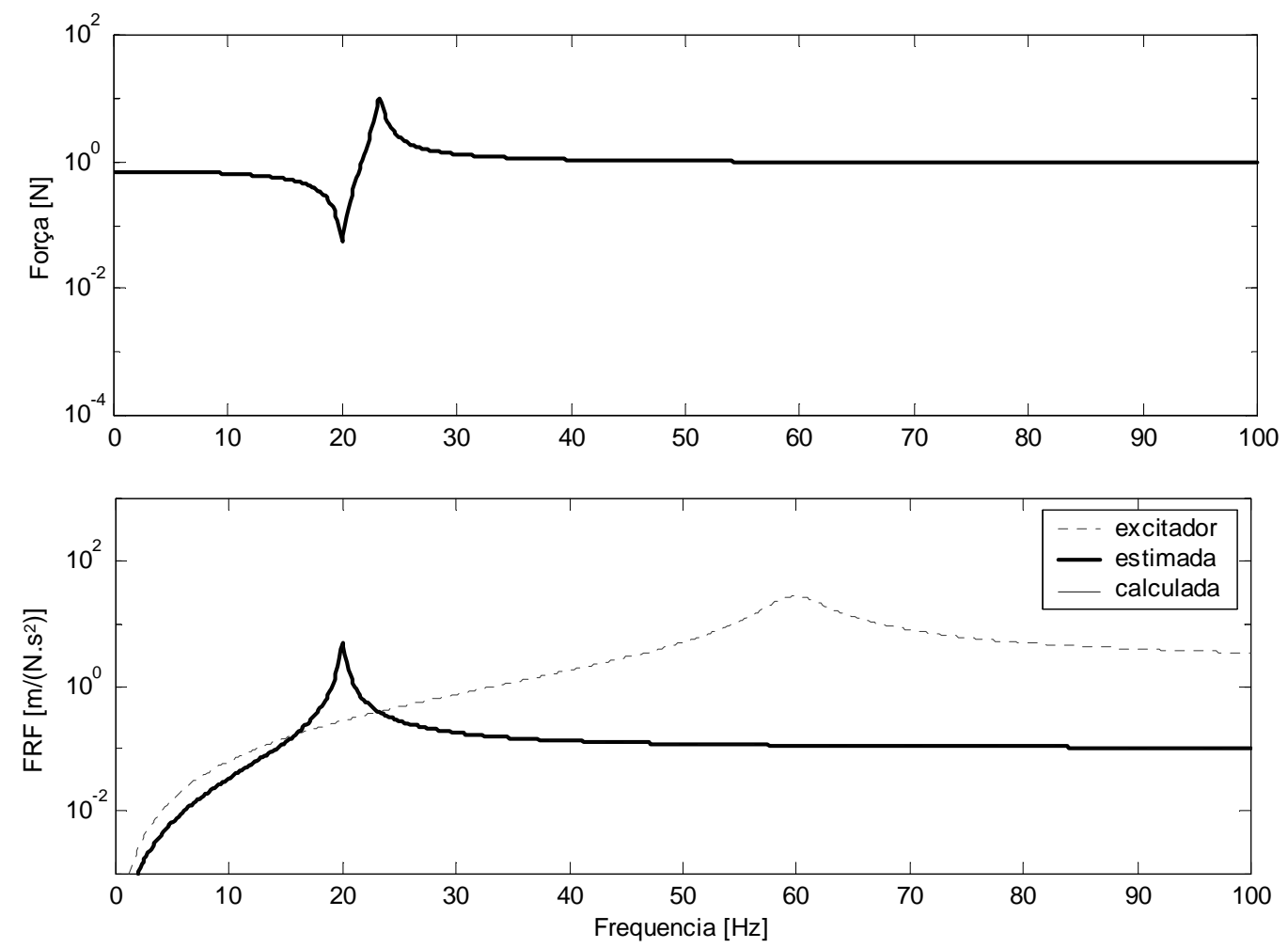

FIGURA 3.20 - Força de entrada e FRFs para estrutura de $10 \mathrm{~kg}$ 


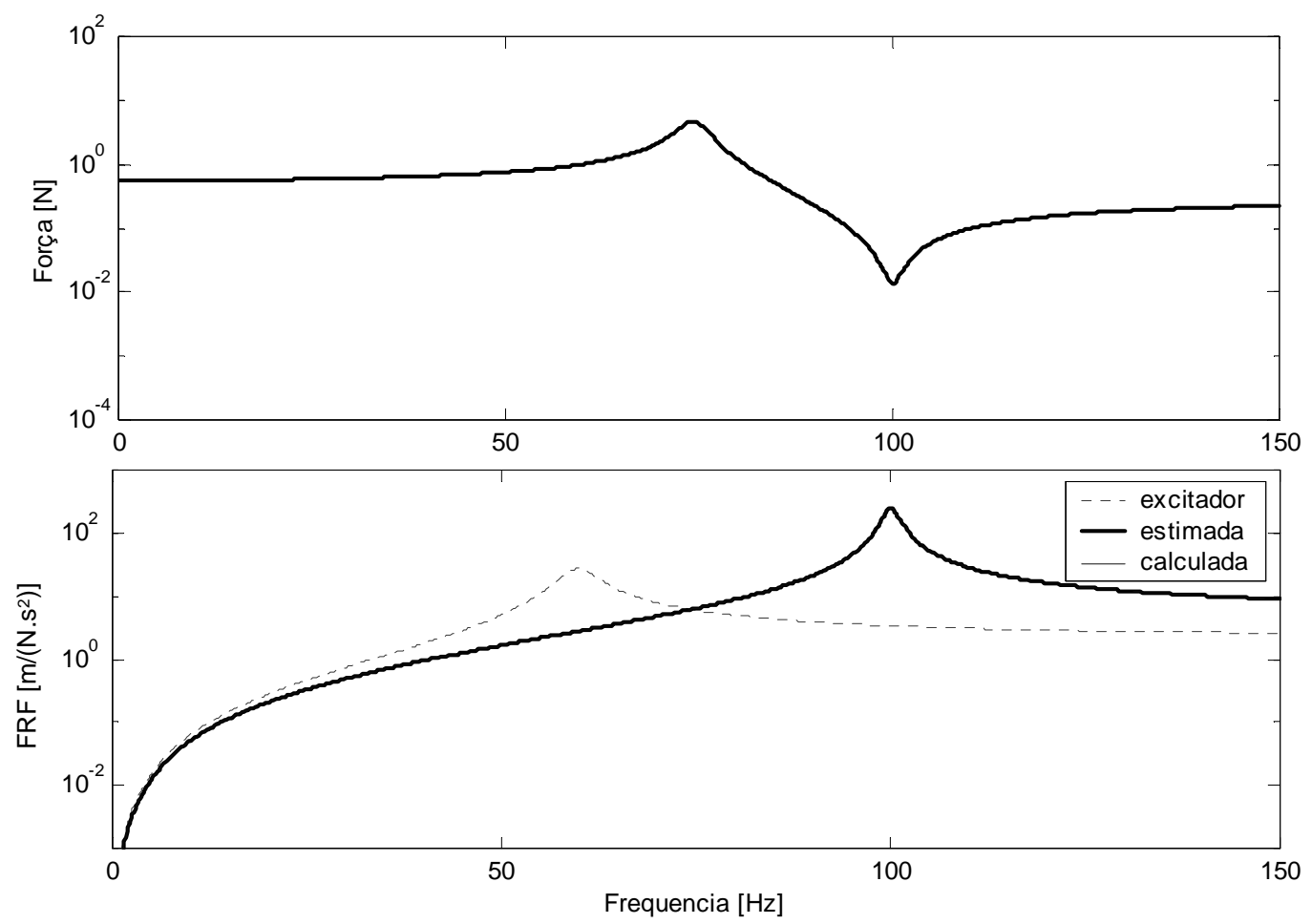

FIGURA 3.21 - Força de entrada e FRFs para estrutura de $0,2 \mathrm{~kg}$

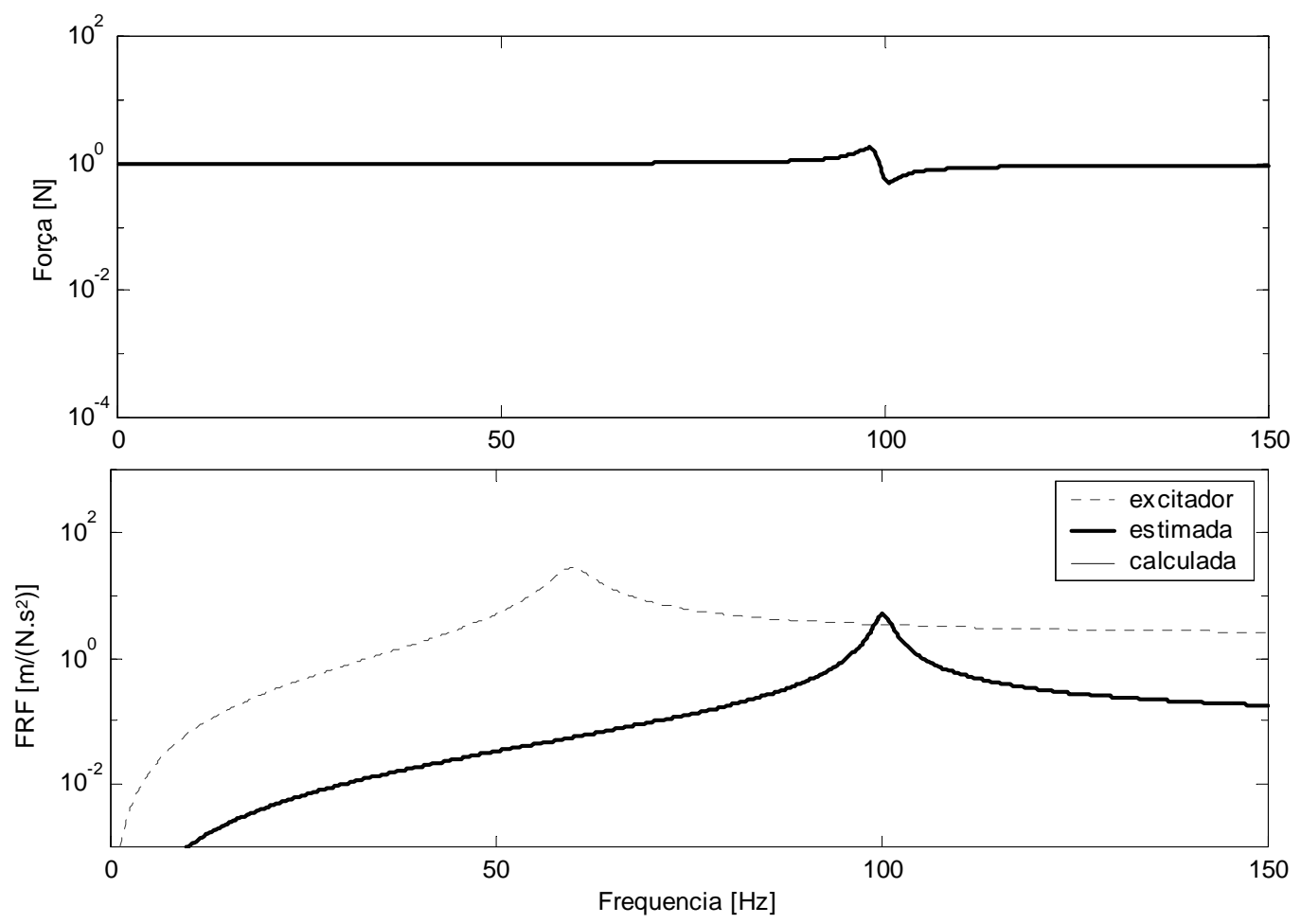

FIGURA 3.22 - Força de entrada e FRFs para estrutura de $10 \mathrm{~kg}$

A seguir consideram-se as mesmas estruturas agora com 2 GDL. Desta forma, aumenta-se gradativamente a complexidade dos modelos, e procura-se observar a ocorrência dos mesmos fenômenos. Os resultados obtidos estão ilustrados nas Figs. 3.23 a 3.26 . 
O que se observa destas simulações é o efeito diferenciado da interação excitador estrutura na queda de força, nos casos de freqüências abaixo ou acima da freqüência de suspensão da armadura. Para os casos em que a estrutura apresenta freqüências naturais abaixo da freqüência natural da armadura, as quedas de força são sucedidas por máximos locais, enquanto que para freqüências acima da freqüência natural da armadura, as quedas de força são antecedidas por estes máximos (RAO, 1987)

Nos resultados ilustrados pelas Figs. 3.23 a 3.26, novamente as freqüências naturais e suas respectivas amplitudes, não mostram diferença significativa entre os resultados teóricos e as simulações experimentais. Porém, no caso das estruturas mais leves $(0,2 \mathrm{~kg})$, alguma desconexão já pode ser observada nas anti-ressonâncias. Ainda, para o caso da estrutura de $0,2 \mathrm{~kg}$, as quedas na força são mais acentuadas, o que leva a crer que o fenômeno de queda esteja ligado diretamente com a relação entre as massas da armadura e do item de teste.

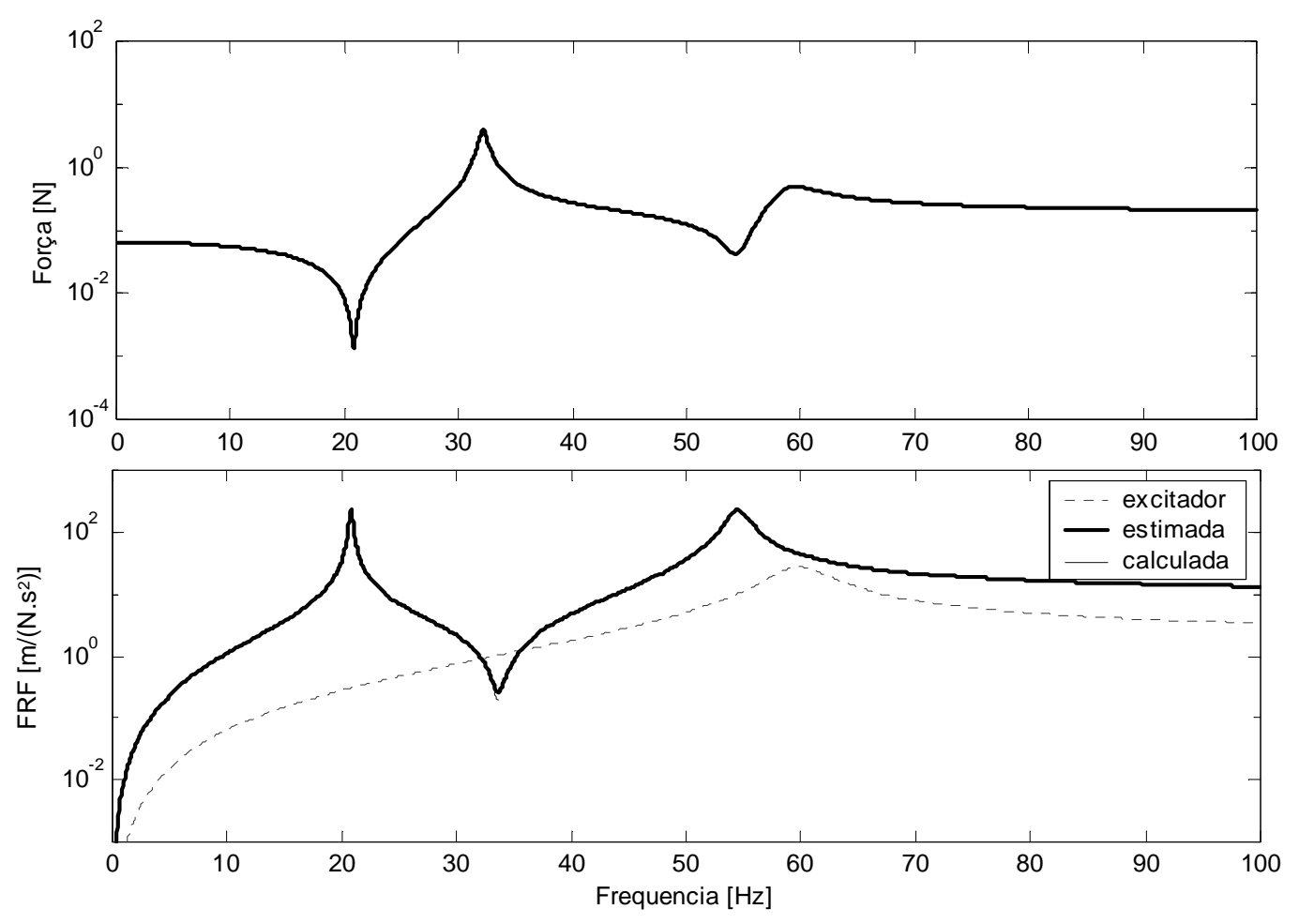

FIGURA 3.23 - Força de entrada e FRFs para estrutura de 0,2 kg

Quanto à parcela mecânica do fenômeno de queda da força de excitação, OLSEM (1986) afirma que quanto maior a razão $\mathrm{m}_{\mathrm{s}} / \mathrm{m}_{\mathrm{a}}$ (sendo $\mathrm{m}_{\mathrm{s}}$ a massa da estrutura e $\mathrm{m}_{\mathrm{a}} \mathrm{a}$ da armadura) menores serão os efeitos de queda na força. Enquanto UNHOLZ (1961) afirma o contrário, ou seja, que para diminuir os efeitos de queda na força seria preciso aumentar a massa da armadura. Contudo, MOUCH et al. (1990) atribuem o efeito, não à massa da estrutura mas sim à relação ente massa da armadura e massa modal da estrutura, o que as simulações demonstradas aqui vêem corroborar. 

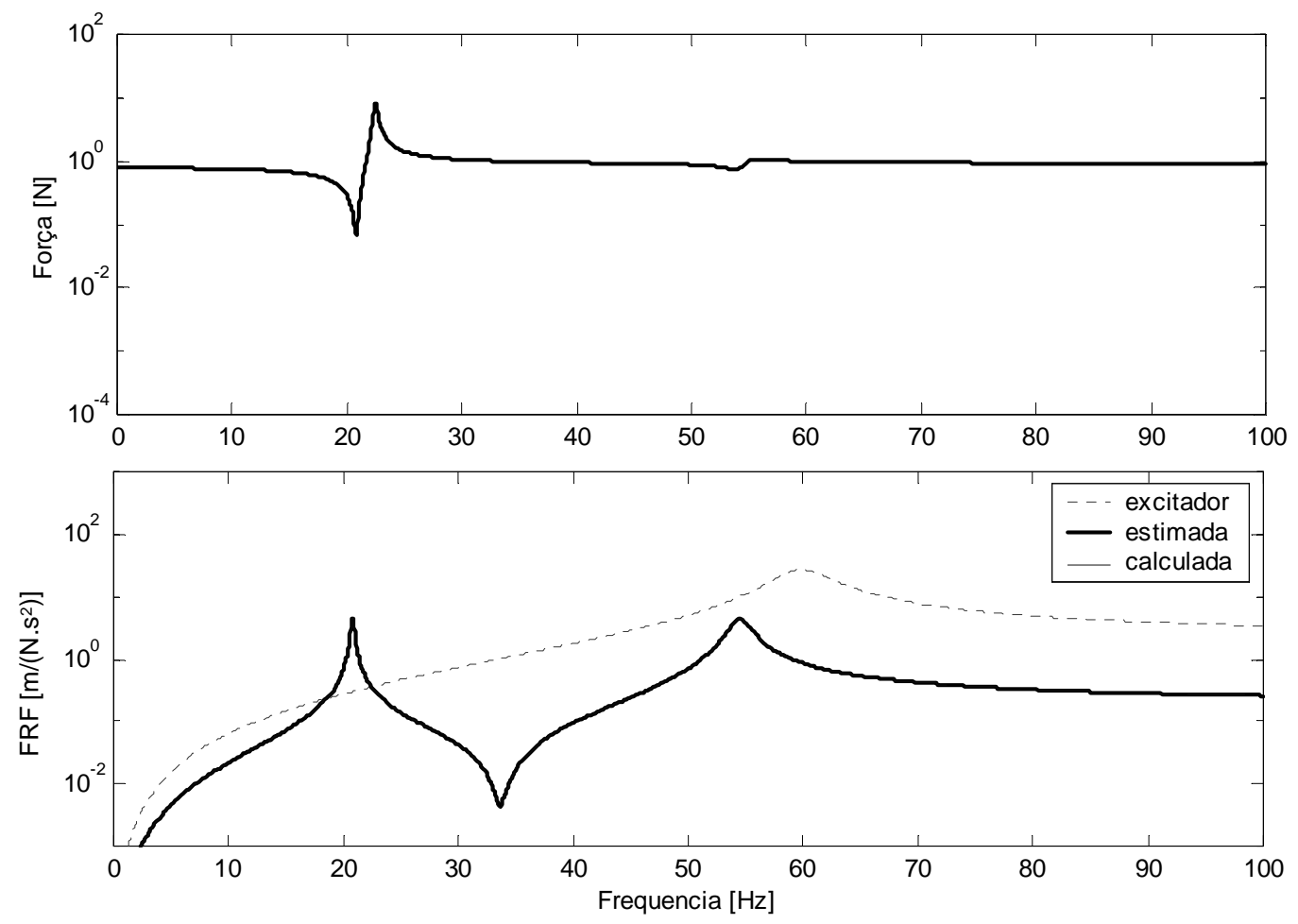

FIGURA 3.24 - Força de entrada e FRFs para estrutura de $10 \mathrm{~kg}$
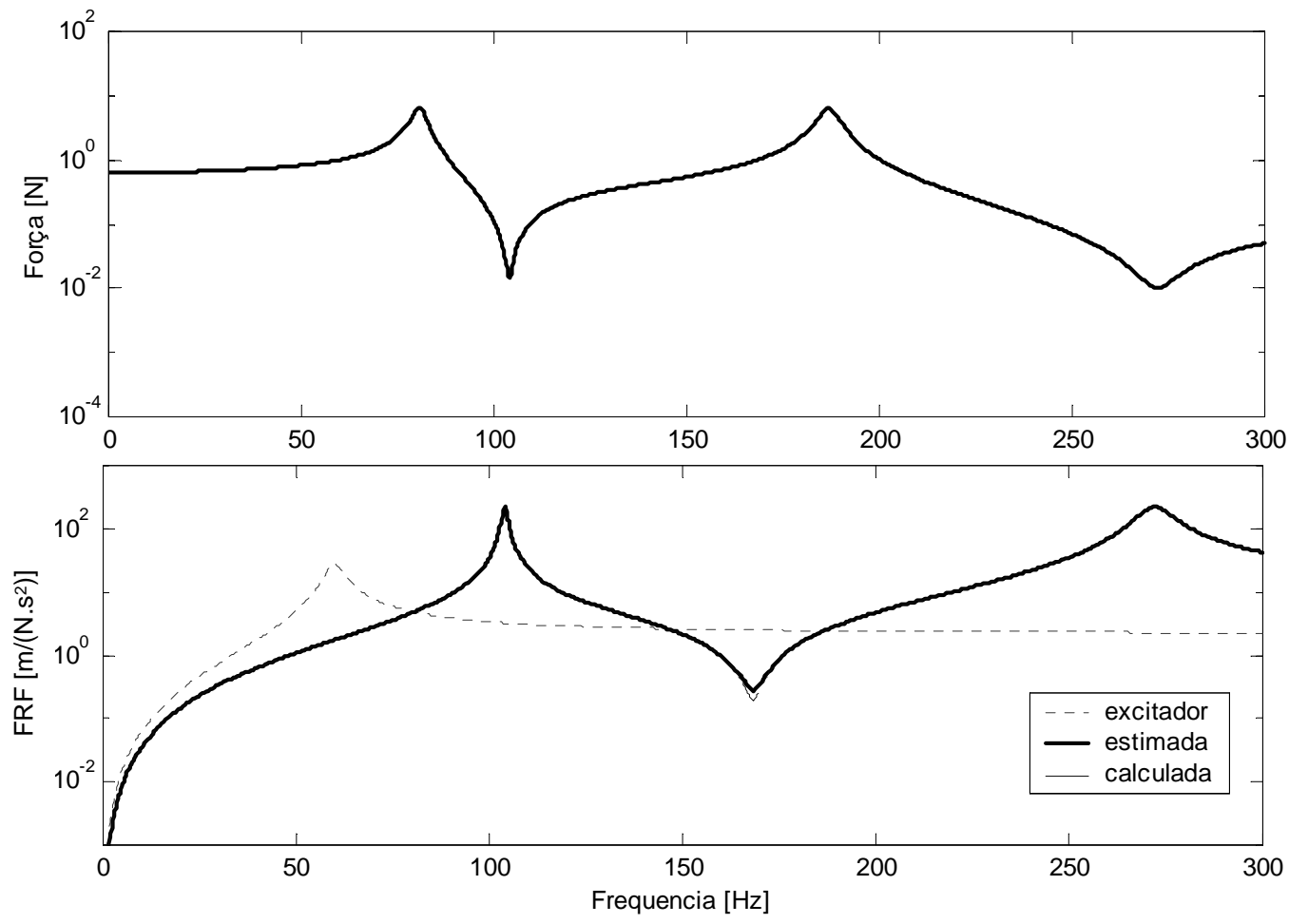

FIGURA 3.25 - Força de entrada e FRFs para estrutura de 0,2 kg 


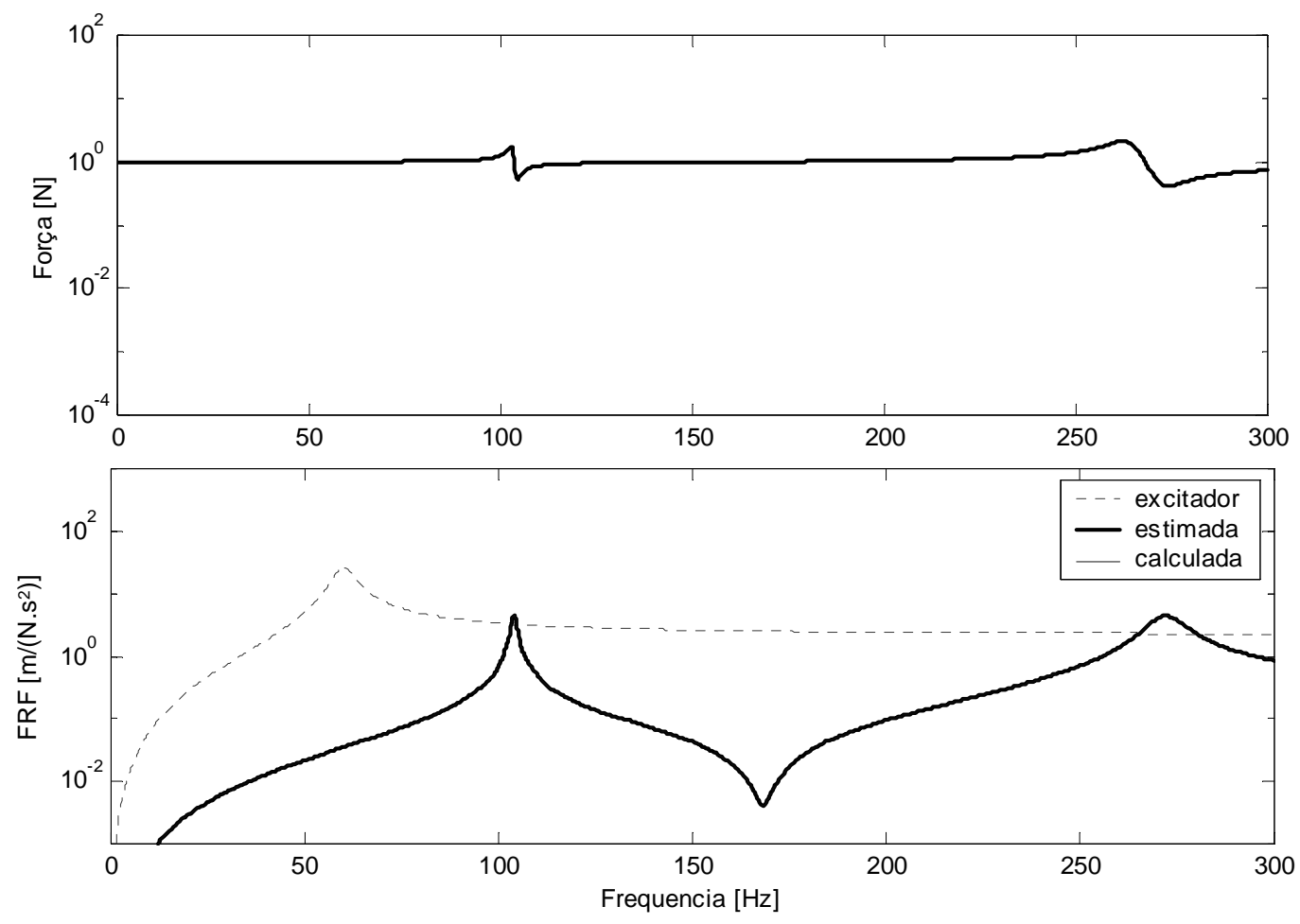

FIGURA 3.26 - Força de entrada e FRFs para estrutura de $10 \mathrm{~kg}$

Por fim, as mesmas simulações foram realizadas com modelos das mesmas estruturas, considerando-se agora 5 GDL. Os mesmos fenômenos observados até então se repetem para estes casos.

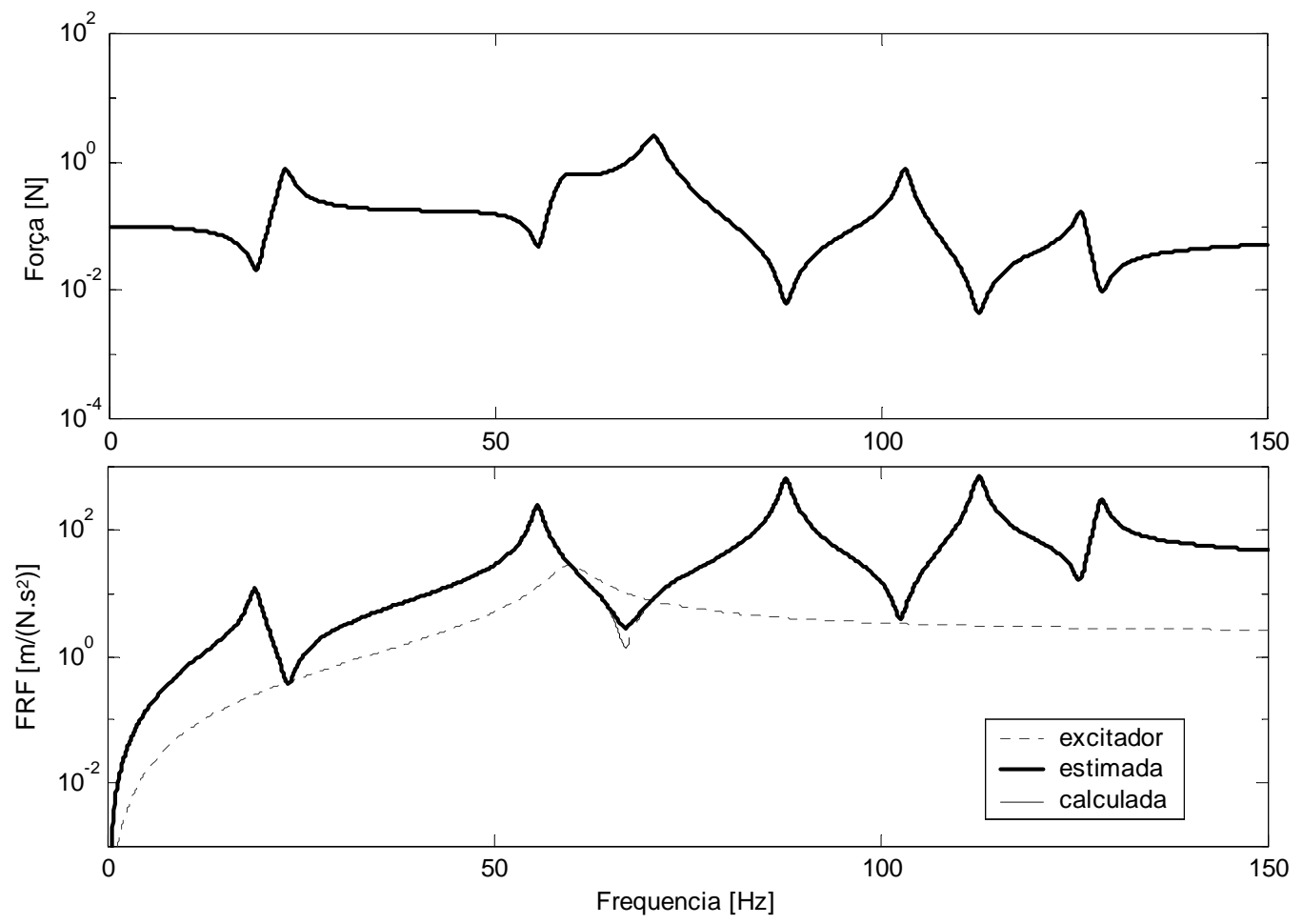

FIGURA 3.27 - Força de entrada e FRFs para estrutura de 5 GDL e 0,2 kg 

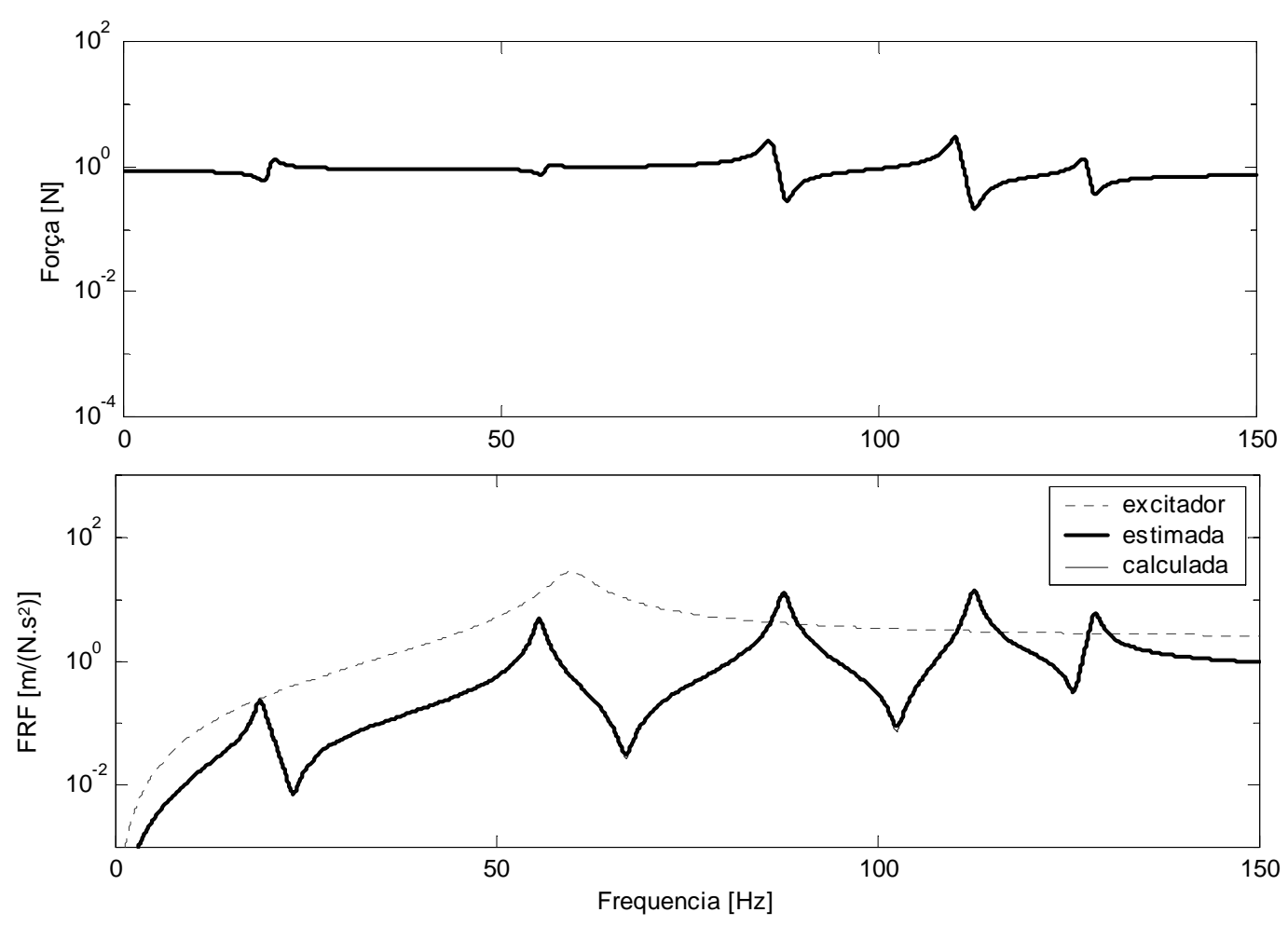

FIGURA 3.28 - Força de entrada e FRFs para estrutura de 5 GDL e 0,2 kg

As quedas de força mostram-se mais acentuadas no caso da estrutura de $0,2 \mathrm{~kg}$. A sucessão de máximos e mínimos de força obedece às relações observadas nas Figs. 3.23 a 3.26 para os casos de 2 GDL. Com resultados como estes, considera-se a abordagem teórica bem sucedida, no que diz respeito aos modelos mecânicos. Com isso, parte-se então para a modelagem eletromecânica, considerando-se agora as características elétricas do excitador e do amplificador, e os efeitos da queda de tensão observados no modo de tensão.

\subsubsection{MODELO ELETROMECÂNICO (MODO DE TENSÃO)}

Parte-se então para o modelo eletromecânico. Os resultados apresentados nesta seção referem-se ao mesmo modelo ilustrado na Fig. 3.17, com base na Eq. 3.19, que tem como entrada do sistema a tensão fornecida aos circuitos armadura. Trata-se, portanto, do modo de tensão de operação. Para o modo de corrente, para o qual a corrente é dada, recai-se sobre o modelo mecânico com $F_{e}=H_{f} I$, como simulado anteriormente.

RAO (1987) relaciona a parcela eletromagnética do fenômeno de interação com um denominado amortecimento eletrodinâmico, ou seja, uma parcela adicional de amortecimento é introduzida no sistema quando se considera a parcela eletromagnética. Esta interfere de forma considerável na dinâmica do excitador, como fora observado na Fig. 3.11, e conseqüentemente no mecanismo de excitação como ilustrado a seguir (Figs. 3.29 a 3.38). 


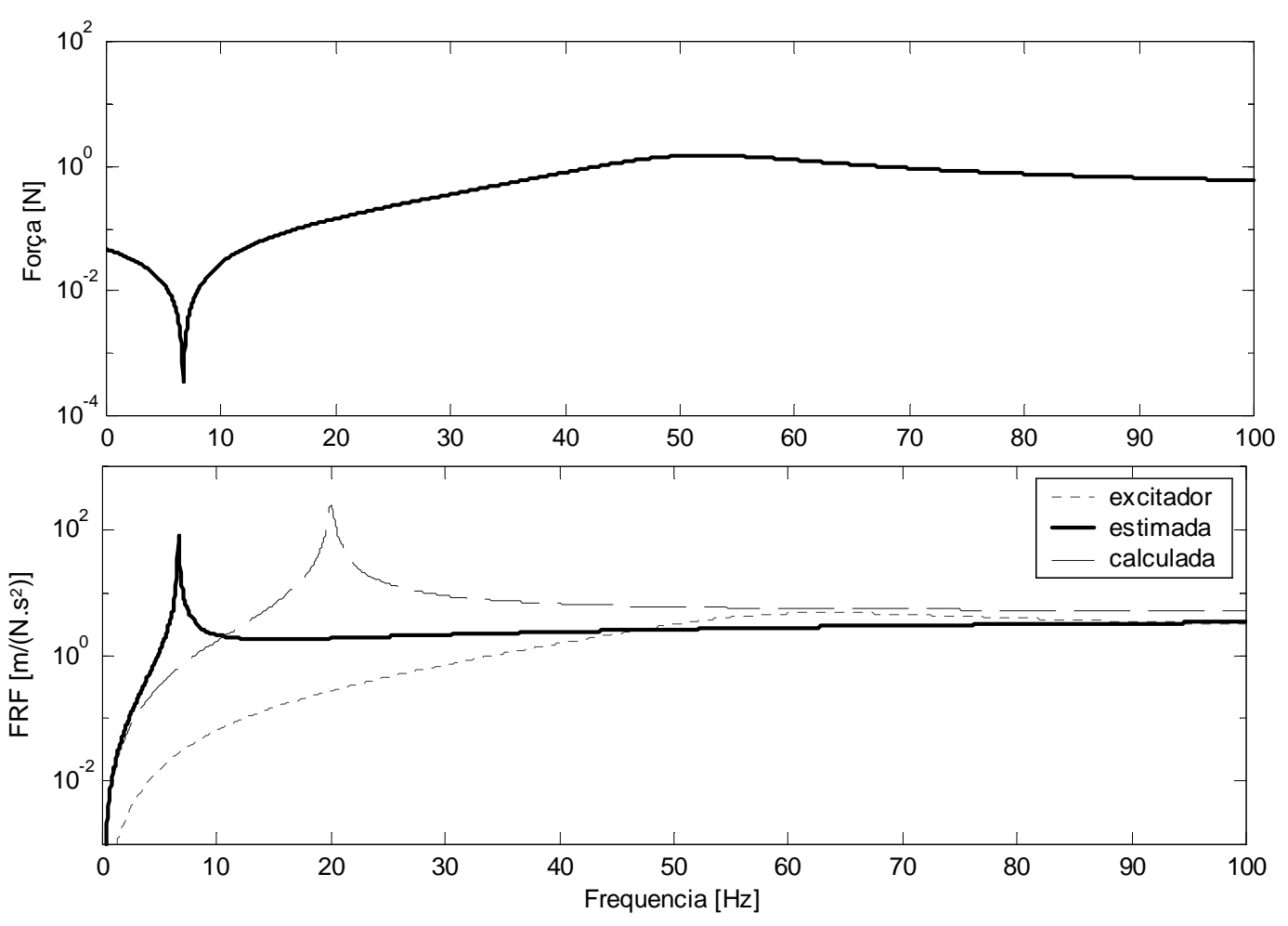

FIGURA 3.29 - Força de entrada e FRFs para estrutura de $0,2 \mathrm{~kg}$

As simulações foram repetidas para o mesmo conjunto de estruturas analisados na sessão anterior. Observa-se que o efeito do sistema elétrico se evidencia na forma de um forte amortecimento, como observado na seção 3.1.2, que indistintamente afeta as amplitudes e freqüências naturais identificadas nas FRFs estimadas.

Mesmo para o caso da estrutura de $10 \mathrm{~kg}$ com freqüência natural de $20 \mathrm{~Hz}$ que tinha influência imperceptível no caso mecânico (Fig. 3.22), o efeito da interação no caso eletromecânico é significante (Fig. 3.30).

Ainda, para o caso da estrutura de $0,2 \mathrm{~kg}$, tanto a queda na força quanto o efeito destrutivo na FRF estimada são mais acentuados, o que novamente relaciona o fenômeno de queda de força com a relação entre as massas da armadura e do item de teste (MOUCH, 1990).

Efeitos análogos podem ser observados para os casos com 2 GDL (Figs. 3.33 a 3.36) e para um sistema com 5 GDL (Fig. 3.37), sendo que as distorções causadas nas FRFs estimadas, se aplicam não somente às anti-ressonâncias mas também às ressonâncias, mesmo para a estrutura de $10 \mathrm{~kg}$. 

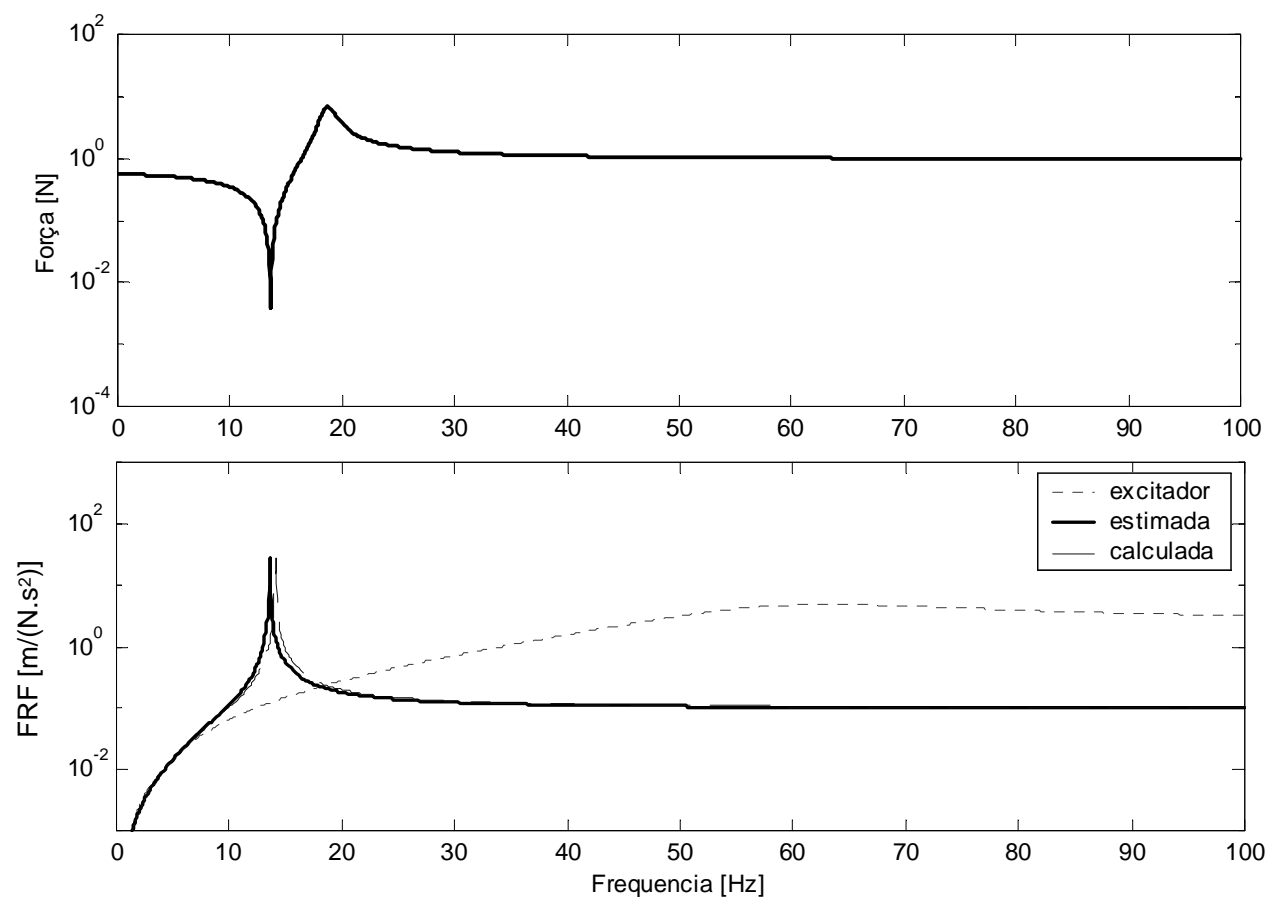

FIGURA 3.30 - Força de entrada e FRFs para estrutura de $10 \mathrm{~kg}$
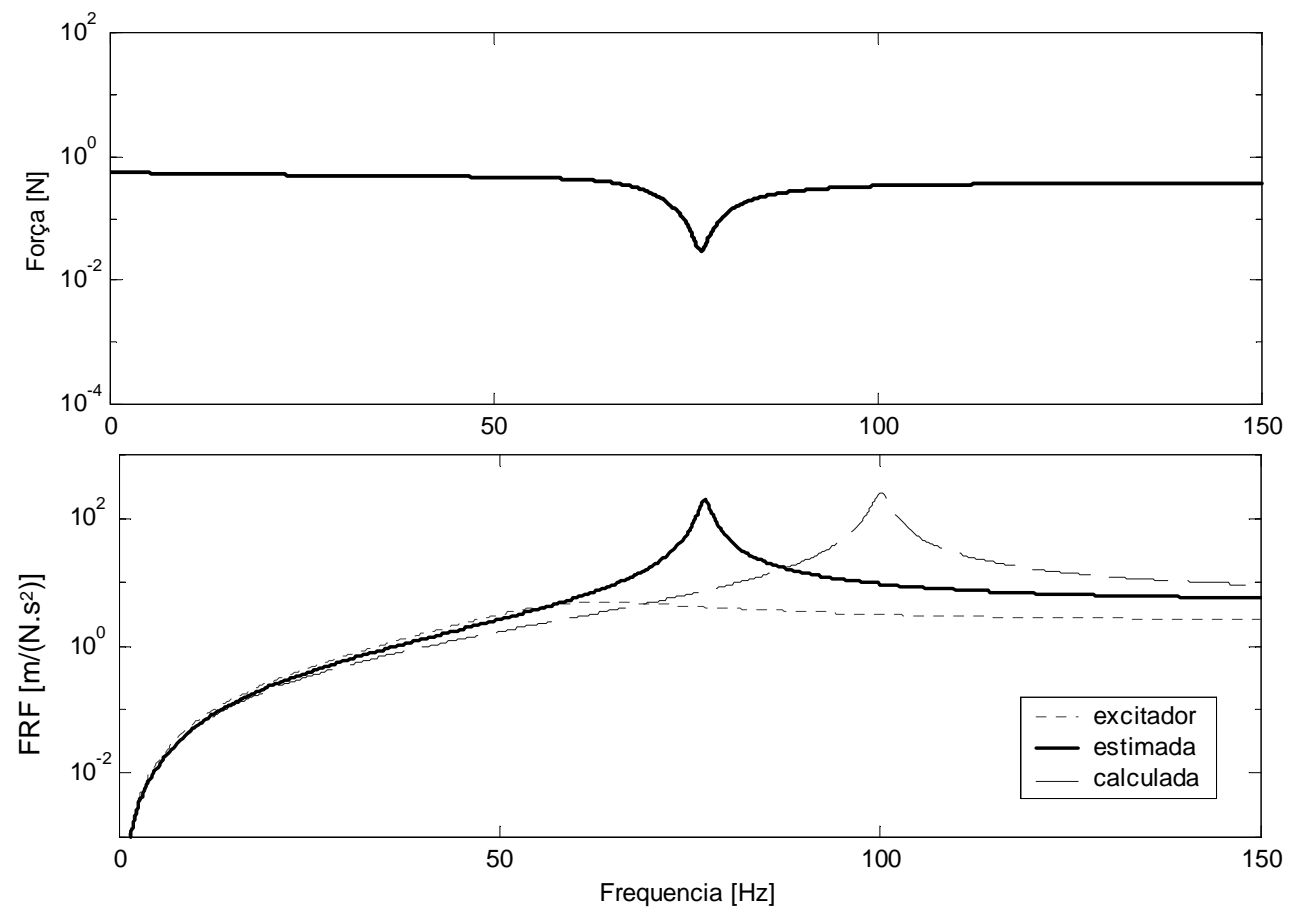

FIGURA 3.31 - Força de entrada e FRFs para estrutura de $0,2 \mathrm{~kg}$ 


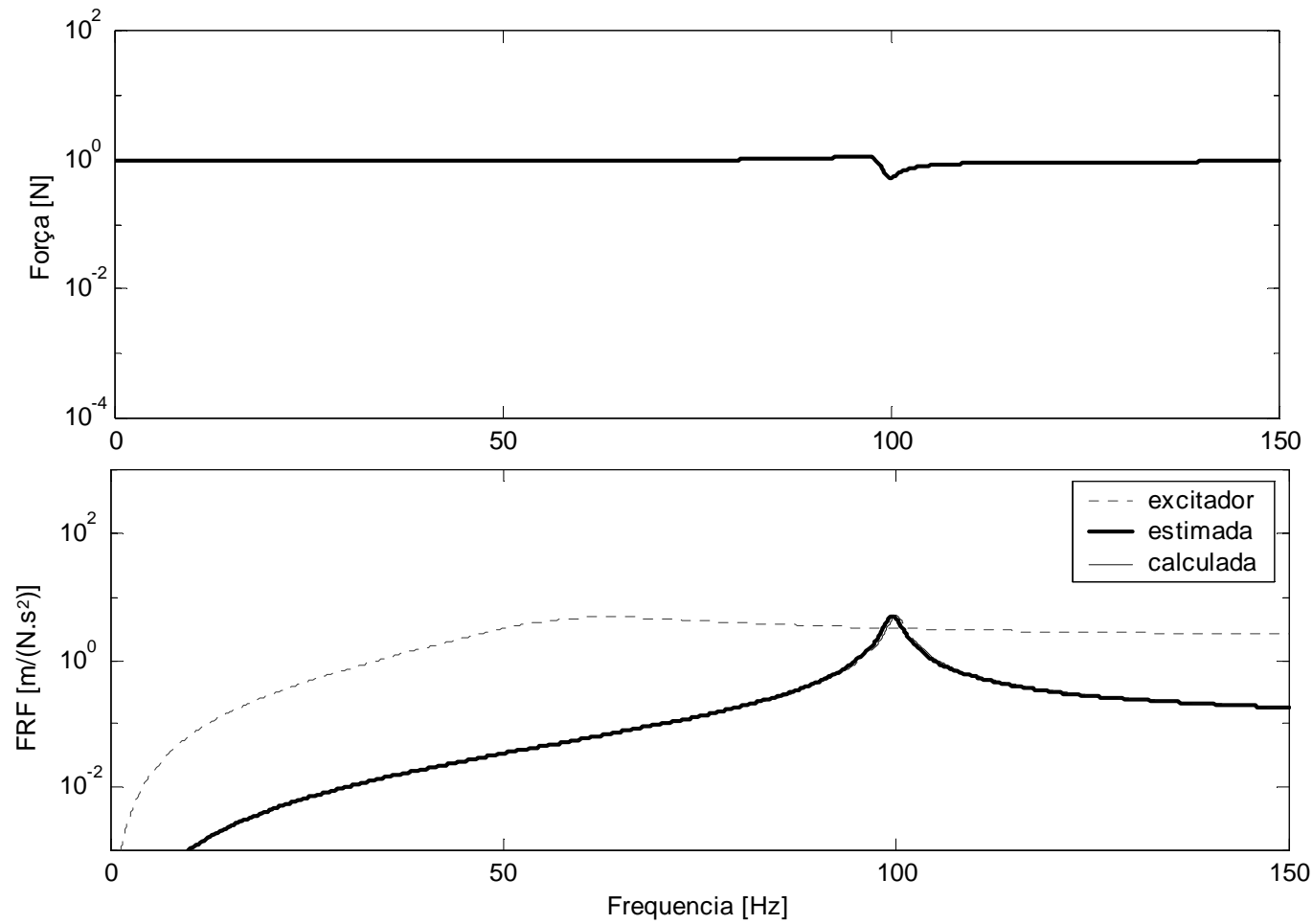

FIGURA 3.32 - Força de entrada e FRFs para estrutura de $10 \mathrm{~kg}$
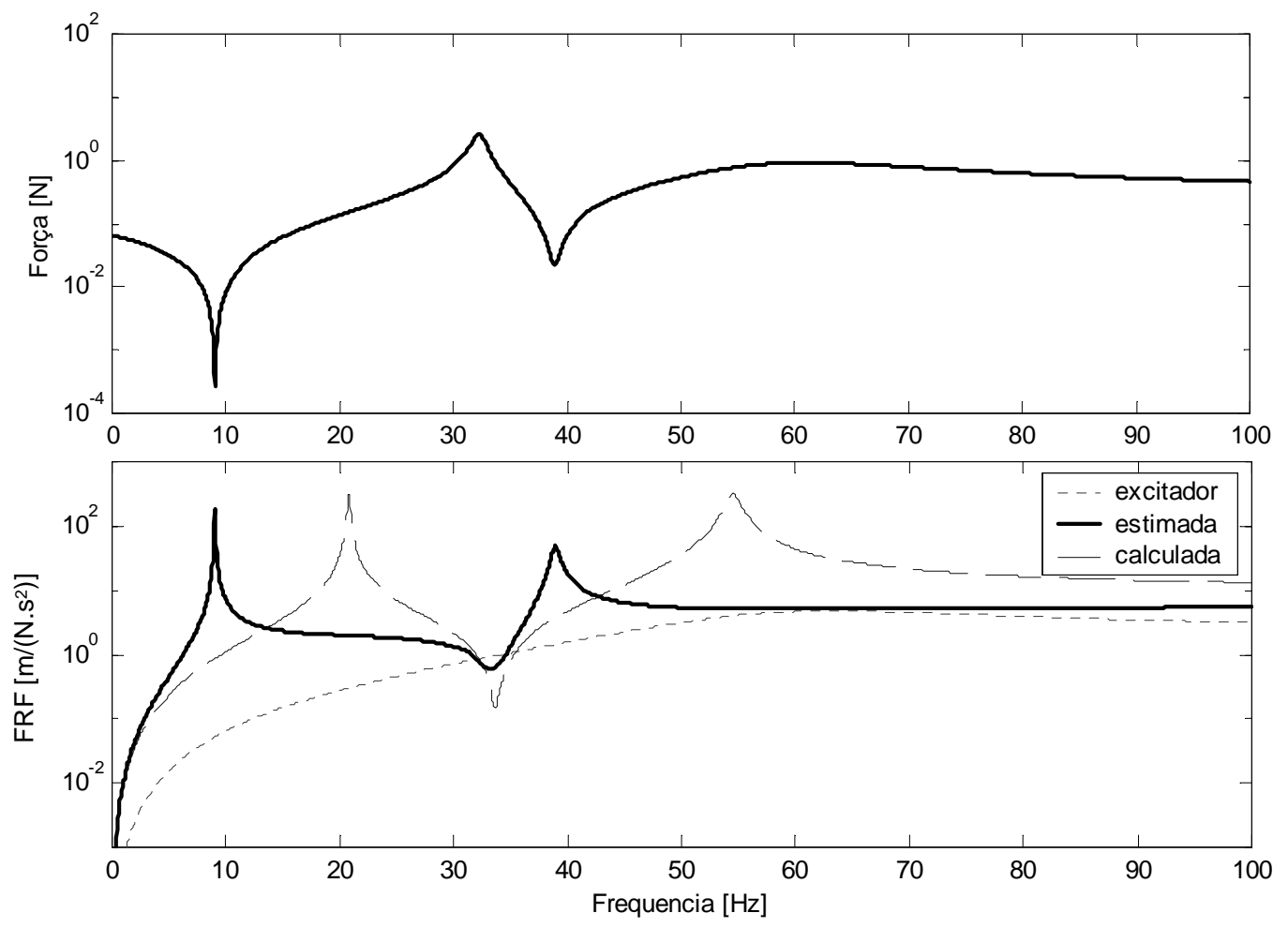

FIGURA 3.33 - Força de entrada e FRFs para estrutura de $0,2 \mathrm{~kg}$ 

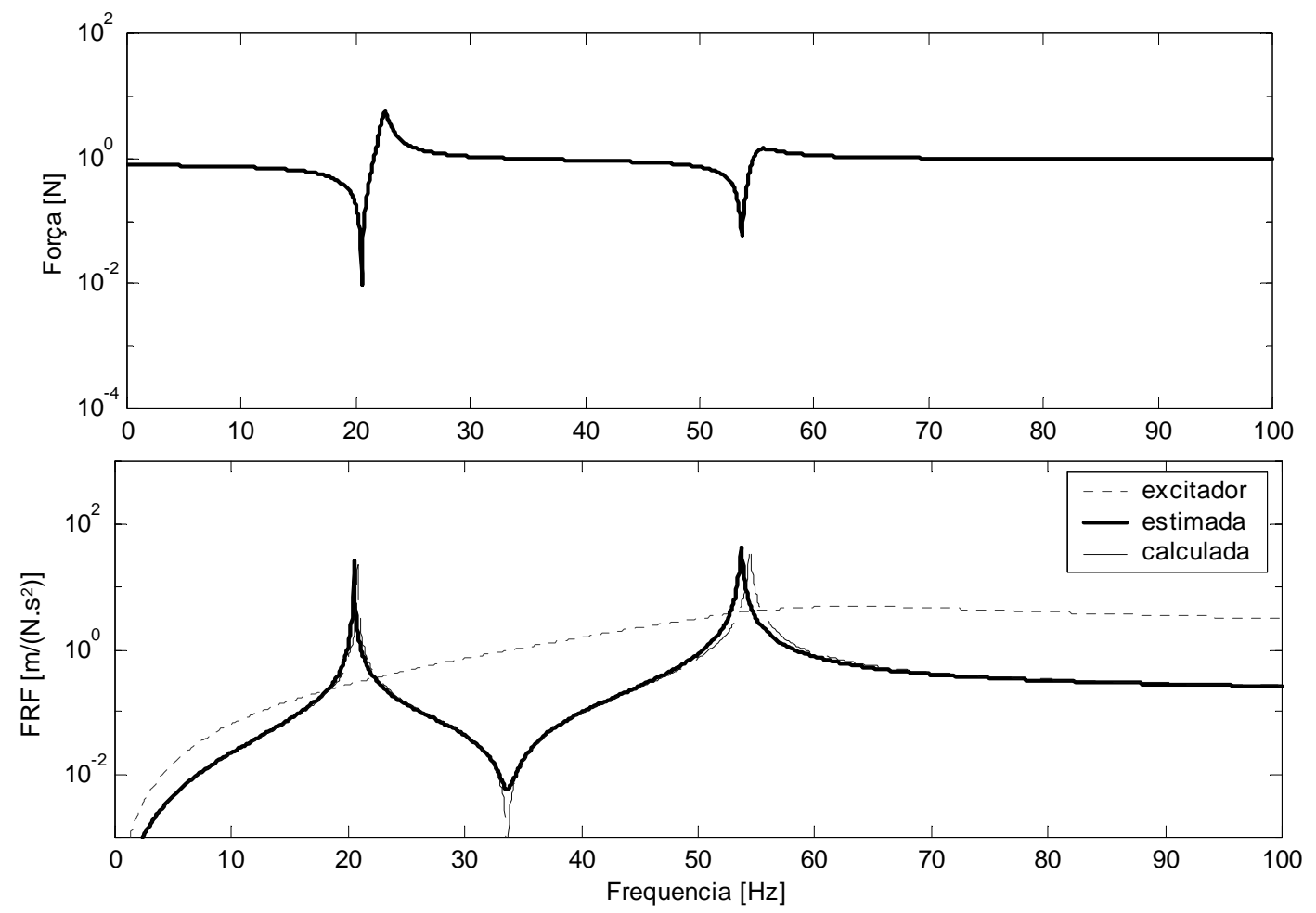

FIGURA 3.34 - Força de entrada e FRFs para estrutura de 10 kg
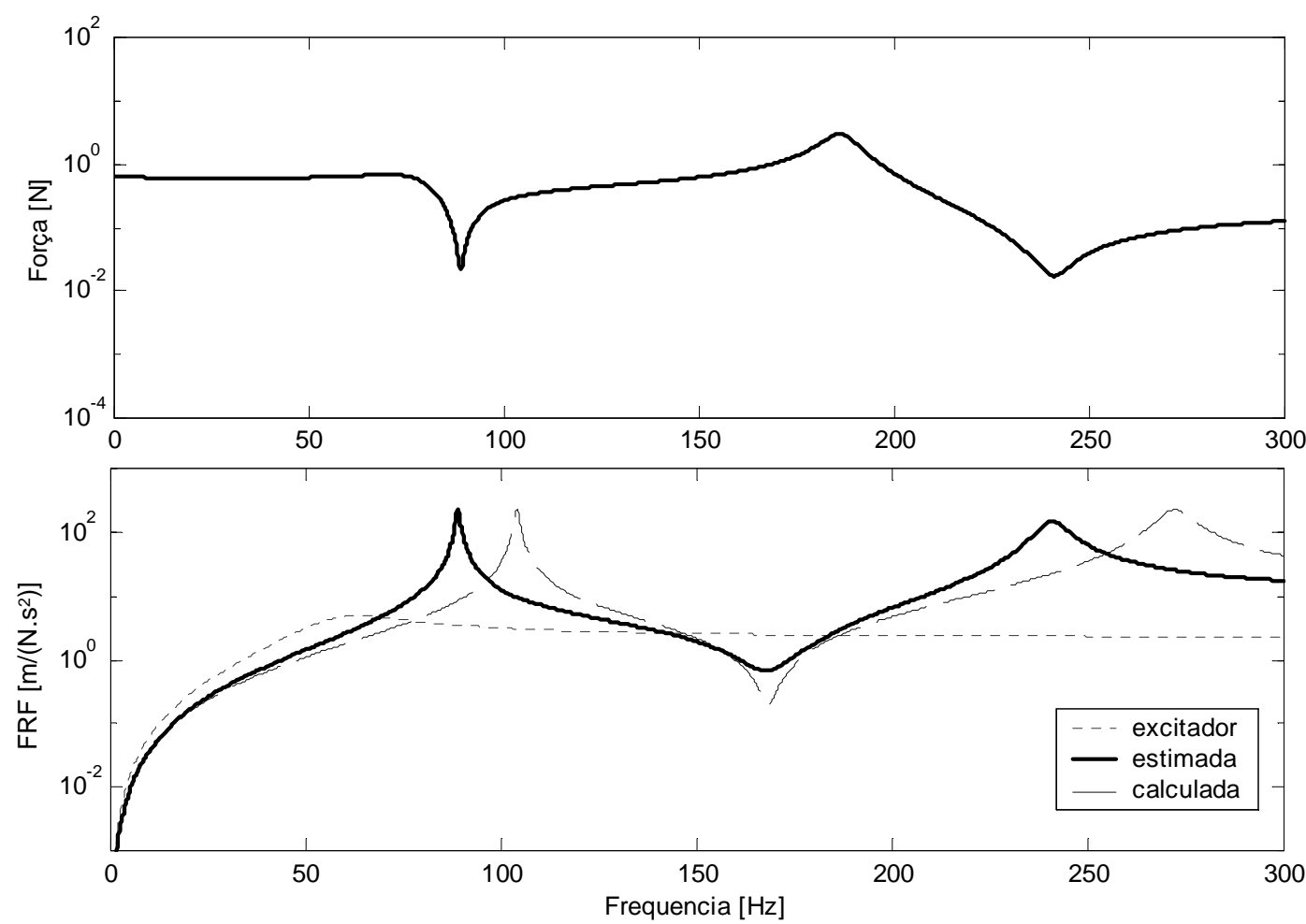

FIGURA 3.35 - Força de entrada e FRFs para estrutura de $0,2 \mathrm{~kg}$ 

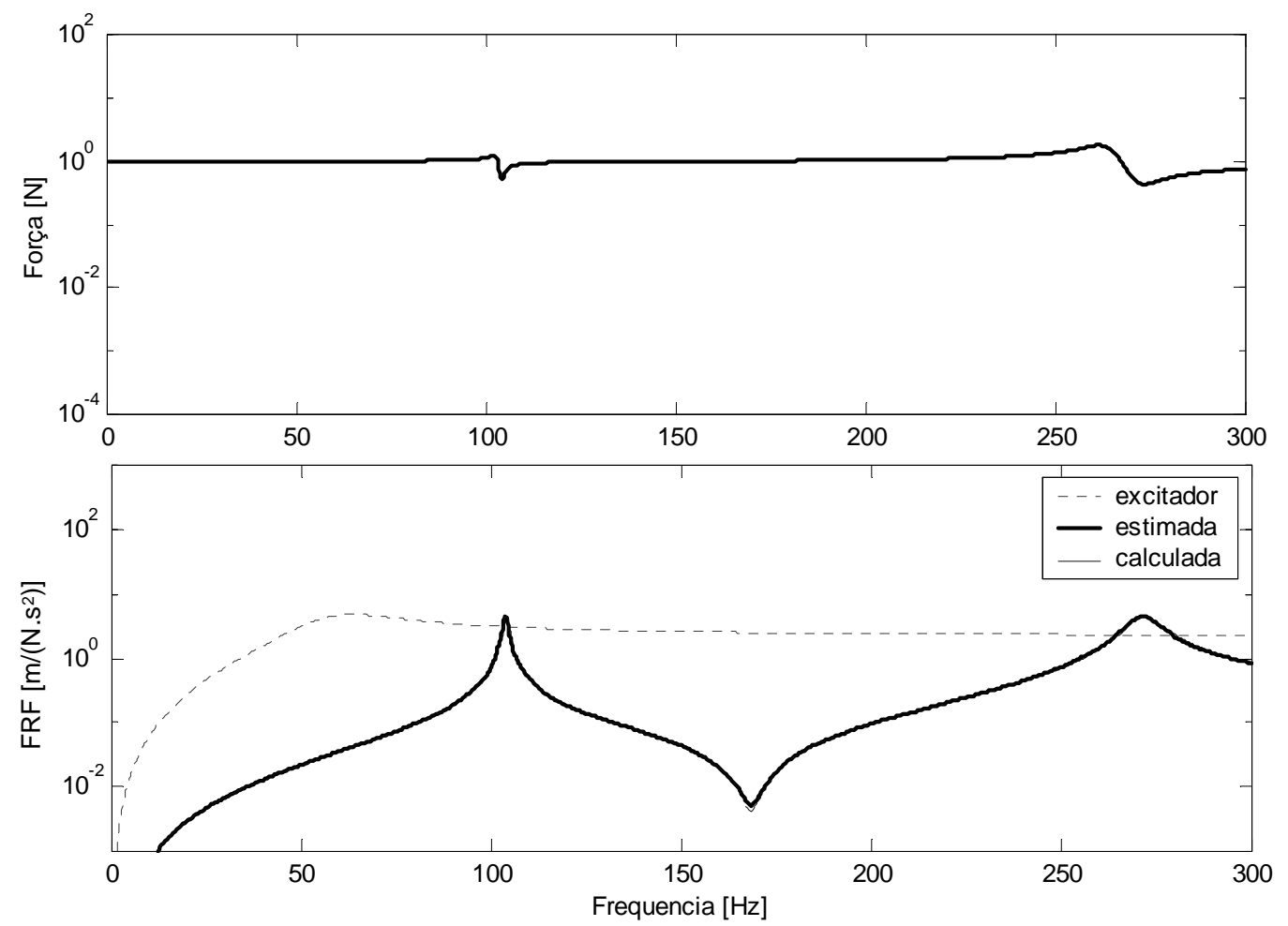

FIGURA 3.36 - Força de entrada e FRFs para estrutura de 0,2 kg
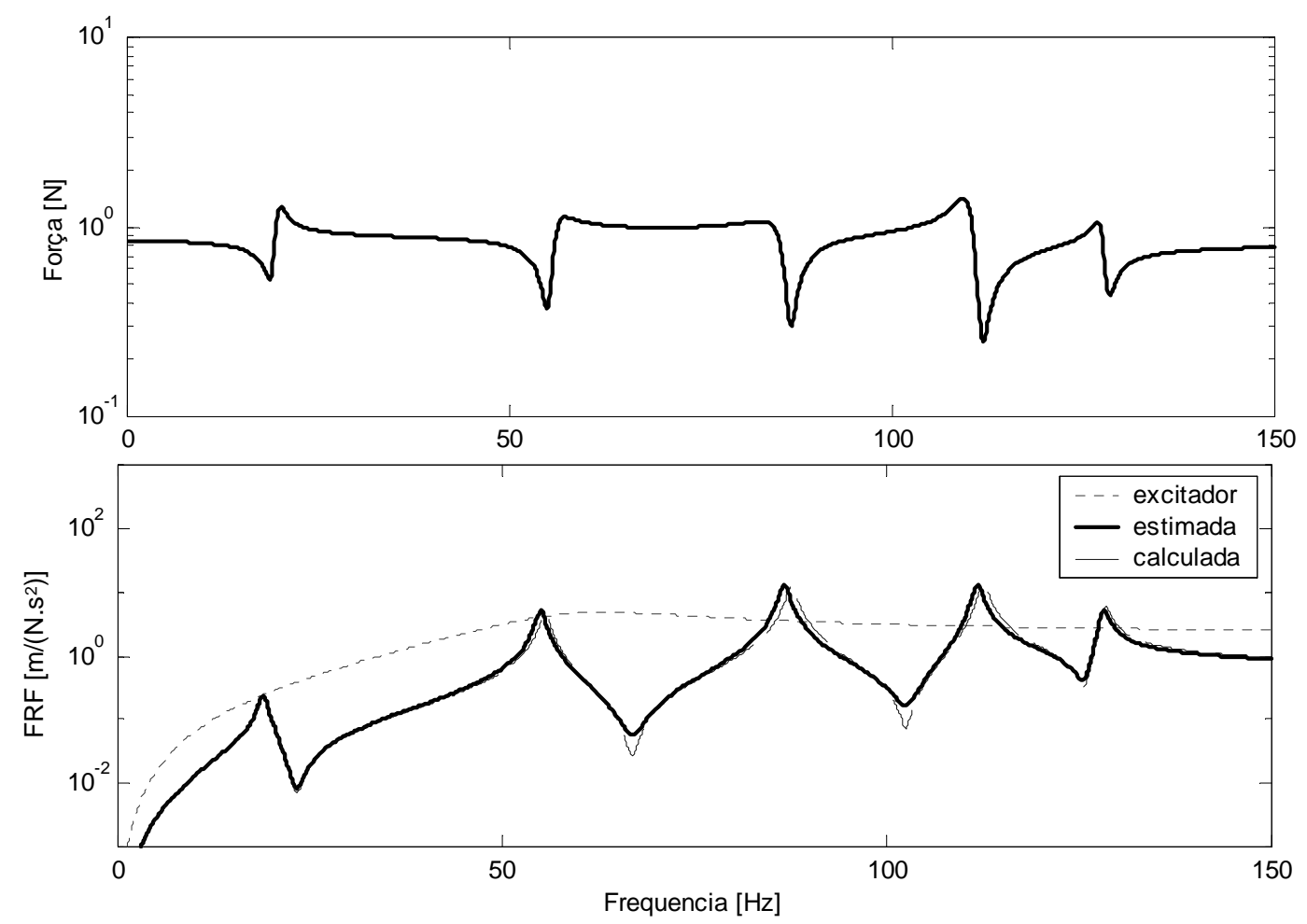

FIGURA 3.37 - Força de entrada e FRFs para estrutura de $10 \mathrm{~kg}$ 


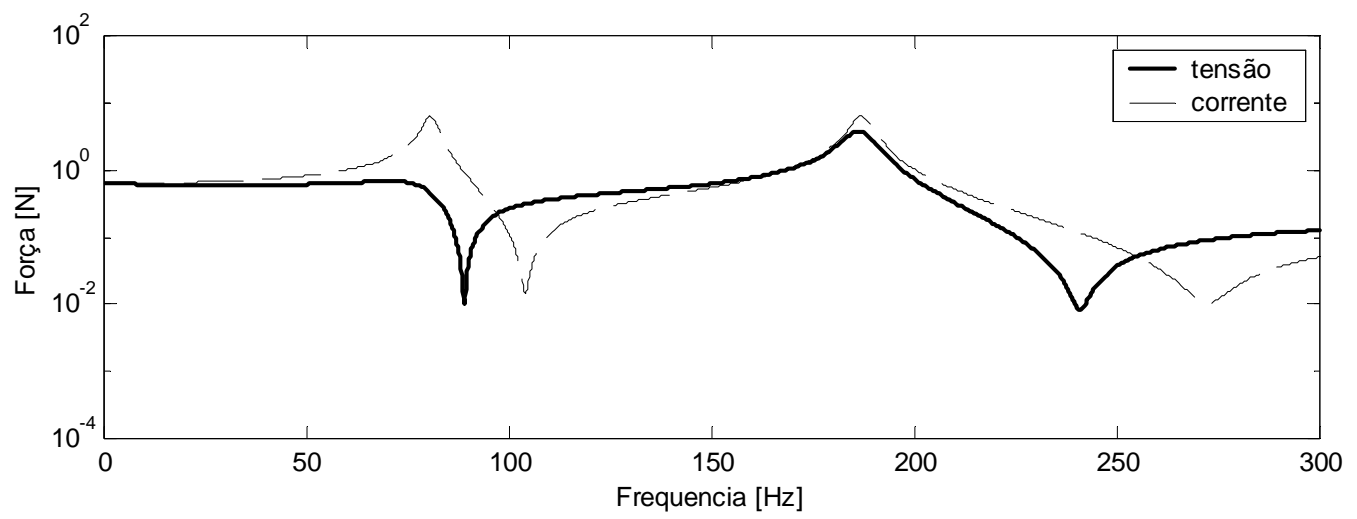

FIGURA 3.38 - Comparação entre as forças de entrada para estrutura de $0,2 \mathrm{~kg}$

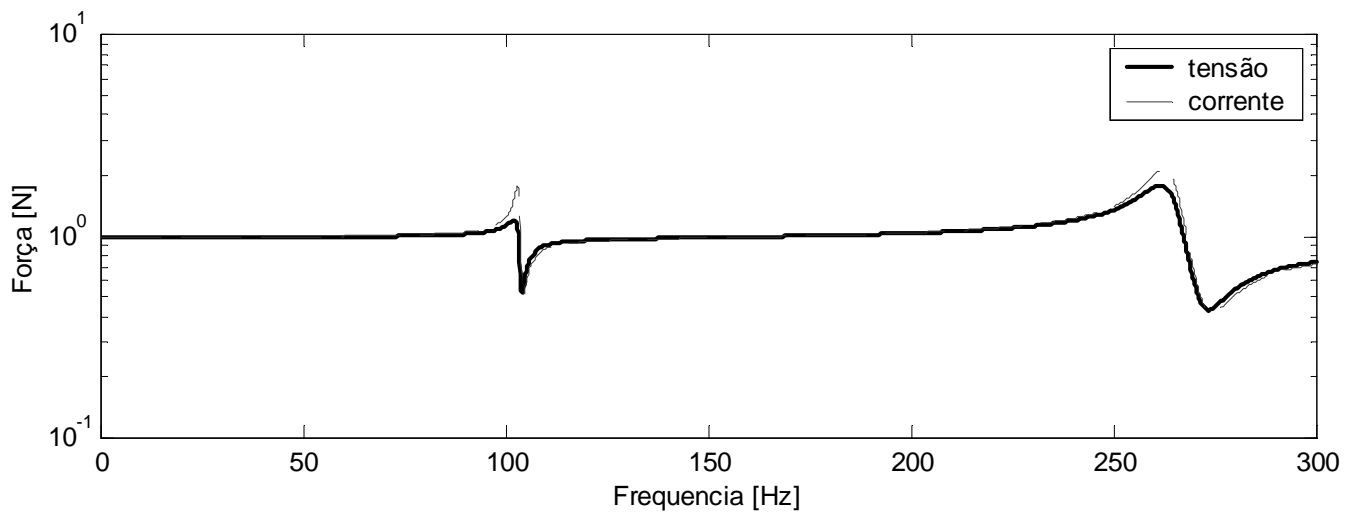

FIGURA 3.39 - Comparação entre as forças de entrada para estrutura de $10 \mathrm{~kg}$

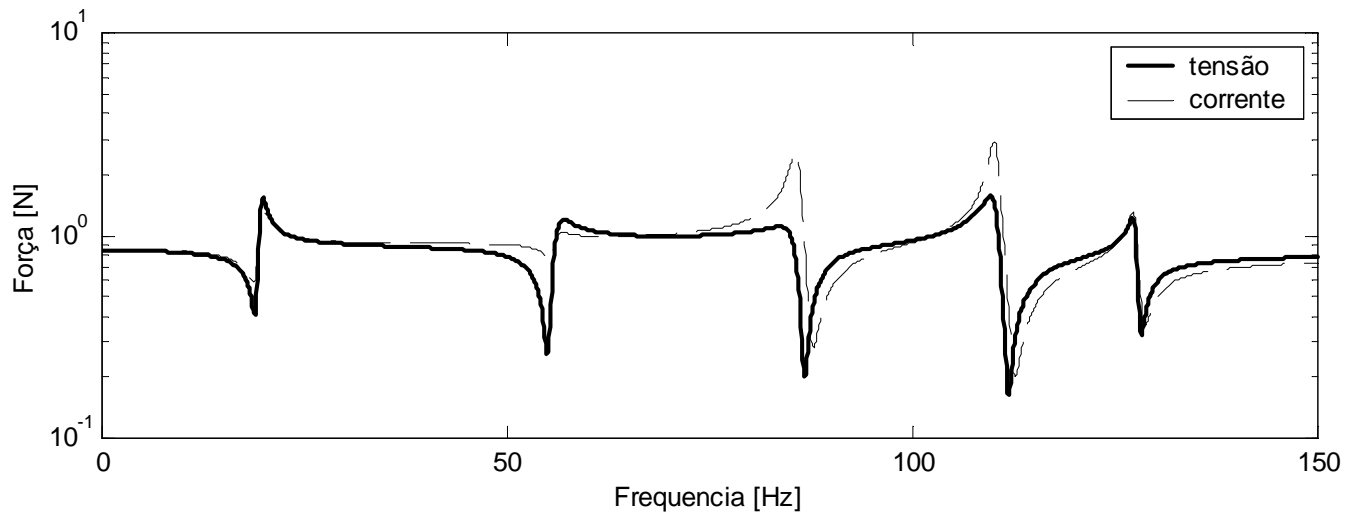

FIGURA 3.40 - Comparação entre as forças de entrada para estrutura de $10 \mathrm{~kg}$

Outra questão a se considerar, são os esforços a que as estruturas são submetidas durante os testes. VAROTO (1996) afirma que sob condições de teste em laboratório, uma estrutura pode ser submetida a esforços dinâmicos que não vivencia em seu uso normal. Neste processo a estrutura pode ser danificada, ou mesmo submetida a condições extremas que interfiram em hipóteses assumidas como de linearidade, por exemplo.

As forças calculadas para os casos de operação em modo de corrente e tensão, ilustrados nas Figs. 3.38, 3.39 e 3.40, mostram que a manutenção do nível de tensão nas 
proximidades das freqüências naturais resulta em força muito elevada sendo transmitida à estrutura nas freqüências próximas das freqüências naturais da estrutura.

\subsubsection{Modelo Considerando Graus de Liberdade Rotacionais}

Para as simulações com uma estrutura, considera-se o modelo com 2 graus de liberdade (translacionais e rotacionais) ilustrado na Fig. 3.40.

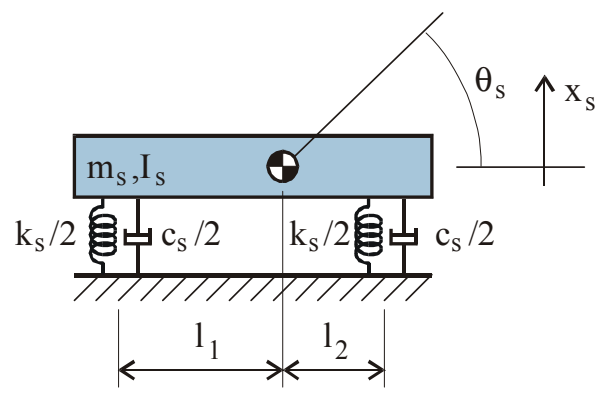

FIGURA 3.41 - Estrutura com 2 GDL

As acelerâncias obtidas com este sistema podem ser vistas na Fig. 3.41.
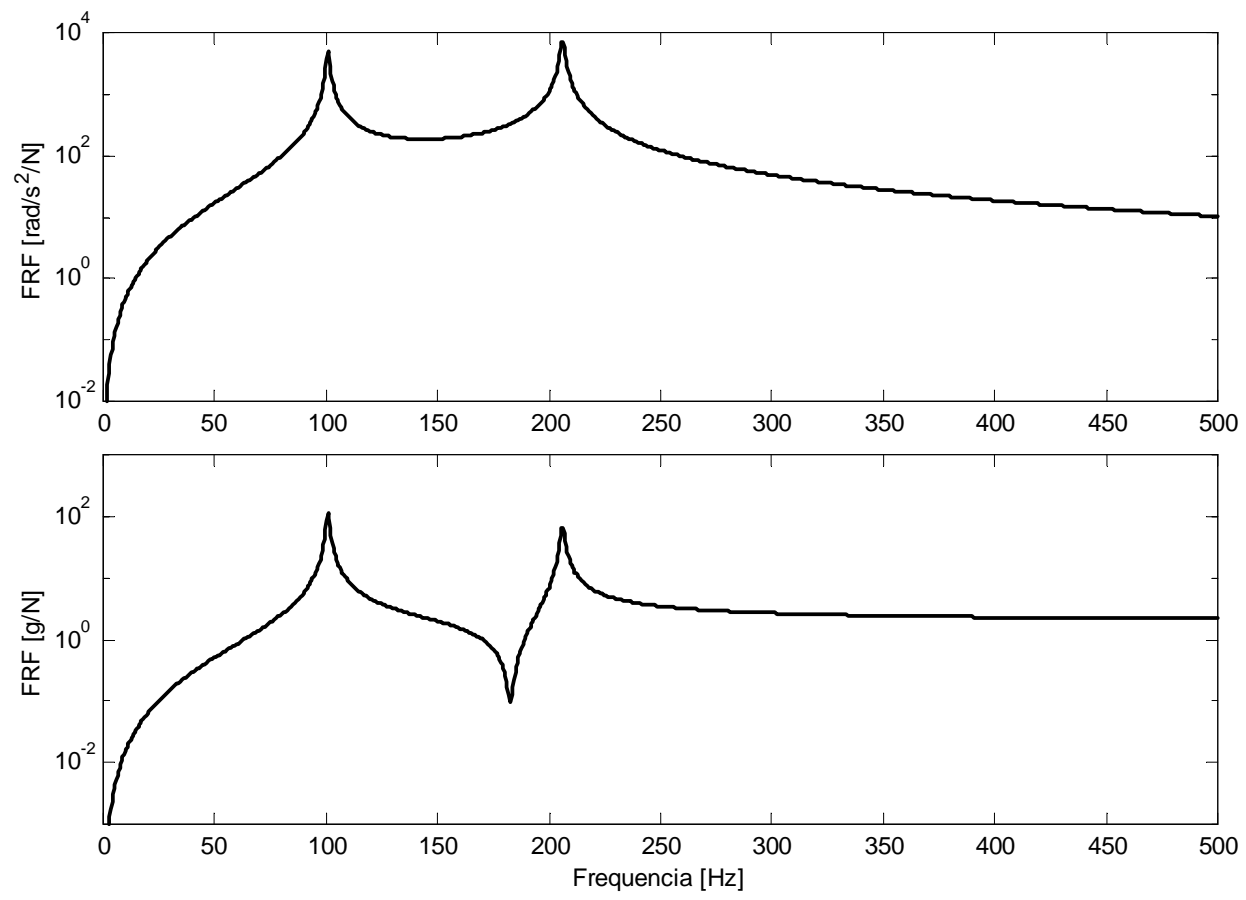

FIGURA 3.42 - Acelerâncias de translação e rotação

McCONNELL (1995) sugere um método para calcular as forças entre o excitador e a estrutura (Fig 3.42). As equações que seguem representam uma continuação natural do equacionamento proposto por ele, considerando agora os graus de liberdade rotacionais. 

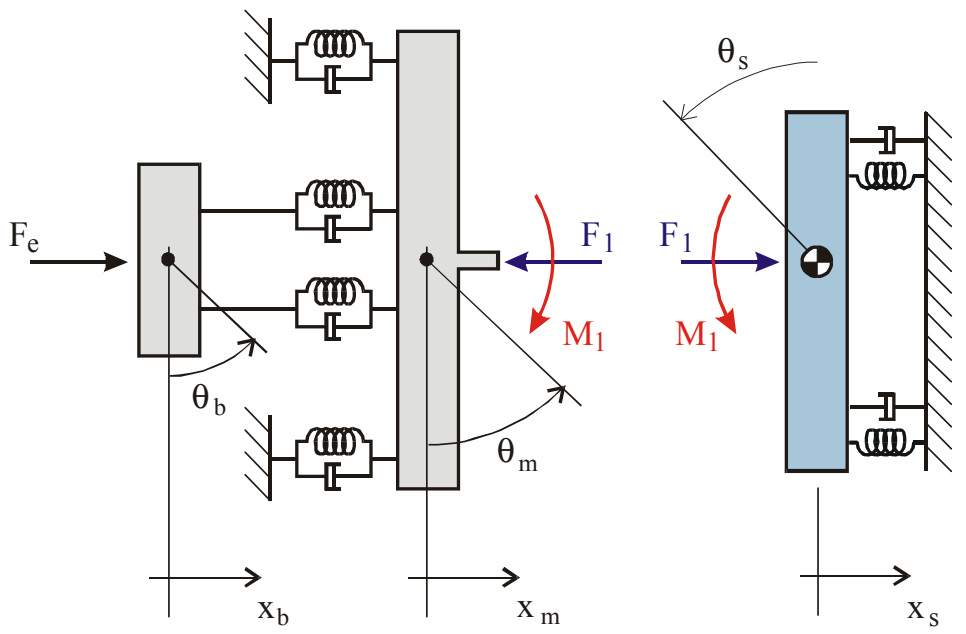

FIGURA 3.43 - Forças e momentos entre o excitador e a estrutura

Baseando-se na Eq. 3.22 e no modelo ilustrado na Fig 3.43, pode-se escrever para a armadura:

$$
\left\{\begin{array}{c}
\ddot{\mathrm{x}}_{\mathrm{m}} \\
\ddot{\mathrm{x}}_{\mathrm{b}} \\
\ddot{\theta}_{\mathrm{m}} \\
\ddot{\theta}_{\mathrm{b}}
\end{array}\right\}=\left[\begin{array}{cccc}
\mathrm{A}_{\mathrm{mm}} & \mathrm{A}_{\mathrm{mb}} & \mathrm{B}_{\mathrm{mm}} & \mathrm{B}_{\mathrm{mb}} \\
\mathrm{A}_{\mathrm{bm}} & \mathrm{A}_{\mathrm{bb}} & \mathrm{B}_{\mathrm{bm}} & \mathrm{B}_{\mathrm{bb}} \\
\mathrm{C}_{\mathrm{mm}} & \mathrm{C}_{\mathrm{mb}} & \mathrm{D}_{\mathrm{mm}} & \mathrm{D}_{\mathrm{mb}} \\
\mathrm{C}_{\mathrm{bm}} & \mathrm{C}_{\mathrm{bb}} & \mathrm{D}_{\mathrm{bm}} & \mathrm{D}_{\mathrm{bb}}
\end{array}\right]\left\{\begin{array}{c}
-\mathrm{F}_{1} \\
\mathrm{~F}_{\mathrm{e}} \\
-\mathrm{M}_{1} \\
0
\end{array}\right\}
$$

e para a estrutura

$$
\left\{\begin{array}{c}
\ddot{x}_{\mathrm{s}} \\
\ddot{\theta}_{\mathrm{s}}
\end{array}\right\}=\left[\begin{array}{cc}
\mathrm{A}_{\mathrm{ss}} & \mathrm{B}_{\mathrm{ss}} \\
\mathrm{C}_{\mathrm{ss}} & \mathrm{D}_{\mathrm{ss}}
\end{array}\right]\left\{\begin{array}{c}
\mathrm{F}_{1} \\
\mathrm{M}_{1}
\end{array}\right\}
$$

nas quais $\mathrm{A}, \mathrm{B}, \mathrm{C}$ e D se referem às FRFs de rotação e translação devido a entradas de força e momento. Os índices ' $m$ ', ' $b$ ' e ' $s$ ' se referem à mesa, bobinas e estrutura respectivamente.

Supondo que a união entre o Excitador e a estrutura é rígida, pode-se escrever as seguintes equações de compatibilidade.

$$
\ddot{\mathrm{x}}_{\mathrm{m}} \cong \ddot{\mathrm{x}}_{\mathrm{s}} \text { e } \quad \ddot{\theta}_{\mathrm{m}} \cong \ddot{\theta}_{\mathrm{s}}
$$

Considerando que dada a simetria do modelo da armadura, os graus de liberdade rotacionais e translacionais são desacoplados, i.e.:

$$
\left[\begin{array}{ll}
\mathrm{B}_{\mathrm{mm}} & \mathrm{B}_{\mathrm{mb}} \\
\mathrm{B}_{\mathrm{bm}} & \mathrm{B}_{\mathrm{bb}}
\end{array}\right]=\left[\begin{array}{ll}
\mathrm{C}_{\mathrm{mm}} & \mathrm{C}_{\mathrm{mb}} \\
\mathrm{C}_{\mathrm{bm}} & \mathrm{C}_{\mathrm{bb}}
\end{array}\right]=\left[\begin{array}{ll}
0 & 0 \\
0 & 0
\end{array}\right]
$$

as Eqs.(3.28), (3.29) e (3.30) resultam em: 
$\left\{\begin{array}{l}A_{m m}\left(-F_{1}\right)+A_{m b}\left(F_{e}\right)=A_{s s}\left(F_{1}\right)+B_{s s}\left(M_{1}\right) \\ D_{m m}\left(-M_{1}\right)=C_{s s}\left(F_{1}\right)+D_{s s}\left(M_{1}\right)\end{array}\right.$

Finalmente, como resultado obtém-se:

$$
\begin{aligned}
& \mathrm{F}_{1}=\frac{\mathrm{A}_{\mathrm{mb}}}{\left(\mathrm{A}_{\mathrm{ss}}+\mathrm{A}_{\mathrm{mm}}+\frac{\mathrm{B}_{\mathrm{ss}}+\mathrm{C}_{\mathrm{ss}}}{\mathrm{D}_{\mathrm{ss}}+\mathrm{D}_{\mathrm{mm}}}\right)} \mathrm{F}_{\mathrm{e}} \\
& \mathrm{M}_{1}=\left(\frac{\mathrm{C}_{\mathrm{ss}}}{\mathrm{D}_{\mathrm{ss}}+\mathrm{D}_{\mathrm{mm}}}\right) \mathrm{F}_{1}
\end{aligned}
$$

A Fig. 3.44 ilustra a força $\left(\mathrm{F}_{1}\right)$ e o momento $\left(\mathrm{M}_{1}\right)$ atuantes na estrutura, para o modelo mecânico adotado.
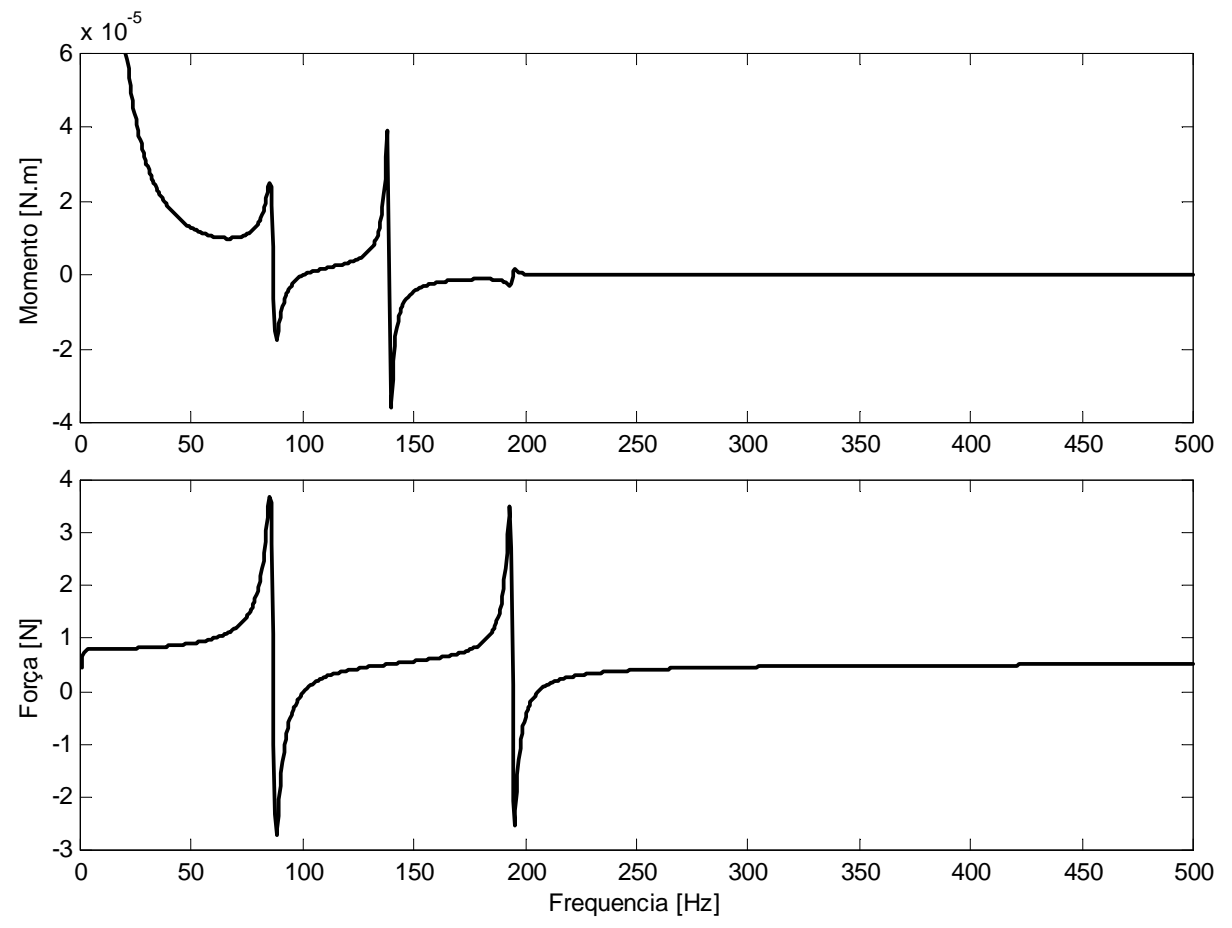

FIGURA 3.44 - Força e momentos atuando na estrutura

A Fig. 3.45 ilustra a força e o momento obtidos, considerando-se as características eletrodinâmicas do Excitador.

OLBRECHTS et al. (1993) aborda o problema de forças e momentos indesejados introduzidos pelo sistema de excitação. A queda da força, bem como os momentos aplicados no transdutor de força (Fig 3.45), são as principais razões para as mudanças na amplitude e freqüência das respostas medidas.

Os efeitos relativos à queda da força de excitação, neste caso, são os mesmos abordados nos modelos translacionais, ou seja, a queda de força nas proximidades das freqüências de ressonância da estrutura resulta em baixa relação sinal / ruído, o que 
prejudica a qualidade dos dados adquiridos, ainda, o efeito do amortecimento eletrodinâmico faz com que esta queda na força ocorra em outra freqüência que não a freqüência de ressonância da estrutura, podendo alterar a freqüência identificada experimentalmente.
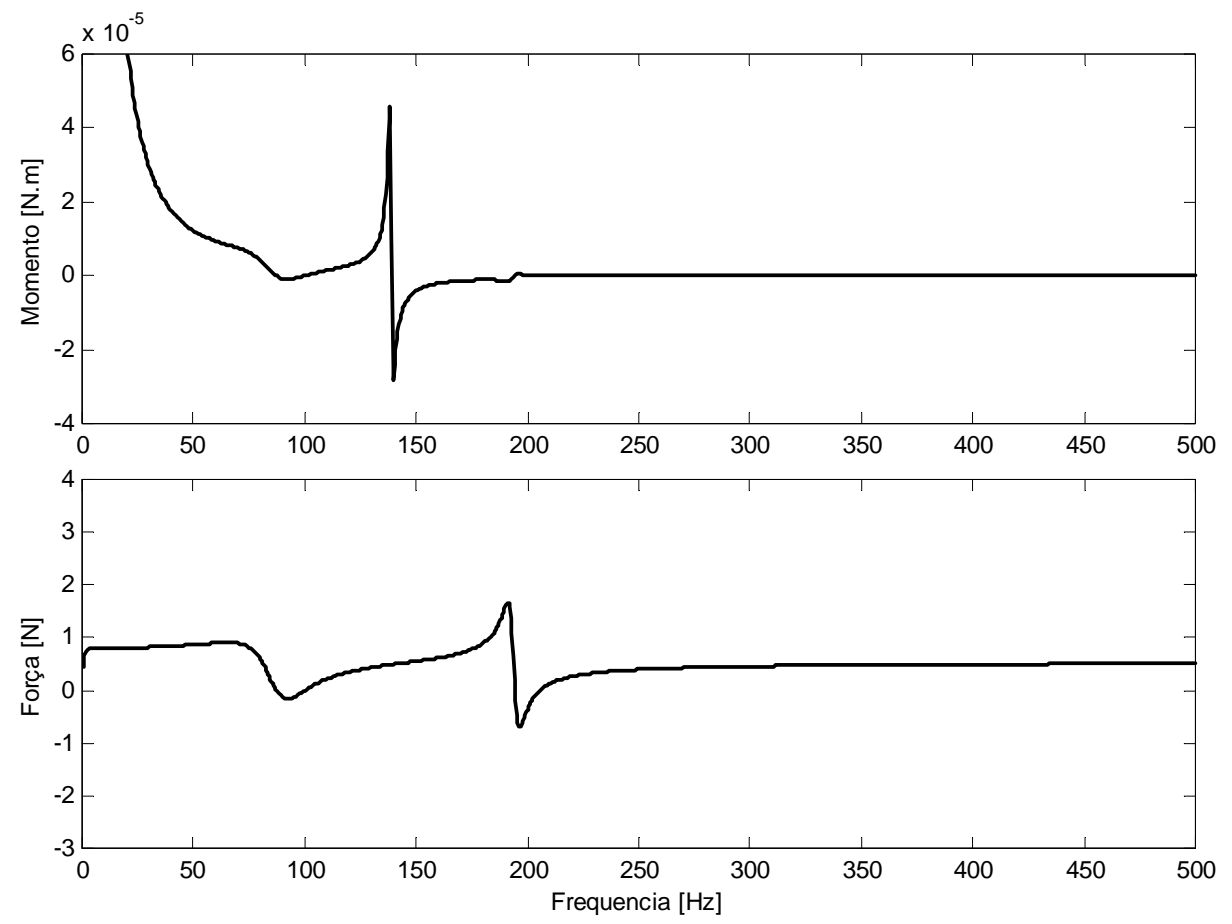

FIGURA 3.45 - Força e momentos atuando na estrutura

No que diz respeito aos GDLR da estrutura e da armadura, os principais efeitos desta interação residem no fato de que os fatores de calibração dos transdutores de força são fortemente afetados quando estes são submetidos a momentos (VAROTO \& McCONNEL, 1993a). Ainda, os efeitos de amortecimento eletromagnético não mostram surtir efeito sobre a rotação da estrutura e da mesa nas simulações. Deste modo, há que se esperar uma diferença significativa nas respostas obtidas com a mesma estrutura, variando-se a forma de fixação da mesma sobre o excitador. Os resultados dos testes ilustrados no próximo capítulo mostram que tais considerações não podem ser negligenciadas.

\subsubsection{ENSAIOS COM MÚltiPla EXCiTAÇão}

O principal objetivo desta seção é o de fornecer dados a respeito da interação excitador estrutura em testes com múltipla excitação. Para tanto, adota-se uma estrutura com 5 GDL (Fig 3.46) à qual conectam-se dois excitadores. Inicialmente os excitadores são considerados idênticos, com massa de armadura de $0,45 \mathrm{~kg}$ e freqüência natural de $59 \mathrm{~Hz}$. A fim de verificar a influência de excitadores diferentes, atuando simultaneamente, realizam-se as mesmas simulações considerando-se a relação entre as massas das armaduras $\mathrm{m}_{\mathrm{a} 1} / \mathrm{m}_{\mathrm{a} 3}=10$. 
As simulações com múltipla excitação foram realizadas considerando-se o modelo eletrodinâmico de 1 GDL do excitador, proposto anteriormente, e o sistema de 5 GDL da estrutura ilustrado na Fig 3.46, sendo:

$$
\begin{aligned}
& \mathrm{m} 1=\mathrm{m} 2=\mathrm{m} 3=\mathrm{m} 4=\mathrm{m} 5=2 \mathrm{~kg} \\
& \mathrm{k} 1=\mathrm{k} 2=\mathrm{k} 3=\mathrm{k} 4=\mathrm{k} 5=387000 \mathrm{~N} / \mathrm{m} \\
& \mathrm{c} 1=\mathrm{c} 2=\mathrm{c} 3=\mathrm{c} 4=\mathrm{c} 5=21 \mathrm{~N} . \mathrm{s} / \mathrm{m}
\end{aligned}
$$

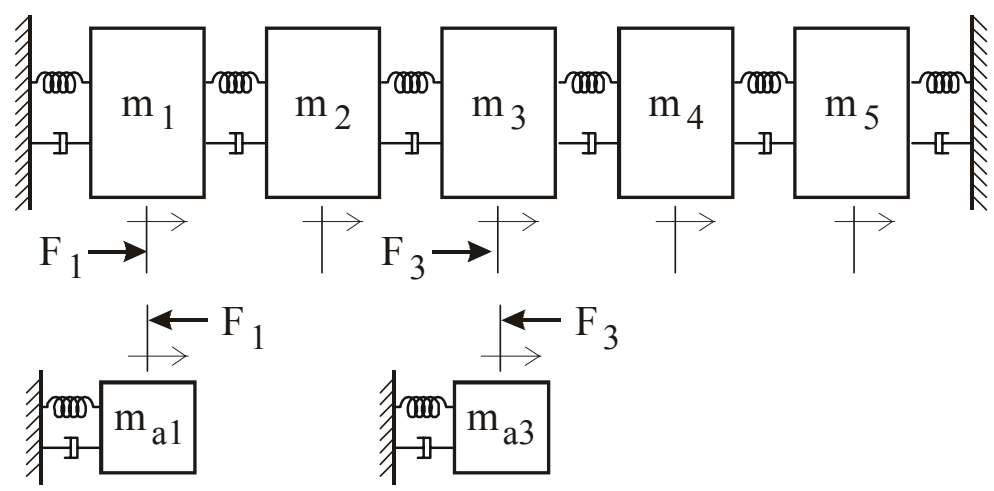

FIGURA 3.46 - Modelo mecânico de 5 GDL com 2 excitadores

Para os testes simulados, os excitadores foram posicionados em $\mathrm{m}_{1}$ e $\mathrm{m}_{3}$. Desta forma, o segundo excitador 2 não deve interferir nos modos de vibrar pares, já que $m_{3}$ é nó destes modos, como pode ser visto na Fig. 3.47.

Neste tipo de teste, as FRFs são obtidas através dos espectros cruzados de autoespectros, como indicado na Eq. 1.11. Considerando-se os sinais de entrada não correlatos, para o sistema de 5 GDL excitado em 2 pontos de entrada, como descrito pela Eq. 3.35.

$$
\left[\begin{array}{ll}
\operatorname{Gyx}_{11} & \mathrm{Gyx}_{13} \\
\operatorname{Gyx}_{21} & \mathrm{Gyx}_{23} \\
\operatorname{Gyx}_{31} & \mathrm{Gyx}_{33} \\
\mathrm{Gyx}_{41} & \mathrm{Gyx}_{43} \\
\operatorname{Gyx}_{51} & \mathrm{Gyx}_{53}
\end{array}\right]=\left[\begin{array}{ll}
\mathrm{H}_{11} & \mathrm{H}_{13} \\
\mathrm{H}_{21} & \mathrm{H}_{23} \\
\mathrm{H}_{31} & \mathrm{H}_{33} \\
\mathrm{H}_{41} & \mathrm{H}_{43} \\
\mathrm{H}_{51} & \mathrm{H}_{53}
\end{array}\right]\left[\begin{array}{cc}
\mathrm{Gxx}_{11} & 0 \\
0 & \mathrm{Gxx}_{33}
\end{array}\right]
$$

Uma das principais hipóteses adotadas para estas simulações é a de que as forças são não-correlatas. Caso contrário isto tornaria a matriz de auto-espectros [Gxx] singular e conseqüentemente não inversível. Contudo, em termos práticos, sabe-se que mesmo que os sinais enviados pelos geradores a cada um dos excitadores não sejam correlatos, o seu acoplamento simultâneo à estrutura torna as forças correlatas nas vizinhanças das ressonâncias (MAIA \& SILVA, 1997). 


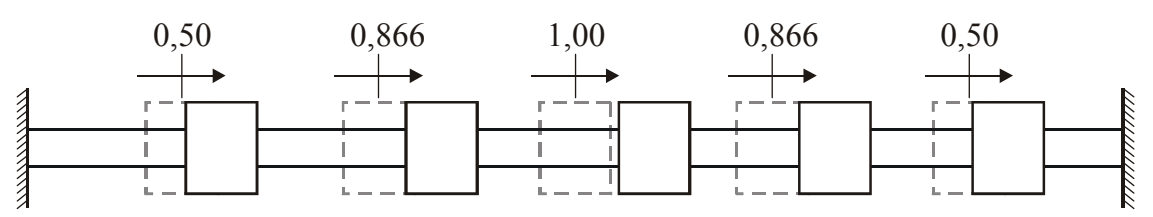

$\mathbf{1}^{\mathbf{0}}$

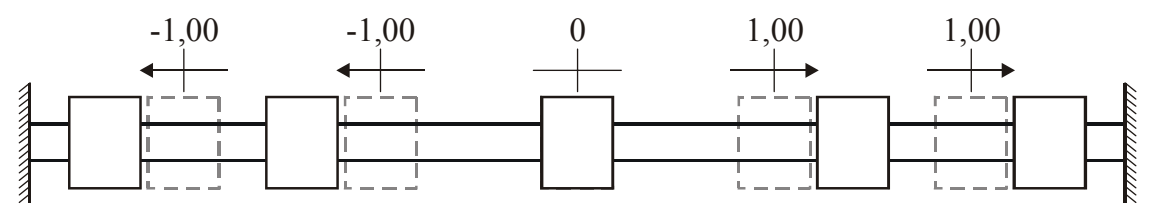

$2^{\mathbf{o}}$

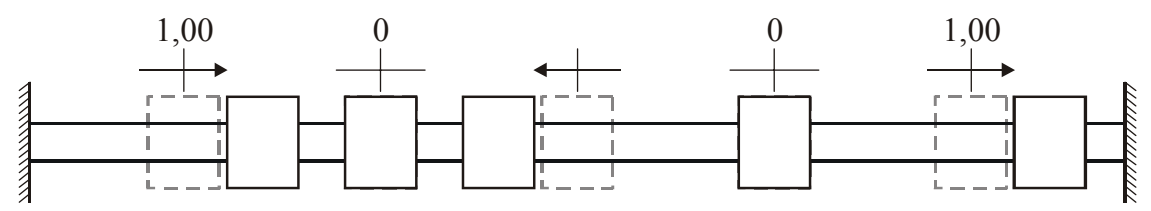

$\mathbf{3}^{\mathbf{0}}$

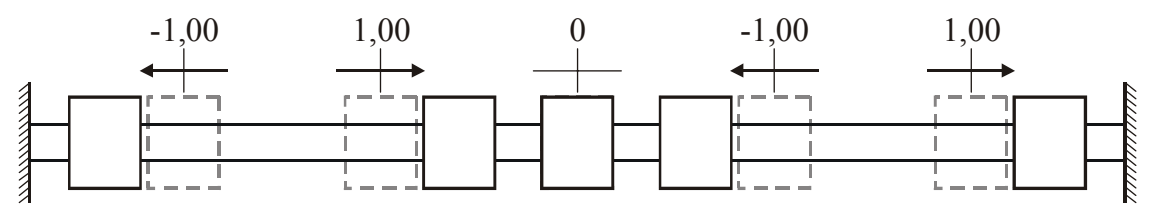

$4^{0}$

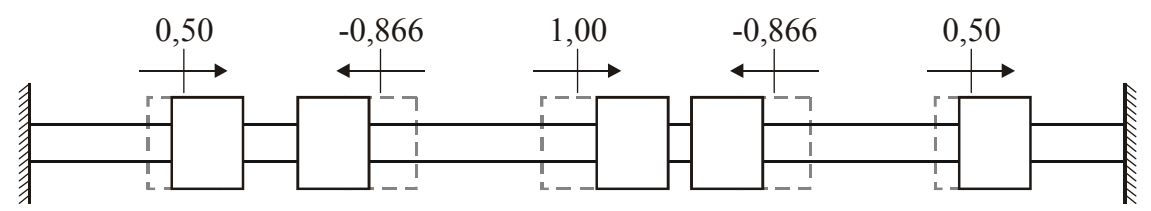

$\mathbf{5}^{\mathbf{0}}$

FIGURA 3.47 - Modos de vibrar do sistema de 5 GDL

As forças de contato então são calculadas, seguindo um equacionamento similar ao adotado para sistemas SISO e SIMO.

Considerado-se que a união entre os excitadores e a estrutura é ideal:

$$
\mathrm{A}_{\mathrm{a} 1} \cong \mathrm{A}_{1} \quad \text { e } \quad \mathrm{A}_{\mathrm{a} 3} \cong \mathrm{A}_{3}
$$

Ainda:

$$
\left\{\begin{array}{l}
\mathrm{A}_{1}=\mathrm{H}_{11} \cdot \mathrm{F}_{1}+\mathrm{H}_{12} \cdot \mathrm{F}_{2} \\
\mathrm{~A}_{3}=\mathrm{H}_{31} \cdot \mathrm{F}_{1}+\mathrm{H}_{33} \cdot \mathrm{F}_{3} \\
\mathrm{~A}_{\mathrm{a} 1}=\mathrm{H}_{\mathrm{a} 1}\left(\mathrm{fe}_{1}-\mathrm{F}_{1}\right) \\
\mathrm{A}_{\mathrm{a} 3}=\mathrm{H}_{\mathrm{a} 3}\left(\mathrm{fe}_{3}-\mathrm{F}_{3}\right)
\end{array}\right.
$$

Substituindo a Eq. 3.36 na Eq. 3.37 tem-se:

$$
\left\{\begin{array}{l}
\mathrm{H}_{11} \cdot \mathrm{F}_{1}+\mathrm{H}_{12} \cdot \mathrm{F}_{2}=\mathrm{H}_{\mathrm{a} 1}\left(\mathrm{fe}_{1}-\mathrm{F}_{1}\right) \\
\mathrm{H}_{31} \cdot \mathrm{F}_{1}+\mathrm{H}_{33} \cdot \mathrm{F}_{3}=\mathrm{H}_{\mathrm{a} 3}\left(\mathrm{fe}_{3}-\mathrm{F}_{3}\right)
\end{array}\right.
$$

Rearranjando as equações em Eq. 3.38 em termos de $F_{1}$ e $F_{3}$, obtém-se: 


$$
\left[\begin{array}{cc}
\frac{\mathrm{H}_{11}+\mathrm{H}_{\mathrm{a} 1}}{\mathrm{H}_{\mathrm{a} 1}} & \frac{\mathrm{H}_{13}}{\mathrm{H}_{\mathrm{a} 1}} \\
\frac{\mathrm{H}_{31}}{\mathrm{H}_{\mathrm{a} 3}} & \frac{\mathrm{H}_{33}+\mathrm{H}_{\mathrm{a} 3}}{\mathrm{H}_{\mathrm{a} 3}}
\end{array}\right]\left\{\begin{array}{l}
\mathrm{F}_{1} \\
\mathrm{~F}_{3}
\end{array}\right\}=\left\{\begin{array}{l}
\mathrm{fe}_{1} \\
\mathrm{fe}_{3}
\end{array}\right\}
$$

Desta forma, dadas a matriz de FRFs e as forças eletromagnéticas, $\mathrm{fe}_{1} \mathrm{e} \mathrm{fe}_{2}$, obtêm-se as forças de entrada $F_{1}$ e $F_{3}$, ou seja, os auto-espectros de entrada Gxx.

De maneira análoga ao equacionamento obtido para simulação de teste SISO, no o qual as FRFs estimadas são calculadas a partir das acelerações obtidas para o conjunto excitador + estrutura, obtêm-se os espectros cruzados Gyx. Assim, obtêm-se as FRFs conforme a Eq. 3.35.

Portanto, como anteriormente, adota-se uma estrutura com 5 GDL e massa total de $10 \mathrm{~kg}$ e dois excitadores semelhantes com massa de armadura de $0,45 \mathrm{~kg}$ e considerase que ambos atuam com o mesmo nível de excitação. As forças e as FRFs obtidas podem ser vistas nas Figs. 3.48 a 3.50 .

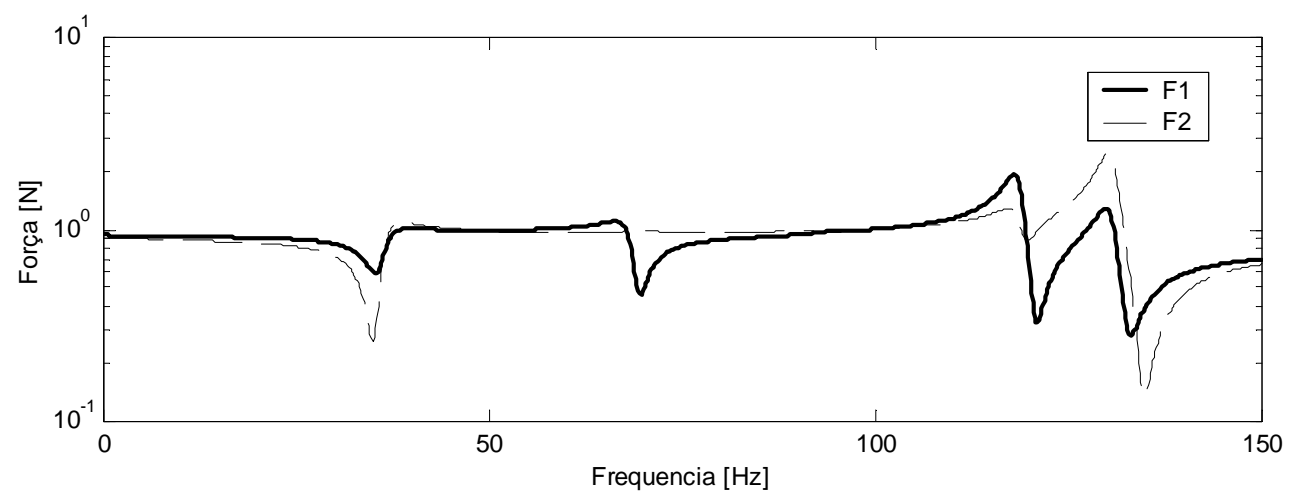

FIGURA 3.48 - Força de excitação em teste MIMO

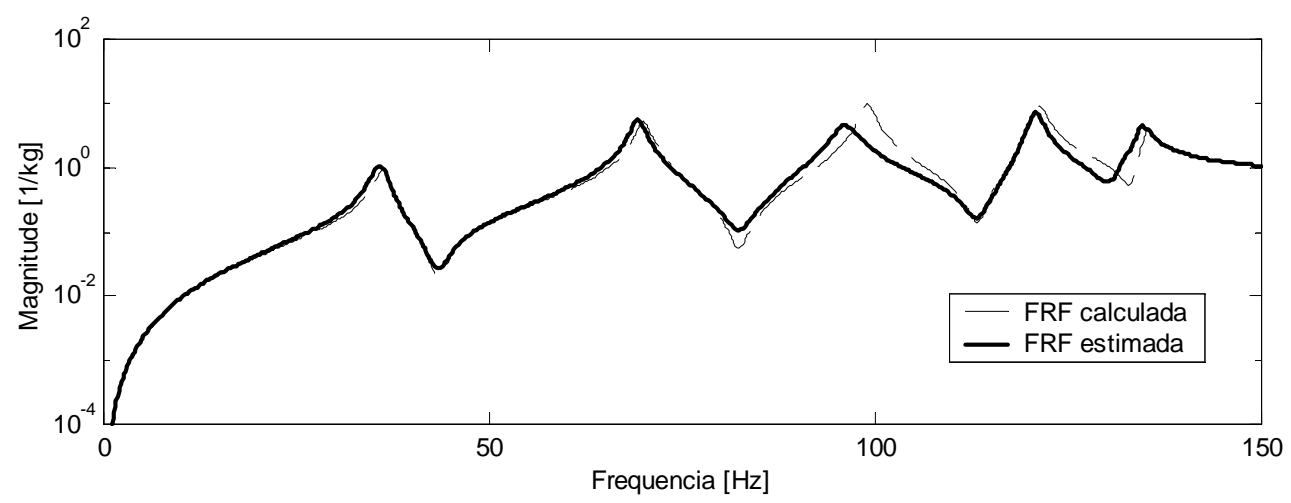

FIGURA 3.49 - $\mathrm{H}_{11}$ para teste MIMO

Pode-se observar que as FRFs estimadas continuam a apresentar distorções em relação às FRFs calculadas. Mesmo considerando as forças não-correlatas, o fato de haver uma força atuando em $\mathrm{m}_{3}$ muda a resposta medida em $\mathrm{m}_{1}$. Isto não alteraria os resultados obtidos, visto que as FRFs são estimadas através de espectro cruzados de 
aceleração e força, porém, a parcela de movimento em $m_{1}$ induzida por $F_{3}$ afeta

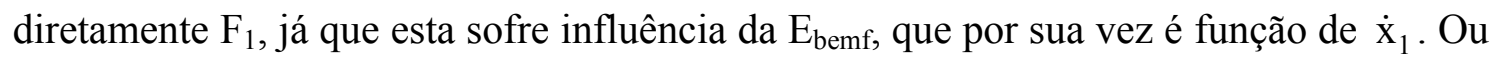
seja, por mais que se garanta o desacoplamento entre as fontes de excitação, é inevitável que a parcela de velocidade de um ponto de excitação, devido à força introduzida por outro ponto de excitação, interfira na tensão de retorno do primeiro, e conseqüentemente em sua força.

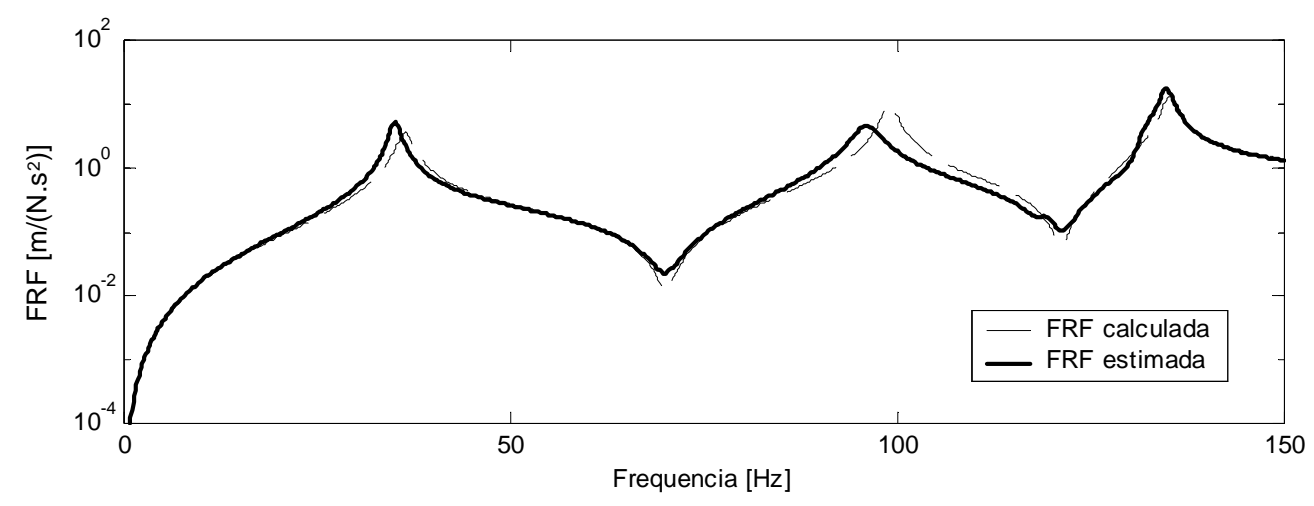

FIGURA $3.50-\mathrm{H}_{33}$ para teste MIMO

Por razão desta interação, devido ao efeito cruzado dos excitadores, ambas as forças não apresentam queda na região entre 80 e $110 \mathrm{~Hz}$ (Fig 3.48), relativa à terceira freqüência natural da estrutura. Contudo, ainda pode-se observar uma distorção significativa nesta faixa de freqüência nas FRF estimadas (Figs. 3.49 e 3.50).

A Fig. 3.51 ilustra a superposição de $F_{1}$, para os casos de simples e múltipla excitação. Como previsto, nas freqüências próximas aos modos de vibrar pares, pode-se observar pouca ou nenhuma influência de $\mathrm{F}_{3}$ em $\mathrm{F}_{1}$.

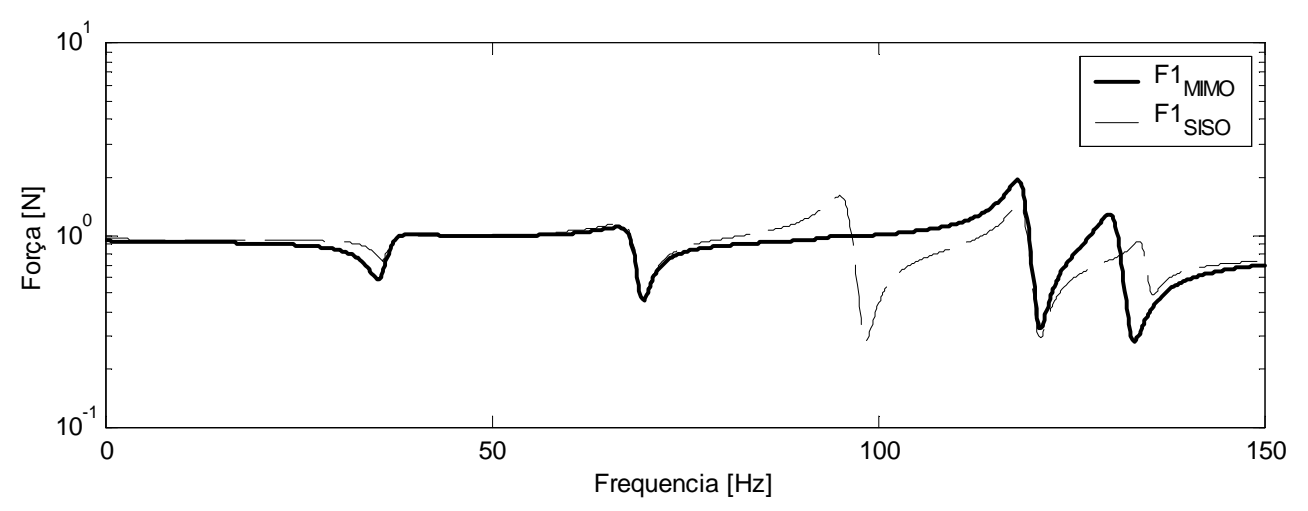

FIGURA 3.51 - Comparação entre forças: SISO e MIMO

As Figs. 3.52 e 3.53 comparam as forças e FRFs obtidas com excitadores iguais e diferentes, quanto à massa de armadura. Nas simulações com excitadores diferentes, a razão $\mathrm{m}_{\mathrm{a} 1} / \mathrm{m}_{\mathrm{a} 3}$ entre as massas é de 10 vezes. Neste caso, tanto a força $\mathrm{F}_{1}$ quanto a FRF $\mathrm{H}_{11}$ são praticamente iguais até a quarta freqüência natural. 
$\mathrm{O}$ mesmo pode ser dito a respeito da força $\mathrm{F}_{3}$ e da $\mathrm{FRF} \mathrm{H}_{33}$ (Figs. 3.54 e 3.55). Este tipo de comportamento indica que a interação entre os excitadores e a estrutura está relacionada, não somente com a relação entre suas massas, mas também com o ponto de aplicação das forças e os modos de vibrar.

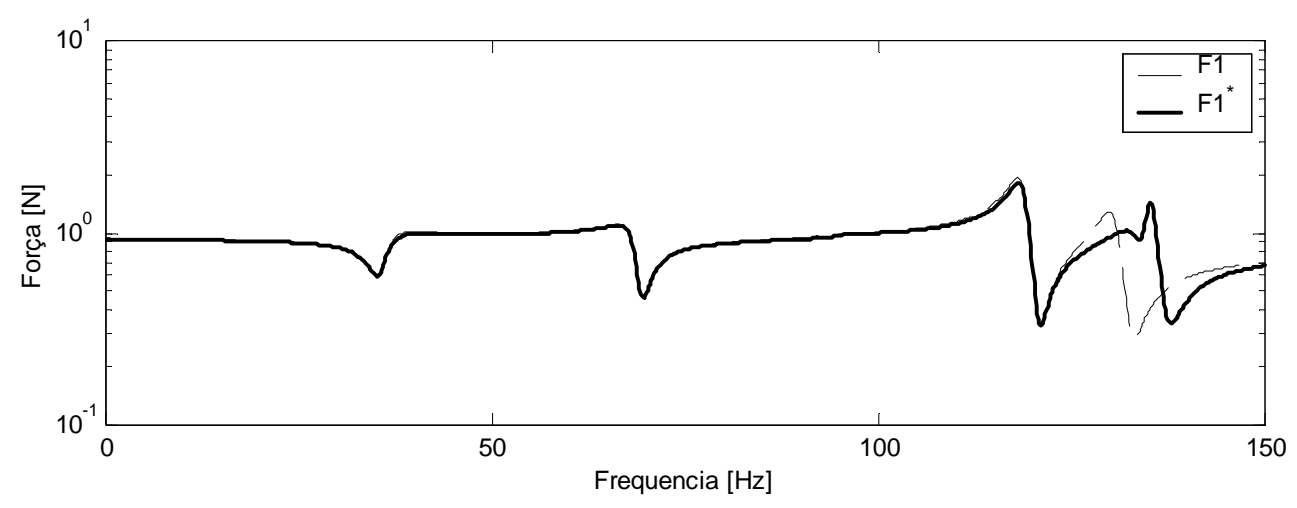

FIGURA 3.52 - Comparação entre forças: excitadores iguais $\left(F_{1}\right)$ e diferentes $\left(\mathbf{F}_{1}{ }^{*}\right)$

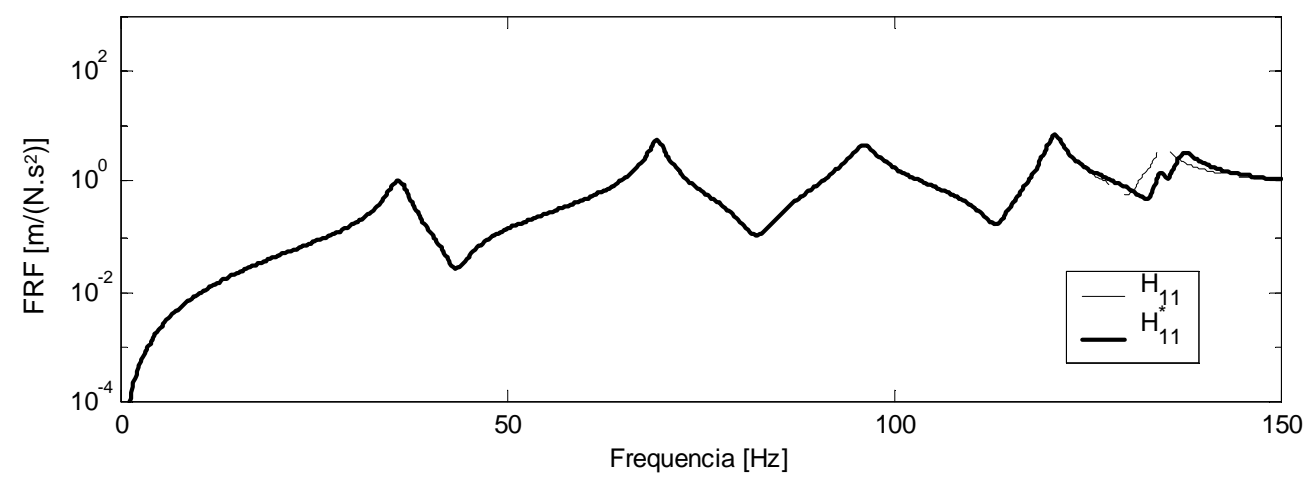

FIGURA 3.53 - Comparação entre FRFs: excitadores iguais $\left(\mathrm{H}_{11}\right)$ e diferentes $\left(\mathrm{H}_{11}{ }^{*}\right)$

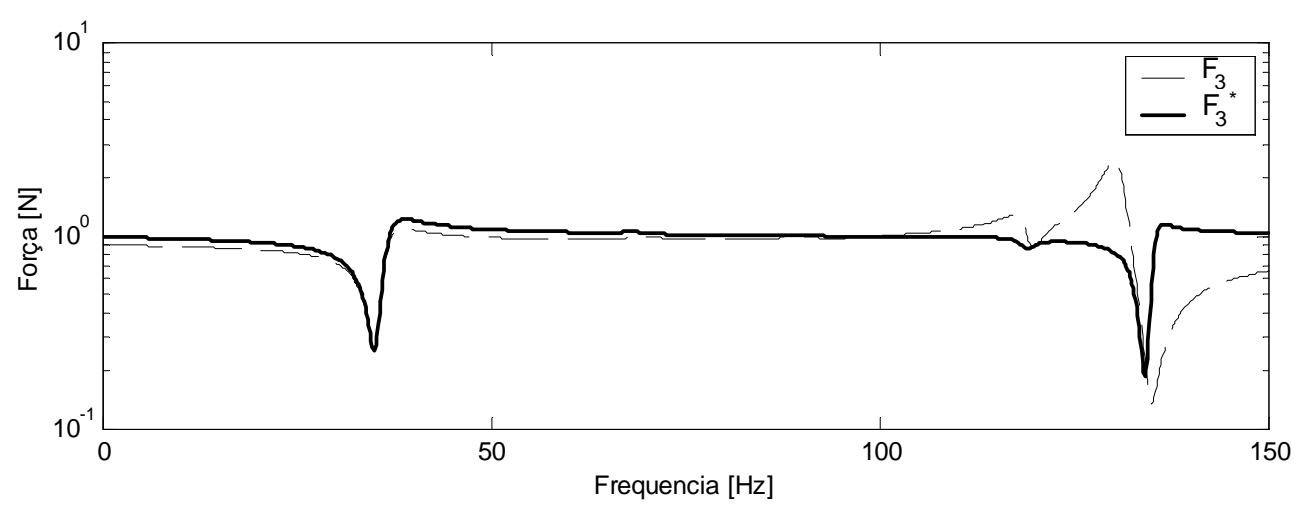

FIGURA 3.54 - Comparação entre forças: excitadores iguais (F3) e diferentes $\left(\right.$ F3* $\left.^{*}\right)$ 


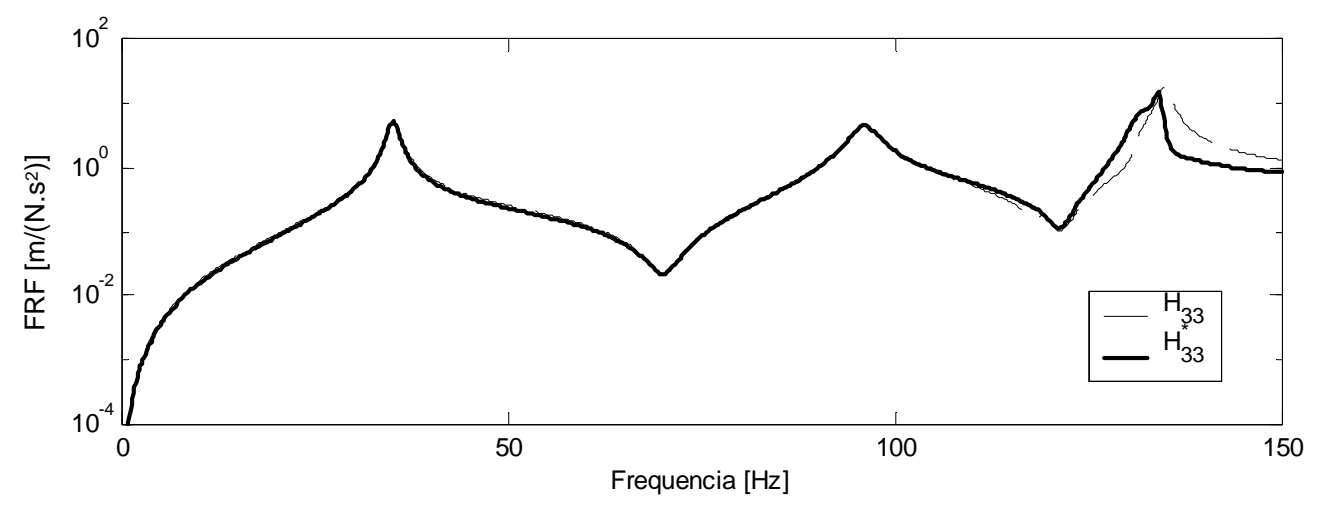

FIGURA 3.55 - Comparação entre FRFs: excitadores iguais $\left(\mathrm{H}_{33}\right)$ e diferentes $\left(\mathrm{H}_{33}{ }^{*}\right)$

Com os resultados obtidos até então, observa-se que o uso de múltiplos excitadores pode melhorar a uniformidade das forças transmitidas à estrutura (Fig. 3.51), resultando em FRFs estimadas, que se aproximam bem das FRFs originais da estrutura. Mesmo considerando que os sinais enviados aos excitadores sejam nãocorrelatos, é inevitável que haja interação entre eles, visto que a tensão de retorno ( $\left.E_{b m e f}\right)$ depende da velocidade do ponto de excitação, que por sua vez é resultado da superposição dos efeitos de todas as fontes de excitação.

O uso de excitadores diferentes revelou discrepâncias nas mesmas funções obtidas com excitadores idênticos, sobretudo na força do excitador de menor massa (Fig. 3.54), o que indica outra característica deste tipo de teste, ou seja, excitadores menores estão mais sujeitos aos efeitos de interação. Ainda, o fato dos efeitos desta interação terem se tornado mais evidentes em determinada faixa de freqüência que nas demais, indica a existência de uma combinação ótima de número de atuadores e de seu posicionamento na estrutura, dadas as características dinâmicas dos excitadores e da estrutura. 


\section{INTERAÇÃO EXCITADOR / ESTRUTURA: RESULTADOS EXPERIMENTAIS}

Analogamente às simulações, os ensaios realizados se dividem em dois grupos: $\mathrm{O}$ primeiro destinado à identificação do excitador propriamente dito. $\mathrm{O}$ segundo grupo de ensaios se destina à identificação do fenômeno de interação excitador estrutura.

\subsection{IDENTIFICAÇÃO DINÂMICA DO EXCITADOR}

Esta seção tem como objetivo verificar o comportamento dinâmico do excitador, tendo em vista os resultados obtidos analiticamente no capítulo anterior. Para tanto são realizados alguns ensaios, tendo o próprio excitado como item de teste. Com estes ensaios pretende-se verificar características do o comportamento dinâmico descrito pelos modelos mecânicos e eletromecânicos como ressonâncias da base, armadura e bobinas, o efeito eletromagnético na resposta da armadura e faixa útil de operação do excitador.

Basicamente, os ensaios foram realizados de duas formas: testes de impacto na mesa do excitador e testes tendo um outro excitador montado contra o excitador sob estudo. Por fim se estabelece uma comparação entre os modelos simulados e os resultados obtidos com os testes.

Inicialmente, pretende-se verificar o efeito da suspensão da base, freqüência natural da armadura, e amortecimento eletromagnético. OLIVEIRA \& VAROTO (2002b) sugerem o seguinte arranjo experimental (Fig. 4.1) para obtenção destas características dinâmicas de um excitador. O ensaio consiste em impactar a armadura do excitador com um martelo instrumentado e medir a força de entrada e a aceleração da mesa. O uso do martelo é uma alternativa ao método sugerido por LANG (1997) para o caso de armaduras muito amortecidas, como é caso do modelo 4812 da B\&K. O martelo utilizado neste ensaio é um B\&K 8202 e um acelerômetro B\&K 4375. 


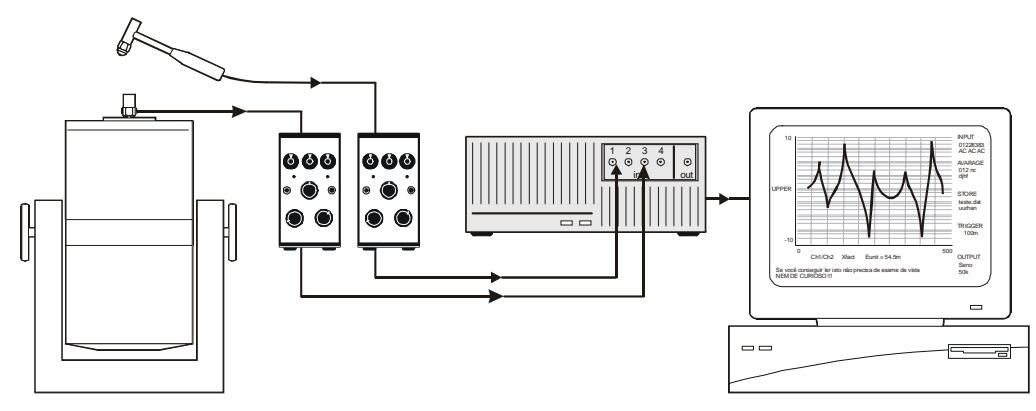

FIGURA 4.1 - Arranjo experimental de ensaio de impacto.

Os resultados obtidos com este ensaio podem ser vistos nas Figs. 4.2 e 4.3.

A Fig. 4.2 apresenta as FRFs obtidas para o ensaio de impacto em duas configurações: Suspensão da base rígida e flexível. Observa-se a freqüência natural da base flexível em torno de $8,5 \mathrm{~Hz}$ e da armadura em torno de $58 \mathrm{~Hz}$, coerente com os resultados apresentados na Fig. 3.4.

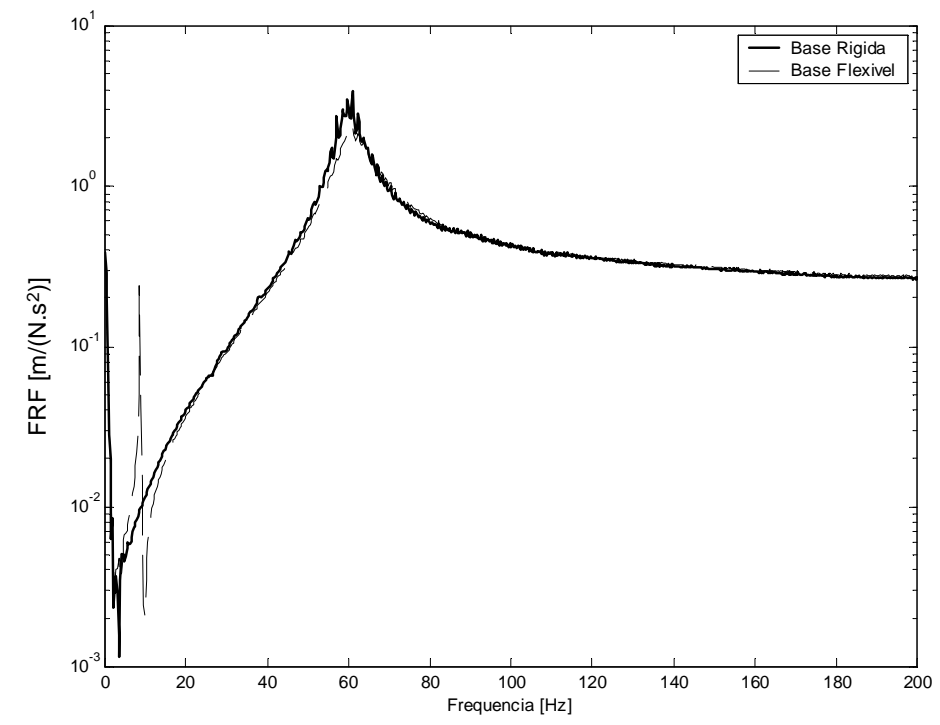

FIGURA 4.2 - FRF de ponto da mesa do excitador - base rígida e flexível

A Fig. 4.3 ilustra as FRFs para o mesmo teste realizado em duas novas configurações: Inicialmente com o amplificador desligado e em seguida ligado, ou seja com as bobinas energizadas. Em ambos os casos a configuração da suspensão da base é flexível. Neste caso, pode-se observar o efeito do amortecimento eletromagnético, como na Fig. 3.11. Ainda, observa-se que este amortecimento não tem efeito sobre a ressonância da base. 


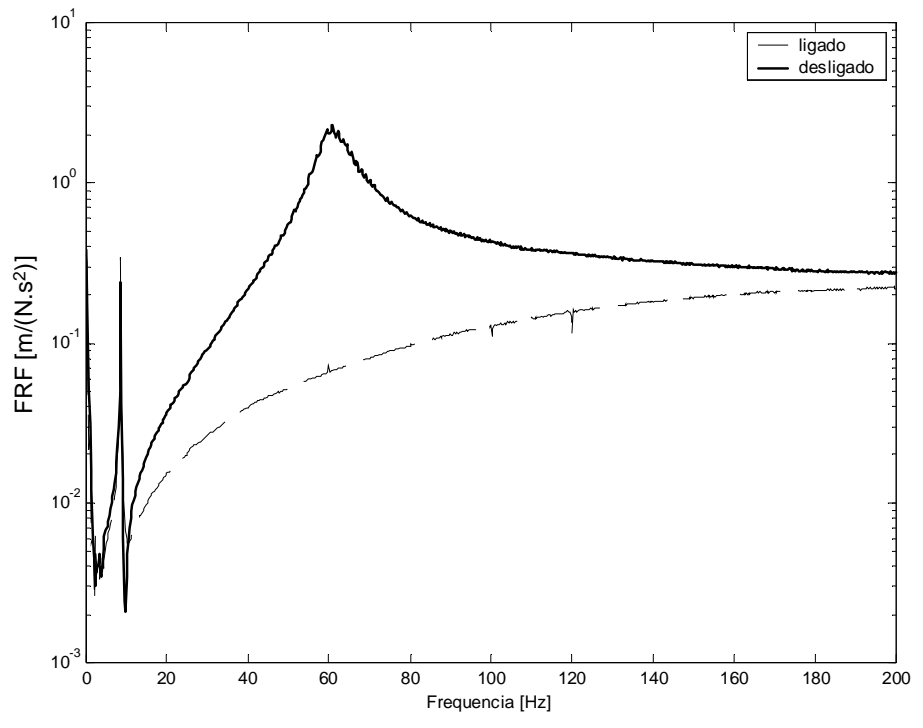

\section{FIGURA 4.3 - FRF de ponto da mesa do excitador - amplificador ligado e desligado}

Outra forma de se obter tais características dinâmicas do excitador é montá-los conforme ilustra a Fig. 4.4 (OLIVEIRA \& VAROTO, 2002a). Neste tipo de ensaio, o excitador que se deseja estudar deve ficar desligado, ou apenas energizado, enquanto o outro excita o sistema. Os sinais medidos neste ensaio são: força de entrada ' $F$ ', aceleração da armadura ' $A$ ' e tensão de saída ' $E$ ', sendo esta a tensão gerada nas bobinas do excitador sob estudo devido ao movimento da armadura. Estas grandezas podem ser vistas na Fig. 4.5. Observa-se que dada a diferença entre estas grandezas, as mesmas estão ilustradas em [V] sendo a sensibilidade de cada canal de 1[V/Unidade]. Neste caso o excitador ativo é um MB Dynamics Modal 50 enquanto que o excitador sob estudo é o B\&K 4812.

A fim de observar a faixa útil de operação do excitador de forma experimental, realiza-se o mesmo teste descrito no arranjo experimental da Fig. 4.4 para uma banda de freqüência de 0 a $10 \mathrm{kHz}$. A Fig. 4.6 ilustra as FRFs obtidas, nas quais pode-se observar a freqüência natural das bobinas, algo em torno de $7 \mathrm{kHz}$, condizente com os dados obtidos analiticamente (Fig 3.6). O manual da B\&K (1974) indica 7,2 kHz para esta freqüência. Observa-se ainda que a faixa útil de operação do excitador vai até os $5 \mathrm{kHz}$. O mesmo ensaio foi realizado com o amplificador ligado e desligado. Pela comparação das duas FRFs obtidas, pode-se observar que o amortecimento eletromagnético interfere menos neste modo.

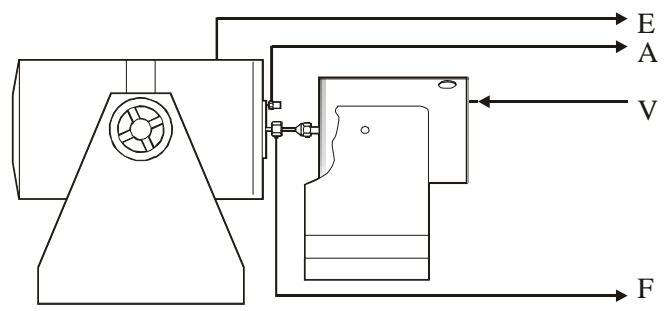

FIGURA 4.4 - Arranjo experimental de excitador contra excitador. 


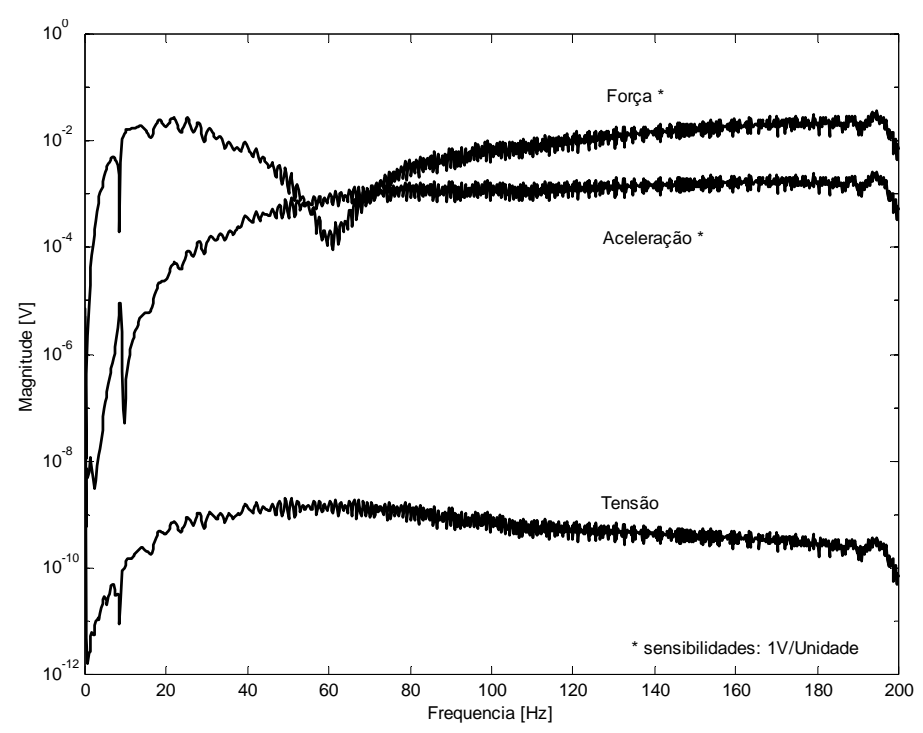

FIGURA 4.5 - Aceleração, força e tensão medidas do excitador B\&K 4812.

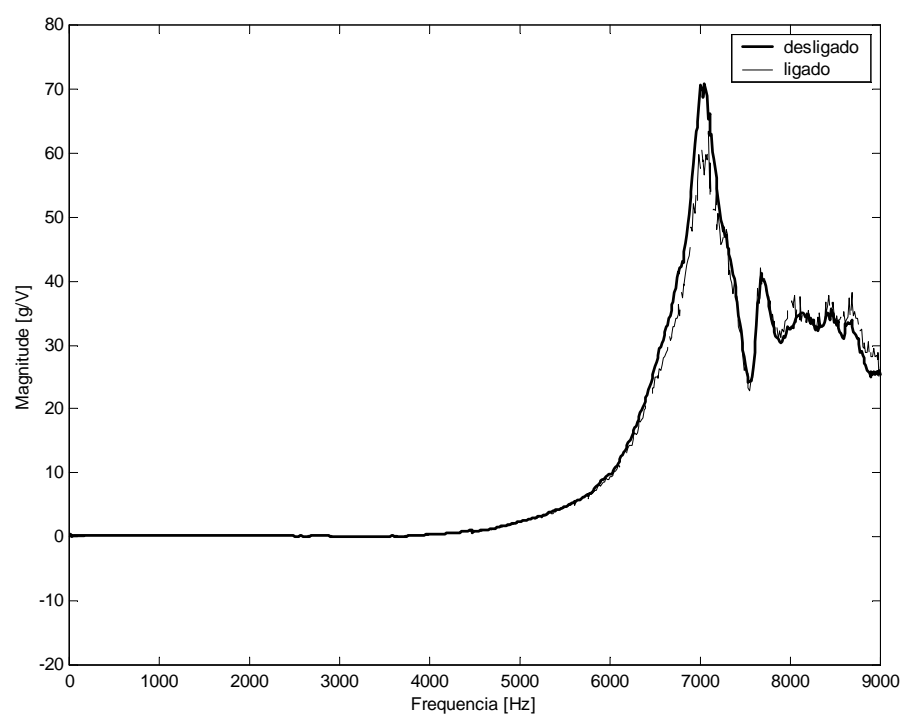

FIGURA 4.6 - FRFs do excitador B\&K.

Outra forma de obter um resultado similar sem, contudo, necessitar de dois excitadores, é medir a FRF entre a aceleração da armadura e o sinal enviado ao próprio excitador, como proposto por OLIVEIRA \& VAROTO (2002a).

Com a finalidade de determinar a intensidade dos sinais provenientes do funcionamento do sistema de arrefecimento do excitador, foram medidos os sinais de força e aceleração da mesa no mesmo arranjo experimental (Fig 4.4), agora, com o excitador ativo desligado, e o excitador sob estudo ligado. Os resultados obtidos estão ilustrados na Fig. 4.7. Observa-se uma componente em $100 \mathrm{~Hz}$ e uma em $120 \mathrm{~Hz}$, que dependendo do nível de excitação utilizado pode resultar em um nível significativo de ruído. 


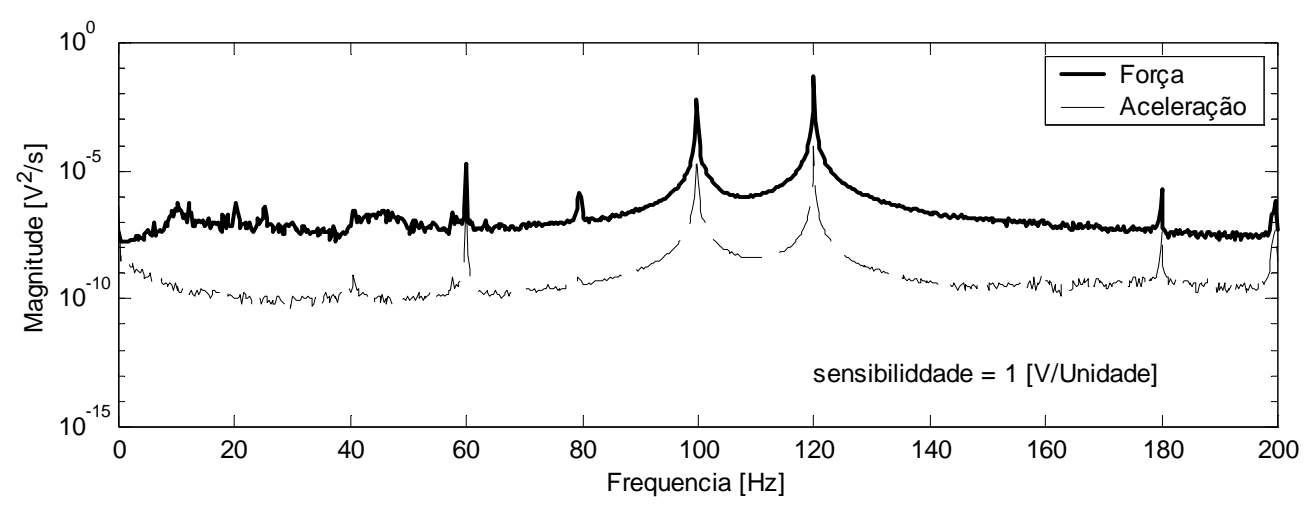

FIGURA 4.7 - FRFs do excitador B\&K.
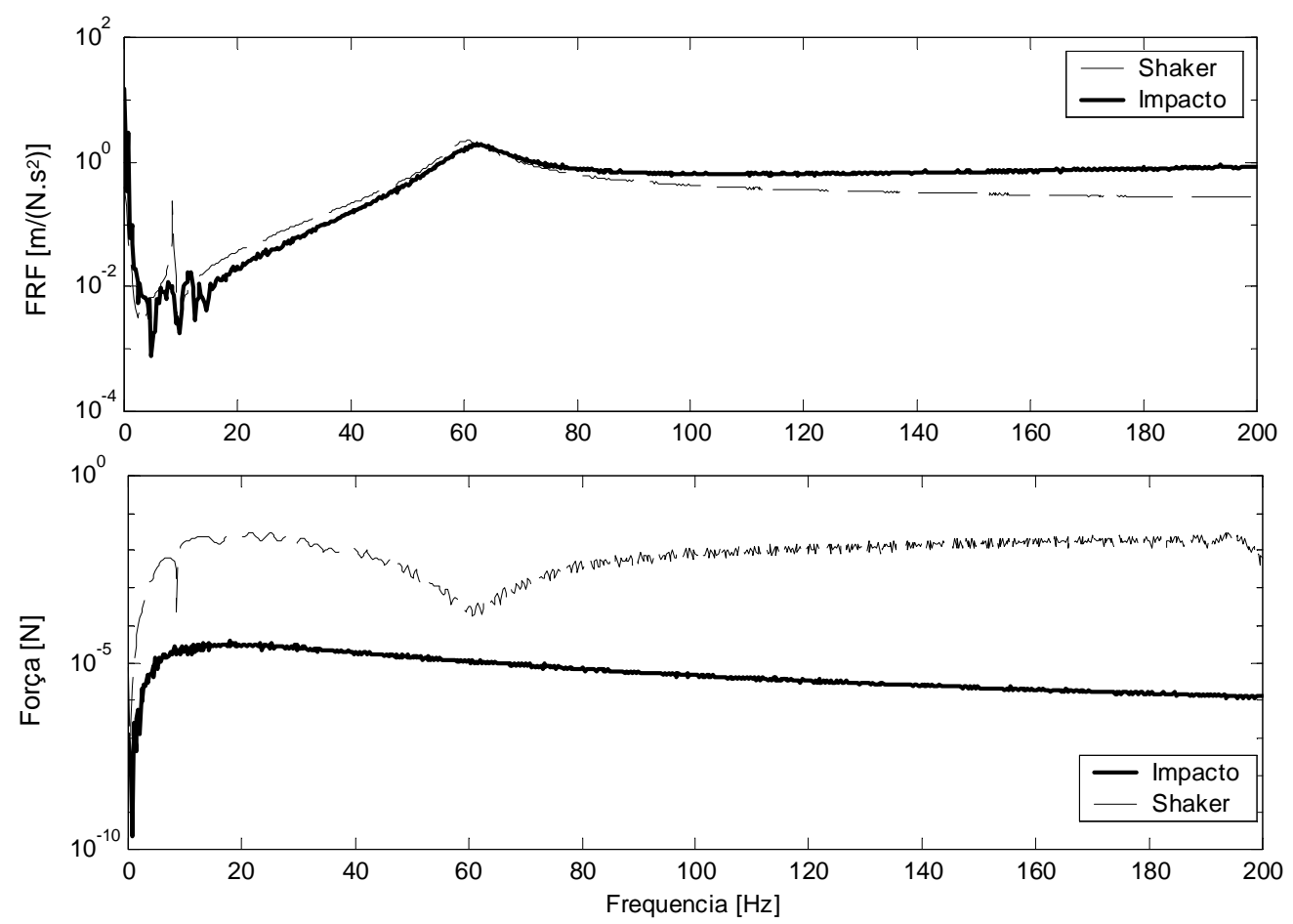

FIGURA 4.8 - FRFs do excitador B\&K e forças de entrada.

Finalmente, comparando-se os resultados obtidos com impacto (Fig 4.1) e com outro excitador (Fig. 4.4), observa-se na Fig. 4.8 uma comparação entre as FRFs e os respectivos sinais de força obtidos a partir cada um dos ensaios realizados com o excitador B\&K. As frequiências naturais obtidas através dos dois métodos são levemente diferentes, sendo a do ensaio com martelo $(62 \mathrm{~Hz})$ um pouco maior que a dos excitadores $(59 \mathrm{~Hz})$. Uma das razões evidentes para este fenômeno é a interação do excitador MB com o excitador sob estudo, vide queda na força de excitação.

\subsubsection{GRAUS DE LibERDADE ROTACIONAIS DA ARMADURA}

Realizam-se alguns testes iniciais a fim de validar os modelos desenvolvidos considerando-se graus de liberdade rotacionais (GDLR) para o excitador. Tais testes 
consistem basicamente dos mesmos testes de impactos, agora em diferentes pontos da armadura (Fig. 4.9) e medidas de aceleração translacional e rotacional.

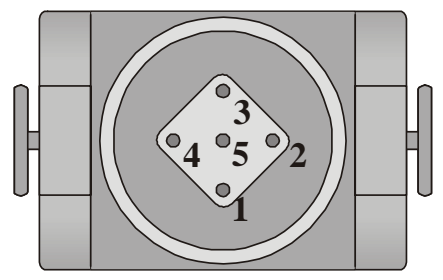

FIGURA 4.9 - Vista de topo do excitador B\&K 4812.

As Figs. 4.10 a 4.12 ilustram os resultados obtidos com os testes de impacto sobre a mesa do excitador, nos quais $\mathrm{H}_{\mathrm{mn}}$ denota as FRF com entrada no ponto ' $\mathrm{n}$ ' $\mathrm{e}$ saída no ponto 'm', conforme Fig. 4.9.

A comparação entre $\mathrm{H}_{45}$ e $\mathrm{H}_{42}$, ilustrada na Fig. 4.10, revela que quando excitada de forma simétrica em relação ao seu eixo principal, a armadura não apresenta movimento de rotação. Porém, quando a força de excitação é aplicada fora de centro, uma segunda ressonância surge por volta de $290 \mathrm{~Hz}$, a qual está relacionada com a rotação pura da mesa.

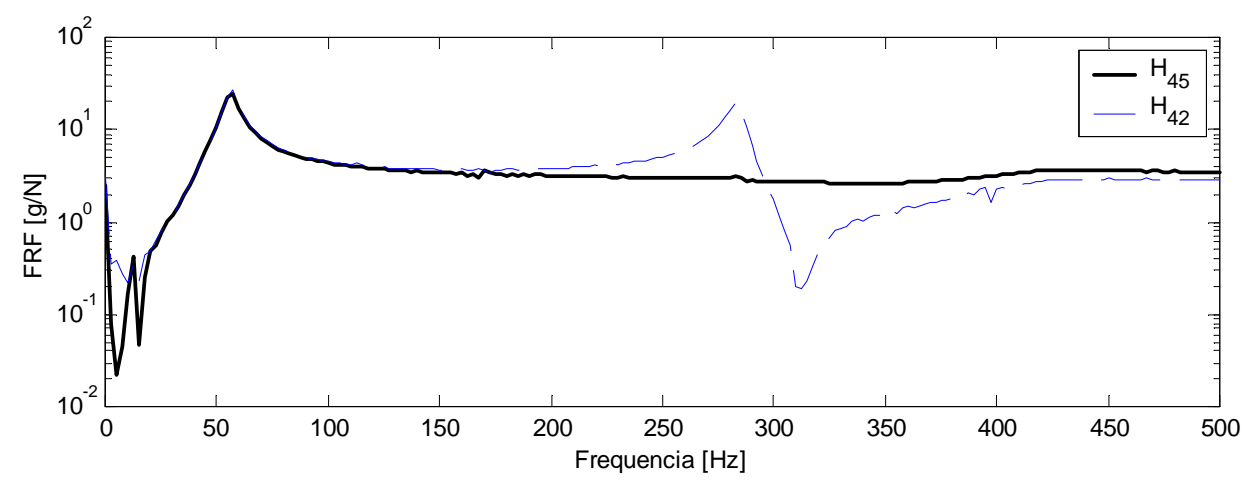

FIGURA 4.10 - FRF da mesa do excitador

A Fig 4.11 mostra que este comportamento é simétrico em relação ao eixo axial do Excitador, já que $\mathrm{H}_{42}$ e $\mathrm{H}_{31}$ são similares.

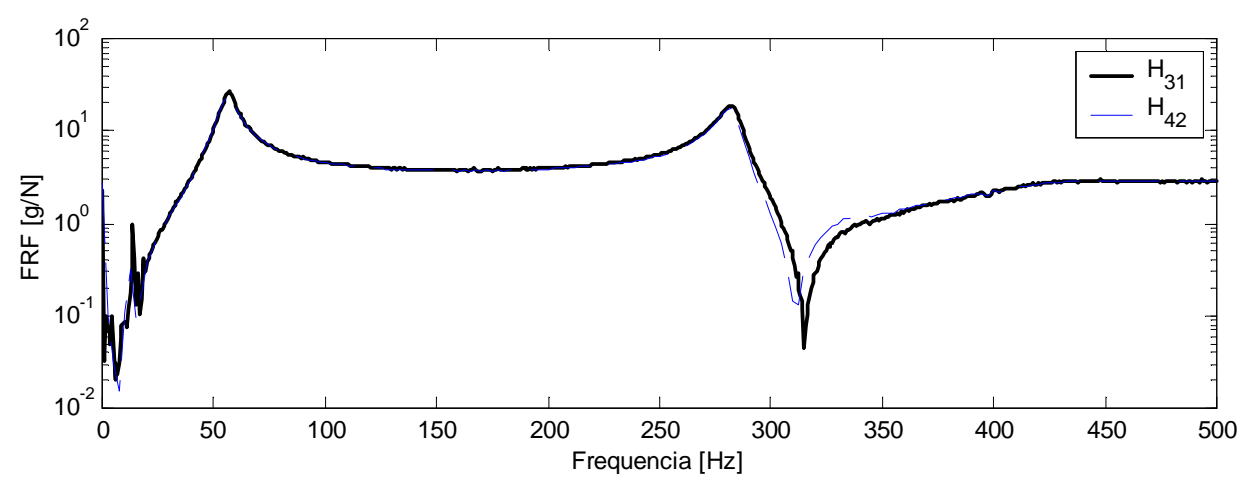

Figura 4.11 - FRF da mesa do excitador 
A Fig. 4.12 mostra os mesmos resultados, agora obtidos com o acelerômetro angular. O ruído presente neste sinais, se deve à baixa sensibilidade deste sensor (Kistler 8836M01) que é de aproximadamente $34 \mu \mathrm{V} / \mathrm{rad} / \mathrm{s}^{2}$, resultando em uma baixa razão sinal / ruído.

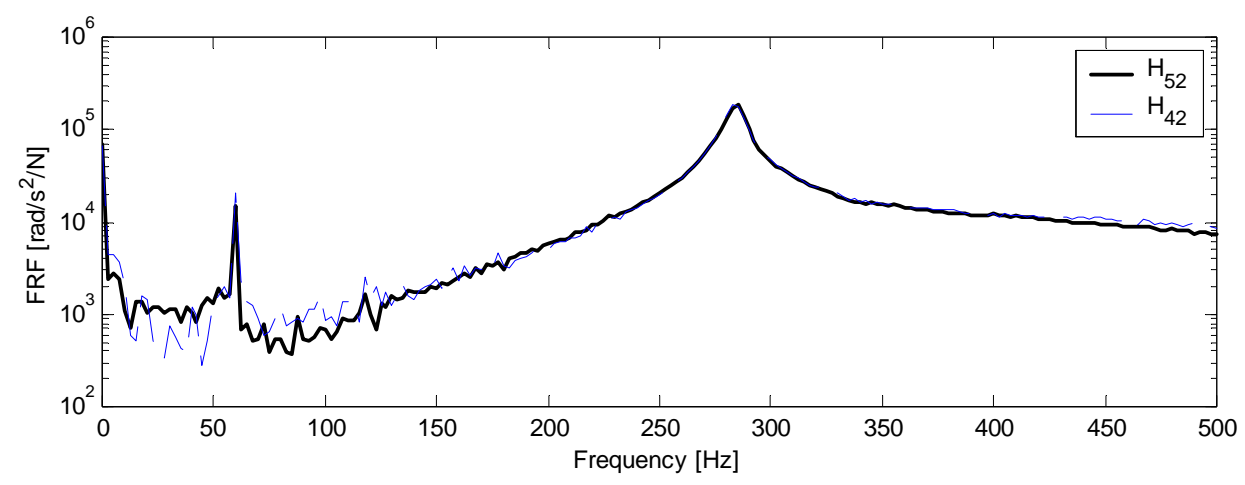

FIGURA 4.12 - FRF da mesa do excitador

Ainda, a Fig, 4.13 confirma o que fora demonstrado pelos modelos teóricos, ou seja, os efeitos eletromagnéticos afetam muito mais o modo translacional da armadura, que o rotacional. Este resultado foi obtido, impactando-se a armadura no ponto 2 e medindo-se as acelerações no ponto 4, com os circuitos do excitador ligados e desligados.

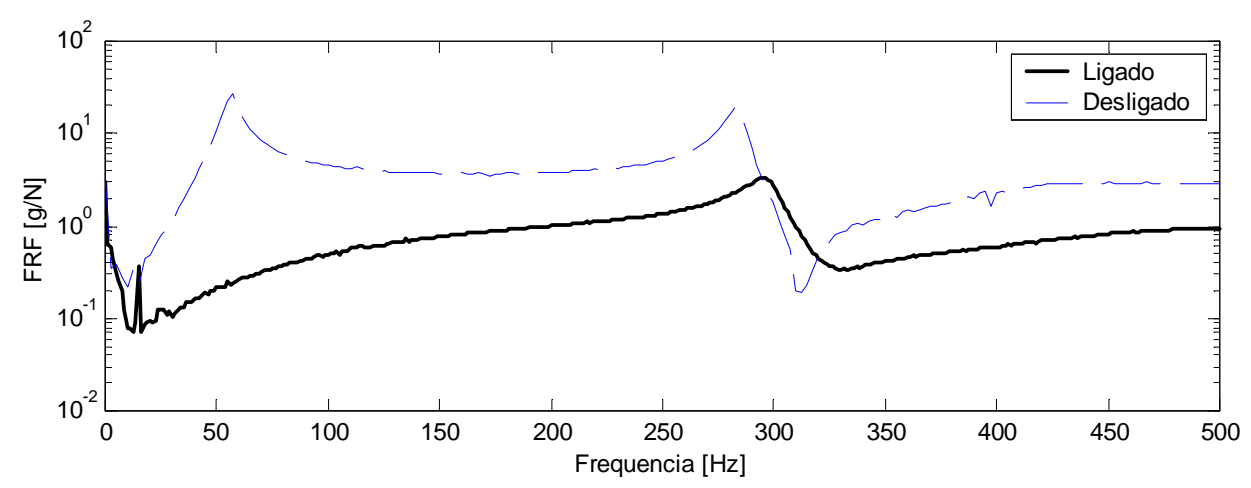

FIGURA 4.13 - Comparação entre FRFs da armadura

\subsection{INTERAÇÃO EXCITADOR / ESTRUTURA}

Os objetivos dos ensaios descritos nesta seção são os de verificar os efeitos da interação excitador / estrutura em diferentes condições de teste, ou seja, com o amplificador operando em modo de tensão e corrente, e em testes em malha fechada (controlando aceleração ou força de entrada na estrutura) e testes com múltipla excitação, etc. $\mathrm{O}$ foco das análises se concentra na qualidade dos dados obtidos, e nas condições impostas ao item de teste. Desta forma apresentam-se comparações entre FRFs, funções coerência e espectros de aceleração e força às quais a estrutura foi submetida. 
Os resultados experimentais descritos a seguir se dividem em cinco grupos: $\mathrm{O}$ primeiro se destina aos métodos de excitação simples (SISO) de uma estrutura canônica, no caso uma viga de aço de seção retangular. Neste tópico são abordadas as condições de operação do amplificador de potência e os testes em malha fechada. No segundo, são relatados testes realizados com estruturas mais complexas, como um pneumático e uma estrutura tubular. A seguir apresenta-se um estudo relativo ao uso adequado de estimadores de FRFs para testes com excitadores eletrodinâmicos. O quarto grupo de testes se dedica à identificação e validação dos fenômenos envolvendo GRDR do excitador e da estrutura, como descrito analiticamente no item 3.2.3. Por fim, ensaios realizados com dois excitadores, tendo como item de teste o mesmo chassi tubular utilizado anteriormente.

\subsubsection{EXCITAÇÃo SimPLES DE ESTRUTURAS SiMPLES}

Para verificar o fenômeno de interação entre o excitador e uma estrutura, adotouse uma viga de aço com dimensões 25,4 x 8,5 x 1000 [mm], motivado por estudos anteriores (VAROTO \& McCONNELL , 1993), (HAN, 1998), (OLIVEIRA \& VAROTO, 2002b).

Com esta viga, submetida às mesmas condições de contorno (Fig. 4.14) foram realizados os seguintes ensaios:

- Excitador em malha aberta e modo de tensão

- Excitador em malha aberta e modo de corrente

- Excitador em malha fechada com aceleração constante

- Excitador em malha fechada com força constante

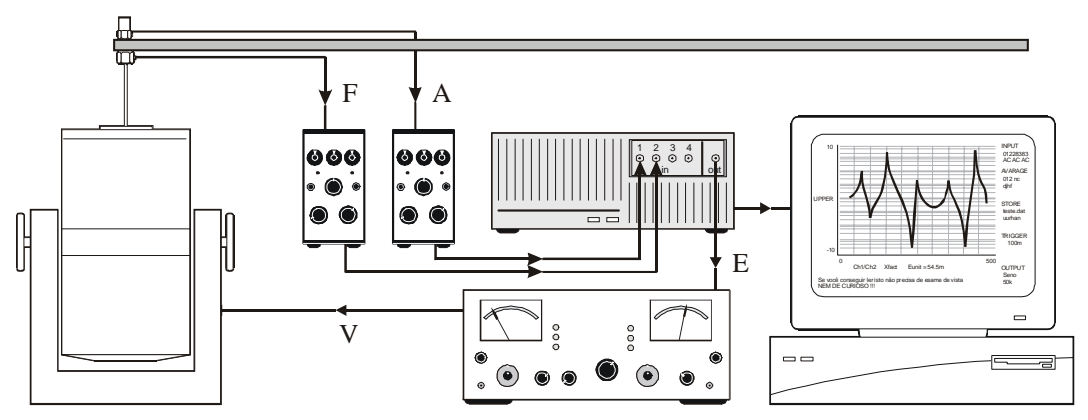

FIGURA 4.14 - Arranjo experimental da viga de aço

Durante todos os ensaios o ganho do amplificador permaneceu inalterado, sendo aproximadamente unitário, ou seja, V = E. O controle de excitação foi feito por meio do software de controle de sinais aleatórios SignalStar ${ }^{\circledR}$ da Data Physics, em conjunto com um analisador de 16 canais Agilent VXI com comunicação com o PC por uma placa fire wire E1432. 
O princípio de funcionamento do controlador pode ser descrito da seguinte forma (Fig 4.15). Num estágio inicial, um ruído branco é enviado ao sistema (Amplificador + Excitador + Estrutura). Os sinais de resposta são obtidos e então as funções de transferência do sistema são estimadas pelo controlador. Baseado nas funções de transferência e na estratégia de controle adotada, o controlador gera um novo sinal de entrada para o sistema, de forma a obter o conteúdo em frequiência préestipulado para o sinal de saída.

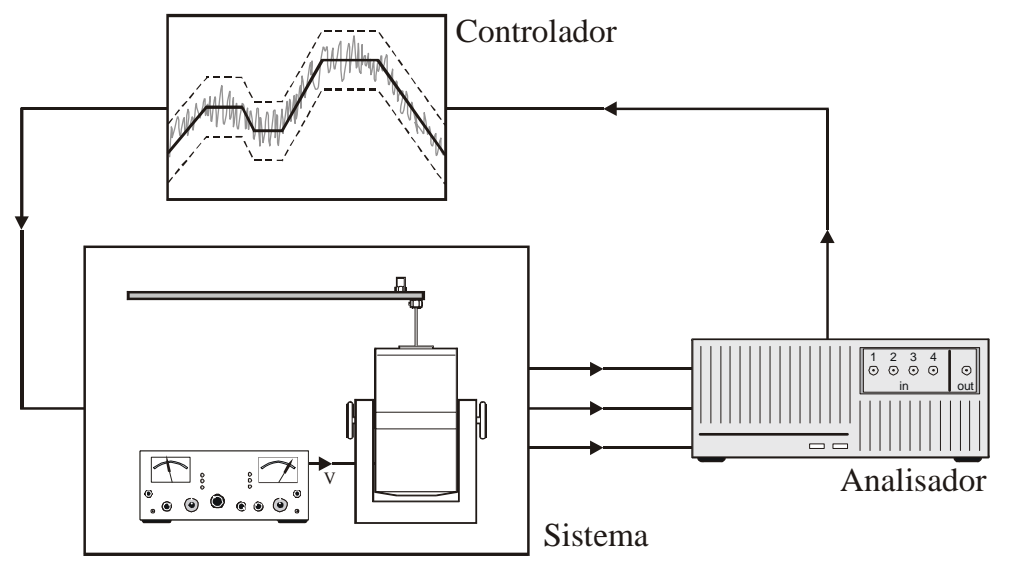

\section{FIGURA 4.15 - Diagrama de blocos do arranjo experimental em malha fechada}

Parte do processo de configuração da estratégia de controle consiste em estipular o conteúdo em freqüência do sinal a ser controlado, e margens de tolerância para este sinal, da seguinte forma (Figs. 4.16 e 4.17): Para cada ponto de controle desejado estipula-se o valor desejado, define-se um valor de tolerância superior e inferior, definindo-se assim a margem de tolerância dentro da qual o sinal estará contido. Um alarme soa toda vez que este limite é ultrapassado. Além disso, por uma questão de segurança, dos equipamentos e do item de teste, estipula-se um limite além do qual o teste é interrompido. A definição destes parâmetros requer um conhecimento prévio do comportamento da estrutura e certa experiência por parte do operador (CAMPENDELLI \& TONI, 1991).

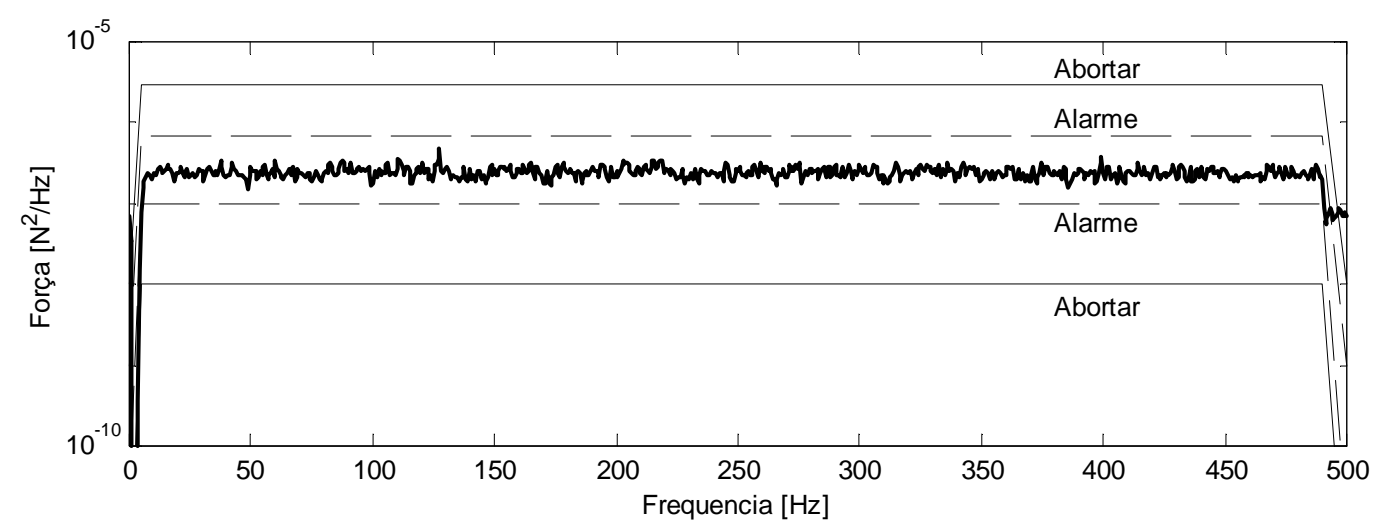

FIGURA 4.16 - DAE da força controlada e suas faixas de tolerância 


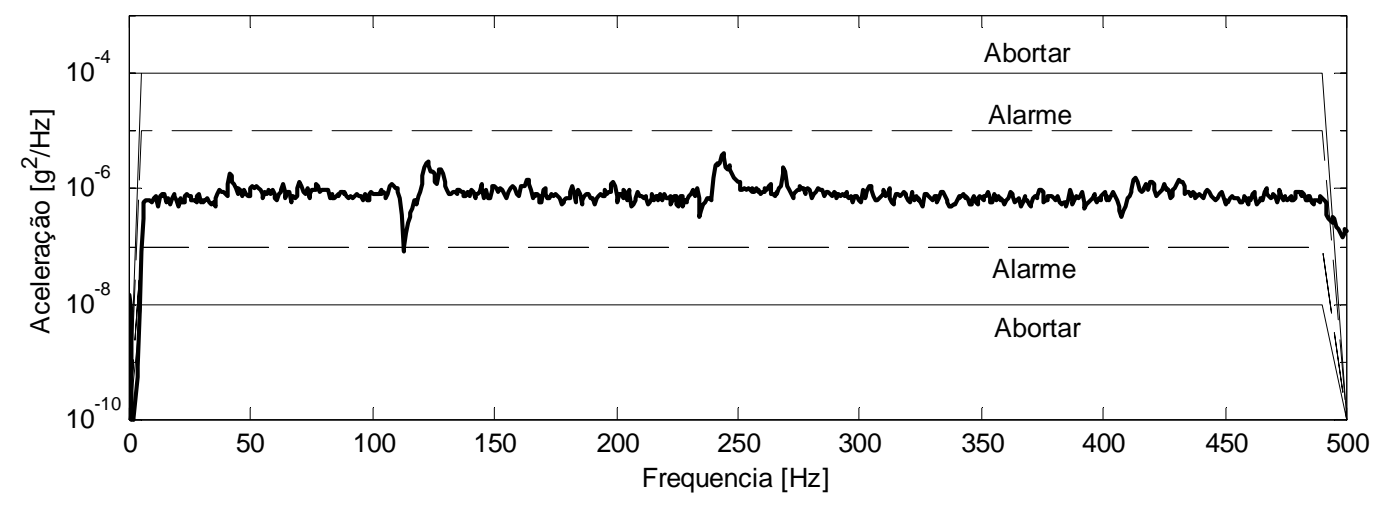

\section{FIGURA 4.17 - DAE da aceleração controlada e suas faixas de tolerância}

A realização este tipo de teste tem como principal objetivo, servir como parâmetro de comparação entre as técnicas clássicas. Além disso, pretende-se, no futuro, planejar ensaios com outros tipos de estruturas, e conteúdos em freqüência variados, visando uma melhoria na qualidade dos dados obtidos. Ainda, avaliar os limites desta técnica, e sua aplicação na reprodução de sinais de vibração do campo, no ambiente do laboratório (VAROTO, 1996).

Os dados obtidos com os ensaios com estrutura estão descritos a seguir. Nos dados ilustrados nas Figs. 4.18 a 4.19, FRFs obtidas a partir de ensaio de impacto, foram usadas como termo de comparação entre as obtidas com ensaios via excitador (HAN, 1998).

Na Fig. 4.18 observa-se a FRF da viga com o excitador operando em modo de tensão. Observa-se grande diferença entre elas, algumas mais significativas em freqüência, outras em amplitude ou mesmo em ambas.

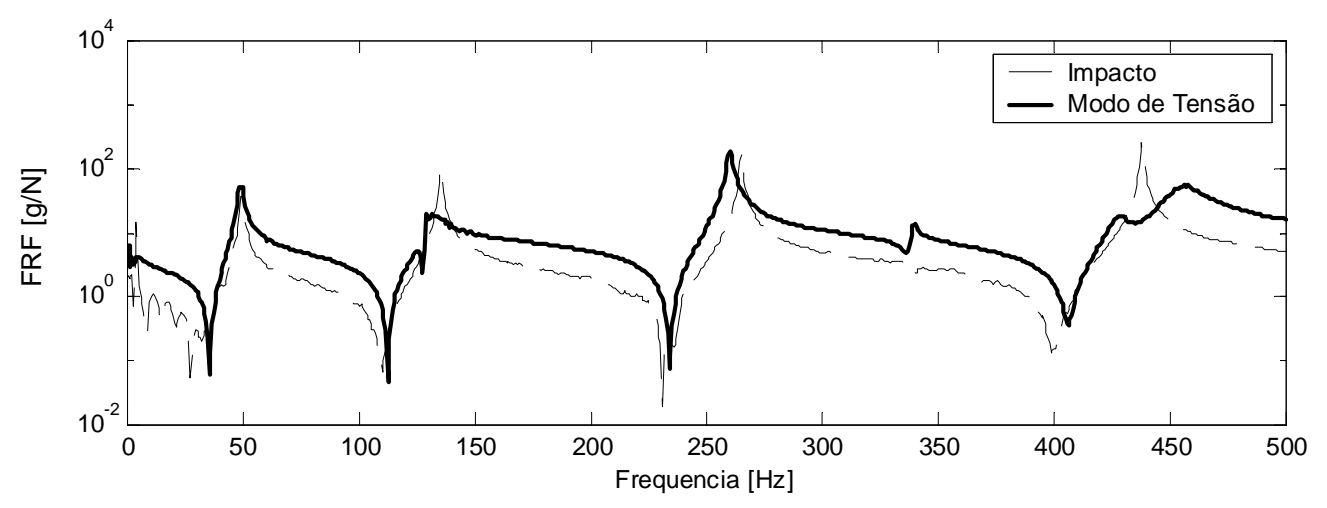

\section{FIGURA 4.18 - FRFs da viga para impacto e excitador em modo de tensão}

O mesmo dito a respeito do modo de tensão pode-se dizer a respeito do modo de corrente (Fig 4.19). Ainda, esperava-se uma aproximação melhor neste caso, visto que neste modo de operação os efeitos da tensão de retorno ' $E_{\text {bemf }}$ ' seriam compensados pelo amplificador. Contudo o que se observa são distorções ainda maiores nas regiões de freqüências naturais. 


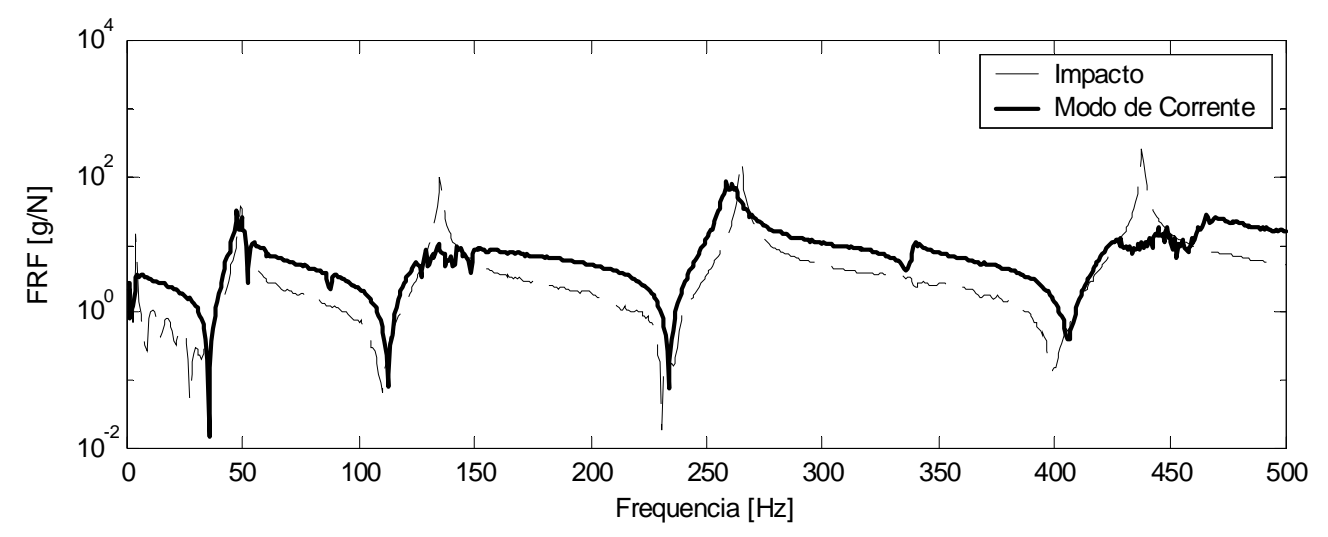

FIGURA 4.19 - FRFs da viga para impacto e excitador em modo de corrente

O fenômeno observado aqui, não contradiz o que fora discutido no capítulo de simulações. Ao contrário, vem demonstrar a necessidade de um cuidado extra, quando operando um excitador em modo de corrente. Como discutido anteriormente, enquanto o amplificador tiver potência para suprir os efeitos degenerativos da tensão de retorno, ele o fará. Como resultado pode-se observar um excesso de energia sendo transmitido à estrutura, justamente nas proximidades de suas freqüências naturais. Um dos possíveis resultados deste carregamento excessivo pode ser visto na Fig 4.19.

A Fig. 4.20 compara as FRFs e funções coerência obtidas em modo de corrente, com a tensão inicial de $2 \mathrm{~V}$, a mesma utilizada em todos os ensaios aqui descritos, e outro realizado com tensão de $500 \mathrm{mV}$. Neste caso, como a força transmitida à estrutura era baixa, as acelerações não atingiram valores tão altos nas vizinhanças das ressonâncias. Como resultado temos ressonâncias mais bem definidas e uma função coerência melhor.

A Fig. 4.21 compara as FRFs e funções coerência obtidas em modo de tensão e em modo de corrente, com tensão de entrada de $500 \mathrm{mV}$. Ainda assim, neste caso, os resultado obtidos em termos de coerência, são melhores para o modo de tensão, apesar das FRFs serem praticamente idênticas.

Iniciam-se então os ensaios em malha fechada. Primeiramente, controla-se a aceleração da armadura, fazendo-a constante na faixa de 5 a $500 \mathrm{~Hz}$.

Os resultado obtidos podem ser vistos na Fig. 4.22. Tais resultados são comparáveis, em termos de qualidade, ao ensaio em modo de tensão. Todavia, sabe-se que o ponto de interesse da estrutura não verificou acelerações superiores à estipulada.

Seguem então os resultados obtidos para força constante (Fig 4.23) sendo estes os que melhor se aproximam do impacto.

A Fig 4.24 compara FRFs e função coerência para ensaios em malha fechada. Observa-se que a definição das ressonâncias, bem como a função coerência é bem melhor para o caso de força constante, visto que o método de cálculo da FRFs é o $\mathrm{H}_{1}$, sensível a ruído na entrada, ao que o controle de aceleração deixa o sistema susceptível. 

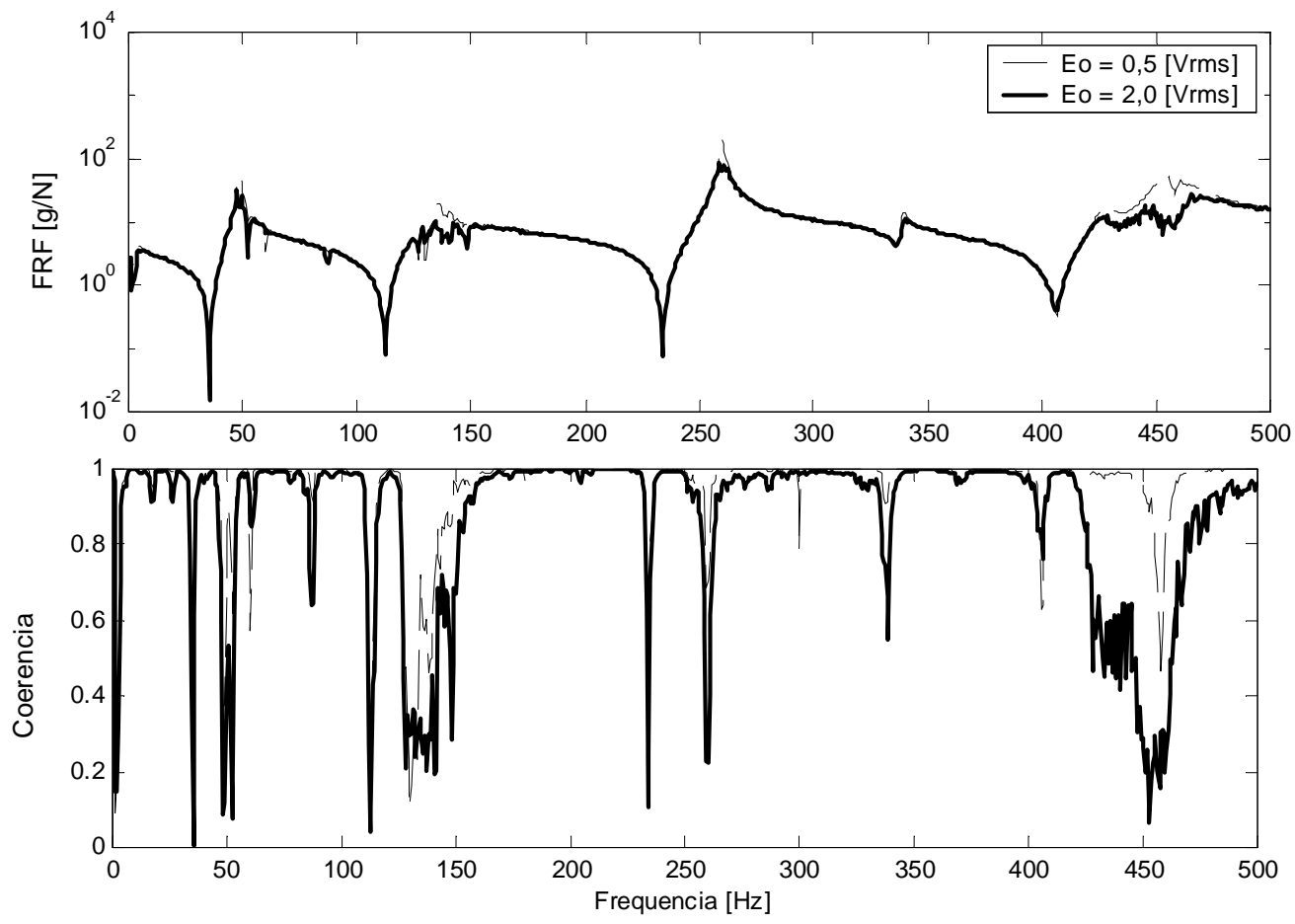

FIGURA 4.20 - FRFs e Coerência da viga para excitador em modo de corrente
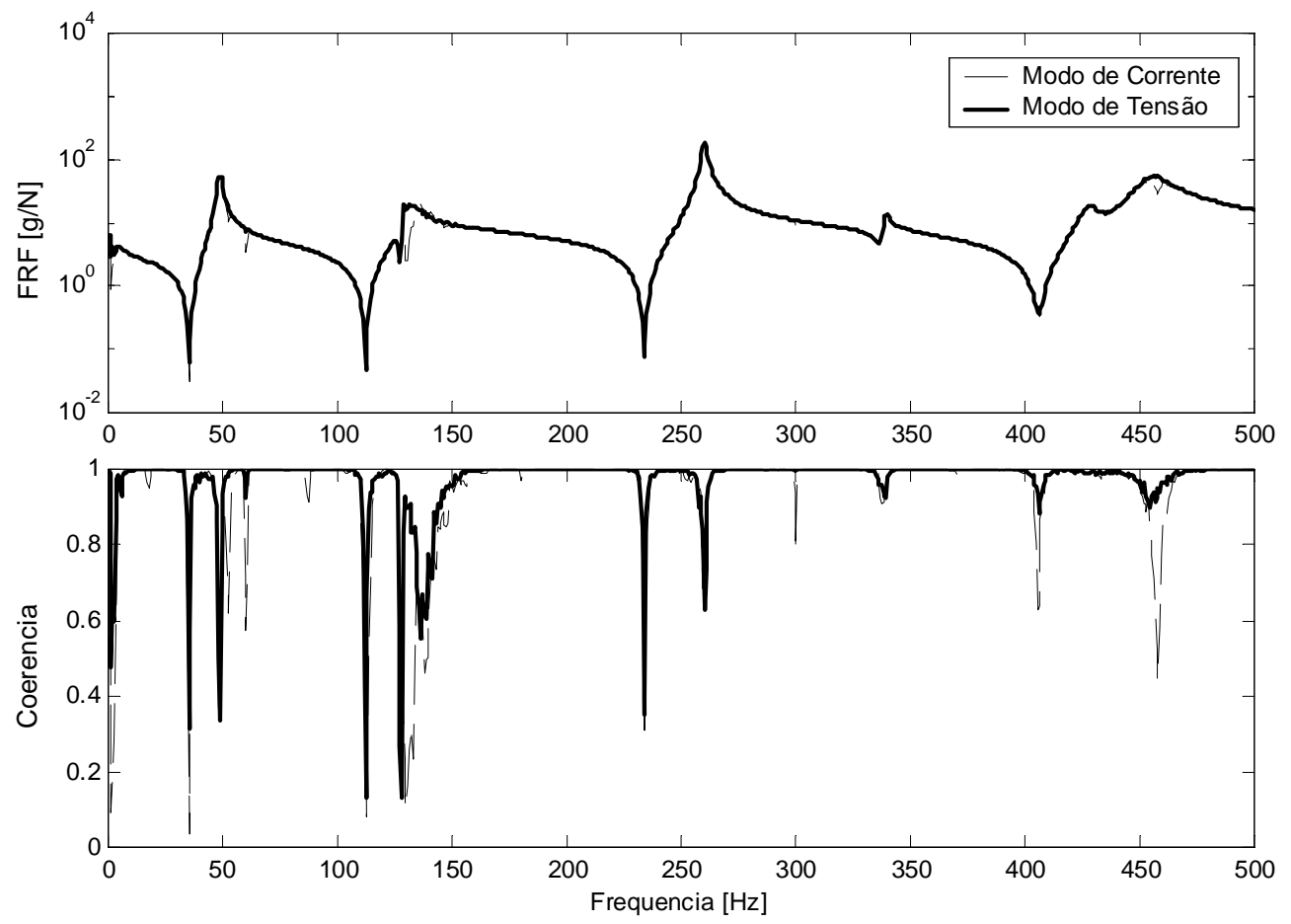

FIGURA 4.21 - Comparação entre FRFs e Coerência para modo de tensão e corrente 


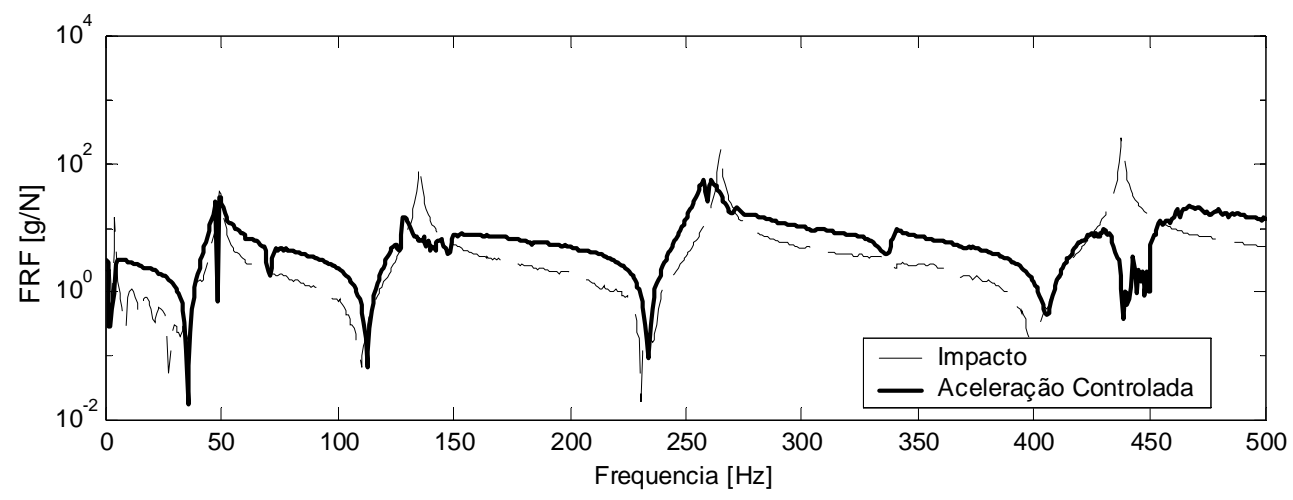

FIGURA 4.22 - FRFs da viga para impacto e excitador com aceleração constante

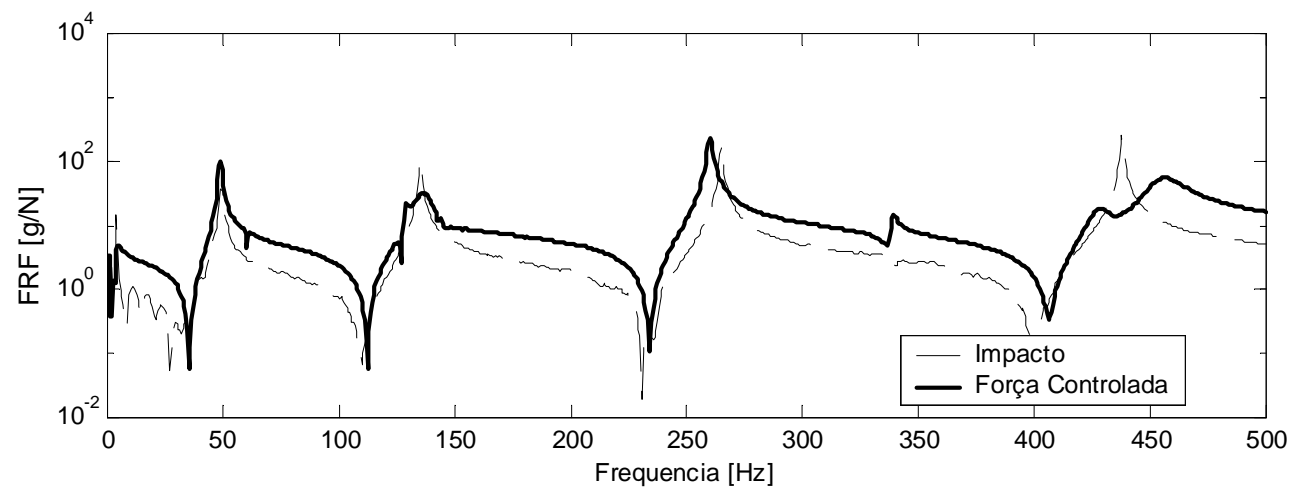

FIGURA 4.23 - FRFs da viga para impacto e excitador com força constante
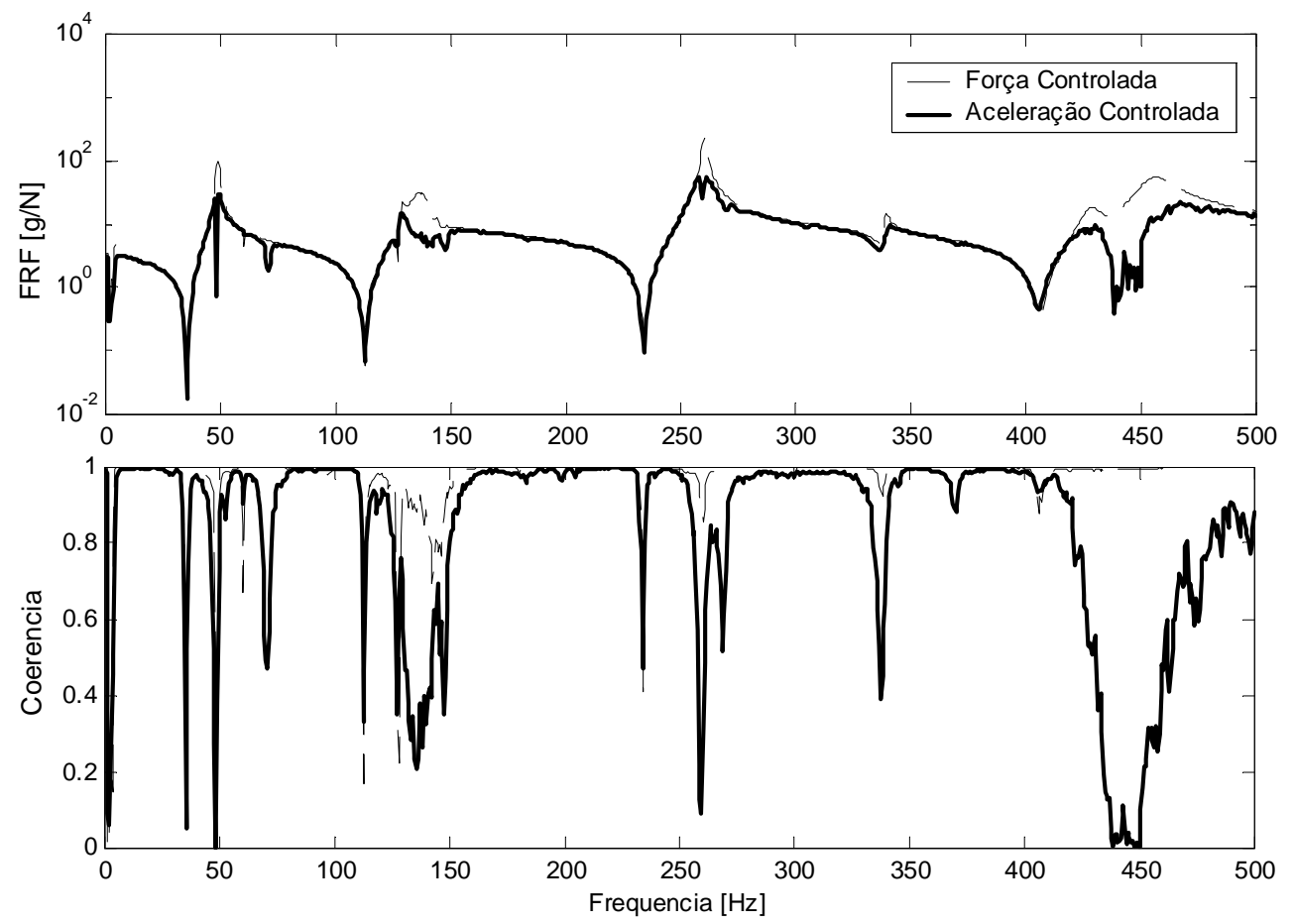

FIGURA 4.24 - Comparação entre FRFs e Coerência para aceleração e força constante

Os resultados que seguem, Figs. 4.25 a 4.27, são comparações entre as densidades auto-espectrais de aceleração obtidas nos ensaios com excitador. O intuito 
desta comparação é verificar o nível de aceleração a que a estrutura é exposta em cada um dos ensaios.

Observa-se dos dados obtidos, que além do ensaio com excitação controlada, o modo de tensão é o que menos agride a estrutura, impondo-a a níveis de aceleração, que nas regiões mais drásticas representam $1 / 10$ do que o ensaio com força controlada oferece, e chegando a quase 1/100 do modo de corrente, sendo este o mais severo.

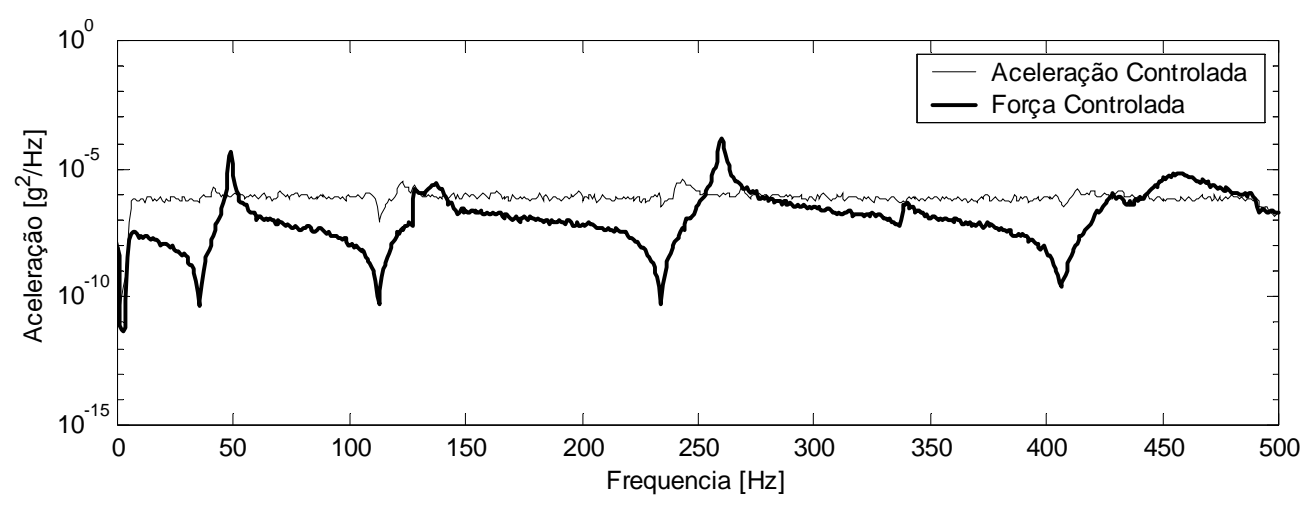

FIGURA 4.25 - DAE de aceleração para ensaios de malha fechada

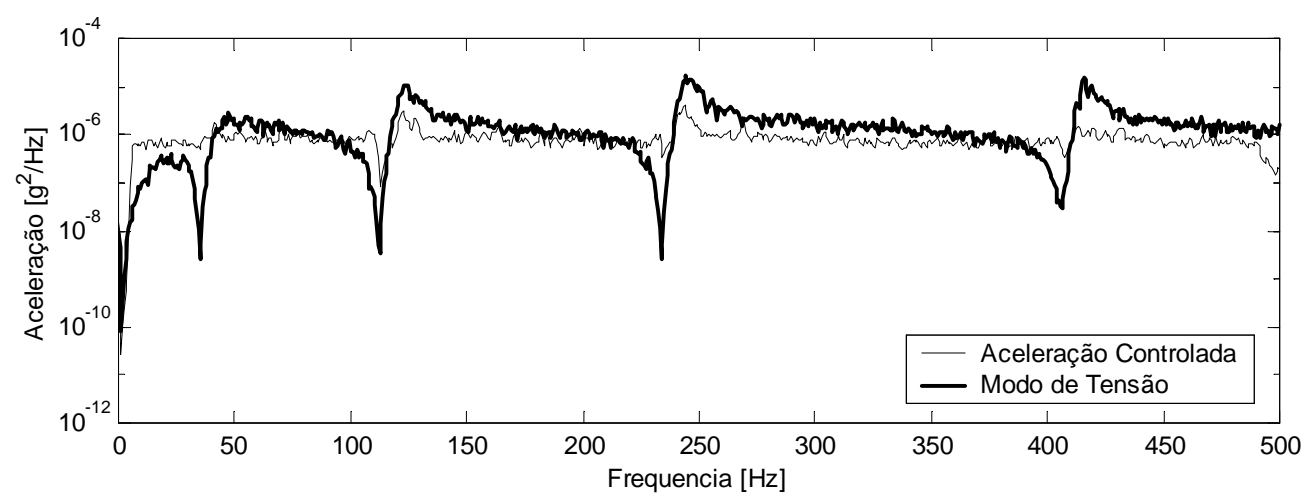

FIGURA 4.26 - DAE de aceleração para ensaios de malha fechada e modo de tensão

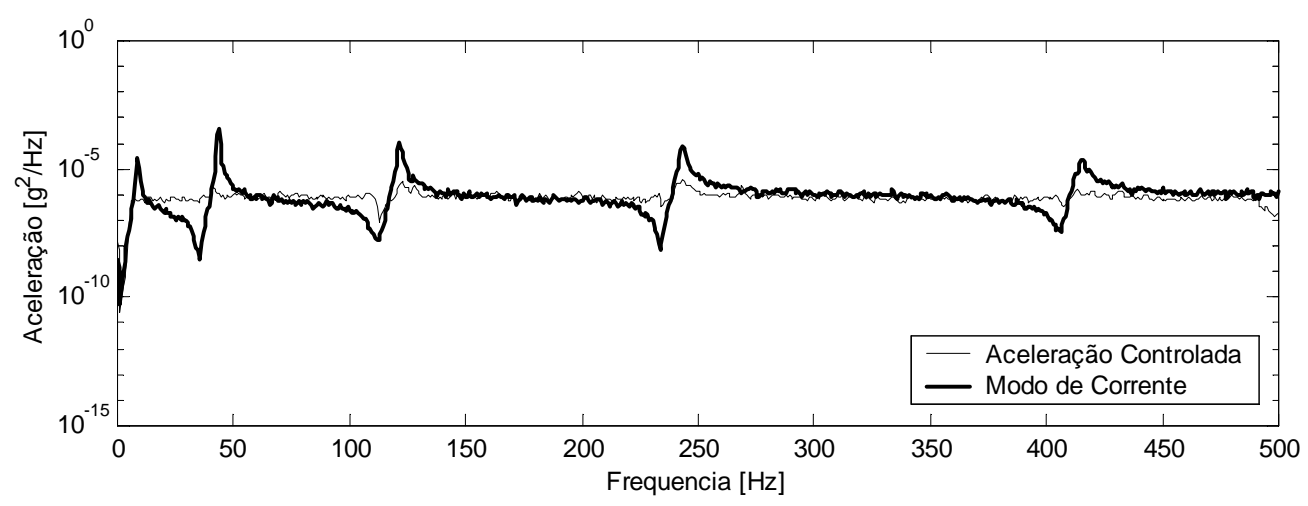

FIGURA 4.27 - DAE de aceleração para ensaios de malha fechada e modo de corrente 
Observando-se então as forças (Figs. 4.28 a 4.30), em relação aos testes com força controlada.

Neste caso, os níveis mais altos de força podem ser observados nos testes com aceleração controlada. Nas regiões de anti-ressonância da estrutura, observam-se os maiores valores de força, já que o sistema tem que aumentar a energia fornecida ao excitador a fim de manter o nível de aceleração. Sendo assim, este tipo de teste (aceleração controlada) requer cuidados especiais de planejamento, já que pode causar danos à estrutura e aos equipamentos de teste, se excedidos níveis de tensão, corrente ou força.

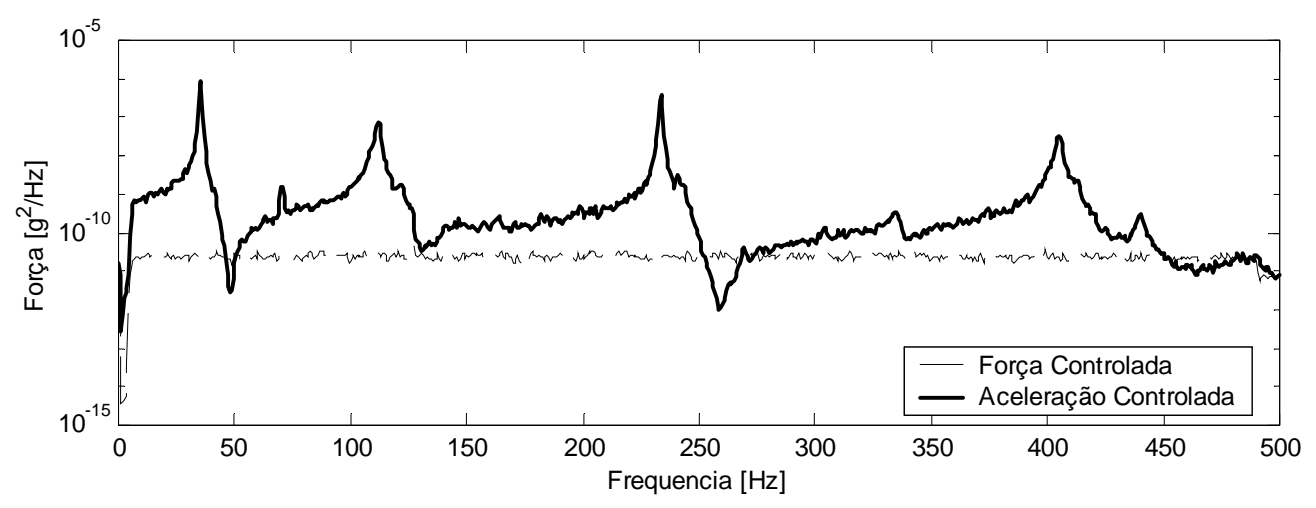

FIGURA 4.28 - DAE de força para ensaios de malha fechada

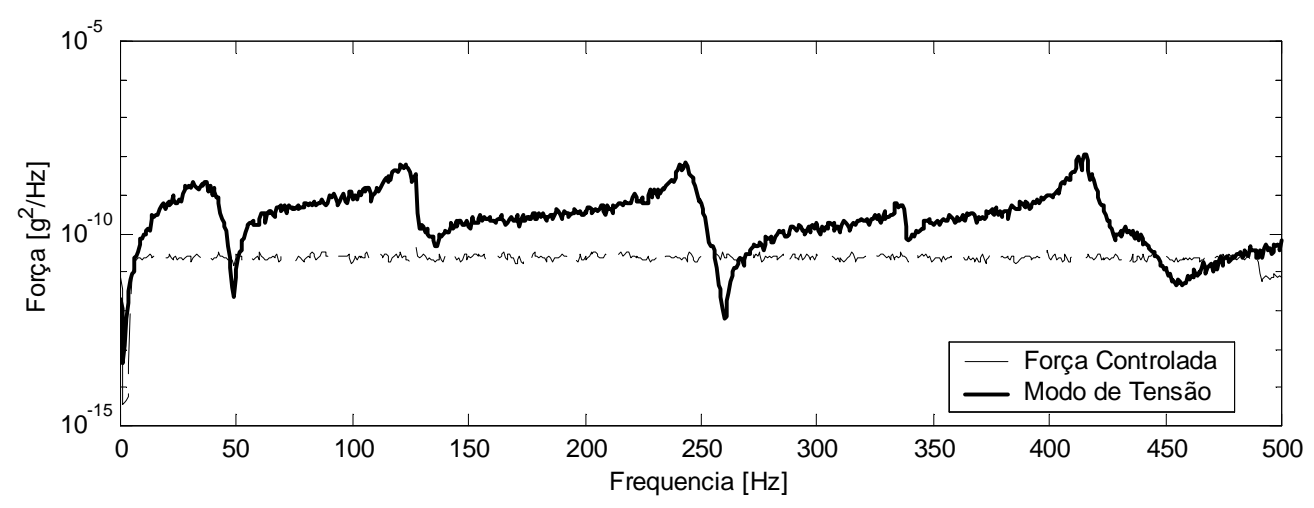

FIGURA 4.29 - DAE de força para ensaios de malha fechada e modo de tensão

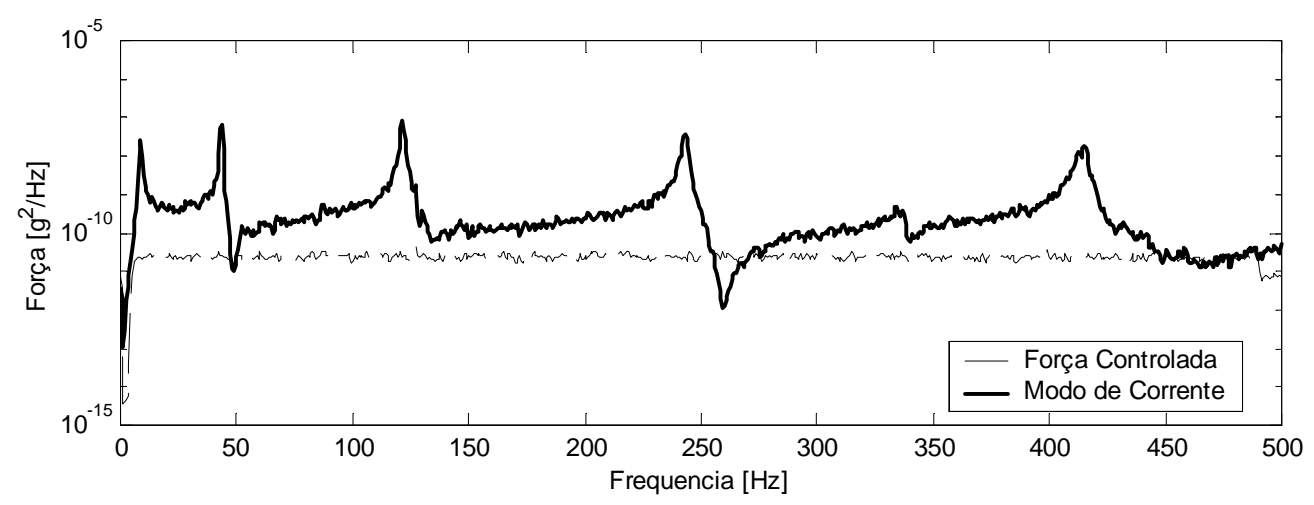

FIGURA 4.30 - DAE de força para ensaios de malha fechada e modo de corrente 


\subsubsection{EXCITAÇão Simples de ESTRUTURAS COMPLEXAS}

Os testes apresentados a seguir vêem complementar os dados obtidos até então para o caso de um único excitador. Apresentam-se dados obtidos com estruturas mais complexas como um pneumático e um chassi tubular de um protótipo de veículo tipo gaiola.

A Fig. 4.31 ilustra a força de entrada, a FRF e a função Coerência obtidas com o pneumático, no caso um de tamanho médio (Pirelli 215/75R 17.5), aplicado em veículos comerciais leves. A excitação foi aplicada radialmente, pelo centro da banda de rodagem (Fig 4.32). Mesmo em se tratando de uma estrutura consideravelmente amortecida, o que resulta em menor velocidade do ponto de excitação e conseqüentemente da armadura, podem-se observar as quedas na força de excitação em freqüências próximas às freqüências de ressonância da estrutura.
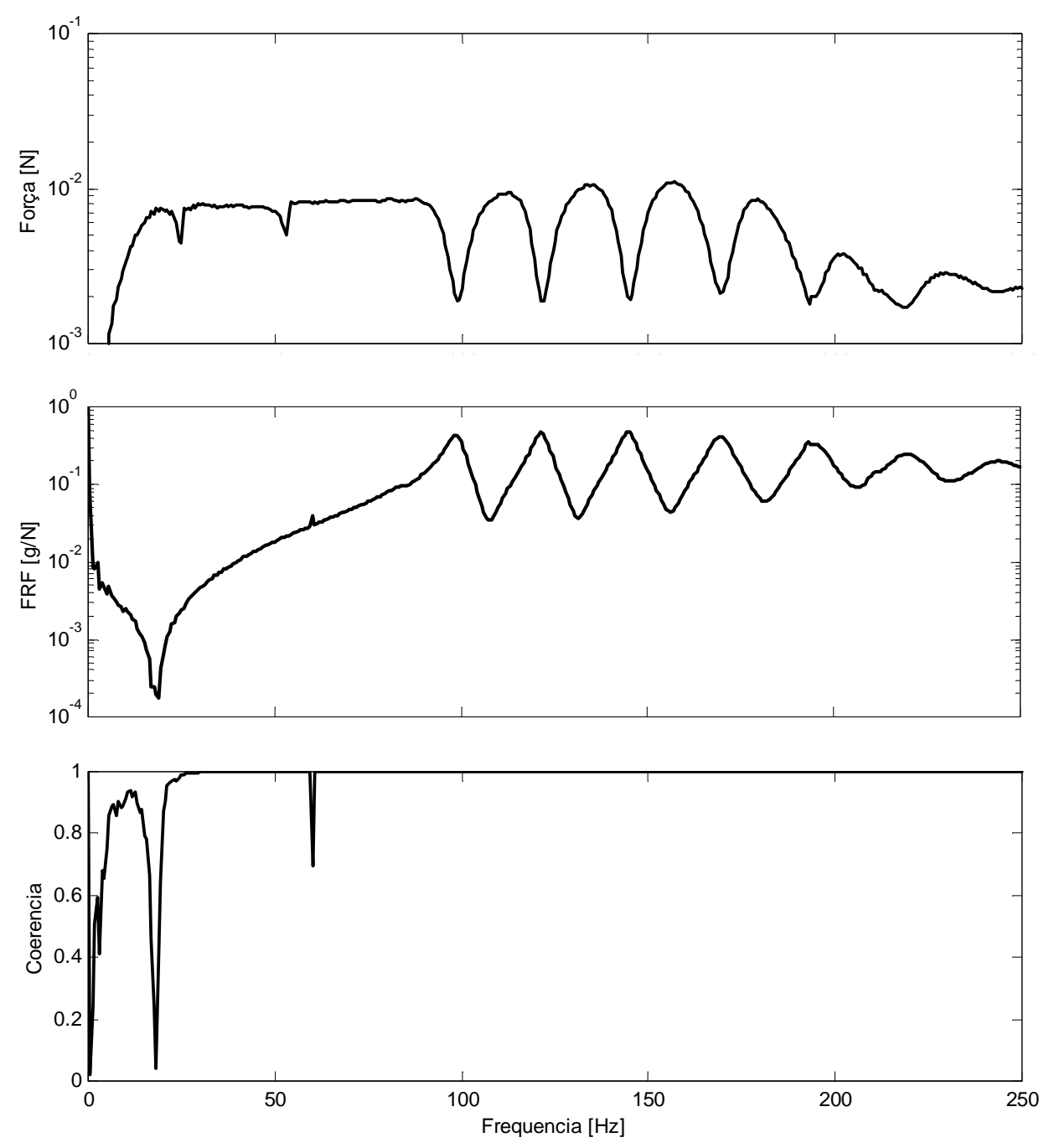

FIGURA 4.31 - Força de entrada, FRF e Coerência

Mesmo na presença das quedas de força, foi possível manter um bom nível de sinal o que garante uma relação sinal / ruído satisfatória. Como conseqüência, a função 
coerência ilustrada na Fig 4.31 é praticamente ideal na banda de freqüência de interesse, apresentando um valor baixo em $60 \mathrm{~Hz}$ relativo ao ruído da rede de energia.

Os testes foram realizados com o excitador B\&K 4812, operando em modo de tensão com sinal senoidal transiente (Chirp) na faixa de 0 a $500 \mathrm{~Hz}$. Fez-se uso de janela retangular nos sinais de entrada e saída. No lugar do transdutor de força utilizou-se uma cabeça de impedância B\&K 8001.

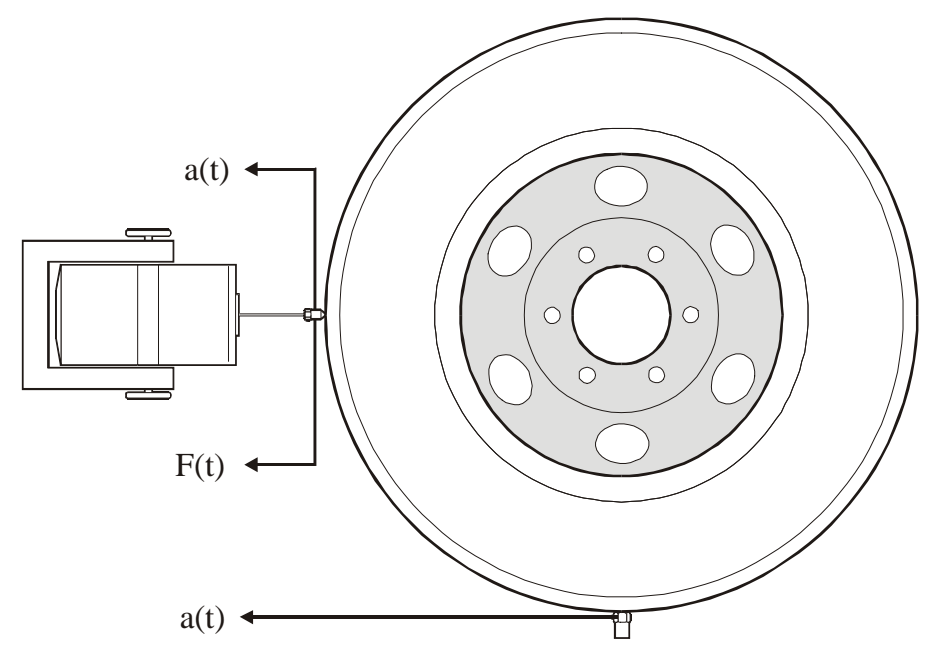

FIGURA 4.32 - Ensaio de Pneumático

A segunda estrutura trata-se do chassi (Equipe EESC-USP Mini-Baja) constituído basicamente de tubos de aço soldados (Fig 4.33).
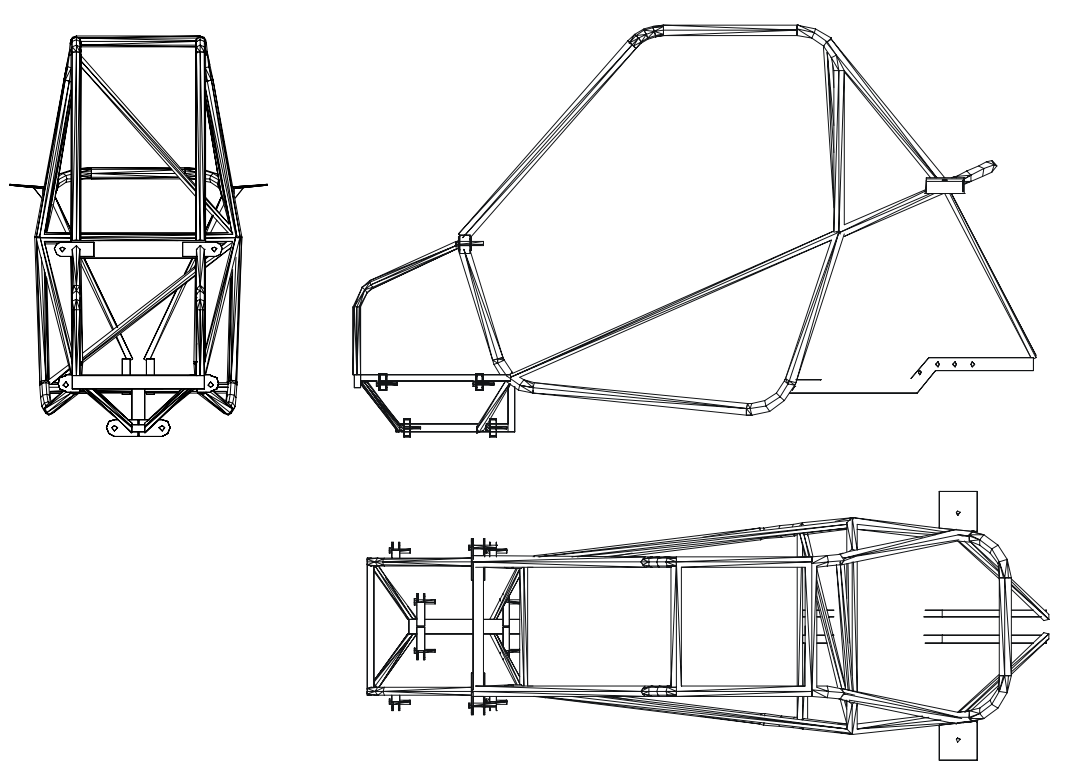

FIGURA 4.33 - Três Vistas do chassi de um veículo protótipo

Nos testes com o chassi utilizou-se o mesmo excitador (B\&K 4812). A força de entrada foi medida com um transdutor de força Kistler 912 e a aceleração com um acelerômetro B\&K 4375. Durante os ensaios fez-se uso de sinal Chirp e janela 
retangular nos sinais de entrada e saída. Os resultados obtidos podem ser vistos nas Figs. 4.35 a 4.37 .

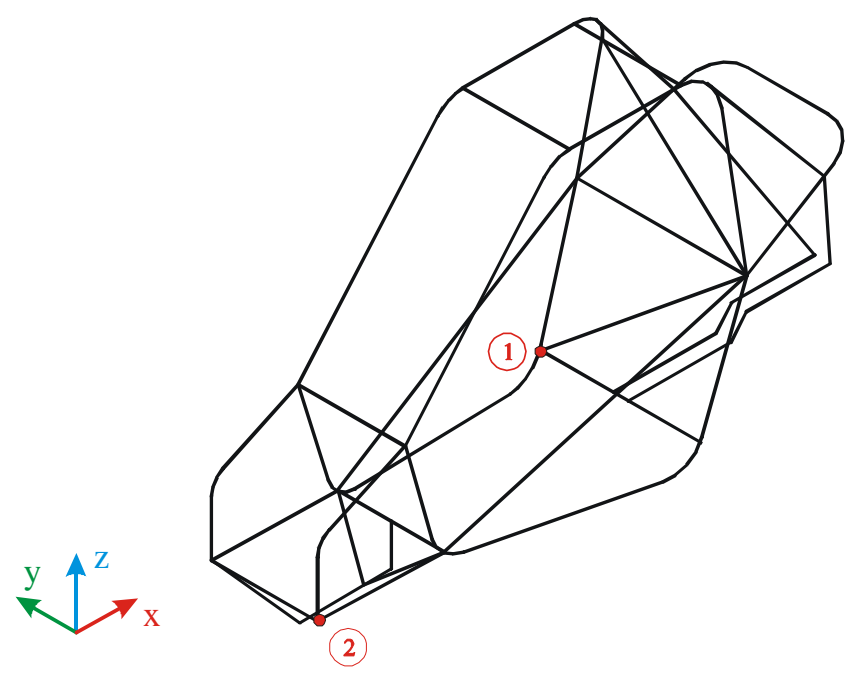

FIGURA 4.34 - Vista isométrica do chassi e pontos de aplicação de força

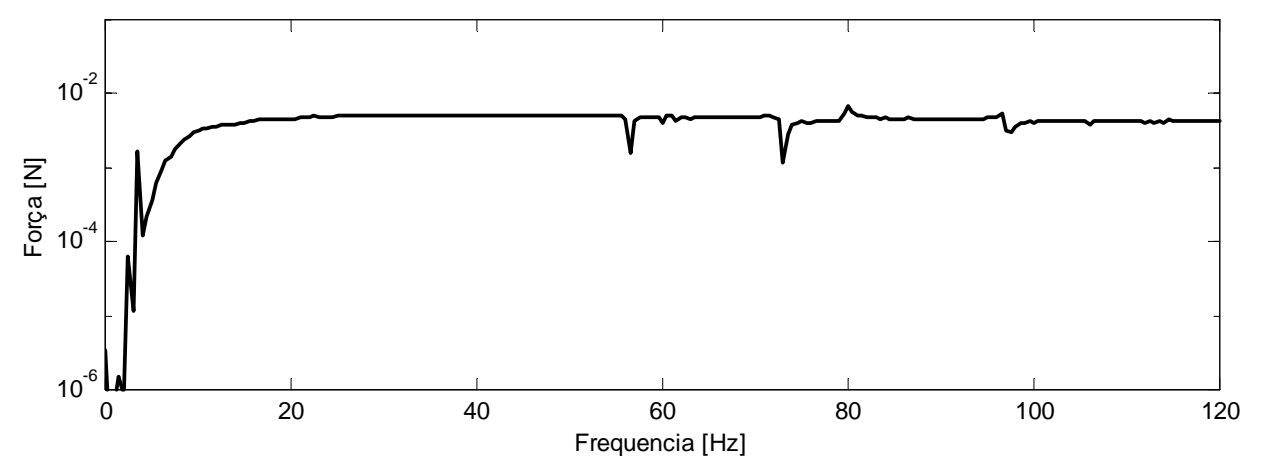

FIGURA 4.35 - Força de excitação $F_{1}$

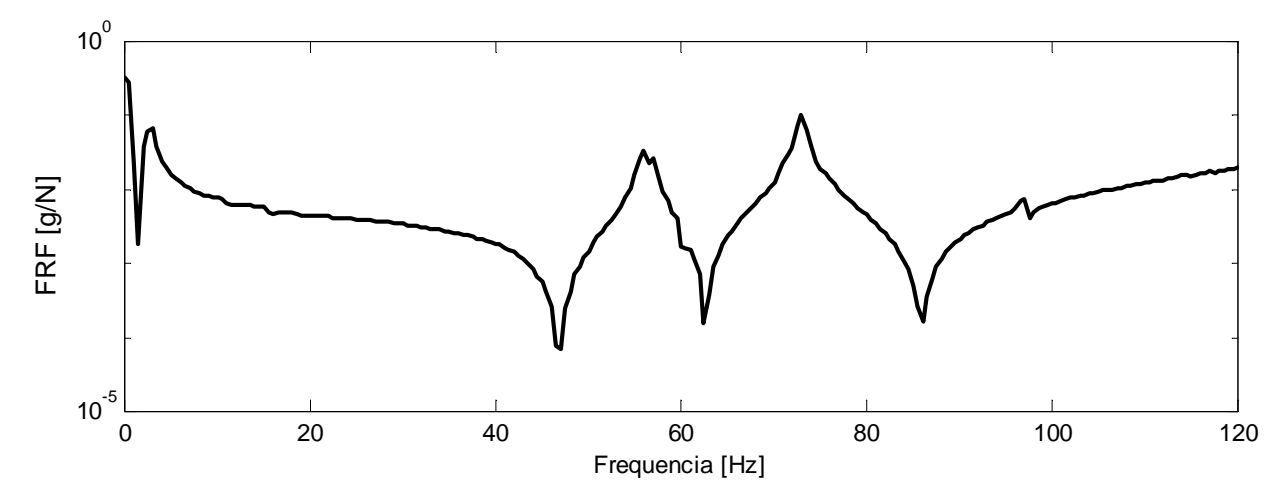

FIGURA 4.36 - FRF de ponto do chassi $\mathrm{H}_{11}$ 


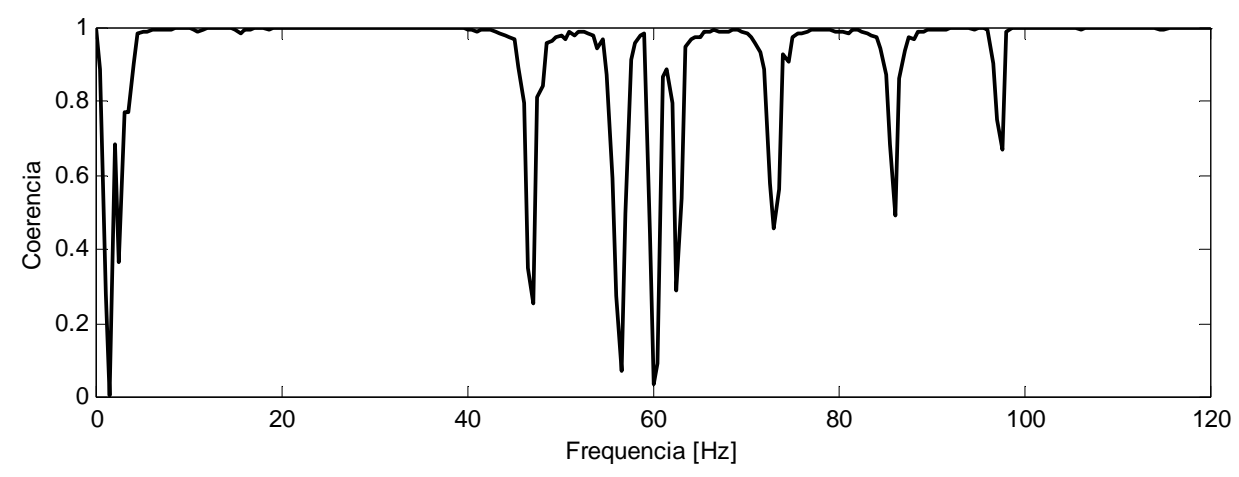

FIGURA 4.37 - Função Coerência

A Fig. 4.35 ilustra a força de entrada. Nela, podem-se observar as quedas de força nas regiões próximas das freqüências de ressonância da estrutura. Neste caso a função coerência (Fig 4.37) assume valores baixos nas freqüências relativas a ressonâncias e anti-ressonâncias da estrutura. Isto se deve principalmente a uma relação sinal / ruído pobre nestas freqüências, seja pela queda na força ou na aceleração.

Portanto, observa-se que no caso do pneumático, mesmo na presença das quedas de força, foi possível manter um bom nível de sinal / ruído. O mesmo não pode ser dito em relação ao chassi. A complexidade da estrutura, no caso do chassi, também se mostra um fator decisivo na qualidade dos dados obtidos. Como será discutido a seguir (Seção 5.3), a escolha adequada do ponto de fixação do excitador, ou mesmo nível de excitação e tipo de sinal adequado para o teste de estruturas mais complexas, sem a realização prévia de uma análise computacional, ou mesmo resultados experimentais de uma estrutura similar, não é uma tarefa trivial.

\subsubsection{O USO ADEQUADO DE ESTIMADORES DE FRFS}

Os resultados experimentais demonstrados a seguir, foram obtidos a partir do arranjo experimental ilustrado na Fig. 4.37. A estrutura sob estudo busca representar uma aeronave (Fig. 4.38). A fuselagem consiste de uma viga de aço $(25,4$ x 9,5 x 1000 $\mathrm{mm}$ ) e as asas e a empenagem horizontal, de chapas de alumínio ( $3 \mathrm{~mm}$ ). A estrutura foi suspensa por cordas flexíveis, a fim de simular uma condição livre-livre. Conforme a Fig. 4.37, um excitador MB Dynamics Modal-50 (3) foi conectado a uma das asas, e um transdutor de força Kistler 912 (4) foi usado para medir s força de entrada, as acelerações foram obtidas com um par de acelerômetros B\&K 4375 (5). Em todos as medidas foram utilizadas janelas retangulares nos sinais de entrada e saída, sendo o sinal de excitação escolhido um Chirp de 0 a $200 \mathrm{~Hz}$. O analisador espectral utilizado foi um Tektronix 2630 (1). O amplificador de potência (2) foi ajustado para operar em modo de tensão. 


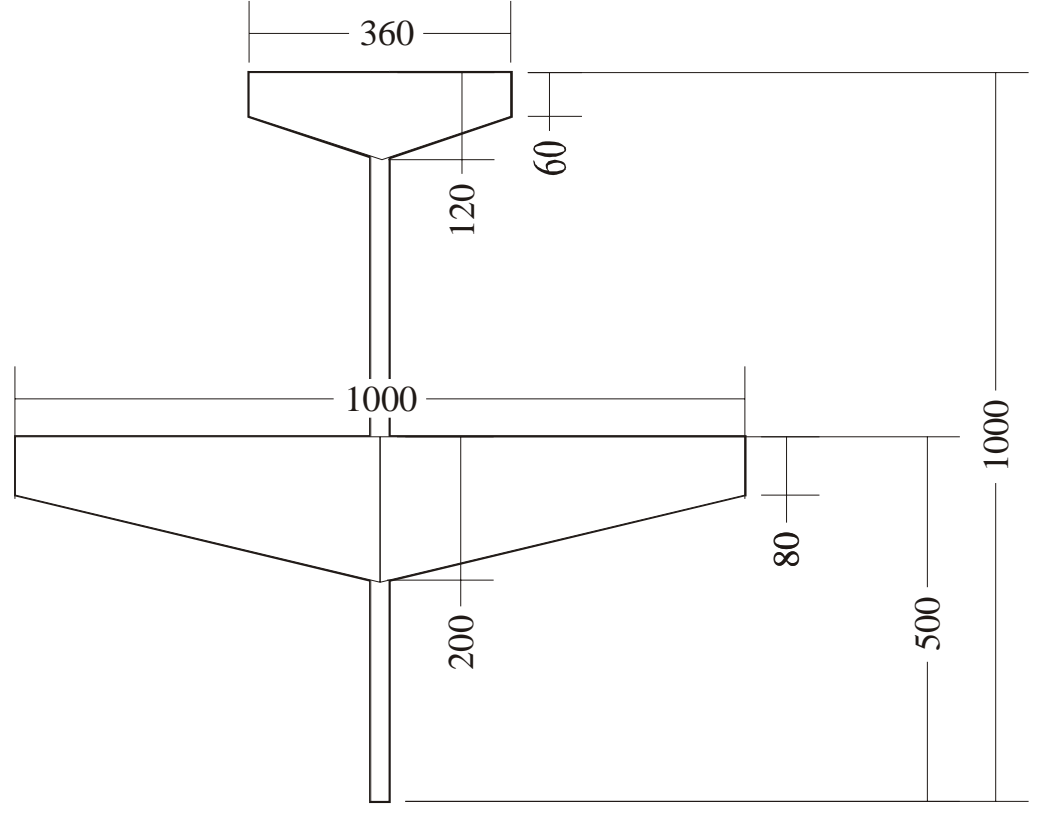

FIGURA 4.38 - Estrutura construída para ensaios (dimensões em mm)

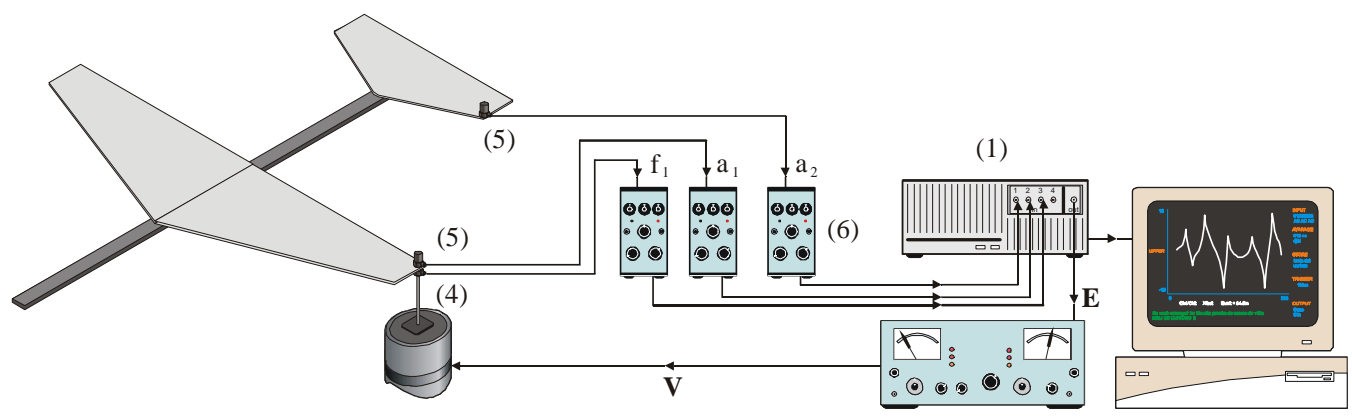

(3)

(2)

(7)

\section{FIGURA 4.39 - Arranjo experimental}

As Figuras de 40 a 43 ilustram as funções obtidas com condições ideais, i.é., a melhor relação sinal ruído obtida com este arranjo experimental.

A Fig. 40 ilustra os espectros de aceleração dos pontos 1 e 2, respectivamente na asa $\left(A_{1}\right)$ e na empenagem $\left(A_{2}\right)$.

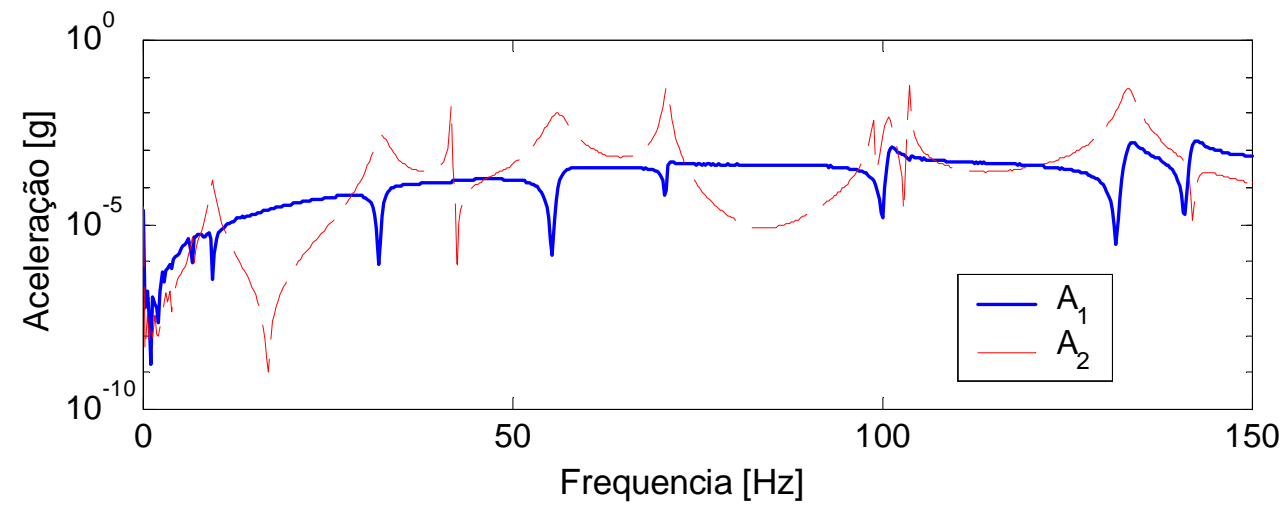

FIGURA 4.40 - Espectros de aceleração 
A Fig. 4.41 ilustra o espectro de força ' $F_{1}$ ' no ponto 1 da asa. Comparando este gráfico com a FRF de ponto ilustrada na Fig 4.42, podem-se observar as quedas de força relativas a todas as freqüências de ressonância em $\mathrm{H}_{11}$.

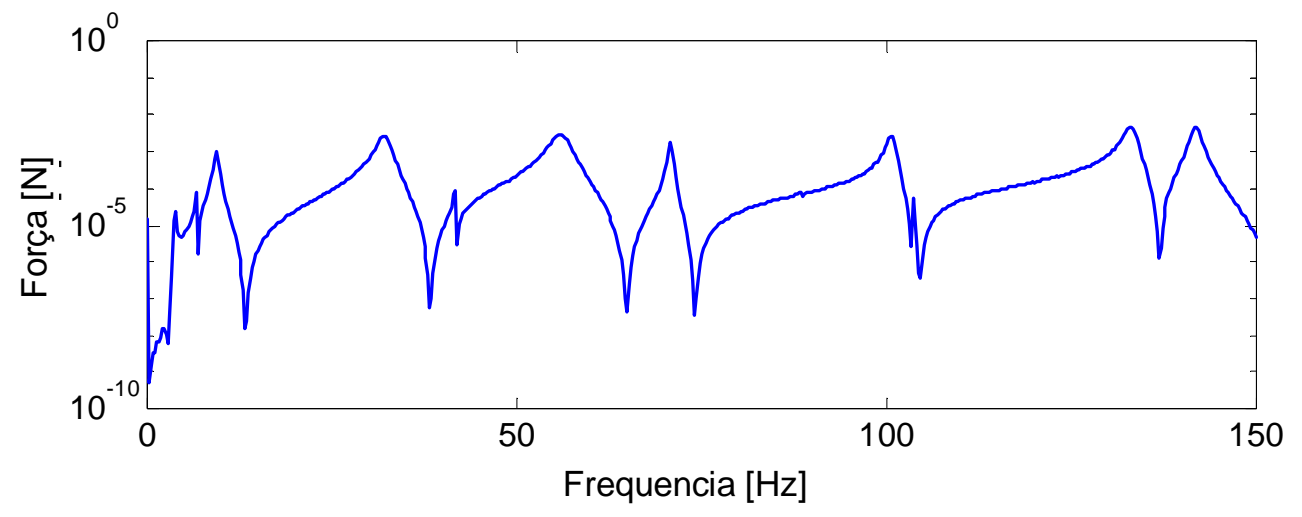

FIGURA 4.41 - Espectro de força

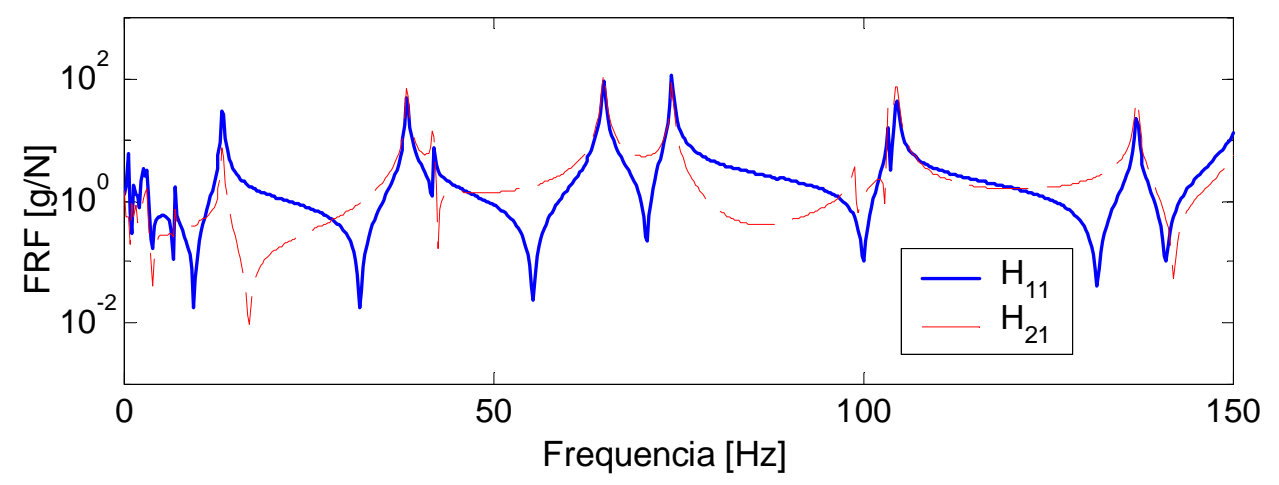

FIGURA 4.42 - FRFs do sistema

O bom condicionamento dos sinais neste teste podem ser constatados pela análise das funções coerência ilustradas na Fig. 4.43.

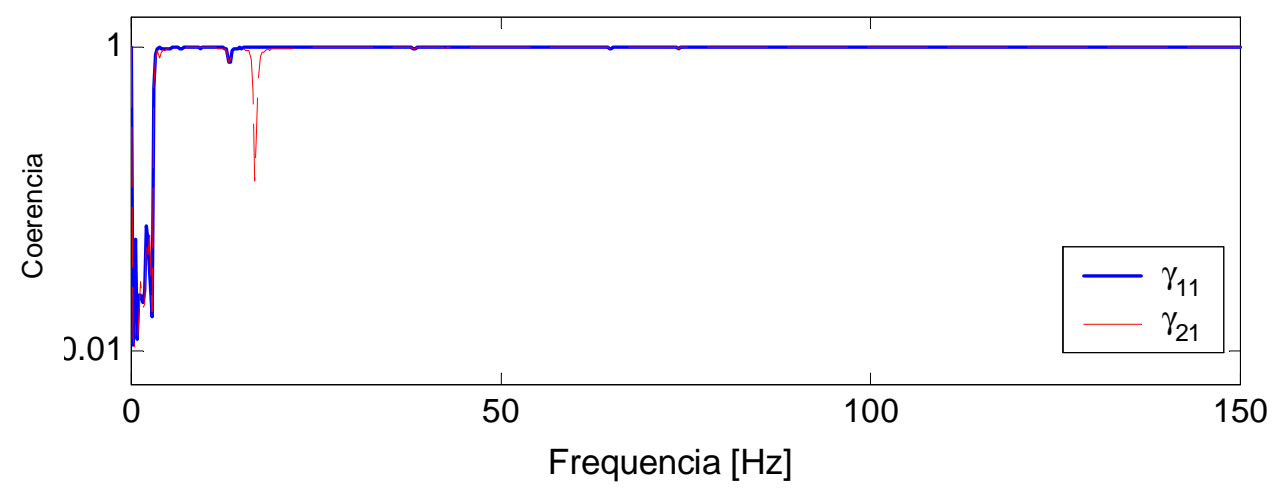

FIGURA 4.43 - Funções Coerência

Os testes descritos a seguir foram realizados com o intuito de demonstrar os efeitos de ruído nos sinais de entrada e saída em cada um dos canais de entrada e saída nas FRFs obtidas com diferentes estimadores. 
A FIgura 4.44 ilustra o arranjo experimental utilizado para introduzir ruído nos canais de entrada. Para tanto se fez uso de uma unidade de teste da B\&K (3), modelo ZZ 0201. Esta permite que um sinal analógico (2) sofra modificações como atrasos, e a adição de ruído em vários níveis. Os resultados obtidos com estes testes podem ser vistos nas Figs 4.45 a 4.48 .

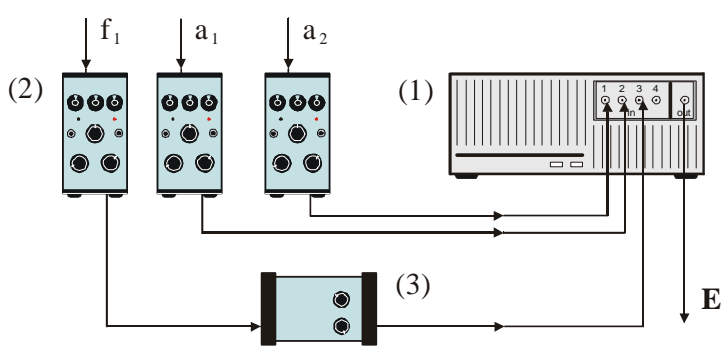

FIGURA 4.44 - Arranjo experimental com adição de ruído ao sinal de entrada

Uma comparação entre FRFs de ponto $\left(\mathrm{H}_{11}\right)$ obtidas com estimadores $\mathrm{H}_{1}$ e $\mathrm{H}_{2} \mathrm{e}$ a função coerência $\gamma_{11}$ pode ser vista na Fig. 4.44. Neste caso o estimador $\mathrm{H}_{2}$ se mostra mais eficiente, visto que o ruído no sinal de entrada se torna significativo quando há queda na força de excitação. Dada a sensibilidade do estimador $\mathrm{H}_{1}$ a ruído no canal de entrada, e à relação sinal ruído nas proximidades das freqüências de ressonância, podese observar que todos os picos em $\mathrm{H}_{111}$ estão corrompidos. Da mesma forma, a função coerência assume valores baixos nas vizinhanças das freqüências de ressonância.
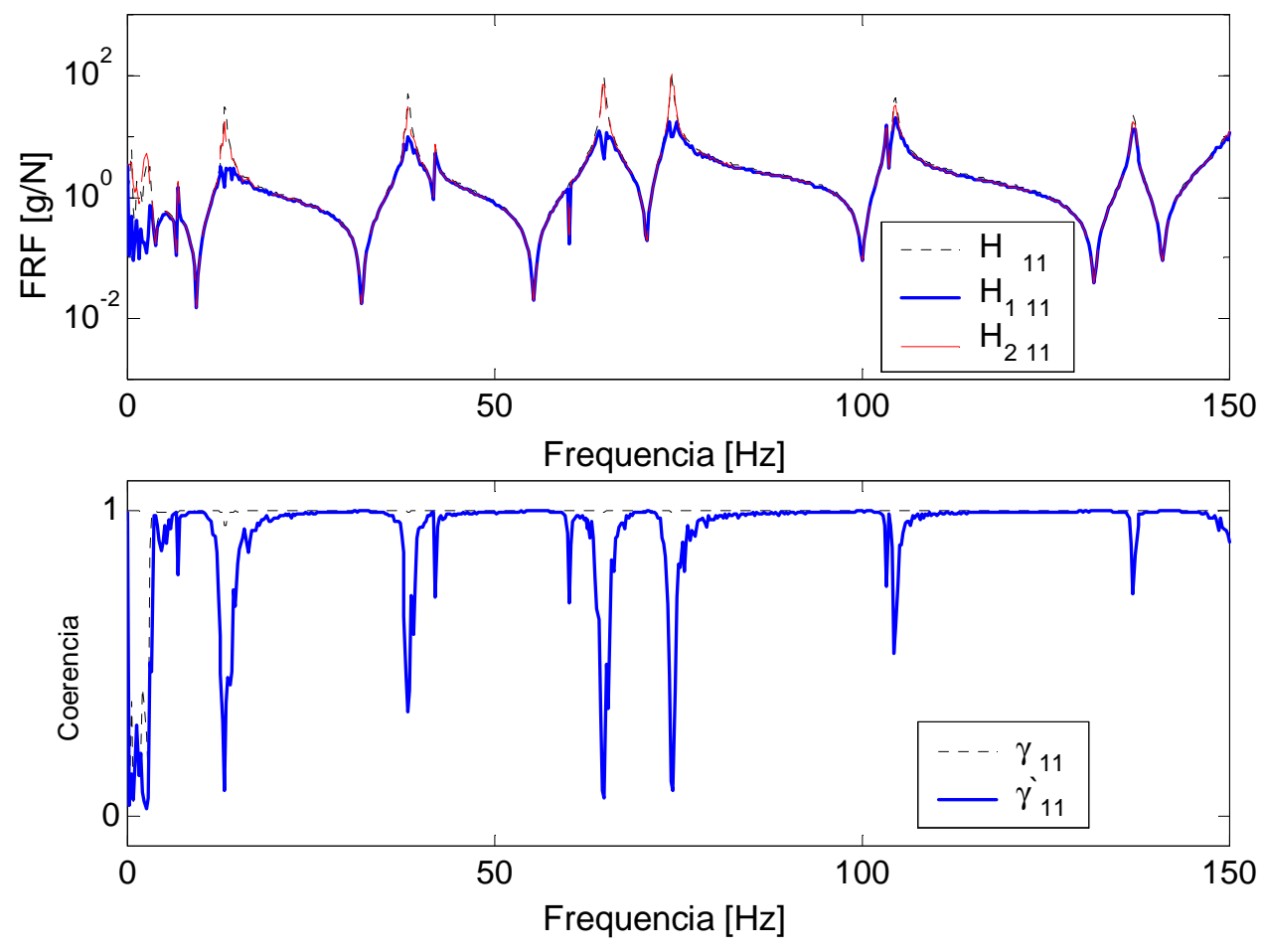

FIGURA 4.45 - FRFs de ponto e funções coerência com ruído no sinal de entrada 
Analogamente, a Fig. 4.46 ilustra os mesmos resultados para FRFs de transferência. Neste caso, pode-se observar que o estimador $\mathrm{H}_{2}$ superestimou alguns valores de ressonância, como demonstrado analiticamente por MAIA \& SILVA (1997). Ainda, o estimador $\mathrm{H}_{1}$ continua exibindo distorções significativas nas regiões de ressonâncias da estrutura.
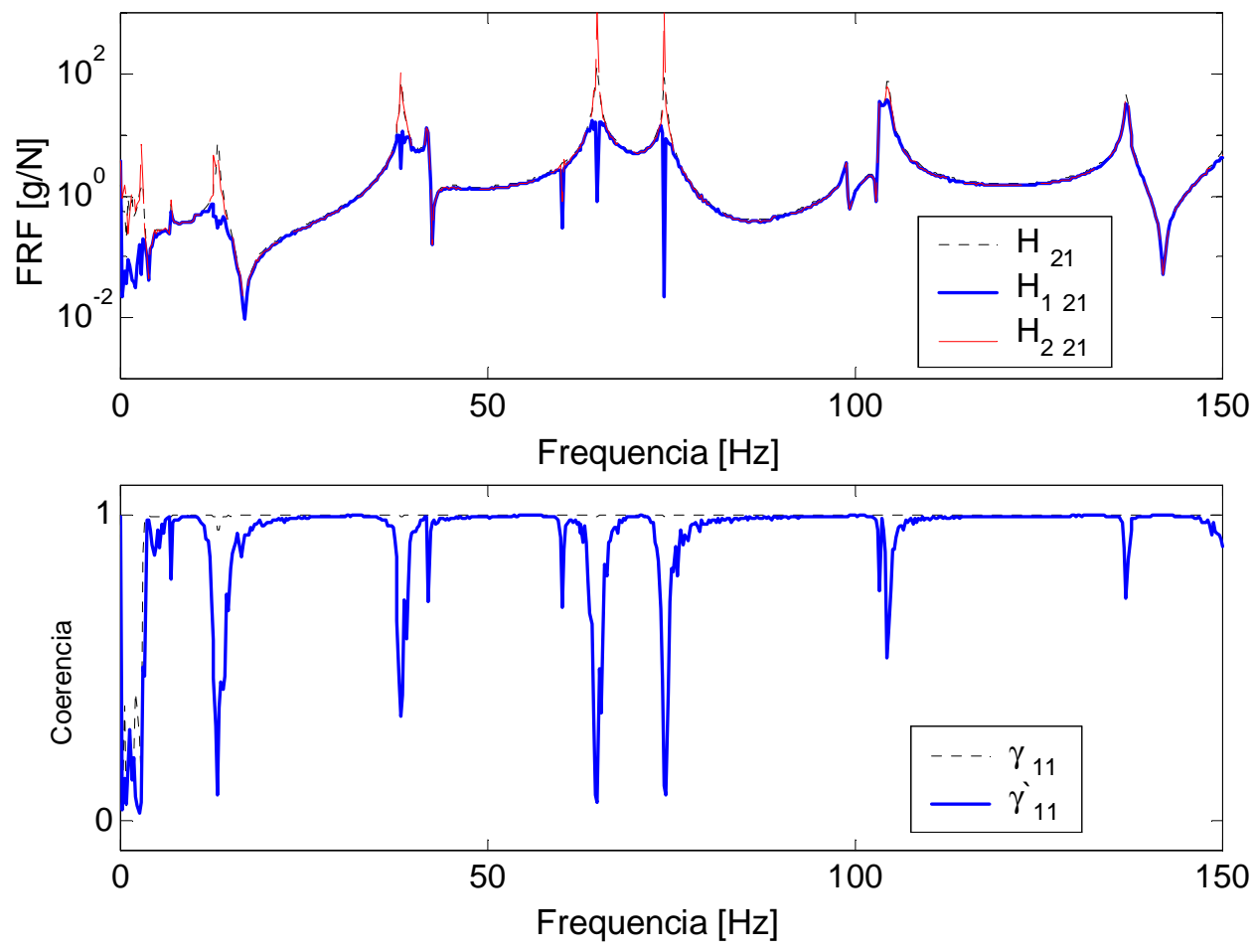

FIGURA 4.46 - FRFs de transferência e função coerência com ruído no sinal de entrada

As Figs. 4.47 e 4.48 ilustram métodos alternativos para a obtenção das FRFs: os estimadores $\mathrm{H}_{3}$ e $\mathrm{Hv}$, demonstrados no Capítulo 1. Ambos os métodos foram implementados no pós-processamento dos sinais, visto que o analisador utilizado não dispunha deste recurso.

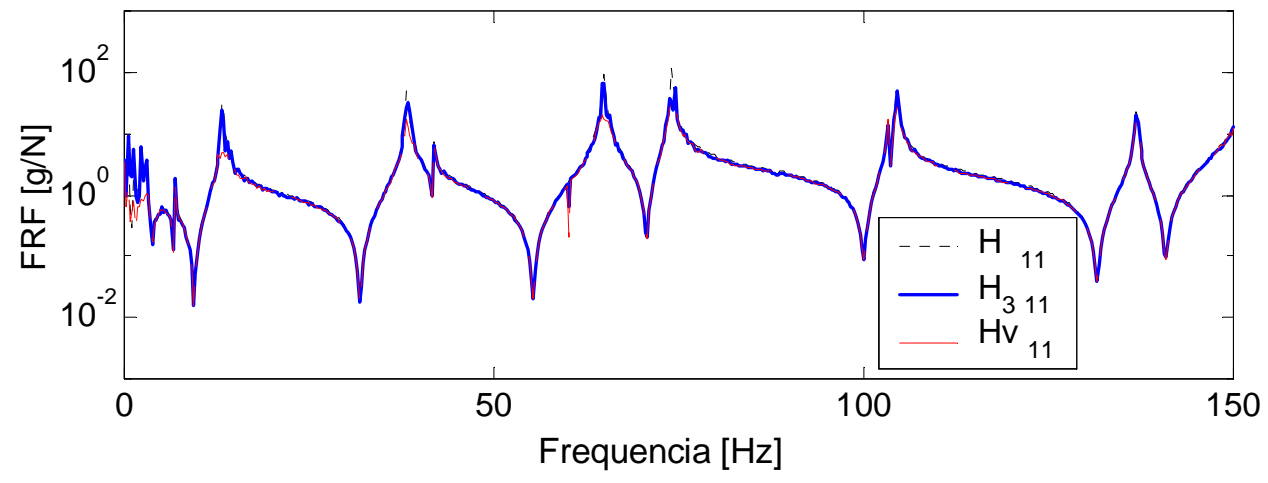

FIGURA 4.47 - FRF de ponto com ruído no sinal de entrada 
Apesar de sua fácil implementação, o estimador $\mathrm{H}_{3}$ necessita de 3 canais para a medida de uma FRF, enquanto que $\mathrm{Hv}$ pode ser obtido apenas com auto-espectros e espectros cruzados dos sinais de entrada e saída. Contudo, o cálculo de uma FRF com Hv, requer a solução de um autoproblema para cada linha espectral.

A despeito de suas vantagens e desvantagens, ambos os métodos mostraram bons resultados, tanto na identificação de ressonâncias, como de anti-ressonâncias.

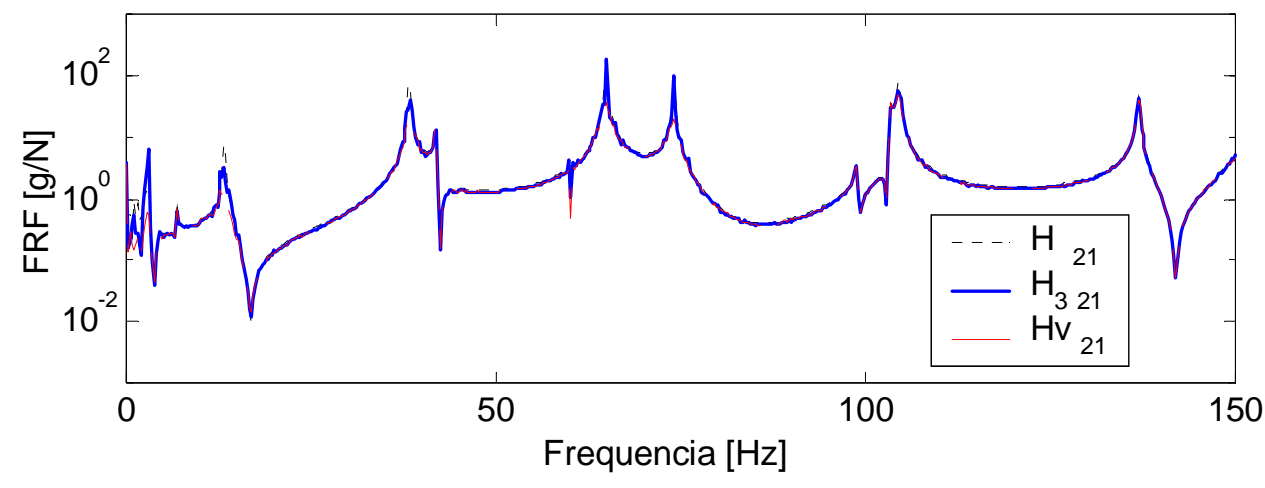

FIGURA 4.48 - FRF de transferência com ruído no sinal de entrada

Os mesmos testes realizados até então, foram repetidos, agora com adição de ruído no canal de saída.

A Fig. 4.49 ilustra o arranjo experimental utilizado para introduzir ruído nos canais de saída. Os resultados obtidos com estes testes podem ser vistos nas Figs 4.50 a 4.53 .

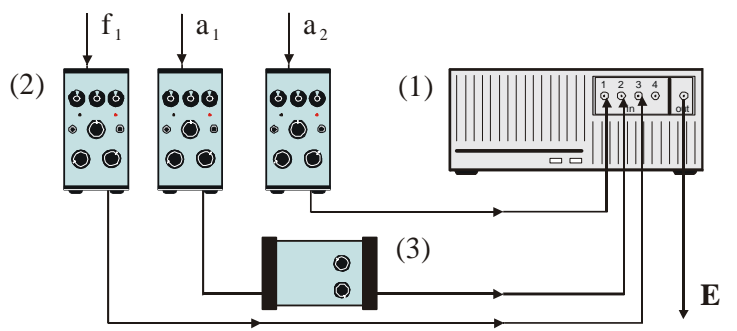

\section{FIGURA 4.49 - Arranjo experimental com adição de ruído ao sinal de saída}

Neste caso, as ressonâncias são melhor definidas, já que a razão sinal / ruído é satisfatória. $\mathrm{O}$ mesmo não pode ser dito quanto às anti-ressonâncias. Pelos resultados ilustrados nas Figs. 4.50 e 4.51, pode-se constatar que o estimador $\mathrm{H}_{1}$ é indicado quando há ruído no sinal de entrada. Este não apresenta distorções, a não ser nas antiressonâncias, o que pode ser constatado pelas funções coerência, que assumem valor igual a um para praticamente todas as ressonâncias. 

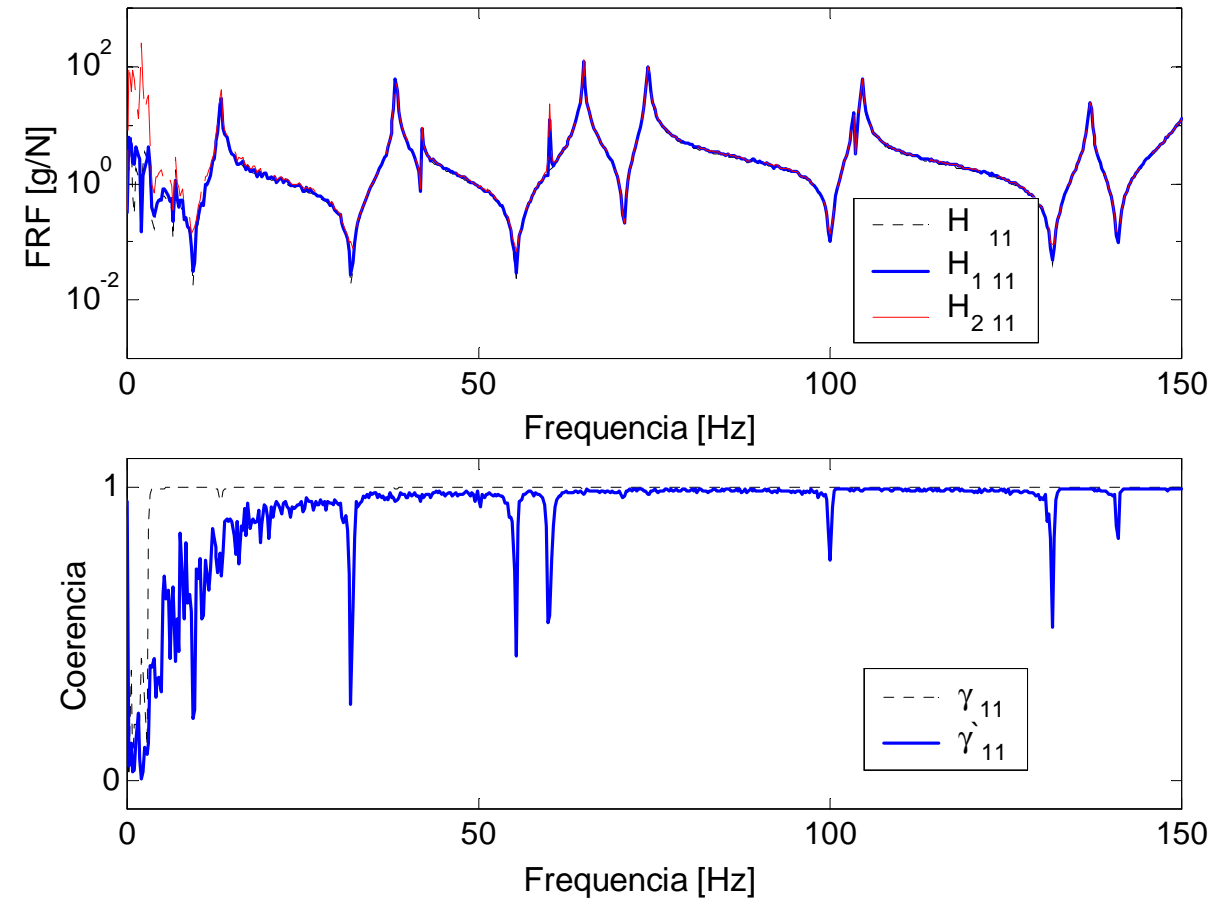

FIGURA 4.50 - FRFs de ponto e funções coerência com ruído no sinal de saída
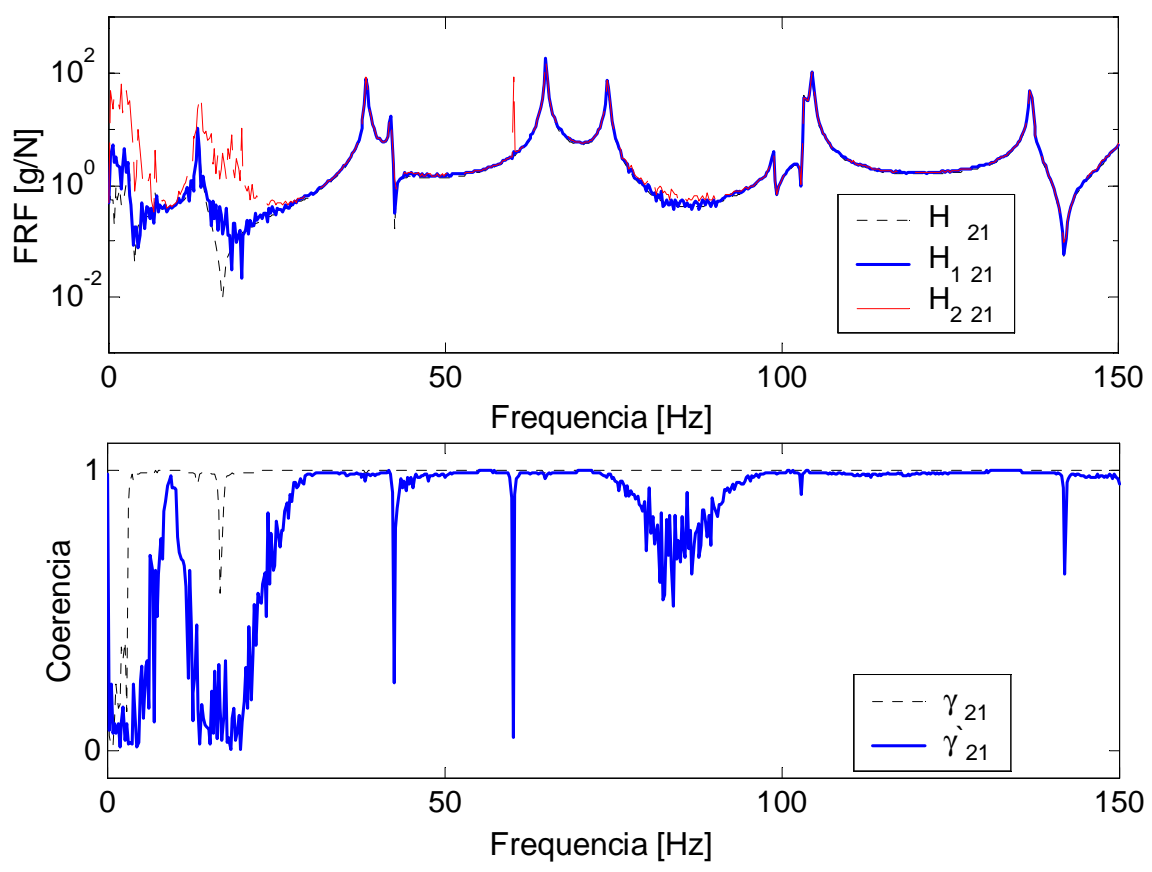

FIGURA 4.51 - FRFs de transferência e funções coerência com ruído no sinal de entrada

Ainda, $\mathrm{H}_{3}$ e $\mathrm{Hv}$ mostram melhores resultados que $\mathrm{H}_{1}$ e $\mathrm{H}_{2}$, como pode ser visto nas Figs. 4.52 e 4.53 . 


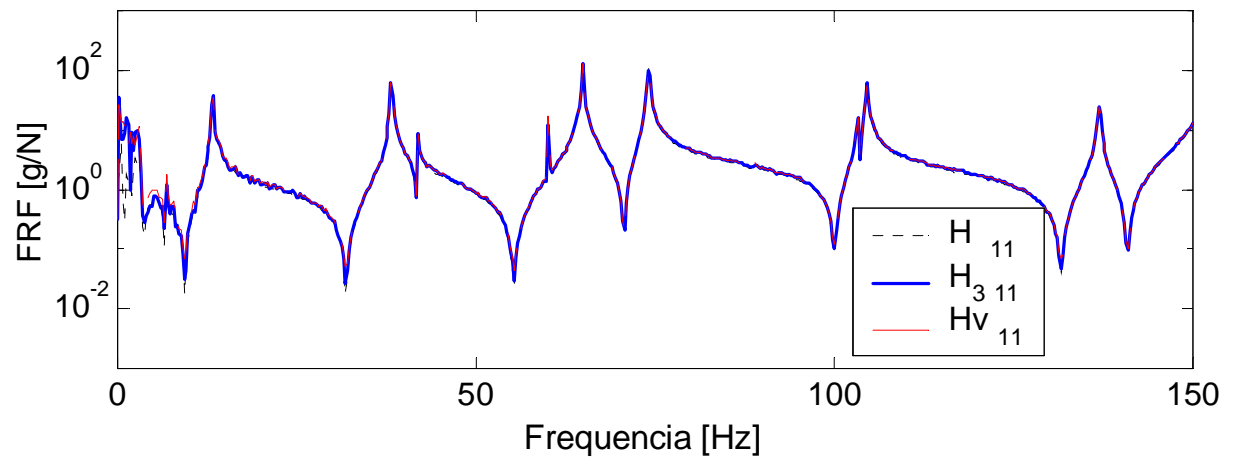

FIGURA 4.52 - FRF de ponto com ruído no sinal de saída

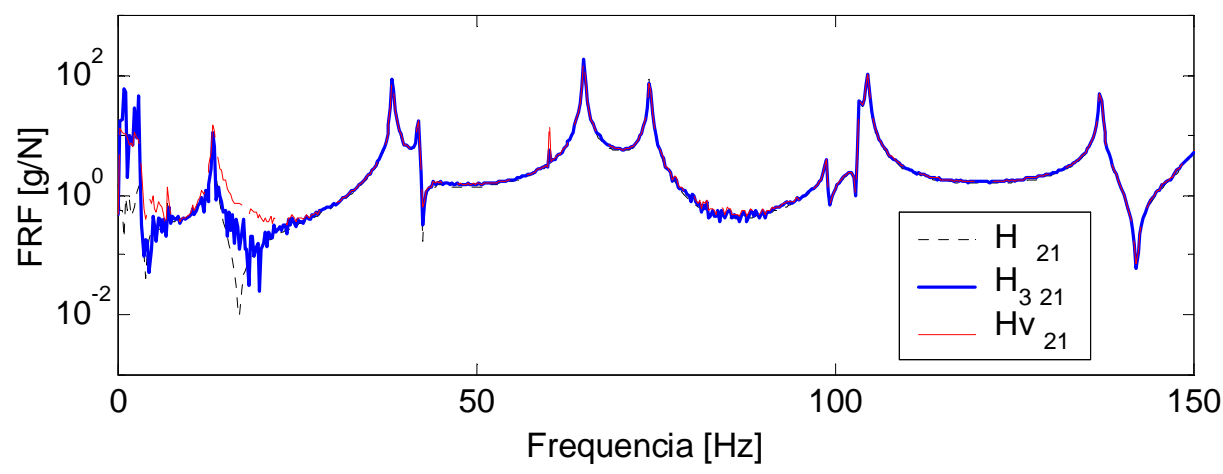

FIGURA 4.53 - FRF de transferência com ruído no sinal de saída

Com isso, métodos como $\mathrm{H}_{3}$ e $\mathrm{Hv}$ se mostram mais eficientes na estimativa de FRF em testes com excitadores eletrodinâmico, nos quais a queda de força for um fator considerável.

\subsubsection{Graus DE LIBERDADE RotACIONAIS DA ARMADURA}

Os testes descritos a seguir têm como objetivo verificar os efeitos de acelerações angulares e momentos transmitidos entre o excitador e a estrutura, na qualidade dos dados obtidos.

Para estes testes adotou-se uma estrutura canônica, uma viga de aço (25,4 x 9,5 x $1000 \mathrm{~mm}$ ) em condição livre-livre, dada a familiaridade com seu comportamento dinâmico e por apresentar características interessantes para este tipo de teste, como grandes movimentos translacionais e rotacionais das suas extremidades, para praticamente todos os modos de vibrar.

A Fig. 4.54 ilustra os arranjo experimental básico utilizado durante os testes com estrutura. Os equipamentos utilizados foram um excitador B\&K 4812 (3), um transdutor de força Kistler 912 (4) para medir a força de entrada, um acelerômetro B\&K 4375 (5) para medir as acelerações translacionais. LOFRANO et al. (2002) demonstram outras técnicas para obter FRFs de aceleração angular por força de entrada, porém dada a disponibilidade de um acelerômetro angular Kistler 8836M01, este foi utilizado para medir as acelerações angulares. Foram utilizadas janelas retangulares nos sinais de 
entrada e saída. O sinal de excitação foi um Chirp na faixa de freqüência de 0 a $500 \mathrm{~Hz}$. O amplificador operacional (2) foi ajustado para operar em modo de tensão.

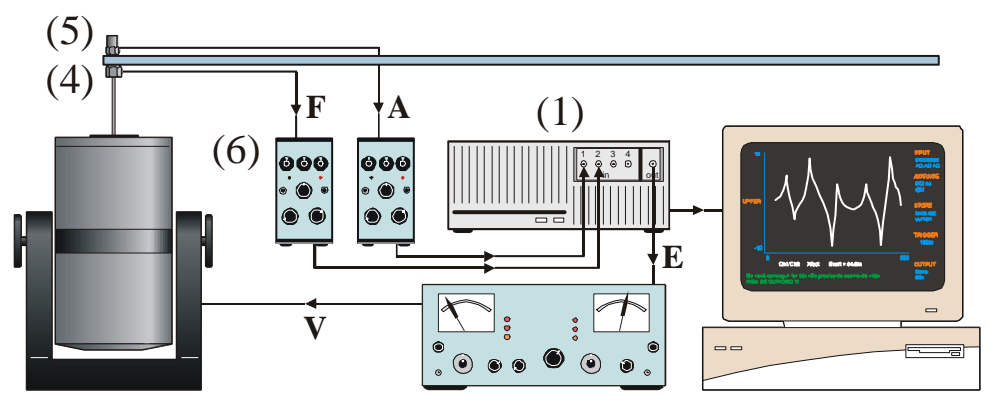

(3)

(2)

(7)

\section{FIGURA 4.54 - Arranjo experimental}

A Fig. 4.55 ilustra as diversas formas de fixação da estrutura ao excitador, para esta série de testes. Estas diferentes configurações foram utilizadas com o intuito de observar a interferência de cada elemento da cadeia na qualidade dos resultados adquiridos.

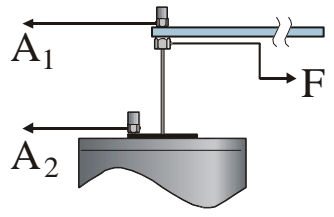

(a)

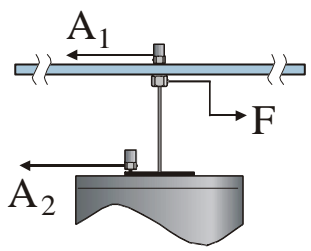

(c)

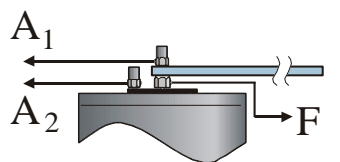

(b)

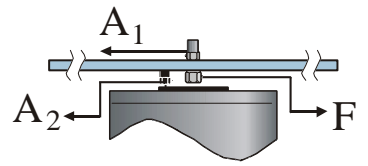

(d)

\section{FIGURA 4.55 - Fixação da estrutura}

Os resultado a seguir se referem aos testes realizados com a estrutura.

A Fig. 4.56 ilustra as respostas para o caso ideal, no qual a estrutura está suspensa por cordas flexíveis e é excitada por meio de uma haste flexível (stinger), como na Fig. 4.55 (a) e (c). Ambas as curvas ilustradas na Fig. 4.56 tratam-se de FRFs de ponto, uma tomada na ponta e a outra no centro da viga. Como o centro da viga é nó para todos o modos de vibrar pares, estes não aparecem nas FRF tomadas no centro. 


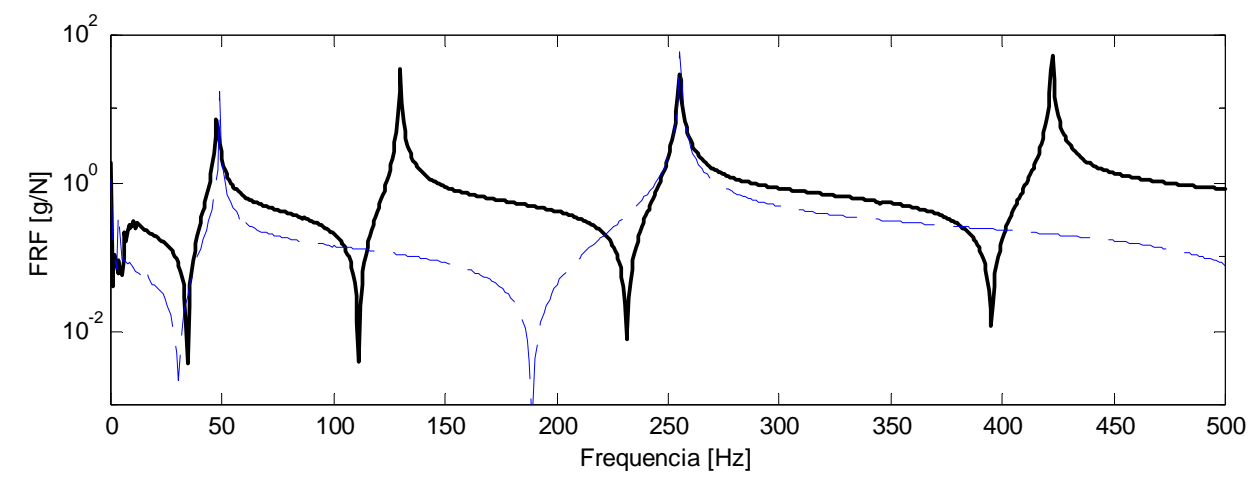

_ Ponta _ _ Centro

\section{FIGURA 4.56 - FRFs da viga}

A Fig. 4.57 compara os resultado obtidos para o caso ideal, e uma FRF obtida com a aceleração da mesa, como na Fig. 4.55 (a). Estas se mostram idênticas até o segundo modo, mas se tornam significantemente diferentes a partir dos $200 \mathrm{~Hz}$. Ainda, podem-se notar duas novas ressonâncias entre 300 Hz e 400 Hz.

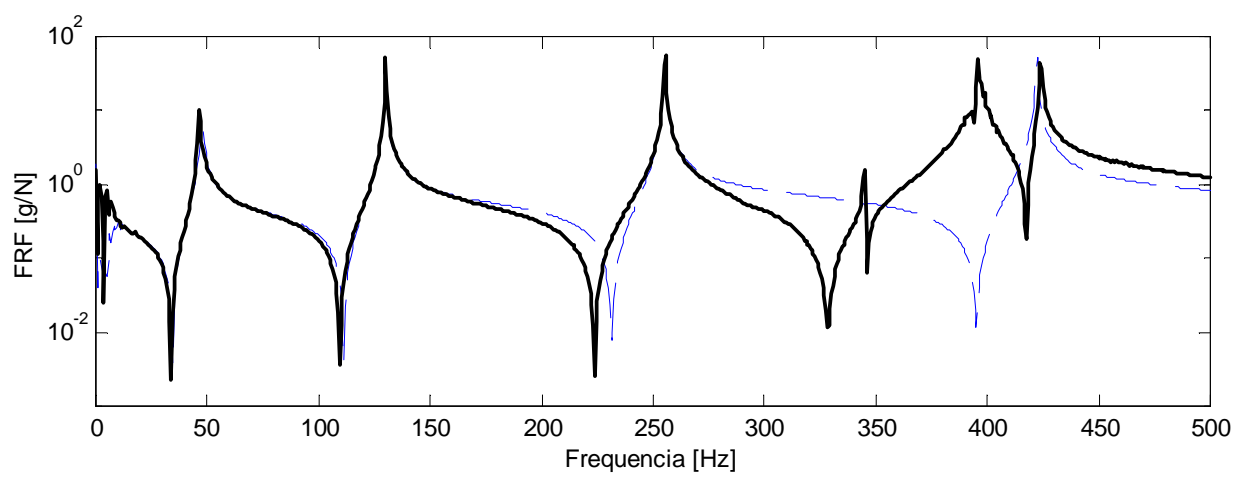

_ FRF de ponto _ FRF da Mesa

FIGURA 4.57 - FRFs medidas no ponto de excitação e na mesa do excitador

A Fig. 4.58 compara as FRFs obtidas da mesma forma ilustrada anteriormente, contudo para acelerações angulares do ponto de medida e da mesa do excitador. É possível notar distorções na FRF da mesa, nas mesmas freqüências demonstradas na Fig. 4.57, o que indica a presença de rotação da mesma que é 'filtrada' pela stinger.

A Fig. 4.59 compara a FRF obtida com a viga fixada diretamente sobre a mesa do excitador, como na Fig. 4.55 (b). Alterações consideráveis em amplitude e freqüência podem ser notadas após a primeira freqüência natural.

A Fig. 4.60 compara as FRFs obtidas da mesma forma ilustrada anteriormente, contudo para acelerações angulares. As mesmas alterações significativas podem ser observadas. 


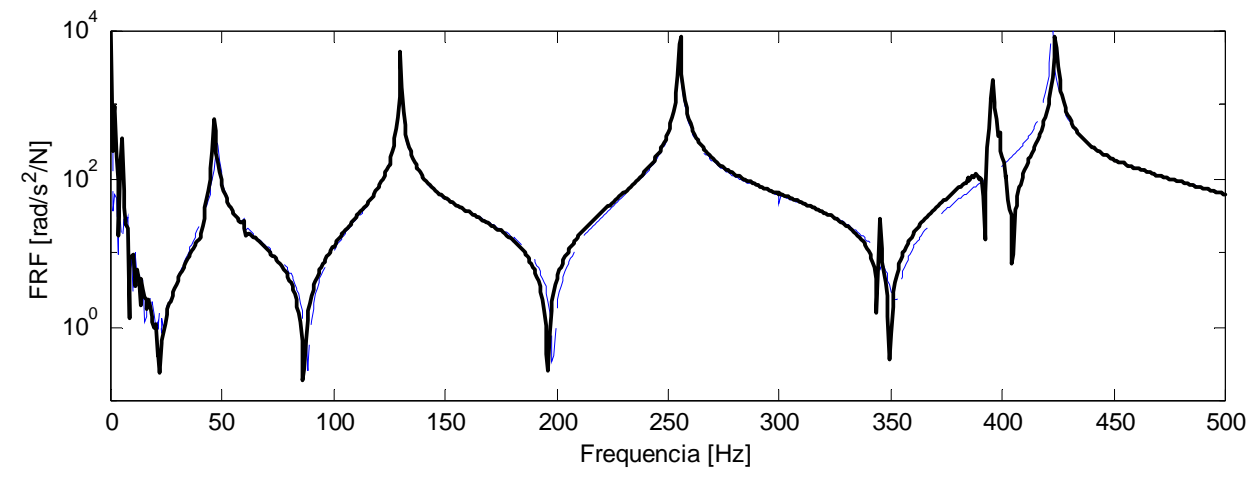

_ FRF de ponto _ FRF da Mesa

FIGURA 4.58 - FRFs angulares medidas no ponto de excitação e na mesa do excitador

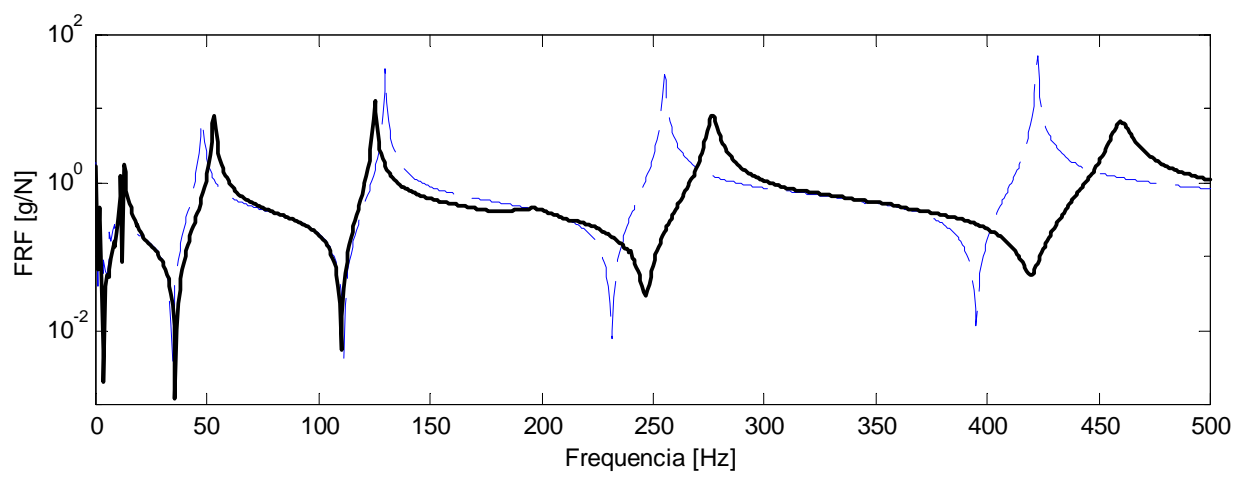

_ Sem stinger _ _ Com stinger

FIGURA 4.59 - FRFs obtidas com diferentes configurações

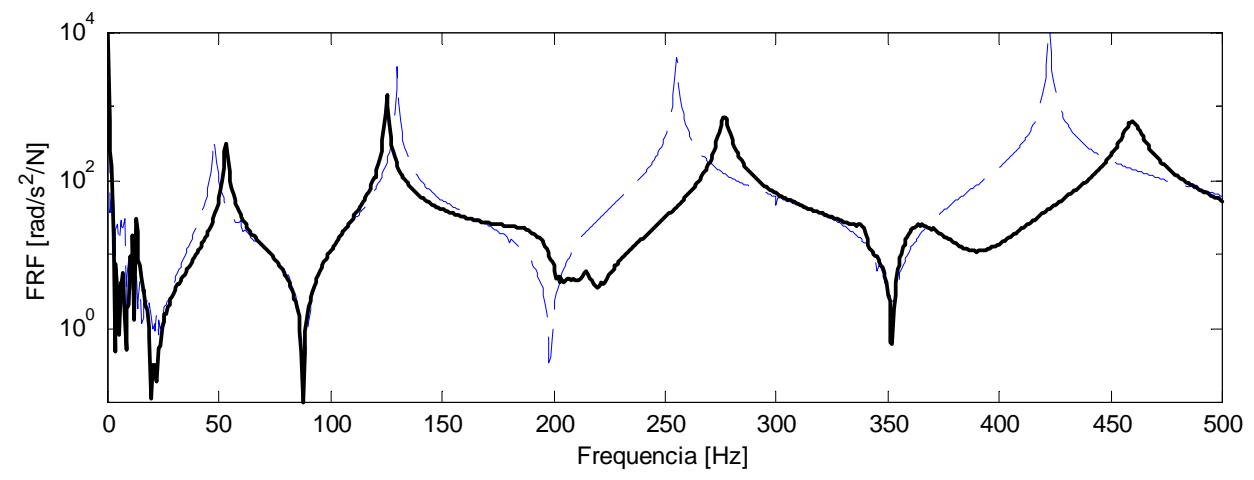

_ Sem stinger _ _ Com stinger

FIGURA 4.60 - FRFs angulares obtidas com diferentes configurações

A Fig. 4.61 ilustra duas FRFs obtidas com a viga fixada diretamente sobre a mesa do excitador. A linha tracejada é a mesma ilustrada na Fig. 4.59, enquanto a linha cheia é a FRF obtida com a viga fixada em um dos cantos da mesa. Pode-se notar que esta mudança, amplifica as discrepâncias entre os sinais medidos após os $250 \mathrm{~Hz}$, ou seja, quando a rotação da mesa é mais significativa. 


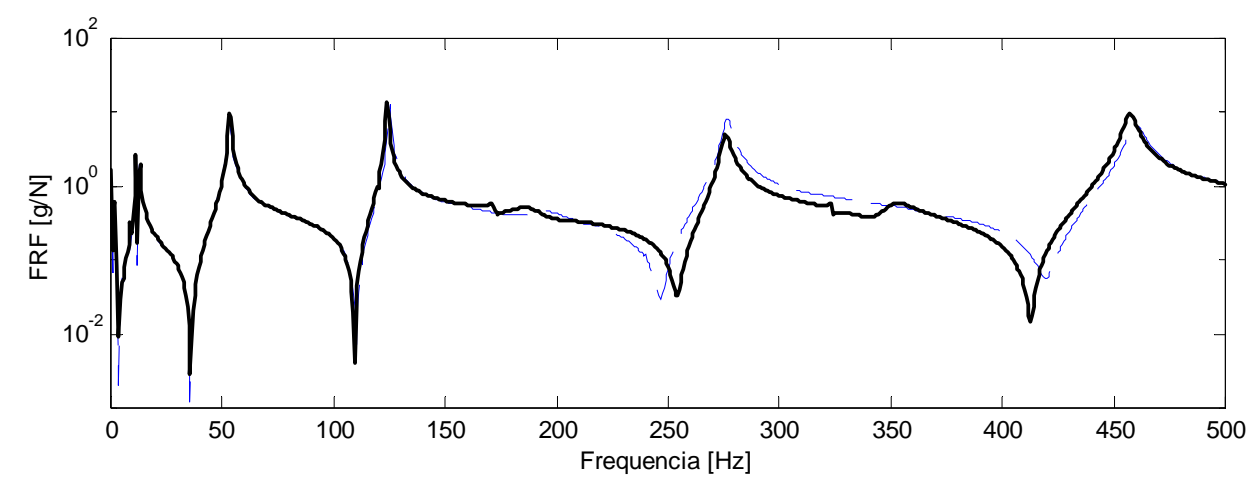

_ Canto da mesa _ _ Centro da mesa

FIGURA 4.61 - FRFs obtidas com diferentes configurações

Finalmente, a Fig 4.62, ilustra as FRFs obtidas de forma análoga às anteriores, contudo fixando-se a viga pelo centro. Este teste foi feito com o intuito de verificar o efeito de uma estrutura desbalanceada montada sobre a mesa do excitador. A viga montada sobre o centro do excitador, apresenta resultados muito similares ao teste com stinger, já que o ponto de excitação não apresenta movimento de rotação para os modos ímpares, e os modos pares não são excitados. Contudo, ao mudar o ponto de fixação sobre a mesa, do centro para um dos cantos, as respostas obtidas apresentam diferenças em amplitude. Isto se deve ao fato, do desbalanceamento gerado pela estrutura sobre o excitador, provocar rotação da mesa e conseqüentemente carregar o transdutor de força com momento, o que pode afetar sua calibração, como demonstrado por VAROTO \& McCONNELL (1993a).

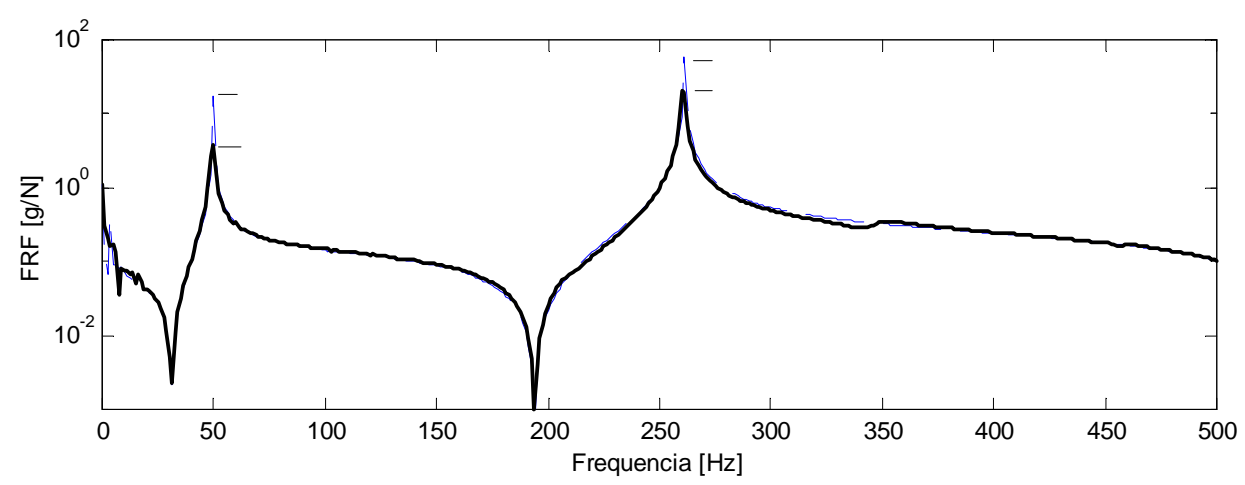

_ Canto da mesa _ _ Centro da mesa

FIGURA 4.62 - FRFs obtidas com diferentes configurações

\subsubsection{Múltipla EXCITAÇÃo}

Os testes iniciais realizados com múltiplas entradas tiveram como item de teste o mesmo chassi utilizado nos testes SISO (Figs. 4.33 e 4.34)

A Fig. 4.63 ilustra duas FRFs de ponto de testes SISO, tomadas em locais diferentes do chassi. É possível ver que determinados modos presentes na FRF de linha tracejada, não estão presentes na FRF de linha cheia. Isto indica que, no segundo caso, o excitador foi posicionado próximo, ou sobre um ponto nodal destes modos. Em 
estruturas de geometria complexa, a determinação do melhor ponto para fixação do excitador não é trivial (NAPOLITANO \& BLELLOCH, 2003). Um modelo prévio da estrutura, em elementos finitos, por exemplo, pode ser de grande auxílio, na determinação prévia do(s) ponto(s) de excitação.

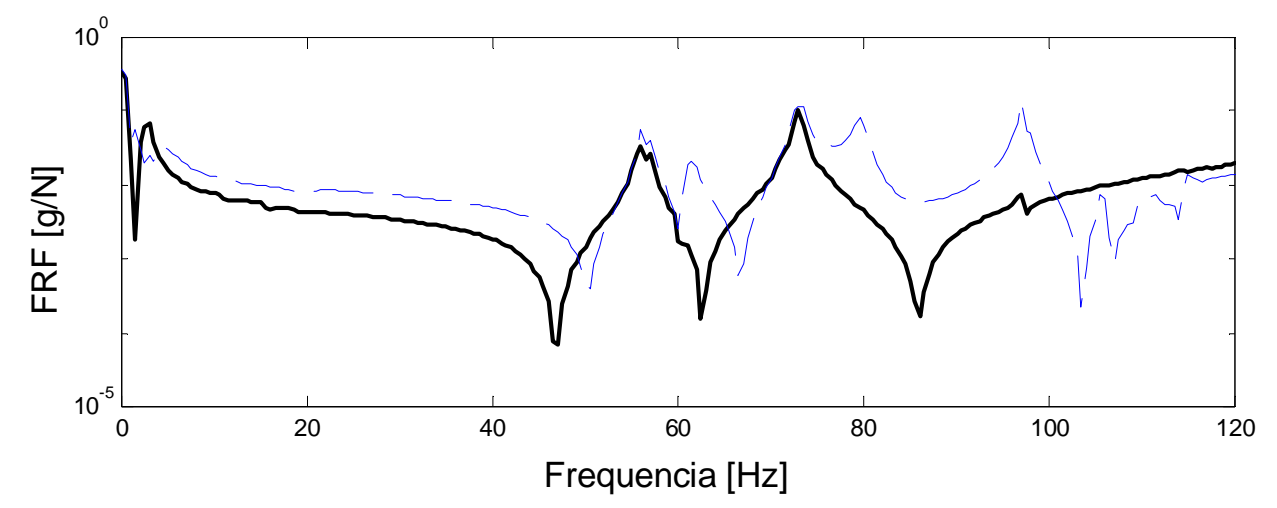

FIGURA 4.63 - FRFs de ponto do chassi

Por vezes ainda, é impossível excitar todos os modos de interesse com um só excitador em um arranjo experimental único (HUNT, 1991). Tomando o caso de uma viga de secção retangular, por exemplo. Podem-se dividir os seus modos de vibrar em dois grupos: modos em plano e fora do plano. No primeiro estão os modos de vibrar axiais. No segundo grupo os modos de flexão (nos dois eixos) e os de torção. Seria preciso ao menos 3 excitadores para excitar todos estes modos de vibrar em um só arranjo experimental.

Portanto, nos testes iniciais realizados com o chassi foram utilizados dois excitadores, alimentados com sinais aleatórios, ambos operando em modo de tensão e conectados aos pontos (1) na direção z (MB Dynamics Modal - 50) e (2) na direção y (B\&K - 4809). Os sinais de entrada e saída foram ponderados por uma janela hanning e computados de 0 a $120 \mathrm{~Hz}$.

Devido à disponibilidade de analisadores com apenas um gerador, os testes consistem de múltiplas entradas correlatas, ou seja, testes em que os excitadores são alimentados com o mesmo sinal. WEAVER \& PASTRNAK (1985) propõem o uso desta técnica e demonstram uma melhoria significativa dos parâmetros obtidos, em se tratado das frequiências naturais, fatores de amortecimento e modos de vibrar. Num teste com 2 excitadores e 49 pontos de medida, descrito por WEAVER \& PASTRNAK (1985), o desvio padrão dos parâmetros médios obtidos diminui consideravelmente, bem como os modos de vibrar se apresentam mais suaves, graças a melhor distribuição de energia promovida pelos excitadores. 


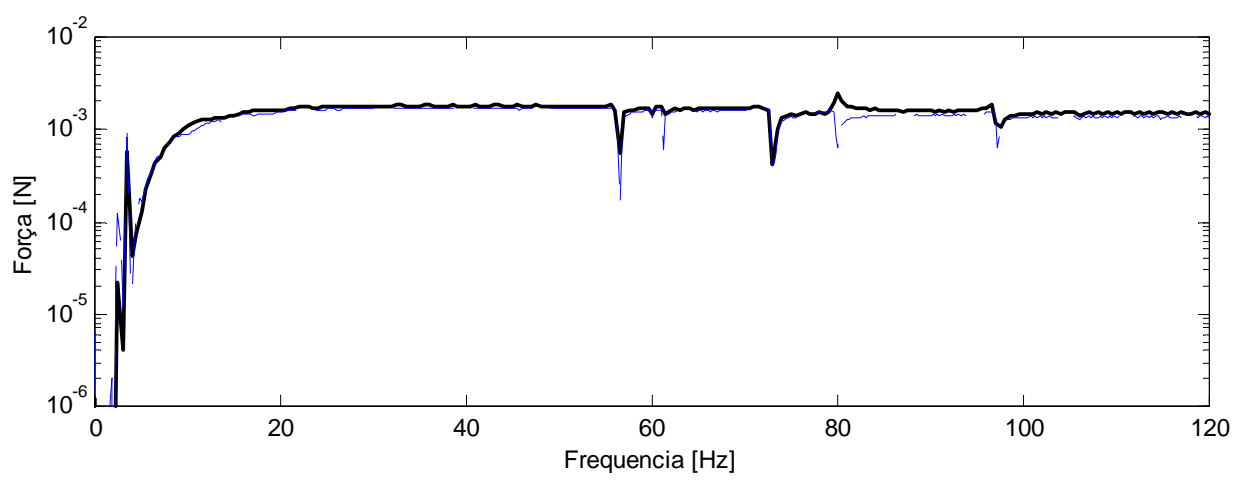

_ SISO _ MIMO

FIGURA 4.64 - Comparação entre forças para os casos SISO e MIMO

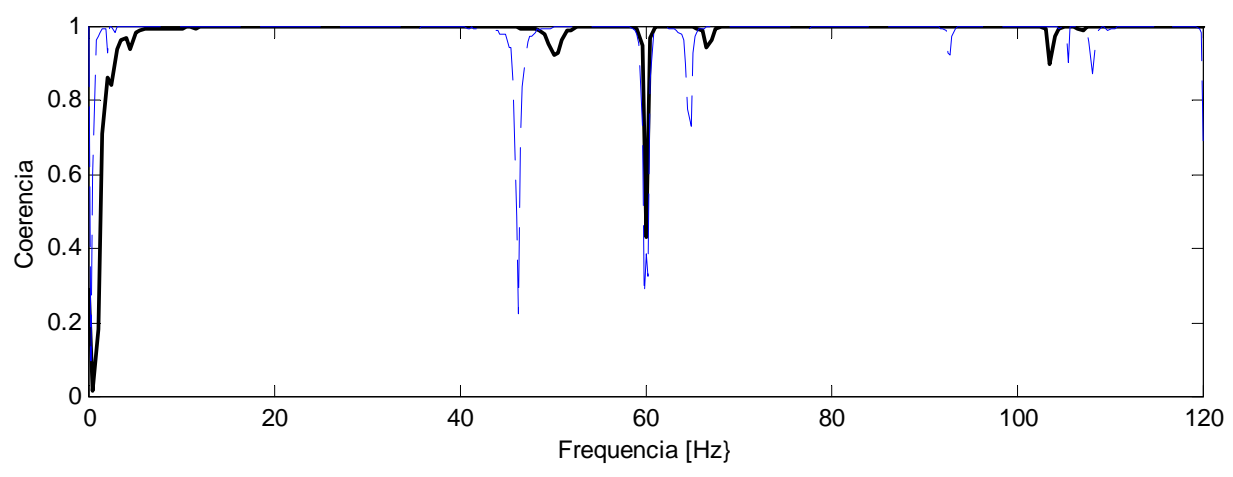

_ SISO _ MIMO

\section{FIGURA 4.65 - Comparação entre funções Coerência para os casos SISO e MIMO}

O mesmo efeito pode ser atribuído aos resultados obtidos com os testes realizados com o chassi (Fig 4.64). A Fig. 5.22 compara as forças obtidas com os testes com um único excitador (SISO) e com dois excitadores (MIMO). Como resultado, as quedas de força no caso MIMO são minimizadas, ou até mesmo anuladas, como ocorre em 61,25 Hz. Ainda, pode-se observar um aumento da força de excitação em $80 \mathrm{~Hz}$. Efeitos como estes são similares aos observados nas simulações (Fig 3.51).

Outra evidência da melhor distribuição de energia pela estrutura, pode ser observada na Fig. 4.65. Observa-se que a função coerência obtida com o teste MIMO é melhor que a função coerência obtida para o mesmo par saída / entrada, no caso SISO.

Com isso, constata-se que há uma melhoria significativa na qualidade dos dados adquiridos, na força de excitação e no tempo do teste, já que mais modos são obtidos com o mesmo arranjo experimental. 


\section{CONClusões}

As principais conclusões, tomadas com base nos modelos analíticos, simulações e ensaios realizados neste trabalho, revelaram característica intrínsecas aos ensaios envolvendo excitadores eletrodinâmicos.

A configuração do excitador com relação à suspensão da base, geralmente com uma massa muito maior que a da armadura, e esta por sua vez apoiada sobre uma suspensão flexível, resultam em pouco movimento sendo transmitido à fundação e conseqüentemente a estruturas que eventualmente compartilhem da mesma fundação, melhorando assim a qualidade dos resultados.

Realizaram-se ensaios com o intuito de verificar os efeitos eletromagnéticos no comportamento dinâmico do excitador. Verificou-se experimentalmente através de ensaios de impacto com o excitador ligado e desligado, que os efeitos eletromagnéticos introduzem rigidez mas principalmente amortecimento adicional ao sistema.

Os testes de excitador contra excitador revelaram uma interferência do excitador ativo no comportamento do excitador sob estudo. Contudo, outro método foi proposto para verificação da faixa de operação do excitador.

Ainda, nos sinais de força e aceleração medidos com o excitador sob estudo ligado (e sem sinal) observa-se uma componente em $100 \mathrm{~Hz}$ e uma em $120 \mathrm{~Hz}$. Este resultado revela que dependendo do nível de excitação utilizado, o ruído proveniente do sistema de arrefecimento pode ser significativo.

Num estudo da dinâmica da armadura, esta mostrou possuir duas frequiências naturais, uma correspondente a toda sua massa sobre a suspensão e outra, mais alta, relativa ao movimento oposto em fase da mesa e da bobina. Neste caso a força transmitida pela mesa para a estrutura tende a cair rapidamente em freqüências próximas a esta ressonância. Defini-se desta forma, a faixa útil de operação do excitador, que como demonstrado, pode ser obtida analítica e experimentalmente. É importante observar ainda, que com o aumento da massa da estrutura ligada à mesa, esta freqüência tende a diminuir.

A queda de força se mostrou um fenômeno primeiramente mecânico, resultante do acoplamento entre a estrutura e a armadura, sendo a parcela eletromagnética do fenômeno caracterizada principalmente como um amortecimento. Os efeitos 
eletromagnéticos então, vêem amenizar as distorções na força, amenizando a intensidade dos picos e vales.

$\mathrm{O}$ efeito da queda de força se mostra mais intenso no modo de tensão que no modo de corrente. Este fenômeno se deve ao fato do amplificador, quando operando em modo de corrente, compensar as perdas devido à tensão de retorno ( $\left.\mathrm{E}_{\text {bemf }}\right)$ gerada pelo movimento das bobinas no campo magnético do excitador. Porém, os ensaios realizados com estrutura, mostraram que o modo de corrente pode submeter a estrutura a esforços demasiados, podendo prejudicar a qualidade dos dados ou até mesmo danificar a estrutura. Ainda, as simulações realizadas demonstram que o fenômeno de queda de força está ligado diretamente à relação entre as massas da armadura e a massa modal da estrutura.

Considerando-se os ensaios em malha fechada, observa-se que os melhores resultados foram atingidos com força controlada, tanto no que diz respeito à definição das FRFs como as funções coerência. Uma das razões principais deste fato, se deve ao uso do estimador $\mathrm{H}_{1}$ para o calculo das FRFs, já que este se mostra sensível a ruído no canal de entrada. Sendo assim, ao se controlar a aceleração, por exemplo, a queda acentuada de força em freqüência próximas das ressonâncias da estrutura desfavorece a relação sinal / ruído do canal de entrada. Ainda, observando-se as condições a que a estrutura é exposta nos diversos testes realizados com a viga de aço (Figs 4.25 a 4.30), o que oferece maior risco de agressão à estrutura é o modo de corrente em malha aberta que chega a expor o item de teste a acelerações 100 vezes maiores que o menos agressivo (modo de tensão). Neste tipo de teste corre-se o risco de danificar a estrutura, expondo-a a níveis de excitação que ela não vivencia em uso normal (VAROTO, 1996), o que no caso de um protótipo de grande valor, ou de uma estrutura única, como um satélite, seria desastroso. Porém, os testes em malha fechada com força controlada, se mostram uma alternativa eficiente do ponto de vista de qualidade dos dados obtidos, sem contudo, submeter a estrutura a esforços dinâmicos extremos.

Os ensaios de impacto sobre a armadura revelaram outra característica considerável do comportamento dinâmico da mesma, sendo que esta se mostrou sensível ao desbalanceamento (OLIVEIRA \& VAROTO, 2002b). Este tipo de comportamento pode interferir drasticamente nos resultados, já que pode submeter o transdutor de força a momentos, comprometendo a acuidade dos dados medidos.

Das análises de testes realizados com a viga de aço, nos quais várias técnicas de excitação foram empregadas como ensaios em malha aberta e fechada, surge a motivação para o estudo de estimadores de FRFs.

A interpretação dos dados provenientes das simulações de sistemas MIMO não é trivial. Em alguns casos os efeitos de queda na força de excitação são amenizados, em outros acentuados. Mesmo que fosse possível atuar simultaneamente em uma estrutura com sinais completamente não-correlatos, o fato de haver mais de uma fonte de 
excitação, muda a resposta da estrutura e conseqüentemente afeta o fenômeno de interação. Resultados como o apresentado na Fig. 3.51, onde a interação cruzada das forças resulta em um espectro constante de excitação, mostram que há possibilidade de controle de múltiplas fontes de excitação para cancelamento das quedas na força.

$\mathrm{O}$ uso de excitadores distintos revelou diferenças nas mesmas funções obtidas com excitadores idênticos, sobretudo na força do excitador de menor massa (Fig 3.54), o que indica outra característica deste tipo de teste, ou seja, excitadores menores estão mais sujeitos aos efeitos de interação cruzada entre os excitadores. As Figs. 3.53 e 3.55, indicam que a interação entre os excitadores e a estrutura em testes com múltipla excitação, está relacionada, não somente com a relação entre suas massas, mas também com o ponto de aplicação das forças e os modos de vibrar de interesse, ou seja, a relação entre a amplitude e a fase dos pontos de excitação em cada um destes modos.

Em relação aos testes com múltipla excitação, verifica-se que por mais que se garanta o desacoplamento entre as fontes de excitação, é inevitável que haja interação cruzada entre os excitadores, ou seja, que a parcela de velocidade de um ponto de excitação, devido à força introduzida por outro ponto de excitação, interfira na tensão de retorno do primeiro, e conseqüentemente em sua força, o que se verifica nas Figs. $3.51 \mathrm{e}$ 4.64.

Com os resultados dos testes, observa-se que o uso de múltiplos excitadores pode melhorar a uniformidade das forças transmitidas à estrutura, resultando em quedas de força minimizadas, ou até mesmo anuladas, como ocorre em 61,25 Hz na Fig. 5.23. Ainda, pode-se observar um aumento da força de excitação em $80 \mathrm{~Hz}$. Outra evidência da melhor distribuição de energia pela estrutura, pode ser observada na Fig. 5.24. Observa-se que a função coerência obtida com o teste MIMO é melhor que a função coerência obtida para o mesmo par saída / entrada, no caso SISO.

\subsection{TRABALHOS FUTUROS}

Investigações futuras quanto ao tema da interação entre excitadores eletrodinâmcios e a estrutura sob estudo podem contemplar os seguintes tópicos:

- Otimização do uso de excitadores em uma determinada estrutura, levando-se em consideração seus limites de deslocamento, força e faixa de freqüência.

- Projeto de dispositivos de fixação de estruturas em testes de excitação via base que minimizem os efeitos de carregamento de momentos entre a estrutura e a armadura.

- Estudo dos efeitos de não-linearidades intrínsecos ao campo eletromagnético do excitador na dinâmica da armadura. 
- Estratégias de controle de excitação que levem em consideração os efeitos de tais não-linearidades.

○ Técnicas de controle de excitação em testes com múltiplos excitadores.

- Estender os estudos apresentados para o caso de excitadores de grande curso e força, bem como a excitadores hidráulicos

- Desenvolvimento de modelos analíticos que possibilitem um estudo mais aprofundado da interação entre múltiplos excitadores e a estrutura sob estudo. 


\section{BIBLIOGRAFIA}

ALLEMANG, R. J., (1994), Vibrations: Experimental Modal Analysis, UC-SDRL-CN20-263-663/664.

B\&K, (1974), Instruction Manual, B\&K Vibration Exciter System V.

CAMPENDELLI, V. L., TONI, P., (1991), "Generation of Signals for Structure Excitation with Given Spectrum of Frequency", Proceedings of the 9 International Modal Analysis Conference, IMAC - 1991 - Vol.1, pp.182-188.

CLARK, M., (1985), "Multi Shaker Modal Testing Using a Modified Transient Random Excitation", Proceedings of the $3^{\text {rd }}$ International Modal Analysis Conference, IMAC - Vol.1, pp. 553 - 557.

COMSTOCK, T., (1981), "Improving exciter performance in modal testing", Proceedings of the $18^{\text {th }}$ International Modal Analysis Conference, IMAC - pp.17701775.

CRAIG, Jr. R. R., (1995), Structural Dynamics, John Wiley \& Sons, NY.

GADE, S., GATZWILLER, K., (1996), "Graphical Interpretation of Input/Output Relationships for SISO and MIMO Measurements", Proceedings of the XIV International Modal Analysis Conference, IMAC - Vol. 2, pp. 1332 - 11341

HAN, S., (1998), "Analysis on the Beam-Exciter Interaction in Modal Testing", Proceedings of the $17^{\text {th }}$ International Modal Analysis Conference, IMAC - pp.16561661

HUNT, D. L., (1991), "Modal Excitation Using Multiple Input Excitation”, Proceedings of the $9^{\text {th }}$ International Modal Analysis Conference, IMAC -Vol.2, p. $1495-1501$

LANG, G. F., (1997), "Electrodynamic Shakers Fundamentals", Sound and Vibration April, - pp. $14-25$

LANG, G. F., (2001), Understanding the Physics of Electrodynamic Shaker Performance, Sound and Vibration - October, - pp. 1 - 9

LOFRANO, M., OLIVEIRA, L.P.R., VAROTO, P.S., (2002), "Techniques for he estimation of angular FRFs in modal testing", International Conference on Structural Dynamic Modeling, Funchal. v. 1.

MAIA, N. M. M., SILVA, J. M. M., (1997), Theoretical and Experimental Modal Analisys, Research Studies Pess Ltd., England, 1997, $1^{\text {st }}$ Edition.

McCONNELL, K. G., (1995), Vibration Testing: Theory and Practice, John Wiley \& Sons, $1^{\text {st }}$ Edition, NY. 
MOUCH, T. A, PETERSON, E. L. e RUSSEM, W. M., (1990), "Modal Excitation: Force Drop-off at Resonances", Proceedings of the 8 International Modal Analysis Conference, IMAC - Vol.2, p.1226-1231.

NAPOLITANO, K.L, BLELLOCH, P.A., (2003) "Automated Selection of Shaker Location for Modal Tests", Proceedings of the 21 International Modal Analysis Conference, IMAC - Vol.1, p.9 - 16.

OLBRECHTS, T., SAS, P., VANDEPITTE, D., (1997), "FRF measurements errors caused by the use of inertia mass shakers", Proceedings of the 15 International Modal Analysis Conference, IMAC - Vol.1, p.188-194.

OLIVEIRA, L.P.R., VAROTO, P.S., (2002a), "On the Interaction Between the Vibration Exciter and the Structure Under Test in Vibration Testing", Sound and Vibration - October - pp. 20 - 26

OLIVEIRA, L.P.R., VAROTO, P.S., (2002b), "On the Force Drop-off Phenomenon in Shaker Testing in Experimental Modal Analysis", Journal of Shock and Vibration, Vol. 9 - pp. 165 - 175

OLIVEIRA, L.P.R., VAROTO, P.S., (2002c), "The Effects of Armature Rotation on Data Quality in Base Driven Shaker Testing", International Conference on Noise and Vibration Engineering - ISMA 2002, Leuven., Belgium. pp. 911 - 918.

OLSEM, N. L, (1986), "Using and Understanding Electrodynamic Shakers in Modal Applications", Proceedings of the $4^{\text {tn }}$ International Modal Analysis Conference, IMAC -Vol.2, p.1160-1167.

OTTE, D., GIALAMAS, T., TSAHALIS, D. BREGANT, L., VAN der AWERAER, H., (1996), "Substructuring by Means of FRFs: Some Investigation on the Significance of Rotational DOFs", Proceedings of the XVI International Modal Analysis Conference, Dearborn, MI.

RAO,D.K, (1987), "Electrodynamic Interaction Between a Resonating Structure and an Exciter", Proceedings of the $5^{\text {th }}$ International Modal Analysis Conference, IMAC Vol.2, p.1142-1150.

TOMLINSON, G.R., (1979), "Force Distortion in Resonance Testing of Structures with Electrodynamic Vibration Exciters", Journal of Sound and Vibration, Vol. 63, No. 3, 1979, p. 337-350.

UNHOLTZ, K., (1961), "Vibration testing machines" - Shok and Vibration Handbook, McGraw-Hill Book Co., New York, v.2, pp. 25.1 - 25.74, ed.1, 1961

VAN der AUWERAER, H., OTTE, D., LEURIDAN, J., BAKKERS, W., (1991), "Modal Testing with Multiple Sinusoidal Excitation", Proceedings of the $9^{\text {th }}$ International Modal Analysis Conference, IMAC - Vol.2, pp. 1485 - 1494

VAROTO, P. S., McCONNELL, K. G., (1993a), “A Model for Force Transducer Bending Moment Sensitivity and Response during Calibration", Proceedings of the XI International Modal Analysis Conference, IMAC - 1993 - Vol. 1, pp. 364 - 368

VAROTO, P. S., McCONNELL, K. G., (1993b), “An FE Study of the Exciter-Structure Interaction in Vibration Testing", Proceedings of the XII International Modal Analysis Conference, IMAC - pp.1018-1025 
VAROTO, P.S., (1996), The Rules for the Exchange and Analysis of Dynamic Information in Structural Vibration, PhD Dissertation, Department of Aerospace and Mechanics, Iowa State University, Ames, IA

WEAVER, H.J., PASTRNAK, J.W., (1985), "Multiple Shaker Excitation Using Coherent Signals", Proceedings of the $3^{\text {rd }}$ International Modal Analysis Conference, IMAC - Vol.1, p. 117 - 123 